\title{
The Literacy Beliefs and Practices of Middle Level English Language Arts Teachers
}

Diane Fine

Follow this and additional works at: https://researchrepository.wvu.edu/etd

\section{Recommended Citation}

Fine, Diane, "The Literacy Beliefs and Practices of Middle Level English Language Arts Teachers" (2015). Graduate Theses, Dissertations, and Problem Reports. 5598.

https://researchrepository.wvu.edu/etd/5598

This Dissertation is protected by copyright and/or related rights. It has been brought to you by the The Research Repository @ WVU with permission from the rights-holder(s). You are free to use this Dissertation in any way that is permitted by the copyright and related rights legislation that applies to your use. For other uses you must obtain permission from the rights-holder(s) directly, unless additional rights are indicated by a Creative Commons license in the record and/ or on the work itself. This Dissertation has been accepted for inclusion in WVU Graduate Theses, Dissertations, and Problem Reports collection by an authorized administrator of The Research Repository @ WVU.

For more information, please contact researchrepository@mail.wvu.edu. 
The Literacy Beliefs and Practices of Middle Level English Language Arts Teachers

\author{
Diane Fine \\ Dissertation submitted \\ to the College of Education and Human Services \\ at West Virginia University \\ in partial fulfillment of the requirements for the degree of \\ Doctor of Education in \\ Curriculum and Instruction/Literacy Studies
}

Aimee L. Morewood, Ph.D., Chair
Allison Swan Dagen, Ph.D.
Charline Barnes-Rowland, Ed.D.
Joy Faini Saab, Ed.D.
Jodi Nichols, Ed.D.
Department of Curriculum \& Instruction

Morgantown, West Virginia

2015

Keywords: young adolescents, literacy, middle school, English language arts teachers Copyright 2015 Diane Fine 


\begin{abstract}
The Literacy Beliefs and Practices of Middle Level English Language Arts Teachers Diane Fine
\end{abstract}

This study presents data from a two-phase phenomenological case study investigation designed to ascertain two middle level English teachers' beliefs about literacy. In addition to revealing the teachers' beliefs about literacy, this study sought to discover the ways in which these literacy beliefs were manifested in the instructional tasks employed by each teacher in her middle level English classroom. A pilot study conducted during the fall semester of 2012 described one middle level English teacher's beliefs about literacy. The final phase of the investigation expanded upon data collected during the pilot study and involved two middle level English teachers. This study utilized open-ended interviews of the two English teachers. Next, classroom observations were conducted in an effort to capture and confirm the teachers' beliefs about literacy during classroom instruction. Observations occurred during the course of a literacy unit in each classroom. Follow-up interviews were conducted as needed during the observation cycle of the final phase of the investigation. Findings from this study revealed that the teachers' beliefs about literacy were not always consistent with their instructional practices. The two teachers involved in this study appeared to have a difficult time discerning and describing their beliefs and instead frequently referenced instructional practices employed in the classroom. The findings of this study suggest implications for middle level teacher education and middle level professional development. 


\section{Dedication}

This work is dedicated to my remarkable husband Steve - steadfast in your patience, understanding, care, support, and belief in my abilities. Without you, Steve, there is absolutely no doubt I would not be the person who I am today. You and you alone have been my greatest inspiration - you set me on the path to success and there are no words that can truly convey the depth of my gratitude. Without your love, support, persistence, encouragement, and stamina this journey would have been impossible. You are my heart and my soul and you will always have my eternal love. Thank you, Steve, I love you.

In loving memory of my brother and best friend for 37 years - Owen J. Moore - you are forever loved and forever missed. I wish you were here to share this accomplishment with me. 


\section{Acknowledgements}

I would like to thank my advisor, Dr. Aimee Morewood - I appreciate the insights that you shared with me. Without your efforts I would not have accomplished this goal. I would also like to express my gratitude to each member of my dissertation committee, Dr. Allison Swan Dagen, Dr. Joy Saab, Dr. Charline Barnes Rowland, and Dr. Jodi Nichols. Thank you for your insightful comments and support throughout this process. A special thank you goes to Dr. Jodi Nichols. From the moment I met you, Jodi, you have inspired me and encouraged me to persevere. Without you I would have abandoned this endeavor long ago. Thank you for giving me the determination and strength to move forward when I had given up on myself.

As I reflect on the many people who inspired this work I would be remiss to ignore the most influential professional community along my educational journey. "Mountain Valley Pastures" school system (MVP Schools) has been the most valuable and significant stop in my journey. You welcomed me into your community and treated me like family from the moment I arrived. You set me on the path to my successful and exhilarating career as a teacher and educator. The boundless opportunities that I had to learn and grow within your community have shaped who I am today. You have given me the freedom to come and go as I have needed along my educational career, always having faith in me and continually providing me the opportunity to learn with and from you. My colleagues, from the district-wide administration to the custodians who kept me and my classroom in order, my former students and their families, and the entire community are cherished friends and advocates. You are the catalysts who inspired me to become the educator I am today. A special thank you goes to my colleagues at the middle school, particularly my two welcoming and willing participants who were most accommodating 
- I have learned my greatest lesson from the two of you. Your participation in this academic endeavor has opened my eyes to a view of literacy that I had overlooked for far too long. Thank you for allowing me to look into your teaching lives in order to learn from you an incredibly valuable lesson.

Finally, this acknowledgement would not be complete if I did not take the time to thank the "Party of Eleven." Each one of you - Steve, Patty, Bill, Ben, Tori, Jon, Shannon, Laura, Alan, and Alea - have had an incredible impact on my life, not only as a teacher and educator, but also as truest friends and surrogate family. My greatest joys in life have come in the years since I met you. From the moment Ben stepped into my first-grade classroom, you have changed and enriched my life in ways too deep to comprehend. You have welcomed me into your life and have allowed me to become a member of your family. That family circle has widened from Virginia to West Virginia and has evolved into the "Party of Eleven." The times we have shared together cannot be described in words. You are my inspiration and as each of you know, I would not have achieved this goal without you. Your continuous support and encouragement (and a few excursions and diversions along the way) have helped me to achieve my greatest accomplishment. Thank you for your love and ceaseless faith in my abilities. Let the party go on! 
Table of Contents

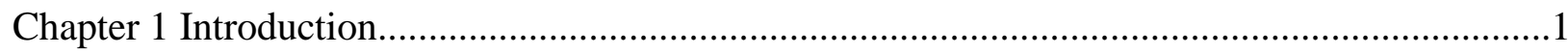

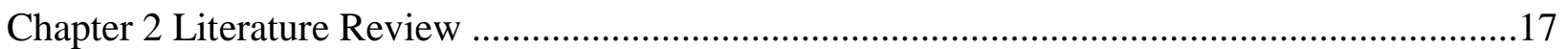

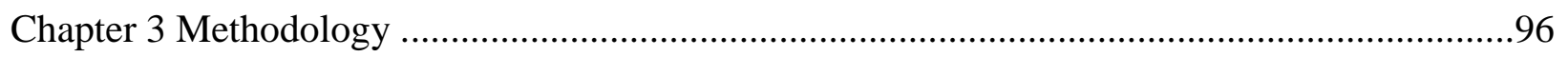

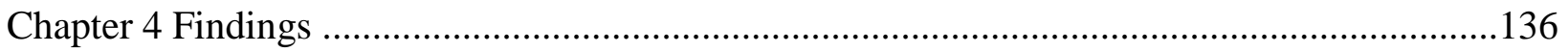

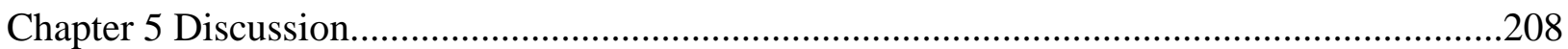

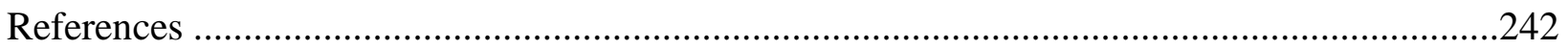

Appendix A Overview of Methodological Considerations Drawn From Articles about

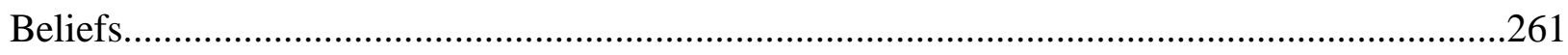

Appendix B Overview of Methodological Considerations Drawn From Adolescent Literacy

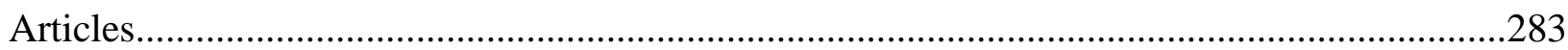




\section{List of Tables}

Table 1 Comparison of Mrs. White's Stated Beliefs about Skills and Instructional Practices

Observed. 148

Table 2 Comparison of Mrs. White's Stated Beliefs about Reading Understanding and Instructional Practices Observed. $154-155$

Table 3 Comparison of Mrs. White's Stated Beliefs about Response to Reading and Instructional Practices Observed.

Table 4 Comparison of Mrs. White's Stated Beliefs about Time to Read and Instructional

Practices Observed.

Table 5 Comparison of Mrs. White's Stated Beliefs about Writing and Instructional Practices

Observed. 164

Table 6 Comparison of Mrs. White's Stated Beliefs about Oral Communication and

Collaborative Teamwork and Instructional Practices Observed. 169

Table 7 Comparison of Mrs. White's Stated Beliefs about Vocabulary and Instructional Practices

Observed. 175

Table 8 Comparison of Mrs. White's Stated Beliefs about Literature and Instructional Practices

Observed. 178

Table 9 Comparison of Ms. Swift's Stated Beliefs about Language Arts and Instructional

Practices Observed. 189

Table 10 Comparison of Ms. Swift's Stated Beliefs about Reading Skills and Instructional

Practices Observed.

Table 11 Comparison of Ms. Swift's Stated Beliefs about Literary Analysis Skills and Instructional Practices Observed. 193 
Table 12 Comparison of Ms. Swift's Stated Beliefs about Regular Literary Terms and Instructional Practices Observed.

Table 13 Comparison of Ms. Swift's Stated Beliefs about Academic Terms and Instructional

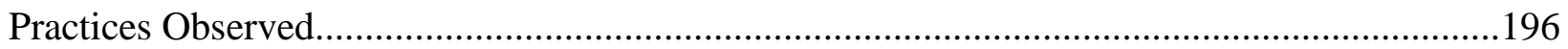

Table 14 Comparison of Ms. Swift's Stated Beliefs about Critical Reading Skills and

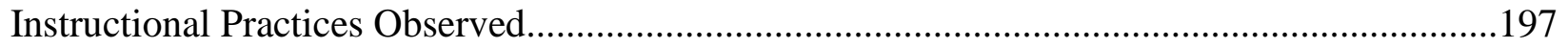

Table 15 Comparison of Ms. Swift's Stated Beliefs about Additional Reading Skills and

Instructional Practices Observed.

Table 16 Comparison of Ms. Swift's Stated Beliefs about Literature and Instructional Practices

Observed. 202

Table 17 Comparison of Ms. Swift's Stated Beliefs about Writing and Instructional Practices

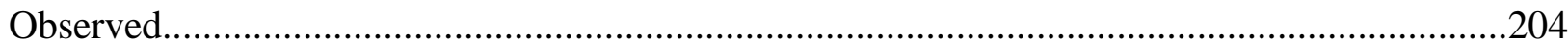

Table 18 Comparison of Ms. Swift's Stated Beliefs about Speaking and Instructional Practices

Observed.. 


\section{List of Figures}

Figure 1. Graphic representation of terms associated with the construct "beliefs" ....................19

Figure 2. Graphic representation of conclusions drawn about teachers' beliefs.......................24

Figure 3. Overview of the theoretical framework......................................................... 106

Figure 4. Layout of Mrs. White's sixth grade English classroom - fall 2014........................139

Figure 5. Visual model depicting Mrs. White's definition of literacy....................................143

Figure 6. Layout of Ms. Swift's sixth grade English classroom - fall 2014..........................180

Figure 7. Visual model depicting Ms. Swift's definition of literacy....................................184 


\section{Chapter One}

\section{Introduction}

Literacy is a concept that has been a focal point in education and in society in general for decades with some endorsing literacy as the key to education (Schmoker, 2006). Near the turn of the century, the International Literacy Association (ILA) (formerly the International Reading Association) asserted in their position statement on adolescent literacy that

Adolescents entering the adult world in the 21 st century will read and write more than at any other time in human history. They will need advanced levels of literacy to perform their jobs, run their households, act as citizens, and conduct their personal lives. They will need literacy to cope with the flood of information they will find everywhere they turn. They will need literacy to feed their imaginations so they can create the world of the future. (Moore, Bean, Birdyshaw, \& Rycik, 1999, p. 3)

In 2012, ILA reiterated the importance of this statement in their updated position statement on adolescent literacy, noting that the literacy demands highlighted in this statement are vital to the continued literacy development of adolescents at the middle and high school levels.

The notion of literacy continually evolves in response to ever-present changes in society. As Scribner (1988) indicated, "The enterprise of defining literacy ... becomes one of assessing what counts as literacy in the modern epoch in some given social context" (p. 72). As a result of this ongoing evolution, there are a multiplicity of paradigmatic views of literacy that continually emerge. In our current society, literacy can be viewed through the lens of basic literacy, functional literacy, secondary literacy, adolescent literacy, content literacy, academic literacy, digital literacy, multiliteracies, critical literacy, and the list goes on and on. There is not time nor space to give voice to each of these noteworthy views of literacy in the context of this study. 
What is quite clear is the fact that in the twenty-first century, literacy is no longer considered to be a "static construct," rather "it has now come to mean a rapid and continuous process of change in the ways in which we read, write, view, listen, compose, and communicate information" (Coiro, Knobel, Lankshear, \& Leu, 2008, p. 23).

One fact that does not appear to change despite this ongoing evolution is that literacy is vitally important to both individual achievement and the overall success of society. Literacy research suggests that when individuals achieve insufficient literacy, there is a negative impact on one's overall opportunities for success in life. This negative impact may include debilitating consequences such as an increased likelihood of dropping out of school, the potential to earn less than sufficient future income, poor health, and a greater likelihood of potential incarceration (Alliance for Excellent Education, 2007). Literacy researchers as well as influential economic, social, moral, and political organizations indicate that literacy plays a pivotal role in the economy of our nation, in the national culture, and in the strength and stability of our society (National Council of Teachers of English [NCTE], 2006; Wise, 2009).

According to the National Council of Teachers of English (NCTE, 2006) schools "represent the most powerful and pervasive means of introducing the next generation into a culture of literacy" (p. 2). Furthermore, literacy is regarded as the cornerstone of student achievement at every grade level (Wise, 2009). It appears that schools play a fundamental role in individual literacy achievement and consequently on the overall success and stability of our nation. Because schools are expected to perform an essential role in the individual acquisition of literacy, the goal of this study is to spend time talking with and observing middle level English language arts (ELA) teachers in an effort to come to some understanding regarding their beliefs 
about literacy and to explore the ways in which these beliefs manifest themselves in instructional practices in the English language arts classroom.

As the forthcoming review demonstrates, research and data associated with young adolescent literacy reveal that an overwhelming majority of our nation's students do not possess the literacy skills required to learn effectively in the content-areas, nor do they grasp the skills needed to successfully negotiate the literacy tasks associated with the continually evolving technological society of the twenty-first century (Meltzer, Smith, \& Clark, 2002). Further, researchers indicate that there may be potential barriers that exist within our nation's schools that impede ongoing efforts to develop effective literacy experiences designed to assist adolescents in acquiring these fundamental literacy skills. It has been suggested that one of these obstacles may be associated with the belief systems held by educators (Meltzer, Smith, \& Clark, 2002; O’Brien, Stewart, \& Moje, 1995). Therefore, this study endeavors to ascertain the beliefs about literacy held by two middle level teachers of English language arts and attempts to unravel the ways in which these individually held beliefs about literacy are revealed in the instructional practices employed in two middle level English language arts classrooms. It is anticipated that by attempting to decipher these ELA teachers' literacy beliefs and practices, the findings of this investigation may lend themselves to considering the ways these teachers' literacy beliefs and practices nurture young adolescents' literacy development in the context of the twenty-first century, where it has been suggested there is a state of crisis regarding adolescent literacy.

Rather than imposing upon this study one particular perspective of literacy, it was the intent of this study to allow the participants' literacy beliefs to guide the direction of the study, based upon their perceived views of literacy. Because the notions of beliefs and literacy are each complex constructs that exist within the mind of individuals, this research investigation 
integrates a case study design with a phenomenological approach to qualitative research. This combined approach provides the opportunity to explore this complex fusion of phenomena (beliefs and literacy) from within the natural context where these phenomena emerge, the middle level ELA classroom. Methods associated with the phenomenological approach provide a unique opportunity to capture the phenomena from each participant's distinctive perspective. One of the primary objectives of a phenomenological approach is to allow the phenomenon of interest (i.e., literacy) to be revealed and described based upon the participant's personal experiences with the phenomenon. Therefore, this study focuses on the participant's unique descriptions of literacy as well as the ways in which this construct is manifested in the instructional tasks employed by each teacher in her middle level ELA classroom.

Since this investigation integrates a phenomenological approach with a case study design, this study aspires to maintain each participant's voice in the final portrayal of literacy rather than applying either the subjective view of the researcher or a theoretical, objective interpretation of the phenomenon based upon preconceived constructs about literacy that already exist within the field. Despite this intended goal, literacy is a vast and often complex concept to understand; therefore, in order to develop background for the reader, several terms that may emerge during the course of this investigation are clarified from my unique perspective as a researcher. Further, to support the reader and to necessitate such a study of teachers' beliefs about literacy, issues associated with the contemporary adolescent literacy perspective and the adolescent literacy crisis are discussed. All statements made in this introduction and in the forthcoming review of literature are intended to provide a general overview of issues believed to be associated with this study rather than to propose hypotheses or to establish a priori frameworks associated with middle level English teachers and their beliefs about literacy. Because this study assumes a 
phenomenological approach, no information included in the forthcoming sections is intended to suggest that there is a singular accepted or precise definition of literacy. The information included in the upcoming sections is intended merely to provide an understanding of the context through which this study emerged.

\section{Initial Guiding Questions}

The following initial research questions guided this study:

1. How do middle level English language arts teachers perceive and describe literacy? What are their beliefs about literacy?

2. How are these literacy beliefs manifested in the instructional practices of the middle level English language arts teachers?

\section{Clarification of Terms}

Literacy is a term that evokes a broad range of meanings that may be dependent upon the social, educational, or cultural context of the conversation in which this term is being discussed. Since any discussion of literacy includes an array of ambiguous terminology, several terms are clarified here in an effort to promote a clearer focus for this study. In the context of this particular study, literacy is not considered a static construct; rather it is viewed as "a process of continuously learning how to become literate" (Leu, 2001, p.1). Tasks associated with the construct, literacy, encompass more than merely "schooled literacy" tasks (Alvermann, 2002). Literacy may be regarded as a recursive process that requires the continual evolution of reading, writing, viewing, listening, composing, problem solving, critical thinking, and communication, each of which is believed to be associated with success in daily life (Leu, 2001; NCTE \& IRA, 1996). From my perspective (as a former first grade teacher, middle school reading specialist, middle school English teacher, and current professor and coordinator of a reading specialist 
program at a state university), literacy is considered to be associated with the manner in which one is able to make sense of the world. My views of literacy are supported by the field (e.g., Irwin, 1991) in that literacy is believed to be associated with acquiring a level of reading, writing, and communication that allows individuals to attain competency in achieving personal goals, in developing to one's full potential, and in functioning successfully in a job and within the global society.

Within the context of this study, reading is considered be a multifaceted social and cognitive process that encompasses more than merely the act of constructing meaning from print (National Council of Teachers of English [NCTE], 2007). Instead, reading requires readers to simultaneously integrate knowledge of the spoken and written language, prior knowledge associated with the topic described in the text, and existing knowledge of culture in order to effectively construct meaning from the text (NCTE, 2004). Further, reading may be viewed as a developmental process that continues to expand through ongoing engagement with a wide array of texts across an individual's lifetime (NCTE, 2004). Reading is considered to be a term that is subsumed by the term literacy, and as such, serves as an essential element needed to achieve both personal and academic success, as well as full participation in civic life and the global society (Alvermann, 2002; Biancarosa \& Snow, 2006; Graham \& Perin, 2007).

In the context of this study, writing is viewed as a tool that has the capacity to improve an individual's reading as well as one's overall ability to learn (Graham \& Hebert, 2010). Writing involves transforming one's thoughts, experiences, feelings, and ideas into written words in an effort to communicate information to others. Writing serves as a vehicle for recording, connecting, analyzing, personalizing, and manipulating critical ideas, which can be used to enhance one's comprehension or understanding of text. As with reading, writing is considered to 
be a fundamental skill necessary for meaningful participation in civic life and in the global economy in addition to playing a critical role in achieving personal and academic success (Graham \& Hebert, 2010; Graham \& Perin, 2007).

The term young adolescent is defined in This We Believe (Association for Middle Level Education, 2010) as students ranging in age from 10 to 15 years old. Additionally, the Association for Middle Level Education suggests that the term middle level education refers to a level of education serving young adolescents rather than on a specific grade plan or school organization. For the purposes of this study, though, the term middle school or middle level (used interchangeably) refers to a school organized around a sixth, seventh, and eighth grade configuration.

One additional clarification that may prove beneficial for understanding this study is the meaning of the term phenomenology as it appears throughout this investigation. For the purposes of this study, phenomenology is a qualitative research method that provides an opportunity to reveal and describe a phenomenon associated with human experience that is typically difficult to access, such as literacy (Giorgi, 1997). A phenomenological approach to qualitative research is integrated with a case study approach for this investigation because the aim of this study is to gain an understanding of this complex phenomenon, literacy, from the first person perspective of middle level English teachers. This approach is the most advantageous method for acquiring a thorough description of the phenomenon from the participants' first person account, followed by a conscientious and rigorous attempt to describe the phenomenon in as precise and detailed a manner as possible. The goal of utilizing this approach is to create a description of the phenomenon, literacy, in terms of the meaning that this particular phenomenon holds for the participants who have experience with the phenomenon. Therefore, this 
investigation strives to include a minimal number of generalities and abstractions so that the phenomenon can be described in as comprehensive a manner as possible, from the perspective of the individuals who willingly participated in this investigation.

Each of the previous terms highlighted in this discussion may hold a multitude of meanings to different individuals. Therefore, the goal of clarifying these somewhat ambiguous terms is not to suggest that the participants in this study should or will view these terms in this particular manner. Instead, this clarification of terms is provided in an effort to promote a clearer understanding of some of the terminology associated with literacy, which may have been arbitrarily defined in similar undertakings.

\section{The Adolescent Literacy Crisis}

Experts in the field of literacy have been confronted with an ongoing problem - every day in America, 3,000 students who possess limited literacy skills drop out of high school (NCTE, 2006). Graham and Perin (2007) and Pinkis (2006) estimate this number to be closer to 7,000 students per day. Either way, this statistic translates into well over one million students who drop out of high school each year. This high dropout rate comes as a result of the fact that there are over eight million students in grades 4-12 across the United States who read below grade level and are therefore, unable to read and write at a level that allows for basic academic success (Biancarosa \& Snow, 2006; NCTE, 2006; Wise, 2009). The Alliance for Excellent Education (2013) estimated that the Class of 2010 alone experienced 1.3 million high school dropouts. These issues, which are associated with limited acquisition of literacy skills that impact adolescents' ability to meet the continually fluctuating literacy demands associated with academic and career success, have led to a nationwide crisis in adolescent literacy (Antonacci \& O’Callaghan, 2011; Biancarosa \& Snow, 2006). 
The adolescent literacy crisis is not a new dilemma. Data from the National Assessment of Educational Progress (NAEP) show that adolescent literacy levels have remained basically unchanged for decades (National Center for Education Statistics, 2009). In 2009, eighth grade students who participated in the NAEP reading assessment achieved an average reading score that was one point higher than in 2007 and four points higher than in 1992. Although this increase appears to suggest growth in reading, these scores were not significantly greater than the scores achieved across this seventeen-year period. As a matter of fact, in 1998 and then again in 2002, eighth grade students achieved the same achievement levels as eighth grade students in 2009. Data from NAEP $(2003 ; 2007)$ reveal that a mere $70 \%$ of adolescents ranging in age from ten to eighteen are capable of reading and writing at basic levels or above (Donahue, Daane, \& Grigg, 2003; Donahue, Daane, \& Jin, 2005; Lee, Grigg, \& Donahue, 2007). This basic achievement level suggests that a student has acquired only partial mastery of the prerequisite knowledge and skills fundamental for proficient academic work (National Center for Education Statistics [NCES], 2011). Further, NAEP data suggests that approximately $23 \%$ of adolescents are able to read and write at a proficient level (Moje, Overby, Tysvaer, \& Morris, 2008), which signifies solid academic performance (NCES, 2011). Even fewer adolescents, $3 \%$, are able to read and write at advanced levels. This designation signifies superior academic performance (Moje, Overby, Tysvaer, \& Morris, 2008; NCES, 2009; NCES 2011). In 2009 the NAEP data examining results from 1992 through 2009 found that there have been fairly negligible gains for most groups of students and that adolescent literacy levels have remained relatively unchanged for decades (NCES, 2009).

In response to the ongoing issues associated with the adolescent literacy crisis, leading researchers and organizations have highlighted concerns that are related to this crisis. For 
instance, the National Council of Teachers of English (2006) cited several national reports that demonstrate the ongoing nature of this crisis in adolescent literacy:

- The American Institutes for Research (AIR) reports that only 13\% of American adults are capable of performing complex literacy tasks.

- The National Assessment of Educational Progress (NAEP) shows that secondary school students are reading significantly below expected levels.

- The National Assessment of Adult Literacy (NAAL) finds that literacy scores of high school graduates have dropped between 1992 and 2003.

- The National Center for Educational Statistics (NCES) reports a continuing and significant reading achievement gap between certain racial/ethnic/SES groups.

- The Alliance for Excellent Education (AEE) points to 8.7 million secondary school students - that is one in four - who are unable to read and comprehend the material in their textbooks.

- The 2005 ACT College Readiness Benchmark for Reading found that only about half the students tested were ready for college-level reading, and the 2005 scores were the lowest in a decade. (p. 4)

In conjunction with these findings, in their decisive, landmark report, Reading Next, Biancarosa and Snow (2006) articulate issues that underscore the adolescent literacy crisis. In a brief section accentuating research associated with the rising literacy demands of society coupled with declining overall nationwide literacy rates, Biancarosa and Snow report the following findings:

- Between 1996 and 2006, the average literacy required for all American occupations is projected to rise by 14 percent. The 25 fastest growing professions have far greater 
than average literacy demands, while the 25 fastest declining professions have lower than average literacy demands (Barton, 2000).

- Compared to ten years ago, significantly fewer adults demonstrate the skills necessary to perform complex and challenging literacy activities (NCES, 2005).

- Both dropouts and high school graduates are demonstrating significantly worse reading skills than ten years ago (NCES, 2005). (p. 8)

Several factors apparently contribute to this ongoing adolescent literacy crisis. Contributing factors may include the quality of classroom teachers, a high rate of teacher turnover, poor academic performance in both English and math where success is linked directly to a student's literacy skills, and the notion that students simply lack the literacy skills needed to keep up with an increasingly complex middle and secondary level curriculum. Although there are a range of factors that appear to contribute to the ongoing literacy crisis, low reading scores appear to be a major predictor of high school dropout rates (Alliance for Excellent Education, 2013; Kamil, 2003; Snow \& Biancarosa, 2003). The fact that nearly 70 percent of all students entering ninth-grade are reading below grade level clearly has implications in this literacy crisis (NCES, 2009). In addition to this fact, the Carnegie Council on Advancing Adolescent Literacy (2010) also noted that the majority of students who do graduate from high school do so without the basic reading and writing skills that will prove necessary for success in college and a future career.

According to the National Council of Teachers of English (NCTE, 2007), test scores and other associated data do not convey the full complexity of the adolescent literacy crisis. NCTE reminds educators that literacy learning is an ongoing and non-hierarchical process that is recursive in nature and requires ongoing development and practice across all levels of education. 
In a joint position statement of the International Reading Association and the National Middle School Association (2002) it is noted that "during the middle school years ... most students refine their reading preferences; become sophisticated readers of informational text; and lay the groundwork for the lifelong reading habits they will use in their personal, professional, and civic lives" (p. 1). Further, these experts in literacy suggest that students at the middle school level deserve continued and systematic instruction in reading.

Despite this call for a focus on ongoing literacy development at the middle and secondary level, major federal and state investments over the past decade have focused on early literacy initiatives rather than on literacy and content-area reading at the middle and high school levels (Alliance for Excellent Education, 2012). Research has shown that these concerted efforts at the K-3 levels have produced the highest achievement in reading for fourth-grade students in the past thirty-three years (Alliance for Excellent Education 2009; Carnegie Council on Advancing Literacy, 2010), yet these efforts have proven insufficient to guard against potential failure in the upper grades. While students' literacy achievements in the primary grades provide the critical foundation for building complex skills that are essential for success in middle and high school learning, it has become clear that many skilled third-grade readers will experience deteriorating literacy skills in the later grades if the teaching of literacy is neglected at the middle level (Biancarosa \& Snow, 2006). Although the 2011 NAEP data shows that the lowest-performing students are showing slight improvement in grades four and eight, the advancements are occurring at too slow a rate and are not comprehensive (Alliance for Excellent Education, 2012; NCES 2011). Maintaining sufficient, ongoing literacy development for young adolescents in the middle school years presents a greater challenge than providing suitable literacy instruction in the primary grades because the literacy tasks young adolescents encounter are influenced by a 
variety of factors, are more sophisticated, and are embedded in a variety of subject matters (Biancarosa \& Snow, 2006).

The statistics associated with the adolescent literacy crisis translate into the fact that more than half of the students entering the middle grades lack the skills needed to read and learn from the texts that will be required in their content area classrooms (Antonacci \& O'Callaghan, 2011; Biancarosa \& Snow, 2006). The disparity between the continually evolving literacy challenges of our highly-technological, global society and the inadequate literacy achievement of eight million struggling readers and writers has contributed to the sense of crisis associated with adolescent literacy (Biancarosa $\&$ Snow, 2006). It is evident that adolescent literacy must be improved in our nation's schools (Biancarosa \& Snow, 2006; Faggella-Luby, Ware, \& Capozzoli, 2009; Graves \& Liang, 2008; Heller \& Greenleaf, 2007; Moje, Young, Readence, \& Moore, 2000). While it has been suggested that all teachers in the middle grades hold some responsibility in bringing about this change (Graves \& Liang, 2008; Heller \& Greenleaf, 2007), it appears that English language arts teachers are often considered to be the authorities on literacy development in the middle school setting (Graves \& Liang, 2008; Heller \& Greenleaf, 2007). The demands placed on middle level English teachers include not only sole responsibility for developing young adolescents' ability to respond to literature, but also primary responsibility for teaching comprehension strategies (Graves \& Liang, 2008).

Improving the core literacy instruction in content area classrooms across the middle school level is an essential step in improving overall literacy achievement for young adolescents (Faggella-Luby, Ware, \& Capozzoli, 2009). However, most middle level content area teachers, including English language arts teachers, have not received extensive training in literacy instruction, which can present a challenge for these teachers (Faggella-Luby, Ware, \& Capozzoli, 
2009; Heller \& Greenleaf, 2007). Research suggests that effective literacy instruction for young adolescents occurs when teachers are well-informed about the nature of literacy development and when these teachers possess an effective array of strategies to teach literacy skills (Graves \& Liang, 2008). Unfortunately, though, since many middle level teachers feel unprepared to teach literacy skills, it is not clear what level of knowledge and understanding middle level teachers hold in regards to literacy and literacy development. In an effort to determine teachers' understanding of and beliefs about literacy, researchers have attempted to ascertain teachers' beliefs and perceptions about literacy. For decades, research has revealed that teachers' beliefs are an inextricable part of their instructional practices and decision-making in the classroom and these beliefs, in turn, strongly influence what they choose to teach and how they teach (Pajares, 1992; Richards \& Lockhart, 1994). Additionally, researchers have persistently suggested that it is vitally important to understand the connections between teachers' beliefs and actions in order to understand effective teaching (Clark \& Peterson, 1986). Contemporary research supports the notion that there is an ongoing need to focus on English language arts teachers' beliefs about literacy as well as the instructional practices associated with literacy instruction because teachers' beliefs, knowledge, and instructional practices have been shown to have a direct impact on students' overall academic performance as well as their overall beliefs about literacy (Fang, 1996; McCutchen, Abbott, et al., 2002; McCutchen, Green, Abbott, \& Sanders, 2009; Mujis \& Reynolds, 2001; Murphy, Delli, \& Edwards, 2004; Yero, 2002; Wray, Medwell, Poulson, \& Fox, 2002; Spear- Swerling \& Brucker, 2004).

\section{Purpose of the Study}

Since issues associated with the adolescent literacy crisis appear to be related in some manner to middle level literacy instruction and potentially with middle level teachers, the 
purpose of this phenomenological case study investigation is to examine two middle school English language arts teachers' beliefs about literacy and their associated instructional practices in a middle school located in a rural area of Northern Virginia. Literacy is regarded as a rather complex construct to define, yet at the beginning phase of the study (and from my perspective), literacy was believed to encompass tasks associated with reading, writing, composing, listening, viewing, problem solving, critical thinking, and communication skills, each of which contributes to the ways in which an individual makes sense of the world. This definition was tentatively held at the outset of this investigation and evolved throughout this study as I revealed the beliefs about literacy held by middle level ELA teachers as they endeavored to teach young adolescents in a rural middle school setting.

Through this phenomenological case study investigation of the perceptions of middle school English language arts teachers, insights gained from the classroom teachers were used to examine and describe the English teachers' beliefs about literacy as well as the instructional methods employed by the English teachers.

\section{Significance of the Study}

This study has the potential to provide beneficial insights for a variety of educational audiences, including middle level ELA teachers and researchers of adolescent literacy. Insights gained from this study may assist ELA teachers as they strive to contemplate their literacy beliefs, which directly influence the choice of instructional practices employed in the middle level classroom. More specifically, this research may prove valuable for individuals such as university instructors, professional development consultants, and school-wide literacy curriculum coordinators who work directly with pre- and in-service teachers, guiding them as they develop their beliefs about literacy and ultimately strive to incorporate meaningful literacy experiences 
designed to assist young adolescents in developing literacy skills that will prove valuable for the twenty-first century.

\section{Outline of the Study}

Thus far, Chapter 1 has presented the introduction, clarification of terms, a discussion of the problem, the purpose, and significance of the study. Chapter 2 contains the review of related literature and research related to the problem being investigated. The literature review describes why researchers focus on classroom teachers' beliefs and perceptions, provides details about the adolescent literacy perspective, and presents a brief overview of middle level instruction, explaining why the focus of this investigation is on middle level English teachers. The methodology and procedures used to collect and analyze data for the study are presented in Chapter 3. The results of data analysis and findings that emerged from the study are contained in Chapter 4. Chapter 5 contains a summary of the study and findings, conclusions drawn from the findings, a discussion, and recommendations for further study. 


\section{Chapter Two}

\section{Literature Review}

This chapter provides a review of the literature and related research pertaining to teachers' beliefs and middle level literacy. The purpose of this study is to examine both the literacy beliefs and the instructional practices of English language arts teachers involved in literacy instruction at the middle school level. Two initial research questions guided this study: 1) how do middle level English language arts teachers perceive and describe literacy; what are their beliefs about literacy; and 2) how are these literacy beliefs manifested in the instructional practices of the middle level English language arts teachers? The intent of this review of literature is to develop background for the reader and is offered to describe some of the issues believed to be associated with the study. This review is not intended to lead toward an a priori conceptualization of the phenomenon, literacy, nor is it intended to suggest any hypotheses associated with middle level English teachers or their beliefs about literacy. Further, this review of literature does not imply that the teachers involved in this study perceive literacy from any particular perspective.

The literature review is divided into three sections. Since the primary focus of this investigation is to reveal middle level ELA teachers' beliefs about literacy, the fundamental goal of the literature review is to emphasize issues associated with researching teachers' beliefs. In order to facilitate an understanding of this concept, the review of literature first offers a description of the various definitions of the term beliefs followed by an overview of studies that have focused on teachers' beliefs. The studies reviewed in this section provided substantial insights that contributed in meaningful ways to the methodological approaches chosen for this study (see Appendix A for an overview of these methodological considerations). 
Next, the review of literature briefly describes research associated with the contemporary secondary view of literacy, the adolescent literacy perspective. This section also acknowledges research associated with middle level instruction because this study takes place in a middle school setting. The last two sections include research that was purposefully selected in an effort to demonstrate the types of research being conducted in association with the adolescent literacy perspective (see Appendix B for an overview of the specific details of each of these research studies). This review of the research is not intended to be an exhaustive review of the research associated with adolescent literacy or middle level instruction. Instead, this review is included to demonstrate some of the various contexts, methodologies, findings, and calls for additional research in this critical area rather than suggesting that the participants in this current investigation should employ the methods and /or instructional approaches suggested by these previous research studies.

\section{Teacher Beliefs or Perceptions}

The notion of beliefs is one that has been studied by researchers for decades across many disciplines including philosophy, psychology, sociology, anthropology, and education. One of the most challenging issues in studying beliefs is that the meaning of this term has not been coherently articulated across disciplines nor across studies. The term beliefs has become synonymous with a range of terms including perceptions, knowledge, theories, psychological constructs, assumptions, personal epistemologies, and many other names (Bryan, 2003; Clark \& Peterson, 1986; DeFord, 1985; Goodman, 1988; Harste \& Burke, 1977; Kagan, 1992; Nespor, 1987; Pajares, 1992). The study of teachers' beliefs is critical to research on teachers and teaching because the act of teaching combines two fundamental processes: 1) teachers' thought processes (also referred to as teacher cognition), and 2) teachers' actions and their observable 
effects (Clark \& Peterson, 1984; Fang, 1996). The diagram in Figure 1 attempts to depict the complexity of the word beliefs, indicating the range of terms that has been used to refer to this rather ambiguous construct.

Figure 1. Graphic representation of terms associated with the construct "beliefs."

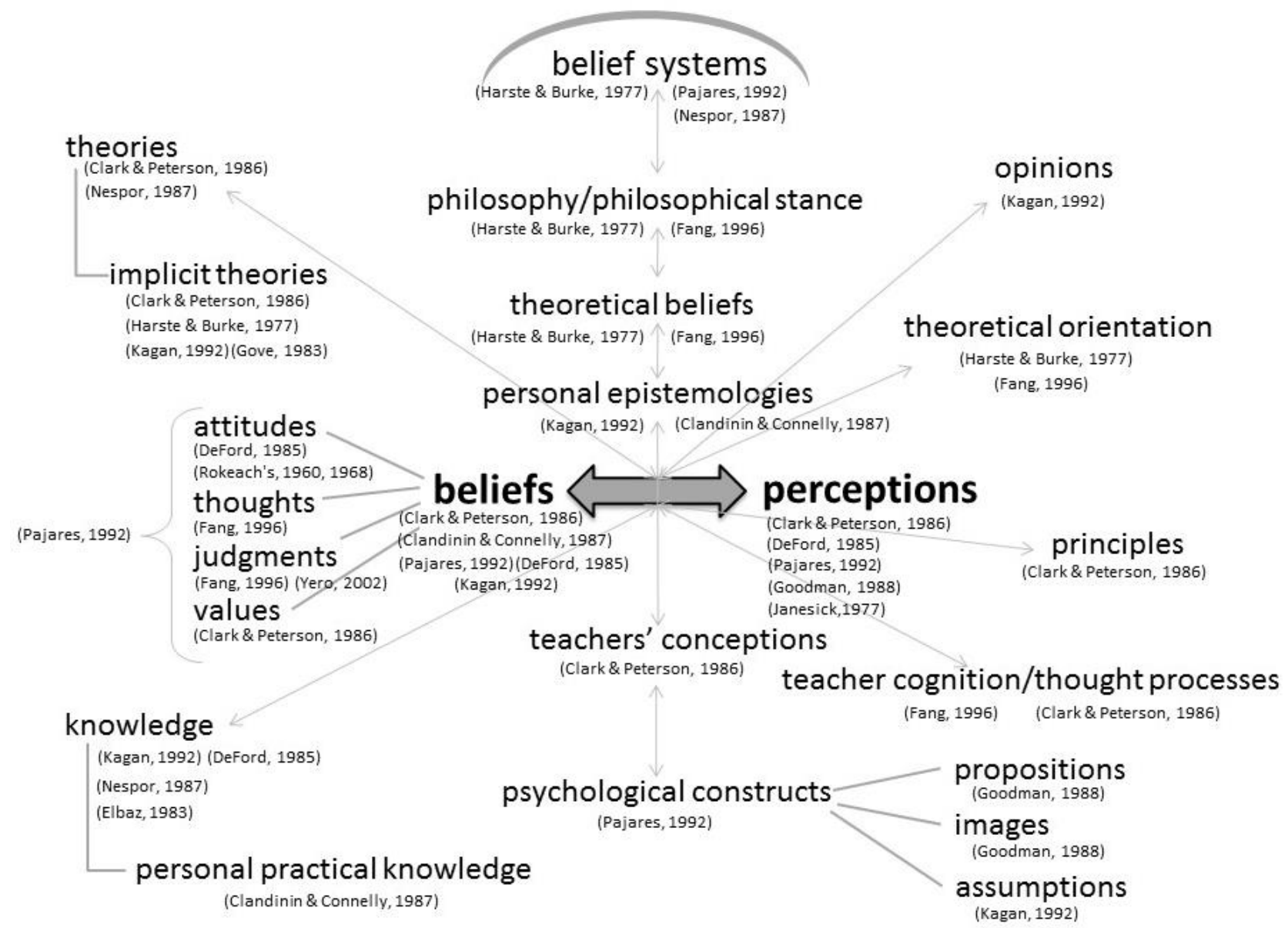

Dewey (1910) was one of the earlier educators who considered beliefs to play an

important role in teaching. Dewey related beliefs with thinking or thought. He viewed beliefs as being associated with what he referred to as the third meaning of thought. Dewey characterized beliefs as resting "upon some kind of evidence or testimony" (p. 1), which at times are simply accepted with little to no validation, while in other instances, justifications in support of the 
beliefs are purposefully sought. Dewey found the notion of beliefs to be critical enough to education to warrant further examination, and in 1933 asserted that beliefs comprise all the matters of which we have no sure knowledge, and yet which we are sufficiently confident of to act upon, and also the matters that we now accept as certainly true, as knowledge, but which nevertheless may be questioned in the future. (p. 6)

Since Dewey's time, many educational researchers have continued to explore the nature of beliefs and their association with teaching (e.g. Clark \& Peterson, 1986; Kagan, 1992; Nespor, 1987; Pajares, 1992; Richardson, 1996). Bryan (2003) analyzed the literature on beliefs and concluded that many researchers have contributed to a more distinct understanding of beliefs, stating that

beliefs are psychological constructions that (a) include understandings, assumptions, images, or propositions that are felt to be true (Kagan, 1992; Richardson, 1996); (b) drive a person's actions and support decisions and judgments (Goodenough, 1963; Pajares, 1992); (c) have highly variable and uncertain linkages to personal, episodic, and emotional experiences (Nespor, 1987); and (d) although undeniably related to knowledge, differ from knowledge in that beliefs do not require a condition of truth (Dewey, 1933; Richardson, 1996). (p. 837)

Further, Bryan asserted that teachers' beliefs play a critical role in how pedagogical knowledge is interpreted, how teaching tasks are conceptualized, and how teaching practices are subsequently enacted in the classroom.

When attempting to define the construct beliefs or perceptions, it is most beneficial to explore each researcher's work in order to determine the unique meaning that has been assigned to the term in the context of the investigation (Clandanin \& Connelly, 1987) because as Pajares 
(1992) noted, "defining beliefs is at best a game of player's choice" (p. 309). Pajares further observed that much of the confusion associated with the term beliefs arises because of a lack of distinction between beliefs and knowledge. Pajares concluded that there is an "artificial distinction between belief and knowledge [that] is common to most definitions" of beliefs, suggesting that beliefs are "based on evaluation and judgment," whereas "knowledge is based on objective fact" (p. 313). Despite the confusion and lack of consistency that exists across research studies, several influential researchers have offered their definition of beliefs.

Goodenough (1963) defined beliefs as comprising implicit or explicit propositions which are deemed to be true that "are accepted as guides for assessing the future, are cited in support of decisions, or are referred to in passing judgment on the behavior of others" (p. 151). Rokeach (1968) also defined beliefs in terms of propositions, stating that beliefs are "any simple proposition, conscious or unconscious, inferred from what a person says or does, capable of being preceded by the phrase, 'I believe that ..."' (p. 113). In an extensive description of the role that beliefs play in learning to teach, Richardson (1996) explained that "attitudes and beliefs are a subset of a group of constructs that name, define, and describe the structure and content of mental states that are thought to drive a person's actions" (p. 102). She defined beliefs specifically as "psychologically held understandings, premises, or propositions about the world that are felt to be true" (p. 103). Further, Richardson asserted that beliefs "do not require a truth condition" (p. 104).

Clark and Peterson (1984) borrowed from Nisbett and Ross (1980) in order to define teachers' beliefs. In this definition, teachers' theories or beliefs are referred to as a form of knowledge known as propositional knowledge. According to Clark and Peterson, teachers' beliefs are characterized as the rich collection of knowledge that teachers possess. This 
accumulation of knowledge is believed to influence teachers' interactive thoughts and decisions as well as their instructional planning. Additionally, Clark and Peterson referenced Janesick's (1977) definition of perspective as differing from that of beliefs. Perspective is defined as "a reflective, socially-derived interpretation of experience that serves as a basis for subsequent action" (Clark \& Peterson, 1984, p. 111). This definition is linked with teachers' perspectives which combine "beliefs, intentions, interpretations, and behavior that interact continually and are modified by social interaction" (Clark \& Peterson, 1984, p. 111). A teacher's perspective is said to serve as a frame of reference through which teachers make sense of and interpret experiences and which guides teachers in acting rationally in the classroom (Clark \& Peterson, 1984).

Harste and Burke (1977) examined research associated specifically with reading teachers. They used the term theory to refer to the underlying construct associated with teachers' beliefs. They defined a theory as "a system of assumptions through which experiences are organized and acted upon" (p. 32). In their review of reading research, Harste and Burke noted that teachers possess theoretical orientations, which include particular knowledge and belief systems about reading. They explained that in practice, this knowledge and belief system (or theoretical orientation) functions to establish expectations in the classroom as well as strongly influencing a multitude of decisions made by teachers in regard to reading. Further, this belief system serves as a filter through which teachers analyze and interpret new ideas. This organized set of beliefs or theories guide teachers' thinking and behavior and have a direct influence on teaching practice.

Nespor (1987) also referred to beliefs as being associated with theories that teachers develop about instruction. Nespor suggested that these theories influence teachers' decisionmaking and are aligned with personally held belief systems. Nespor viewed these theories as 
being informal, personal, and implicit and as significantly influencing the teaching environment as well as classroom practices.

Finally, Kagan (1992) defined teacher beliefs as "tacit, often unconsciously held assumptions about students, classrooms, and the academic material to be taught" (p.65). These beliefs are implicit and can be linked with learning, students, classrooms, and the subject matter being taught. From Kagan's perspective, “most of a teacher's professional knowledge can be regarded more accurately as belief [that] ... has been affirmed as true on the basis of objective proof or consensus of opinion" (p. 73). Kagan proceeded to explain that a teacher's professional knowledge is situated in three important ways: "in context (it is related to specific groups of students), in content (it is related to particular academic material to be taught), and in person (it is embedded within the teacher's unique belief system)" (p. 74).

It is evident from these varying definitions of beliefs that while there are some indistinct commonalities across these definitions, there exists a broad array of conceptualizations about this obscure term. Although this term has proven challenging to define in the context of research investigations, it is apparent that this is an area of educational research that warrants further investigation. Many of the researchers who have invested their time in examining teachers' beliefs have come to the conclusion that further investigation of teachers' beliefs will prove to be one of the most valuable psychological constructs to teacher education (Kagan, 1992; Pajares, 1992; Pintrich, 1990).

Articulating the need to study teachers' beliefs. Although the construct of beliefs may be defined and characterized in a variety of ways, it is apparent that all teachers hold beliefs about the work they do in the classroom, the subject matter they teach, the roles and responsibilities they hold, and the students with whom they work (Pajares, 1992). The ongoing 
investigation of this construct is vital to the continuing development of the field of education because researchers have found that beliefs influence teachers and their classroom instruction in a multitude of ways. The diagram in Figure 2 summarizes the conclusions drawn by the aforementioned researchers, portraying the range of ways that teachers' beliefs impact their instruction and/or classroom practices.

Figure 2. Graphic representation of conclusions drawn about teachers' beliefs.

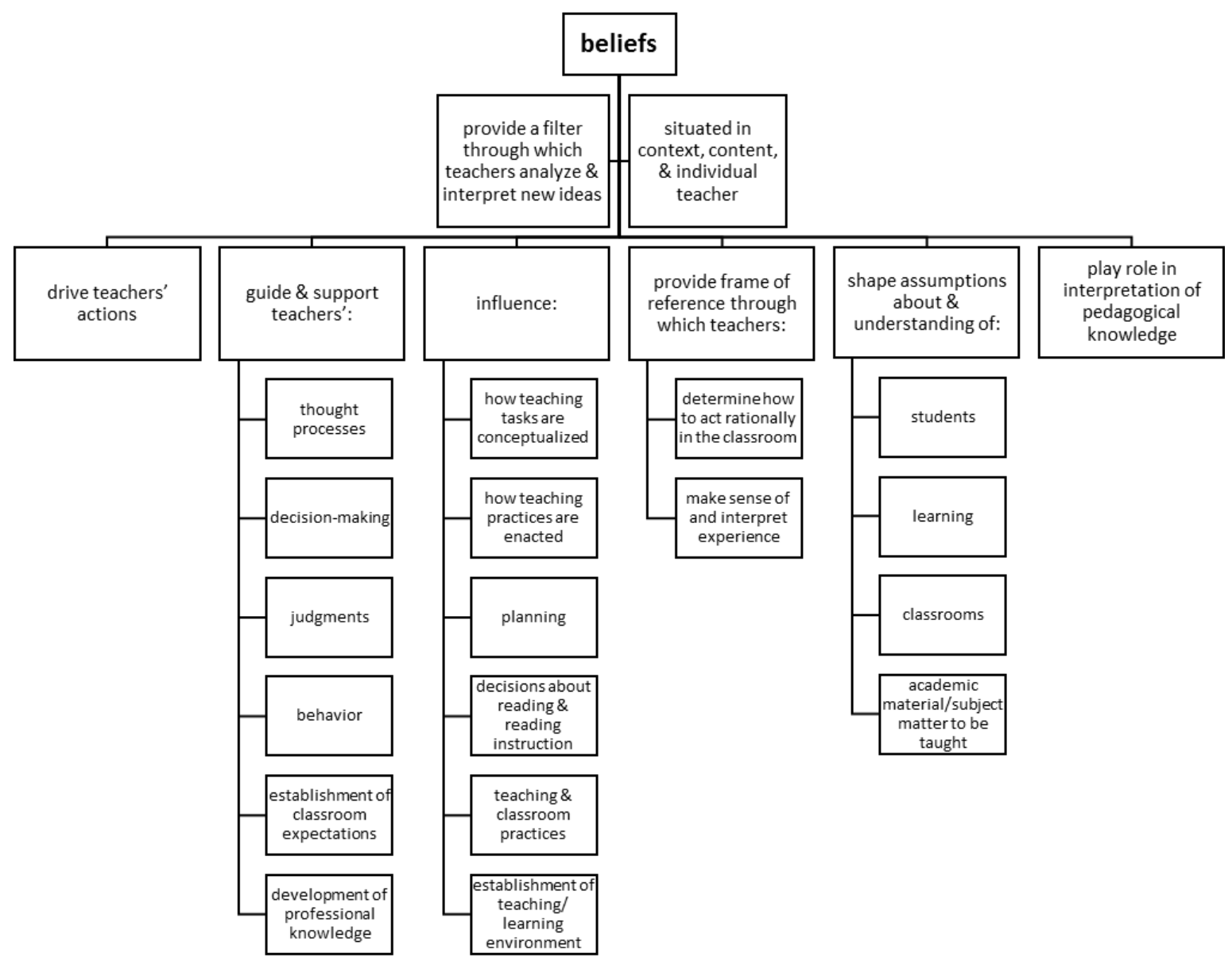

Teachers' beliefs clearly play a vital role in shaping the educational landscape. This is a construct that, although difficult to reveal and explicate, must continue to be examined within the context of the authentic classroom environment. The challenge in studying this construct is situated in the fact that individual's beliefs are implicit, in-the-head conceptions that are difficult 
for individuals to isolate, discern, and describe. Rokeach (1968) and Pajares (1992)

acknowledged the fact that individuals tend to have a difficult time accurately articulating their beliefs. This presents a challenge because as Kagan (1992) posits, teachers' beliefs and perceptions are uniquely situated within the context, content, and mind of each individual teacher. Researchers have attempted to address this issue through various research techniques across decades of research associated with teachers' beliefs.

In order to explore teachers' beliefs, Rokeach (1968) suggested that this research must consider the various ways that individuals are able to provide evidence of their espoused beliefs. He explained that beliefs reveal themselves through belief statements, through an individual's intentionality to act or behave in a predisposed manner, and through behaviors that are related in some manner to the belief in question (Rokeach, 1968). As Pajares (1992) noted, beliefs are constructs that cannot be observed directly or measured through an instrument; instead, they must be inferred from what people say, intend, and do. Pajares mentioned an important caveat to this assumption, though. He explained that there is a great deal of complexity associated with studying teachers' beliefs because teachers hold an array of beliefs that are not only connected directly to teaching and learning, but also to matters that extend beyond their profession. $\mathrm{He}$ noted that although these general belief systems clearly influence teachers' instructional practices, these beliefs are not the beliefs that researchers are interested in examining. Instead, when researchers are exploring a teacher's beliefs, they are attempting to isolate the teacher's unique educational beliefs associated with a specific area of interest to the researcher. These unique beliefs are said to be more specific to the overall educational process (Pajares, 1992). Therefore, researchers must specify precisely what facet of a teacher's belief system they are attempting to isolate and define. For instance, in the context of the current investigation, I 
endeavor to reveal middle level English language arts teachers' beliefs associated with literacy. Two terms, beliefs and perceptions, are used interchangeably since, as the review of literature on beliefs illustrated, these two terms are synonymous and have been used by numerous researchers to refer to the same psychologically held construct. As a direct consequence of the intended goal of revealing teachers' literacy beliefs, I utilized a methodological approach that provided an opportunity to identify, understand, and describe literacy from the subjective viewpoint of the participants involved in this investigation. By employing this methodological approach (described in Chapter 3), I was able to maintain the participant's voice in the description of literacy beliefs and practices rather than assuming either my subjective viewpoint or a predetermined theoretical or objective interpretation of literacy.

The complexity of issues associated with studying teachers' beliefs clearly play a role in limiting the number of studies associated with investigating teachers' beliefs. Pajares (1992) alleged that this is why the study of beliefs has been "avoided by all but the most resolute investigators and have [typically] been relegated to the domains of philosophy or mysticism" (p. 317). Despite this reluctance to study teachers' beliefs, researchers have undertaken this endeavor because research suggests that teachers' beliefs constitute an integral part of the knowledge through which teachers perceive and process information and implement tasks in the classroom (Clark \& Peterson, 1986; Fang, 1996; Munby, 1982). It is likely that this is one of the reasons that research findings show that there is "a strong relationship between teachers' educational beliefs and their planning, instructional decisions, and classroom practices" (Pajares, 1992, p. 326). This finding is important to ongoing educational research because it is believed that studying both teachers' beliefs and their instructional practices has the potential to influence 
students' academic performance, while also enhancing overall educational effectiveness (Brophy \& Good, 1974; Clark \& Peterson, 1986; Fang, 1996).

Researchers have set out to identify teachers' beliefs and perceptions through a variety of methodological approaches. Some researchers have attempted to ascertain teachers' beliefs through more traditional, paper-pencil based instruments, while others have utilized open-ended approaches based upon qualitative means. The paper-pencil based instruments used to measure teachers' beliefs generally utilize self-report questionnaires that include Likert-style survey responses (see DeFord, 1985; Duffy \& Metheney, 1979; Lenski, Wham, \& Griffey, 1998). Research approaches that employ qualitative measures typically include think aloud protocols, retrospective interviews, stimulated recall, journal keeping, focused interviews, ethnographies, the use of metaphors, and policy capturing techniques (see Dooley \& Assaf, 2009; Fang, 1996; Munby, 1986, 1987; Munby \& Russell, 1990; Nolen, 2001). Still other researchers have utilized a combination of measures, often integrating quantitative means with qualitative means using methods such as the repertory grid technique, Q-sort tasks, questionnaires coupled with interviews and observations, surveys, and other means that generally integrate a case study approach (see Dadds, 1999; Mallette, Henk, Waggoner, \& DeLaney, 2005; Murphy, Delli, \& Edwards, 2004; Rimm-Kaufman \& Sawyer, 2004; Theriot \& Tice, 2008).

Additionally, a number of dissertations have recently emerged that have attempted to examine teachers' beliefs associated with various content areas (see Al-Arfajr, 2001; Guise, 2009; Howerton, 2006; Maziarz, 2007; Meyer, 2009; Poole- Christian, 2009; Vélez, 2010; Weingartner, 2008). It has been suggested that the more traditional self-report belief inventories provide limited information from which researchers are able to draw inferences (Pajares, 1992). Pajares indicated that these belief inventories cannot adequately "encompass the myriad of 
contexts under which specific beliefs become attitudes or values that give fruition to intention and behavior" (p. 326); therefore, measures such as open-ended interviews, responses to dilemmas and vignettes, and observation of behavior must be included if richer and more accurate inferences are to be made (Pajares, 1992).

In response to the potential narrowing of views that may be associated with quantitative measures, it appears that qualitative research methods are emerging as the most relevant and promising methodology for more effectively acquiring the types of inferences needed to adequately determine teachers' beliefs and their instructional practices (Pajares, 1992); this view is supported by several experts in the field. Munby $(1982,1984,1986,1987)$ promoted the use of qualitative methods including using metaphor, biography, and narrative inquiry as a means for understanding the beliefs of teachers. In addition, Schunk (1991) also suggested utilizing case studies or oral histories in order to gain insights into teachers' beliefs. Fang (1996) reiterated the importance of focusing on participants' own narratives in order to acquire the emic perspectives of teachers. Fang explained that through these personal narratives, researchers are better able to reflect on and conceive of the complex interrelationships between teachers' personal experiences and their instructional intentions. Fang advocates the use of narrative inquiry, life history, and autobiography as a means to achieve this goal. Fang contends that these approaches offer the best opportunity to bring new meaning to teacher education and to teachers' opportunities for professional growth and development.

In order to align this current investigation with suggestions made by Pajares (1992) and Fang (1996), I have chosen literacy as the precise facet of a teacher's belief system that I am attempting to isolate and define. Furthermore, because it has been suggested that narrative, qualitative measures provide the most applicable and advantageous methodology for effectively 
acquiring the types of inferences required to adequately determine teachers' beliefs and their associated instructional practices, a qualitative methodological approach that presents an opportunity to identify, understand, and describe literacy from the subjective viewpoint of the participants was employed. By utilizing a narrative, qualitative methodological approach (described in Chapter 3) I was able to maintain the participants' unique voices in the descriptions of their literacy beliefs and practices.

\section{Extant Studies of Teachers' Literacy Beliefs}

Teachers' beliefs have been studied through various methods for decades, with many of those studies focusing on issues associated with literacy. This review of research on teachers' literacy beliefs examines studies that have utilized quantitative, qualitative, and mixed methods approaches in an effort to identify and/or understand teachers' beliefs associated with literacy. First, studies employing quantitative approaches are discussed. Next, studies utilizing qualitative approaches are described. Then studies that integrate quantitative and qualitative methods are examined, followed by several recent dissertations that utilize a variety of research methods to explore teachers' beliefs about literacy.

Quantitative studies of teachers' beliefs. Several quantitative instruments have been developed over the years in an effort to determine teachers' beliefs about reading and/or literacy. These measures utilize Likert-style survey question formats designed to ask teachers to rank statements associated with reading or literacy. Each of the measures described in this review were subjected to critical evaluation in an effort to determine the extent to which the statements adequately represented teachers' reading or literacy beliefs and were also subjected to reliability and validity studies. Following an overview of three measures, the reading propositional inventory (Duffy \& Metheney, 1979), the Theoretical Orientation to Reading Profile (TOPR) 
(DeFord, 1985), and the Literacy Orientation Survey (LOS) (Lenski, Wham, \& Griffey, 1998), some limitations associated with these quantitative measures are described.

Duffy and Metheney (1979) determined that prior to 1977 research on teachers' beliefs about reading had been nearly nonexistent. In response to this dearth of research, Duffy and Metheny chose to examine whether or not teachers possessed beliefs about reading. Further, if these beliefs did indeed exist, they wanted to explore the ways in which these beliefs influenced the teachers' instructional decisions as well as student outcomes. Through a multi-step process, the researchers identified a range of teacher decision-making categories, used these categories to develop statement cards for teachers to review, and then utilized this information to create Likert-scale questions to include on their "reading propositional inventory." The researchers used classroom observations to pinpoint the teacher decision-making categories, which included judging pupil success; criteria for forming instructional groups; allocation of time to reading activities; allocation of time to ability groups; favored word recognition prompts; comprehension emphasis; and instructional role.

Next, Duffy and Metheney (1979) used the data from the teacher observations to develop statements about instruction that were recorded on cards. These cards were then presented to teachers, where they were sorted by agreement or disagreement with the statements. This work led to the development of a five-point Likert-scale survey that contained six conceptual categories. A factor analysis eventually led to three clusters of beliefs: basal text and linear skills cluster; interest-based, natural language, and integrated curriculum models cluster; and a "confused-frustrated" category, which was later eliminated because this construct could not be validated. Once the Propositional Inventory was validated, the researchers found that when this quantitative measure was used in conjunction with classroom observations, data obtained 
through these means revealed that teachers' professed reading beliefs (as determined by the survey instrument) were generally consistent with their classroom practices. Duffy and Metheny concluded that their quantitative instrument could be used effectively to help determine how teachers view particular reading beliefs and how their decisions differ in practice.

The Theoretical Orientation to Reading Profile (TORP) is another quantitative measure designed to explore teachers' beliefs about reading. The TORP was developed by DeFord in 1985. The purpose of this instrument was to classify a teacher's theoretical orientation to reading instruction. This instrument was developed through a constructivist perspective and was subjected to reliability and validity studies. The information acquired through this measure is said to provide information that is used to help teachers and researchers determine teachers' beliefs about their practices in reading instruction. The results of this instrument provide a consistent measure that profiles teacher-held belief systems accurately and reliably.

In order to develop this instrument, DeFord (1985) examined and categorized instructional programs in reading according to basic distinctions in theoretical orientations that are typically assumed by teachers. This classification led to three clusters of theoretical orientations. The first cluster was a phonics orientation cluster, which emphasized language units smaller than word level units that gradually progressed toward larger word units with increased attention to comprehension. The second cluster was a skills orientation cluster. In this orientation, the emphasis was on building an adequate sight word vocabulary for children to use in reading. The third cluster was a whole language orientation. The focus of this orientation was instructional programs that provided readers with quality literature from the outset of instruction. Once these clusters or orientations to reading were identified, Likert-scale survey questions were developed to be included on the TORP instrument. 
In order to validate the questions for the survey, judges from the field of reading were asked if they agreed that each of the questions were truly indicative of a phonics, skills, or whole language orientation. In addition to these expert reviews of each of the questions, experts from the field of reading were also trained to observe select teachers in order to identify salient features of each theoretical orientation through video recordings of teachers' instruction. During these observations, reading lessons were analyzed for overt and covert indices of teachers' models of reading. The pilot process included 47 experts in the field and 90 teachers of known orientation, including 30 for each of three groups - phonics, skills, and whole language orientations.

The findings of DeFord's (1985) study revealed that a teacher's theoretical orientation acts as a filter for perceiving, understanding, organizing, and acting in the classroom. The data revealed that teacher beliefs influence how readers respond in the learning environment. While this instrument was found to be both a reliable and valid means for classifying teachers based upon their theoretical orientation to reading, DeFord suggested that the most beneficial use of this instrument was in helping researchers and teachers examine the assumptions they hold, to make both research and instruction as consistent and effective as possible, and to develop comprehensive models of reading and instruction based upon clearly defined theoretical positions. In order to achieve this goal DeFord recommended using interviews or observations in conjunction with the TORP in an effort to accurately confirm a teacher's theoretical orientation to reading.

In a study similar to Deford's (1985), Lenski, Wham, and Griffey (1998) developed a Literacy Orientation Survey (LOS) which is a quantitative instrument designed to measure the construct of literacy beliefs and practices in constructivist classrooms. The process of 
developing this instrument began first with defining the practice of "constructivism" as it is associated with literacy learning. During the construction of this instrument, the researchers developed ten constructivist principles, upon which the LOS was based. These principles are: Principle 1: the teacher views literacy as a meaning-making process; Principle 2: the teacher facilitates child-centered instruction; Principle 3: the teacher creates an environment conducive to developing literacy skills; Principle 4: the teacher provides effective instruction in strategic reading practices; Principle 5: the teacher facilitates student writing; Principle 6: the teacher employs flexible grouping; Principle 7: the teacher provides instruction through a thematic approach that integrates subject matter across the curriculum; Principle 8: the teacher employs meaningful assessment; Principle 9: the teacher encourages parental involvement; and Principle 10: the teacher engages in ongoing reflection. As each of the definitions of these ten principles were refined, a preliminary bank of survey items designed to test these principles was developed. As these theory-based belief statements were created, the researchers connected these statements to classroom practice. Initially, a preliminary pool of 118 survey items was developed. Of these items, approximately half of the items focused on beliefs and half focused on practices. Next, a panel of 20 experts in the field of literacy reviewed these statements. This was followed by an item analysis, after which 44 items were retained.

Prior to giving this survey to a pool of teachers, a group of teachers was chosen for the pilot and these teachers were interviewed in order to determine the category of classroom instruction each teacher was most aligned with (traditional, eclectic, or constructivist). Following the interviews, the survey was administered to the pool of 110 elementary teachers. From this pilot work, a final draft version of the LOS instrument was developed, which included 30 items, 15 of which were belief statements and 15 practice statements. Following test-retest 
analysis the respondents were asked to identify their teaching style based on a scale of one through four (one being traditional, two being somewhat traditional, three being somewhat holistic, and four being holistic).

The results of Lenski, Wham, and Griffey's (1998) study revealed that the LOS effectively differentiates between teachers who are traditional or holistic. The research also revealed a definition of traditional, eclectic, and constructivist teaching practices. Lenski, Wham, and Griffey define a traditional teacher as one who uses traditional reading methods such as basal reading instruction, teaches primarily through direct instruction, and views students as "vessels to be filled." An eclectic teacher is one who uses some traditional and some constructivist reading methods, but frequently "basalizes" literature selections and works from a combined traditional and constructivist view about student learning. A constructivist teacher is one who uses whole text and integrated instruction, who teaches using primarily an inquiry approach, and who views students as using prior knowledge to construct meaning to learn. Lenski, Wham, and Griffey concluded that the LOS reveals the degree to which teachers' beliefs and practices are consistent with constructivist philosophy. They suggest that this tool can be used to help teachers determine whether they are following constructivist principles in their literacy instruction. This instrument also gives teachers a sense of whether they tend to be more in line with a traditional, eclectic, or constructivist view of teaching. The results also suggest that this tool can be used to show teachers how closely their beliefs align with their instructional practices in the classroom.

The three quantitative measures, the reading propositional inventory (Duffy \& Metheney, 1979), the Theoretical Orientation to Reading Profile (TOPR) (DeFord, 1985), and the Literacy Orientation Survey (LOS) (Lenski, Wham, \& Griffey, 1998), have been used by researchers in 
an effort to define teachers' beliefs as they are associated with reading and literacy, and have attempted to aid in clarifying the connections between these beliefs and instructional practices. Despite the fact that each of the instruments has undergone rigorous reliability and validity studies, experts in the field of literacy and experts who have studied teacher belief systems have come to the conclusion that these instruments do not have the ability to effectively and accurately portray the entire picture when it comes to identifying teachers' beliefs. Fang (1996), for instance, noted that while these paper-pencil instruments can be used to capture teachers' beliefs about literacy, they fall short of adequately addressing the personal experiences associated with the development of teachers' beliefs and belief systems and how these beliefs influence classroom instruction. Researchers concerned with investigating teachers' beliefs have concluded that the most effective and valuable tools for attempting to discern and describe teachers' beliefs are qualitative measures that provide opportunities to talk with teachers (i.e., formal and/or informal interviews) and to observe their classroom instruction (Fang, 1996; Munby, 1982, 1984, 1986, 1987; Pajares, 1992; Schunk, 1991), which cannot be achieved through strictly quantitative means such as the instruments described in this section. The researchers who developed these quantitative instruments themselves, have even acknowledged that their instruments provide the most distinct representation of teachers' beliefs when these measures are combined with qualitative means such as interviews and/or classroom observations (DeFord, 1985; Duffy \& Metheny, 1979). Some studies have utilized strictly qualitative measures to attempt to discern teachers' beliefs associated with literacy, while even more studies have integrated qualitative approaches with quantitative measures.

Qualitative studies of teachers' beliefs. Qualitative research approaches have proven to be useful in studies of teachers' beliefs and classroom practices associated with literacy. A 
variety of qualitative means have been used to study teachers' literacy beliefs including ethnographic studies, basic qualitative methods, and a preponderance of case studies. Two qualitative investigations are described here, followed by descriptions of studies that integrate qualitative methods with quantitative measures.

In a study associated with the construction of literacy in a kindergarten setting, Nolen (2001) employed an ethnographic approach in order to explore how kindergarten children and their teachers jointly constructed literacy and how this context influenced the motivation of kindergarten children given the fact that tasks associated with reading and writing are particularly difficult for these children. During this investigation, Nolen also examined the classroom teachers' instructional goals in an effort to determine how these goals impacted the construction of literacy and the development of children's motivation to read and write. Nolen studied four kindergarten teachers in three suburban school districts during the course of one school year. During classroom observations, Nolen observed children's motivated behavior and described the context under which these motivated behaviors occurred. This included the children's and teachers' words, actions, and the tasks taking place, within which these motivated behaviors occurred. Nolen gathered data from three different perspectives, the teachers', the students', and her own perspective as an observer. Nolen's data analysis led to the conclusion that together, teachers and students constructed legitimate literate activities in their classrooms. Further, she found that the motivation of students who were at risk was framed by this construction of literate activities.

The results of Nolen's (2001) study that are most interesting to this current investigation of teachers' literacy beliefs are associated with the finding that in the four classrooms involved in this study, four different definitions of successful reading and writing emerged. These 
definitions of literacy (i.e., reading and writing) were consequently learned by the children as a direct result of the literacy tasks that occurred in each classroom as well as through the literate conversations among the members of the classroom community. Nolen concluded that together, teachers and students create the literacy cultures in the classroom. Further, differences in the classroom literacy cultures have the potential to impact the motivation of all students to read and write, but this was particularly the case with children identified as being at-risk for reading and writing difficulties. This research revealed that the kindergarten teachers' beliefs about literacy and their classroom practices influenced the manner in which students connect school literacy activities to their personal lives, the reasons students develop for learning to read and write, the students views about collaboration, and the level of motivation students achieve. This finding is particularly striking because it suggests that teachers' literacy beliefs play a particularly significant role in the classroom environment, influencing not only the teachers' instructional decisions, but also the overall literacy views and potential achievement of students.

Dooley and Assaf (2009) conducted a retrospective cross-case analysis that compared two fourth-grade language arts teachers' beliefs and practices in response to an influx of highstakes tests. Each researcher involved in this study had originally conducted a single-case ethnographic case study (Assaf, 2006; Dooley, 2005) investigating how a fourth grade teacher implemented language arts instruction. Both researchers employed ethnographic and grounded theory methodologies to examine teachers' knowledge through their talk (as evidence of their beliefs) and instruction (as evidence of their practices). As participant observers, both researchers separately spent more than 130 hours over four months in each teacher's school, collecting field notes and conducting formal and informal interviews with each teacher, the teacher's colleagues, and the teacher's students. After observing in each teacher's classroom, the 
researchers then conducted formal and informal interviews of teachers and students in an effort to clarify issues and/or questions that emerged.

Through the course of the original investigations, the focus of each study had shifted to an inquiry into how each teacher responded to pressures related to high-stakes testing because during the investigations it became apparent that pressures associated with high-stakes tests had become prevalent. During the original investigations, each researcher used the participating teachers' knowledge as a theoretical lens through which to view the investigation. Both researchers became interested in determining how context shaped the participating teachers' knowledge. Neither researcher was aware of the fact that a similar study was being conducted until after each individual investigation was complete. The researchers began discussing their findings and were surprised to find similarities and differences across the two investigations. The researchers then decided to use a retrospective cross-case analysis to compare the two language arts teachers' beliefs and practices. Data units for this study included meaning units related to beliefs, which were characterized by statements that the teachers made, and practices, which were characterized by anecdotes recorded in the field notes of the researchers. In order to make comparisons across the two studies, the researchers created a database that consisted of statements used to illustrate beliefs and scenarios used to illustrate practices. Afterwards, the researchers used constant comparative analysis to sort the statements and vignettes into categories. Three categories emerged, which described teachers' knowledge about literacy instruction: atmosphere of engagement, instructional methods, and test mentality.

The findings of Dooley and Assaf's (2009) cross-case analysis are particularly meaningful to the current investigation of middle level English language arts teachers' literacy beliefs and instructional practices. Dooley and Assaf found that the two teachers involved in the 
original studies held similar pedagogical philosophies; the teachers' belief statements were similar across all categories, yet the teachers' practices (or what the researchers referred to as applied knowledge), as well as the contextual factors, were quite different. The two teachers described their reading and writing instruction as incorporating authentic, social encounters with texts so that children develop a mastery of and love for reading and writing. Both teachers talked about using innovative practices that align with "best practices" for literacy instruction and both provided authentic texts to address their students' interests and abilities, yet these books were incorporated into instructional practices in distinctly different ways. One teacher used more peer-led book discussions, encouraged dialogue among classmates, and predominantly used a variety of authentic texts, while the other teacher used teacher-directed reading instruction that focused on specific skills, including how to write a summary or how to look up words in the dictionary. In regards to high-stakes testing, both teachers experienced different test-related pressures within their school contexts. Both teachers disagreed with the pressures related to high-stakes testing, but their beliefs, practices, and most significantly, the contextual factors differed considerably. Both teachers employed high-stakes testing preparation in the classroom, but the differences in their approaches were substantial.

The findings of Dooley and Assaf's (2009) study reveal that although two teachers share very similar literacy beliefs, they employ notably different instructional practices. The researchers concluded that these differences were likely related to contextual differences that exist as a result of the two different school contexts. Dooley and Assaf's study is unique because it focuses on teachers' literacy perspectives and practices within their individual school contexts. Their study differs from this current investigation of English language arts teachers' literacy beliefs and practices in that the two teachers involved in the current study work in the same 
school community (the same context) with the same expectations regarding curriculum and potential testing pressures. The research reported in this document offered the opportunity to explore the similarities and differences in two middle level English language arts teachers' beliefs and practices associated with literacy within a single school context.

Studies of teachers' beliefs that used mixed methods. Many of the studies associated with teachers' literacy beliefs and/or practices have integrated a variety of methodological approaches. A combination of qualitative and quantitative research approaches have been used in several studies in an effort to more adequately achieve an understanding of teachers' beliefs.

Dadds (1999) conducted seven case studies (which later evolved into ten case studies as new members joined) that set out to investigate teachers' values and beliefs about literacy. This study differs from the current investigation in that it is situated in the context of an action research project involving experienced teacher researchers, who focused on improving literacy in primary schools in England. The teacher researchers participating in this study teach in different schools involved in a literacy hour designed to implement a national literacy strategy. Although this study occurred in England, the findings of this study are meaningful to the current investigation of middle level English language arts teachers' literacy beliefs and practices.

Dadds' (1999) study implemented a variety of steps and multiple research methods. On some occasions, groups of teachers met during full staff meetings, while others conducted individual teacher interviews, questionnaires, or open-ended discussions with part of the participating staff group. During full staff meetings a "statements cards activity" was used, where a variety of individual statements about literacy were recorded on separate cards and the teachers discussed and responded to these statements, deciding which statements they thought best represented their views of what they value in literacy for primary children. During project 
meetings a preliminary meta-analysis across findings from the seven different schools was conducted. Next, individual reports were written about the findings and Dadds conducted a final meta-analysis to draw conclusions about what teachers value in regards to literacy.

Dadds (1999) found that no two teachers responded in identical ways and no two schools provided the same collaborative response. An overwhelming conclusion drawn from Dadds' study was that "Literacy can mean very different things to different teachers - even those working in similar environments and with ostensibly similar aims and approaches" (p.10). Other noteworthy findings emerged from this action research project that are of interest to the current investigation. When looking into what teachers value in literacy, Dadds found that literacy is a major and essential form of communication; literacy was viewed as a key human need in the creation of meaning and understanding; teachers held strongly defined views about literacy; many teachers did not restrict literacy to reading and writing and viewed speaking and listening as inevitably integrated with reading and writing. In addition, Dadds found that the teachers believed that literacy is not a disconnected set of skills and abilities, yet the development of a wide array of skills is necessary as a foundation for literacy. Further, the teachers believed that a focus on literacy skills has the potential to lead to disconnected and fragmented literacy learning, with many of the teachers fearing that isolated teaching of skills may drive pedagogy, pushing aside other approaches that emphasize a more holistic approach to literacy that incorporates experience and engagement with texts within purposeful literacy activities. While literacy was viewed as serving a wide variety of purposes within the school context, teachers noted the importance of drawing upon and valuing children's out-of-school and cultural literacies within the school setting. The teachers involved in this study situated the children at the center of their 
teaching and valued their students' interests, noting that they taught responsively and spontaneously based upon their students' interests.

Dadds (1999) made it clear that her study did not intend to make claims as to a single "right" and/or absolute set of values associated with literacy; instead, she sought opportunities for teachers and teacher researchers to scrutinize and challenge their own literacy values as they considered them alongside others' values while also evaluating what they believe to be quality literacy tasks for all students. Most importantly, Dadds' study revealed evidence of teachers' thinking about literacy along with evidence of what teachers believe about and value in the primary literacy curriculum. The findings of Dadds' investigation suggest that a study of middle level English language arts teachers' literacy beliefs and practices may reveal evidence of teachers' beliefs about literacy as well as what they believe to be critical to the middle school literacy curriculum.

Mallette, Henk, Waggoner, and DeLaney (2005) conducted a survey of accomplished middle-level educators in an effort to ascertain their beliefs and values about literacy. This study explored quantitatively and qualitatively how teachers defined themselves as teachers of literacy, how they viewed multiliteracies in adolescents' lives, and what aspects of literacy the teachers valued most in the classroom. The researchers utilized a survey that was divided into two sections designed to collect quantitative and qualitative data. The first section sought details associated with demographics (i.e., grade levels taught, subjects taught, levels of education, other certification and endorsements, professional development, and gender), while the second section probed participants' literacy beliefs and values through open-ended, qualitative questions associated with literacy and literacy instruction. Finally, the last section asked Likert-style questions about the extent to which various topics associated with literacy should be considered 
in teacher education preparation for middle-grades teachers in all subject areas and the literacy instruction of middle-grade students. Participants were asked to indicate if statements were "Essential, Very Important, Somewhat Important, or Not Important" in the middle school setting. The researchers intentionally placed the Likert items after the open-ended questions on the survey in an effort to reduce the influence these statements might exert on the open-ended responses of the participants. Questions included on the survey were designed to reflect research in the literature on adolescent literacy and to capture characteristics of authentic, field-based beliefs and practices of literacy instruction from teachers working in distinguished middle-grades schools. Ninety teachers employed in award-winning middle schools responded to the survey. The results of Mallette, Henk, Waggoner, and DeLaney's (2005) study revealed that teachers rated facets associated with basic literacies (e.g., vocabulary, reading comprehension, word identification, fluency, writing, and literature) as more important than New Literacies (e.g., visual, media, Internet, computer, graphic, critical, and out-of-school literacies). While some of the teachers showed minimal support for bringing out-of-school literacies into school contexts, most of the teachers placed an emphasis on basic literacies and believed that all teachers hold some degree of responsibility for teaching literacy across all grade levels and subject areas. It is important to note that this study took place in award-winning "Blue Ribbon Schools" and likely cannot be generalized to all middle schools. The researchers noted that the participants' responses do not necessarily reflect how they actually teach in the classroom because this was not the focus of this investigation.

While Mallette, Henk, Waggoner, and DeLaney’s (2005) study contributes meaningfully to the current study, it is worth noting that the current study does not take place in a "Blue Ribbon," award-winning school, but rather in an ordinary middle school situated in a rural 
setting. In addition, the current study extends Mallette, Henk, Waggoner, and DeLaney's study because the goal of the current investigation is to identify middle level English language arts teachers' beliefs about literacy and to examine how these beliefs manifest themselves in the instructional practices of the participating teachers' middle level English classrooms.

Theriot and Tice (2008) utilized a collective case study approach to conduct six case studies designed to come to some understanding of the complexity of teachers' knowledge development. The focus of their investigation of six middle-school teachers from one school district was on teachers' beliefs about literacy development in addition to their teaching practices in literacy. In order to avoid misinterpretation and to gain an in-depth understanding of the participants perspectives, the researchers employed multiple sources of data. Data collection occurred through individual, semi-structured interviews in which teachers were asked to share information about their teaching careers and their teaching practices. Participants were also asked to respond to an instrument designed to assist teachers in identifying their beliefs about how an individual reads and how reading is developed. Lastly, the researchers recorded field notes from a two-hour observation of each teacher as the teacher provided literacy instruction in the classroom.

The findings of Theriot and Tice's (2008) investigation revealed that the teachers possessed varying approaches to reading and writing instruction. Teachers varied from using holistic, authentic literacy experiences to tasks dominated by isolated skills instruction. The researchers found that a variety of factors have the potential to interfere with teachers' work as they strive to incorporate instruction that is compatible with their beliefs. They noted that at times, teachers' instruction is not always compatible with their beliefs because of various procedures that have evolved in the context of the teaching environment. Of greatest 
significance, though, is the finding that teachers' perceptions cannot be ignored because teachers' beliefs are an inextricable part of their decision-making and instructional practices. Further, Theriot and Tice suggested that if researchers want to come to a better understanding of effective teaching, then it is important to attempt to understand the connections between teachers' thinking or beliefs and their actions or instruction in the classroom. It is important to note that Theriot and Tice's study took place within the context of a district-implemented workshop focused on developing classroom practices designed to provide authentic literacy experiences as an alternative to traditional practices that focused on isolated skill development. It is, therefore, assumed that these workshops and the ensuing conversations about the implementation of new instructional literacy approaches had some impact on the evolving beliefs and practices being utilized by the six participants in this study.

The current investigation of middle level English language arts teachers differs from Theriot and Tice's (2008) study because the current investigation explores the literacy beliefs and instructional practices of two teachers who are not involved in prescribed workshops that encourage the integration of new approaches to literacy instruction. In addition, the current investigation utilized a series of interviews and observations rather than a single interview followed by a solitary classroom observation. The current investigation also utilized a similar pool of teacher participants, as the participants in Theriot and Tice's study varied in the number of years in the teaching field (from 3 years to 23 years), and the current investigation also had participants ranging in years of experience from 3 to 25 years. Theriot and Tice's study also mirrors the current investigation because Theriot and Tice utilized a data analysis process that looked for themes and patterns that emerged from within the data and they did not utilize 
preconceived categories associated with literacy for purposes of data analysis, as also occured in the data analysis of the current research investigation.

Recent dissertations focused on teachers' literacy beliefs and practices. In recent years, many research dissertations have focused on examining teachers' literacy beliefs and practices across a range of contexts and subject areas. The studies described here employ an array of methodological approaches designed to explore teachers' literacy beliefs.

In a case study of two effective literacy teachers, Al-Arfajr (2001) examined the literacy beliefs of a teacher in a third grade classroom and one in a sixth grade classroom in two different school districts. School administrators identified these two teachers as effective literacy teachers. Data for this investigation were collected over a four-month period through classroom observations, interviews, and artifacts. Non-participant classroom observations were initially conducted. After a couple of classroom observations, a semi-structured interview of each teacher took place, where biographical information was collected prior to interviews exploring the teachers' beliefs about literacy and teaching and learning. Al-Arfajr conducted classroom visits twice a week over a four-month period, for a total of 34 classroom visits (15 in one classroom and 19 in the other). Al-Arfajr spent approximately three hours in each classroom, both interviewing and observing. Observations took place during reading, writing, and language arts sessions and extensive field notes were recorded. In addition to field notes, all visits were audio recorded and transcribed in an effort to provide accurate information. Eight semistructured interviews were conducted using a pre-determined list of questions and topics for exploration. In addition, informal interviews or conversations occurred during classroom visits as the need to clarify information emerged. Additional artifacts were collected, which included lesson plans, copies of students' work, worksheets, stories, textbooks, and notes to parents. 
Findings of Al-Arfajr's (2001) study revealed that teachers' understanding of literacy was constructed in relation to three broad and interconnected areas of beliefs: their roles as teachers, their students, and their understanding of learning and learning goals. Six themes emerged that characterized literacy events and activities in each classroom. These included immersion in print; interactive use of language; instructional connectedness and curriculum integration; promotion of students' metacognitive awareness and independence; emphasis on affect and motivation; and effective classroom management. A cross case analysis was conducted and AlArfajr identified many distinct characteristics that shaped literacy teaching. Al-Arfajr found that both teachers displayed characteristics in different forms and at different levels and it was revealed that reading and writing were strongly connected to each other and to other literacy skills in both classrooms. In addition, Al-Arfajr also examined the teachers' perceptions of their current teaching situations and different professional experiences that contributed to their professional development.

Al-Arfajr (2001) revealed many factors that contributed to the development of philosophical beliefs and instructional practices. The teachers' literacy beliefs and instruction were influenced by factors related to both personal and professional experiences. The three predominant influences that were revealed included family experiences, school and higher education experiences, and professional experiences associated with the unique teaching situation. The literacy instruction in the two classrooms was meaning-based and emphasized immersion in high-quality literature; this instruction was also connected to reading, writing, and other subject areas. Both teachers integrated teaching of skills into authentic reading and writing tasks and skill instruction in the classrooms emphasized word-level skills, comprehension, and writing skills. Al-Arfajr concluded that literacy instruction in each classroom was supported by 
the teacher's views of teaching, learning, and literacy instruction. Further, the literacy instruction in both classrooms was guided not only by the teachers' literacy beliefs, but also by other knowledge and understandings related to teaching and to learning in general. The results of this study were supported by research associated with teachers' beliefs, which suggests a strong relationship between teachers' thinking and their instructional behaviors in the classroom.

The study conducted by Al-Arfajr (2001) is similar to the current investigation of teachers' literacy beliefs and instructional practices in that interviews and observations were collected as data sources, yet this study differs in important ways. While Al-Arfajr's study took place over a brief four-month time frame in two different school districts, the current investigation spans two school years and investigates two teachers within the same school building. The two teachers in Al-Arfajr's study were elementary trained teachers, responsible for teaching the entire elementary curriculum across the school year. The current investigation examines the literacy beliefs and practices of two middle level English teachers who teach English language arts to sixth grade students.

Howerton (2006) conducted an exploratory qualitative study designed to capture successful middle school language arts teachers' perspectives and beliefs about their roles as reading teachers who teach struggling students. Data for this study were collected through questionnaires, focus group discussions, and interviews. Each of the phases of data collection utilized structured guides intended to lead the participants' conversations. Focus groups were conducted using a focus group guide; semi-structured interview guides were utilized during interviews; and a field note template was developed in order to record responses to questions and other verbal and non-verbal responses during group discussions. The field note template provided an opportunity to make note of emerging themes, patterns, and areas to focus on during 
the data analysis process. The questionnaires used for data collection asked for demographic data as well as the teachers' perceptions about their roles, students, and the type of instruction provided in the classroom. The focus group discussions were facilitated by open ended questions designed to encourage discussion about perceptions and beliefs associated with reading instruction and the role the teachers played in the middle level classroom. The interviews were used as a tool for probing deeper into questions that required reconsideration after the focus groups met. Throughout this study, all discussions and interviews were both video- and audiorecorded. The study commenced with 21 participants who completed a questionnaire, followed by participation in one small focus group, individual interviews, and a final large focus group. The participants in this investigation taught in four middle schools located in a suburban area. Participants included sixth grade teachers, seventh grade teachers, eighth grade teachers, and one teacher who taught sixth through eighth grade.

During the course of this investigation, the primary investigator, Howerton (2006), received assistance from a co-facilitator who attended three of the focus groups. At the conclusion of the focus groups, the co-facilitator met with the primary researcher to debrief and summarize key ideas that emerged in relation to each of the research questions under exploration. Additionally, an assistant moderator aided in the collection of field notes and data analysis. Finally, a transcriber with experience in educational research, transcribed all of the audio-recordings and provided a response or reaction to each discussion, group, and individual. The transcriber was kept unaware of the major research questions in an effort to avoid presenting bias in the responses that were supplied.

The findings of Howerton's (2006) study revealed that at the beginning of the study all of the teachers initially stated they taught reading instruction to their students as a part of their 
language arts curriculum. As the study progressed through the focus group discussions, though, it became evident that the teachers were changing their minds about exactly what they taught and to whom they were willing to teach reading. For most of the teachers in this study, the role of reading instructor was not one that they accepted. Because of their lack of acceptance of this role, the teachers did not define themselves as reading instructors and instead cited a number of reasons for not being able to provide reading instruction in their classrooms (these reasons included non-supportive relationships with administrators and students, professional development that did not provide the knowledge needed to teach effectively, and a belief that atrisk and/or low ability students did not belong in general education classrooms). Howerton revealed a lack of clarity about the roles, responsibilities, and actions that the teachers perceived they fulfilled and enacted in their classrooms. While some stated that they are teachers of reading, the tasks they described as reading activities did not align with what they believed their students needed or were able to do in the classroom. By the end of the study, only eight teachers who had participated in all phases of the study remained. It was evident that the language arts teachers involved in this study viewed themselves in the same light as other content area teachers who define their beliefs about their role by the content area they teach. These teachers revealed that they were more concerned with covering the content and materials associated with the language arts curriculum rather than on than improving the reading or literacy skills students need to access the required curricular materials.

The goal of Howerton's (2006) investigation was to come to a clearer understanding of a group of middle school language arts teachers' roles and responsibilities as they set out to teach students who are perceived as being unsuccessful or at risk for failure in the general education classroom. This group of students included those identified for special education as well as other 
diverse student populations. The study's focus was limited to middle school language arts teachers because, as one of the study's conclusions found, it is often mistakenly assumed that language arts teachers have the knowledge, skills, and pedagogical beliefs needed to provide reading instruction to all students. Although there is an existing belief that language arts teachers are responsible for the ongoing development of reading and/or literacy skills, many of these teachers believe that they are only responsible for providing specific content instruction.

Howerton's (2006) study offered many unique insights that support the current investigation, yet the current study differs from this investigation in significant ways. A primary difference is that the interviews and observations were not narrowed by pre-determined guiding questions or interview guides. The interviews in the current study utilized open-ended questions designed to avoid leading the participants to respond in specific ways. While the current study involved much fewer participants, it is believed that the smaller pool of participants provided a greater opportunity to explore the teachers' beliefs and practices at a much deeper level. Furthermore, additional interviews and observations were conducted in an attempt to come to a better understanding of the teachers' literacy beliefs and instructional practices.

Maziarz (2007) examined middle school content area teachers' beliefs about literacy as well as their instructional practices in an effort to develop an understanding about the relationship between content area teachers' beliefs about literacy and their classroom practice. Maziarz's case study involved one sixth grade middle-school social studies teacher and one seventh grade middle-school science teacher. The researcher in this study was an assistant principal in the middle school but it was noted that she had no supervisory responsibilities for either of the teachers involved in this study. Data sources for this study included two interviews of each teacher, responses to a literacy beliefs profiles, transcripts from three months of 
observations in each classroom, and artifacts collected from each teacher. The first teacher interviews focused on personal background and demographics, beliefs about literacy teaching and learning, and the teachers' perceptions about influences they believe affect their classroom practices. An interview guide was used to lead these initial interviews.

Next, both participants were asked to complete Kucer's (2005) Literacy Beliefs Profile in order to assess their beliefs about literacy learning and classroom practices. The goal of this profile was to assist the teachers in reflecting on their current conceptions of reading and writing. This profile consists of 31 statements, including eight decoding philosophy statements, ten skills philosophy statements, and 13 whole language philosophy statements. This profile is said to be an updated version of DeFord's (1985) Theoretical Orientation to Reading Profile (TOPR) that utilized skills, phonics, and whole language designations to examine teachers' instructional beliefs about teaching reading.

In addition to completing this profile, each participant was observed ten times (over a three month time frame) for the entire length of a 60-minute class period. All observations were audio-recorded and transcribed in an effort to document the literacy practices enacted by each teacher during content-area instruction. Lastly, artifacts were collected from each teacher including teacher-made worksheets, student work samples, copies of transparencies used during instruction, and graphic organizers.

The findings of Maziarz's (2007) investigation revealed that the science teacher's theoretical orientation and classroom practice differed in significant ways from the social studies teacher's. The science teacher relied predominantly on a transmission model of instruction that aligned more with a teacher-centered, skills orientation to literacy. The science teacher held an inconsistent and conflicting belief system regarding literacy. Her views aligned more with an 
eclectic or inconsistent understanding of a whole language orientation to literacy. Classroom discourse was dominated by teacher talk and questions designed to lead students to correct responses with minimal release of responsibility to the students. Conversely, the social studies teacher maintained a consistent belief system regarding literacy. Instruction in this classroom was student centered and demonstrated a clear influence of a whole language approach to literacy. The social studies teacher provided opportunities for students to access prior knowledge, engage in multiple questioning techniques and discussions with others in the learning community, and focused on the co-construction of new knowledge and understanding. The social studies teacher's belief in a whole language orientation to literacy was evident in the instructional strategies employed, which encouraged students to activate the appropriate schema to better comprehend new knowledge and personal understanding of text.

Maziarz's (2007) investigation of middle level content area teachers' beliefs and instructional practices associated with literacy supports the importance of studying the literacy beliefs of middle-school content-area teachers in an effort to determine how those views interact with their classroom practices. It is suggested that studies of this nature have the potential to clarify a range of issues associated with adolescent literacy. Maziarz's study differs from the current investigation of middle level teachers' literacy beliefs and instruction. The current study examines middle level English language arts teachers' conceptions of literacy and although interviews and observations were conducted, a literacy beliefs profile was not used because it was the intent of the current study to avoid leading the participants to a specific understanding of or conception about literacy. By offering the participants a literacy profile to complete, these statements may have inadvertently led the participants to believe that these statements represent the type of information being sought by the researcher. Additionally, the current study takes 
place across two school years in the two teachers' classrooms and strives for open-ended discussions about literacy. As Maziarz suggested, the current study also includes classroom observations across consecutive days in an effort to more thoroughly understand the context of the literacy tasks being implemented in the classroom. Prior classroom observations that took place during the current investigation's pilot study occurred across a semester and occurred on a sporadic basis, leading to intermittent glimpses of the teachers' instructional literacy practices, while the most recent classroom observations took place in a more successive manner in an effort to explore literacy tasks associated across a unit of literacy instruction.

Consistent with qualitative methodologies recommended by Fang (1996) and Pajares (1992), Guise (2009) conducted three detailed case studies of secondary English language arts teachers employing a life history methodology as a means to inform the interview design. Guise's study took place in three different school contexts and focused on acquiring a detailed understanding of the English language arts teachers' beliefs and how their beliefs influenced their instructional practice. In addition, Guise's study sought to examine how the educational contexts mediated the relationship between beliefs and practices as well as the belief negotiations that occurred when the teachers were faced with a misalignment between their beliefs, instructional practices, and/or their educational contexts.

Data for Guise's (2009) investigation were collected through weekly classroom observations over a six month time frame, which were documented through field notes and audio-recordings; artifacts associated with teaching, including lesson plans, handouts, and assessments; and five interviews with each of the three teacher participants, as well as their administrators, and students. The initial interviews were constructed in a manner that allowed for the elaboration of the teacher participants' life stories in order to provide a clearer understanding 
of their beliefs. This technique aligned with a life history approach to qualitative research in which the researcher strives to gain insights into the unique experiences of the participants in a specific context through narrative stories shared by the participants about their lives and life experiences. During later interviews, participants were presented with teaching episodes that had been previously shared that revealed misalignments between their expressed beliefs, their instructional practices, and/or their educational contexts. The participants were asked to reflect on these misalignments in an effort to provide deeper insight into the reasons for their existence. Interviews conducted with the administrators and students provided an opportunity to come to some understanding of the educational context, most specifically the school, curricular, and policy contexts, which aided in determining how these contexts have the potential to mediate teachers' instructional practices. The teaching artifacts were collected from the teacher participants to offer additional evidence of the teachers' instructional practices.

During the course of this investigation, Guise (2009) discovered that the composition of the three teacher participants' core teaching beliefs and their core discipline-specific beliefs varied across the participants. Guise also discerned a level of discomfort from the teachers when they were asked to reflect upon their instructional practices in comparison to their articulated beliefs about teaching, learning, and their students. She noted that each of the teacher participants felt anxiety, discomfort, and a level of uncertainty when asked to engage in this type of critical reflection and analysis.

The overall findings of Guise's (2009) study indicate that teachers tend to hold a diverse array of belief systems about teaching and learning. It was also revealed that teachers may only be consciously aware of and highlight certain beliefs associated with teaching, such as beliefs about students and their families, or beliefs about reading. As the teacher participants engaged in 
the exploration of the misalignments between their beliefs and practices, a clearer understanding of various contextual and emotional factors that mediate that relationship emerged.

Guise (2009) revealed a complex relationship between beliefs, instructional practice, and context. It appeared as though two of the three teachers were unconsciously influenced by the pressure and constraints associated within the context of the current high-stakes testing policy. For two of the teachers, this policy/context appeared to impact the manner in which the teachers approached literature instruction. For instance, it was noted that discussions of literature may be guided by the need to identify one correct answer as is often the case with high-stakes testing. For the third teacher, Guise noted that it was difficult to even discern if a misalignment or alignment existed within this teacher's beliefs because her responses seldom addressed her discipline-specific beliefs about teaching English; this teacher primarily discussed her beliefs about assessment, and shared very few beliefs about the teaching of literature or literacy.

Another potential factor that appeared to influence the teachers in Guise's (2009) investigation was associated with strong or weak administrative leaders. It appeared that when a strong leader guided the school context, teachers had the freedom to make decisions for themselves and had a stronger voice in the overall shaping of the context of the school. On the other hand, when confronted with an administrator with more limited leadership skills, teachers appeared to become more isolated and less involved in the larger school context because they feared that their thoughts would not be heard, respected, or considered. One last finding that Guise discovered was that the teachers appeared to possess a limited amount of beliefs specific to the discipline of writing, which Guise noted, was a critical aspect of the English language arts classroom. 
The current investigation of middle level English language arts teachers' literacy beliefs and practices draws upon Guise's (2009) study in a few distinct ways. First, the current study also investigates the beliefs and instructional practices of English language arts teachers, but the current study is narrowed to middle level teachers rather than secondary teachers in general. In addition, the current study focuses on the views of two participants who teach within the same context; therefore, contextual variables associated with different school communities do not have the potential to obscure the results of this investigation. While Guise's study occurred over a six-month period, the current investigation occurs across two different school years providing the opportunity to explore the teachers' beliefs across time and with different classroom compositions. Finally, the current study draws upon Guise's use of recommended methodological practices, as this current study employed methodological techniques that align with the recommendations offered by the experts in the field of educational research associated with teachers' beliefs (i.e., Fang, 1996; Pajares, 1992). Guise integrated a life history approach to her interview methods in an effort to allow participants to share their life stories to reveal their beliefs about literacy. Guise's approach provided an unstructured and open-ended style that encouraged participants to share narrative stories that could potentially reveal the participants' beliefs associated with literacy.

Guise's (2009) methodological approach aligns with the recommendations of researchers such as Fang (1996), Munby (1982), Pajares (1992), and Schunk (1991) who encouraged the use of narrative means for exploring and understanding teachers' beliefs through life history, biography, autobiography, or other narrative inquiry approaches. These qualitative approaches provide the opportunity for participants to describe their beliefs as well as what they intend and do in the classroom. The current investigation also employs an open-ended, narrative style of 
inquiry intended to provide an unstructured approach that does not lead the participants to believe that there is one precise or absolute construction of literacy.

The current investigation integrated a phenomenological approach with a case study approach. These two qualitative approaches were combined in order to provide the two participants with an opportunity to describe their unique understandings and meanings of literacy from their first-person perspective. This approach expands upon the notion of phenomenology, which is typically associated with psychological constructions of phenomenon (such as dealing with grief), in an effort to come to an understanding of how an experience such as literacy and the teaching of literacy are experienced from the perspective of the individuals experiencing the phenomenon under investigation (i.e., literacy).

By utilizing methods associated with the phenomenological approach, the participants were able to describe literacy and any associated connections to literacy by sharing personal stories that detail how literacy is taught in the classroom as well as the intended purposes of employing various instructional literacy practices in the classroom. The intended goal is to acquire each participant's personal perspective and interpretation of literacy as well as the motivations and actions that drive the instructional decisions associated with literacy in the classroom, without imposing upon the study the research field's subjective interpretation of the phenomenon literacy. Integrating this qualitative approach with a case study approach was intended to provide an opportunity to treat each participant initially as a single case, to be subsequently compared and contrasted to the other case in order to reveal potential commonalities and/or inconsistencies that exist between the two participants. This methodological approach provided the context for the two participants to reveal their beliefs 
about literacy as well as the instructional practices implemented in the classroom in order to teach literacy to middle level students.

In a study of emergent literacy, Poole-Christian (2009) examined preschool teachers' beliefs about emergent literacy and explored the extent to which these beliefs influenced classroom practices associated with emergent literacy. Poole-Christian's investigation took place in two preschools with half- or whole-day classrooms serving three- to four-year old children. One preschool had two classrooms in a privately owned religious affiliated preschool while the second preschool had two classrooms in a public preschool program.

Poole-Christian's (2009) investigation utilized a qualitative approach in which interviews and observations were used as the primary data sources. During the course of the investigation, three visits were made to each of the classrooms in each of the schools. These visits ranged in time from one to three hours and took place over a three-week period during the regular school year. With the help of a research assistant with 15 years of teaching experience, 12 of which occurred in a three- and four-year-old preschool program, the preschool teachers' attitudes and beliefs were acquired through observations followed by in-depth interviews that provided further clarification. The interviews lasted approximately 45-60 minutes and only occurred once unless the researcher found a need to clarify participants' responses. All interviews were audiotaped and transcribed. In addition, classroom observations were audiotaped and later transcribed. Field notes were also taken in order to record activities that encouraged literacy development. In order to guide the classroom observations, an Early Language and Literacy Classroom Observation (ELLCO) was used to develop an observation guide that served as a standardizing means for discovering the strategies that support the teachers' beliefs about literacy in preschool 
children. Finally, a rich description of the classroom and the interactions that occurred between the teachers and their students was developed.

The results of Poole-Christian's (2009) investigation revealed four themes that emerged from the interviews, which were connected to the guiding research questions. These themes were: (a) teacher's role, (b) important literacy concepts, (c) activities that support literacy, and (d) factors influencing teacher beliefs. All of the teachers in Poole-Christian's study considered their role in the classroom to be that of a facilitator. The participants all believed it was their role to guide students in the learning process. Secondly, the teachers all purported that play was as an activity used to support children's literacy development, yet it became apparent during observations that there were very few instances of the teachers actually participating in play activities in an effort to develop meaningful learning experiences for the children.

Another finding in Poole-Christian's (2009) study was that although one-half of the teachers indicated that reading aloud and allowing students to participate in discussion of books was an effective classroom strategy for promoting literacy (the other half simply indicated that book reading was important to literacy), there were no instances of observed read aloud experiences that incorporated discussion and interaction during the reading experience. Instead, when the teachers conducted a read aloud experience, it was simply an oral reading of the text with no discussion or interaction with or about the book. Finally, although the teachers indicated that interactions within the classroom provided opportunities to reflect on what was being learned in the classroom setting, there were very few instances where the classroom environment was structured so that the children's play directly reflected what they had learned. In the context of this investigation none of the participants were able to articulate a focused definition of emergent literacy. The study revealed a discrepancy between the participants professed beliefs 
and the actual activities enacted in their classrooms. Poole-Christian concluded that across all four teachers, stated beliefs about what is important to preschool development was not evidenced in their instructional practices during observations.

The findings of Poole-Christian's (2009) investigation have important implications for the current investigation of middle level English language arts teachers' literacy beliefs and practices. The discovery that the teachers' espoused beliefs and the enacted classroom practices were incongruent suggests that a study of teachers' beliefs and practices is valuable because although teachers may purport a specific belief about an educational construct, it cannot be assumed to be true based solely on that proclamation. Poole-Christian's study supports further investigation of teachers' implied beliefs in conjunction with their explicit practices.

Research suggesting the need to study English teachers. Two studies were particularly relevant to the current investigation of middle level English teachers' literacy beliefs and instructional practices. These two studies by Meyer (2009) and Vélez (2010) highlight critical issues that support the need to further explore English teachers' beliefs about literacy. Each of these studies are reviewed here, followed by a synopsis of how these studies demonstrate gaps in the literature pertaining to English teachers' beliefs about literacy.

Meyer (2009) developed a survey designed to measure middle and high school teachers' knowledge of research-based practices associated with adolescent literacy, the Content-Area Teachers' Assessment of Adolescent Literacy (CATAAL). This 50-item knowledge survey was subjected to various reliability and validity studies. This assessment tool was developed through a variety of steps including framing and writing the assessment using the research base on adolescent literacy. Next, in order to establish the reliability of the tool, internal consistency was determined for each section. Then an item analysis was conducted to measure the quality of the 
individual test items. Finally, in an effort to confirm the validity of the assessment, content and construct validity were measured. During the pilot study, 51 middle and high school English language arts (ELA), Science, and Social Studies teachers who had prior contact with the researcher in some manner completed the pilot assessment. For the second stage, the construct validation of the assessment, 161 teachers solicited through an online survey platform participated in the study. Meyer predicted that English language arts teachers would score significantly different on the assessment than Science and Social Studies teachers; therefore, the sample of teachers for the second phase consisted of teachers from each content area.

Through these processes, Meyer (2009) found that the Content-Area Teachers' Assessment of Adolescent Literacy is a reliable measure of middle and high school content-area teachers' knowledge of adolescent literacy. Surprisingly, the results of the analysis of variance did not reveal significant differences between ELA teachers and either Science or Social Studies teachers. Therefore, construct validity was not established for this assessment. Meyer noted that she was surprised to discover that the knowledge ELA teachers held about adolescent literacy did not exceed that of their colleagues in other content areas. Meyer remarked that she had assumed that teachers of ELA would have a more solid understanding of adolescent literacy than other content-area teachers.

This finding is critical to the current investigation of middle level ELA teachers' literacy beliefs and practices because it appears that many of the studies of literacy that take place at the middle level tend to explore beliefs of other content teachers (i.e., science or social studies) because there is a general assumption by practitioners in the educational field that ELA teachers have a solid background and understanding about issues associated with literacy. Meyer's (2009) finding suggests that middle and high school content-area teachers may not have a solid 
foundation associated with the literacy needs of adolescents, which is fundamental to teaching at this level. Meyers suggested future research designed to more closely examine the value ELA teachers place on literacy as compared to their value of literature. In other words, she suggests that researchers explore if ELA teachers find value in literacy skills outside of the traditional venue of literature study. This is an interesting suggestion that may come to fruition through the current investigation of middle level ELA teachers' literacy beliefs and practices. Because the current investigation is not constrained by specific beliefs about literacy, issues associated with this query may emerge as the teachers describe their beliefs and instructional practices associated with literacy.

In 2010 Vélez examined literacy beliefs and practices from a variety of participants, each of whom played a critical role in a Secondary English Teacher Education program at a university located in the Midwest. A total of twelve individuals from the university participated including four university level methods course instructors (individuals who directly taught any of the four core methods courses), four university level instructors from the English Department, four first year/novice teachers who graduated from the university in 2009 , and four veteran teachers who graduated from the university prior to 2002. The classroom teachers involved in Vélez's study comprised both middle and high school English teachers. In the context of this investigation, Vélez sought to understand how literacy beliefs and practices of the instructors and graduates from a Secondary English Teacher Education program evolved over the past 15 years. By including this array of educators, Vélez was able to examine views about literacy from 12 individuals, each of whom view English as a subject area differently.

The goal of Vélez's (2010) study was to come to some understanding of the core literacy beliefs and instructional practices of the 12 participants. The study spanned two contexts, the 
university and public middle and high schools. Two data sources were collected, in-depth interviews and a series of written documents acquired from all participants. Each participant was interviewed three times over the course of four months. All three of the interviews for one particular participant took place in one day, while for four other participants, the interviews occurred across two separate meetings. The time between these interviews ranged from one week to a month. The first round of interviews utilized a predetermined interview protocol. For the second and third interviews, an interview protocol was developed after conducting the previous round of interviews. Documents that were collected included course syllabi from the faculty, assignments that the graduates had completed during their time as pre-service teachers, lesson plans, and online information from selected participant-created blogs and websites.

Vélez's (2010) investigation of English teachers' beliefs and practices holds many important findings that are associated with the current study. Vélez found that when the participants expressed their beliefs about English, there was a fundamental understanding that literature was the primary component that distinguished English from other subject areas. On the other hand, when discussing English education with participants, there was a broader range of discussion points, including working with children and preparing teachers.

Vélez (2010) found that the instructors appear to operate from a fixed set of beliefs that have been established over their careers, yet these instructors did not hold stagnant views about literacy and literacy instruction. Data revealed that university instructors have adapted their teaching to improve their instruction and to embrace issues of technology. In some cases, these participants also considered ways to help their university level students confront the ongoing emphasis on standards. It was noted that all of the participants recognized that technology and literacy are inextricably linked. 
Further, Vélez (2010) remarked that all participants acknowledged that a range of skills and content encompass the subject English. Vélez observed that literature is still considered the primary focus at the secondary level, but also noted that the study's participants realized that the subject requires attention to other skills as well. As a matter of fact, Vélez indicated that some of the study's participants referred to the teaching of English and literature as synonyms. One of the veteran middle/high school teachers even went so far as to define English as being the study of literature, discussion of literature, and reflection upon literature, suggesting that the subject itself should be called "Literature" rather than English because English teachers teach literature.

Vélez (2010) discovered that some of the participants' responses indicated that a discussion of literacy must move beyond traditional, reductionist views of literacy where reading and writing are viewed as the only two skills or competencies that define literacy. Vélez found that it was the novice teachers' views that were most indicative of a shift toward a more inclusive view of the subject. The novice teachers described the process of reading and writing as being part of literacy but also included being able to effectively use technologies such as the computer, the internet, and television, in addition to other technologies. Furthermore, the novice teachers mentioned that literacy also included skills associated with reading and writing, which focused on developing the ability to express thoughts into words, the ability to make sense of information, and to analyze, interpret, and respond to information.

The veteran teachers defined literacy in much the same way as the novice teachers, acknowledging reading and writing, engagement with text, and making meaningful connections to one's life. Unlike the novice teachers, though, the veteran teachers remarked that graduate educational experiences influenced how literacy is defined as their notions of literacy have evolved over time. The methods course instructors' definition incorporated the ideas that novice 
and veteran teachers included as well as the study of literature and the writing of various literary genres. The most divergent views expressed came from the English educators who did not connect literacy to the context of schools. Instead, they referred to literacy primarily in terms of reading competence, or one's ability or inability to read. The term "illiteracy" was also included in this conversation, focusing on varying levels of comprehension of both texts and the written word.

When considering the ways the participants' views changed across 15 years, Vélez (2010) indicated that the greatest change in perception was associated with writing, noting that the participants' views have shifted from print to screen as they embrace electronic forms of expression and new writing technologies. Interestingly, the views associated with reading, however, have only changed in the sense that there is greater access to more resources, noting that the participants did not perceive a change in how they access text such as reading from textbased print or from a screen.

Vélez (2010) also found that the participants' views of literature appear to be evolving to some degree. Literature was defined by some as including both books and fiction as two elements of literature as a genre. Novice teachers talked about "fiction" as literature, including other genres such as poetry, whereas veteran teachers discussed literature as including fiction, because it was noted that non-fiction was something that aligned more closely with other content areas than it did with English. Literature was viewed as any texts that relate to the narrative style favored by fiction, which may include some forms of narrative non-fiction. The English instructors predominantly related literature to fiction or to printed words, not visual or audiovisual forms. The methods course instructors talked about literature as an artistic form of expression through print text, which has been socially and historically constructed. This 
conversation of literature also contemplated the inclusion of newspapers, magazines, multicultural texts, and children's and youth novels adding to options that extend beyond what was viewed as the canon, or traditional, classic literature. It was apparent that this construction of literature is incomplete, as there did not appear to be consensus regarding specifically which forms of text represent the literature to be taught in a school context.

These two particular studies bring to light essential issues that support the need to further explore English teachers' beliefs about literacy. As Meyer (2009) discovered, there is often times an assumption among educators that English language arts teachers possess a substantial prior knowledge and understanding about literacy. However, as her study revealed, English language arts teachers did not possess a better or more thorough understanding of literacy than their content-area counterparts in the science and social studies fields. It cannot be assumed that ELA teachers have a substantive understanding of literacy because these teachers, who acquire their teacher education through traditional secondary English teacher education programs, do not necessarily receive additional literacy, reading, or writing instructional methods courses beyond those of the other content area teachers.

In traditional secondary education programs offered by most states, preservice secondary level content area teachers are generally required to take only one class associated with literacy development and skills - a content-area reading course (Appleman, 2010; Hall, 2005; Heller \& Greenleaf, 2007; Meltzer, Smith, \& Clark, 2002). In some states, though, there is no requirement for content-area reading courses as part of secondary teacher education, leaving many teachers, including English language arts teachers, lacking the knowledge and expertise to teach literacy (Meltzer, Smith, \& Clark, 2002). This is one of the primary reasons that further studies of English language arts teachers must continue. It is not prudent for literacy researchers to 
overlook this vitally important population of teachers based upon the assumption that these teachers already have in place a substantial and comprehensive understanding and belief system about literacy that meaningfully guides their instructional practices. It is important to note, though, that many of the studies reviewed here do suggest that there are ELA teachers who possess clear and discernable beliefs about literacy, while there are also those who do not.

As Vélez (2010) revealed, it appears that it is the novice teachers who have graduated from college in more recent years who possess an expanded conception of literacy that is more inclusive of an array of tasks associated with literacy that move beyond simply reading and writing to include effective use of technologies while also increasing students' capacity to express thoughts into words, to understand information, and to analyze, interpret, and respond to text and messages in appropriate and skilled ways. If it were the case that all ELA teachers in the field possessed a substantial understanding of literacy, especially as it pertains to adolescents and the evolution of twenty-first century literacy skills, then perhaps our nation's schools would not be faced with a state of crisis in regards to adolescent literacy. It is evident that researchers are making an effort to improve upon the situation, yet it is also clear that this issue has not been resolved. Therefore, the current investigation seeks to unravel the literacy beliefs held by middle level ELA teachers with differing years of experience within a single school setting in hopes of utilizing the findings of this study to make suggestions for teacher educators and the professional development community so that courses and professional development opportunities can be improved upon in an effort to move ELA teachers to the front as literacy leaders in their schools, seeking ways to improve upon literacy across the content areas.

\section{Synopsis of Teachers' Beliefs}


As described here, there has been a continually expanding body of research focused on examining teachers' literacy beliefs in conjunction with their instructional practices. Mallette, Henk, Waggoner, and DeLaney (2005) suggest that because adolescent literacy plays an incredibly important role in the development of an individual's lifelong literacy, literacy researchers need to study literacy from the perspectives of those who work most closely with adolescents, such as middle level English teachers. By listening to the voices of the individuals who have a deep-seated interest in the literacy achievement of young adolescents, researchers may be able to identify factors that would affect meaningful change in the literacy instruction provided to adolescents (Mallette, Henk, Waggoner, \& DeLaney, 2005).

While it has been demonstrated that teachers' beliefs represent a broad and difficult term to characterize and explain, researchers have found that teachers develop unique beliefs about the subjects that they teach, including beliefs associated with literacy (Pajares, 1992). The beliefs held by teachers may have a significant impact upon the lessons and activities teachers implement in the classroom, the manner in which teachers envision their instruction, and the way teachers learn from prior experiences (Brody, 1998). Therefore, the focus of this particular study was to strive to reveal the beliefs that middle level English language arts teachers hold about literacy as well as how these beliefs manifest themselves in their instructional practices. Although the construct "beliefs" is a challenging term, or as Pajares puts it, a "messy construct," the study of teachers' beliefs has the potential to inform education and instructional practice in ways that have yet to be accomplished through traditional research approaches (Pajares, 1992). Fenstermacher (1993) contends that teacher effectiveness research may benefit from the study of teachers' beliefs because teachers' beliefs and perceptions play a decisive role in guiding teachers' actions in the classroom. 
The classroom teacher's beliefs about literacy play a pivotal role in the development of an individual's conception of literacy. Researchers have spent a great deal of time attempting to explore this relationship. Fang (1996) found that literacy is generally shaped by the social relationships created between the classroom teacher and the students. Au (1998) suggested that it is through the conversations, interactions, and relationships with teachers that students develop an understanding of the meaning of literacy, the value of literacy, and the overall functions of literacy. Similarly, Nolen (2001) found that it is through the "daily interaction of teachers and students that literacy is constructed in the classroom" (p. 96). Nolen's findings are consistent with Au's, as she found that through these daily interactions, teachers convey what literacy is, how literacy works, and the importance of literacy.

Despite a call for research examining literacy from classroom teachers' perceptions, Readence, Kile, and Mallette (1998) indicated that research related to secondary level teachers' beliefs about literacy has been scarce, with even fewer studies exploring what middle school teachers believe and value about literacy and literacy instruction from the conception of adolescent literacy. The research field acknowledges the relevance of studying teachers' beliefs because these beliefs, as well as the associated instructional practices, affect student achievement and performance (Fang, 1996; Hativa \& Goodyear, 2002; Mujis \& Reynolds, 2001; Murphy, Delli, \& Edwards, 2004; Wray, Medwell, Poulson, \& Fox, 2002; Yero, 2002). Hativa and Goodyear (2002) indicate that research on teacher beliefs has experienced an increase over the past two decades; further, Rimm-Kaufman and Sawyer (2004) suggest that examining teachers' beliefs is of national relevance because teachers are currently faced with a complex and challenging educational field. 
As the preceding review of literature suggested, the study of teachers' beliefs is essential to the field of education because it has been demonstrated that the individual beliefs of teachers "play a vital role in shaping the objectives, goals, curriculum, and instructional methods" associated with teaching (Yero, 2002, p.1). It is evident that the instructional practices utilized in the classroom tend to be a result of the classroom teacher's beliefs; therefore, studies examining teachers' beliefs can be used in significant ways to inform educational practices. Extant studies of teachers' beliefs often reveal disparate findings such as the fact that literacy can mean very different things to different teachers - even those working in similar environments and with similar goals and approaches. It is clear that teachers can view literacy and literacy learning in a variety of ways, yet even when teachers appear to hold similar beliefs about literacy, the instructional practices employed can be distinctly different. The diverse conclusions drawn from this range of studies suggest that further examining English teachers' beliefs about literacy is a worthwhile venture.

\section{Adolescent Literacy}

Adolescent literacy is a conception of literacy that expands upon the traditionally held secondary reading perspective (Moore, 1996). This contemporary view holds that literacy is a concept that is socially constructed; as such, this notion is based upon a social constructivist perspective. The adolescent literacy perspective encourages educators to acknowledge a conception of literacy that moves beyond basic decoding and comprehension skills to include consideration of the various types of texts students engage with outside of the school setting (Stevens, 2002). This contemporary view of literacy comprises a wider range of tasks, including the development of a student's ability to apply knowledge and skills across subject areas as well as the ability to analyze, reason, and communicate effectively as students pose, interpret and 
solve problems (IRA 2012; Organization for Economic Co-Operation and Development, 2010). Additionally, this adolescent literacy view broadens the notion of text to include the wide array of texts students engage with outside of school, such as digital and multi-media texts that students engage with for their own personal reasons (Alvermann, 2002; Finders, 1997; Moje, 2002). From this broader perspective, students must be encouraged to not only comprehend traditional printed text, but must also be provided with opportunities to comprehend and construct print and non-print text that utilizes words and images (IRA, 2012).

In a study of 25 teachers in grades three through eight, Fisher, Frey, and Lapp (2008) discovered that modeling provides a valuable means through which teachers can explicitly demonstrate for students how readers interact with a variety of texts to improve the reading comprehension of young adolescents. This study, which took place in 25 different urban schools, utilized a series of three classroom observations in each teacher's classroom. Teachers were observed as they conducted a shared reading (or read aloud) in which they modeled their thought processes through the think-aloud approach. The researchers focused on identifying the most frequently occurring components of these shared reading experiences. Using the constant comparative method, the researchers identified four major areas of instruction that occurred across the shared reading experiences that were observed: comprehension, vocabulary, text structures, and text features.

Fisher, Frey, and Lapp (2008) found that the most common component of a shared reading/think-aloud experience was reading comprehension. Teachers focused on reading comprehension strategies such as activating background, inferring, summarizing, predicting, clarifying, questioning, visualizing, monitoring, synthesizing, evaluating, and connecting. When teachers mentioned vocabulary within their think-alouds, it was noted that the teachers involved 
in this study never explicitly defined a word for students or called on students to provide definitions of the key vocabulary terms. Instead, the teachers modeled for the students how to decipher complex words using one of three systems: context clues (using clues provided by the author to understand unknown words), word parts (using "inside-the-word" strategies to figure out word meanings, including prefixes, suffixes, root words, base words, word families, and cognates), and resources (strategies such as asking another person or consulting other sources when outside-the-word and inside-the-word strategies do not prove effective). These two components (comprehension and vocabulary) clearly emphasized methods for developing the students' ability to apply strategies during the reading process in an effort to analyze, interpret, and/or solve problems independently.

The teachers in Fisher, Frey, and Lapp's (2008) investigation also modeled for students the variety of ways that readers can organize information during the reading process by paying attention to the various text structures used by authors. Teachers modeled the differences between informational texts, which are commonly organized into compare/contrast, problem/solution, cause/effect, chronological/sequence/temporal, and description, and narrative texts, which focus on story grammar (including setting, plot, characters, conflict, and so on). Lastly, the teachers in Fisher, Frey, and Lapp's study modeled for students the variety of ways that text features can be used by readers to determine meaning and importance within texts, including features such as headings, captions, illustrations, boldface words, graphs, diagrams, glossaries, etc. Fisher, Frey, and Lapp noted that none of the teachers in this study simply engaged students in question-answer activities that ask students comprehension questions about the texts being read aloud. These lessons were clearly focused on modeling for the students how to independently solve problems and make meaning during reading. 
The findings of Fisher, Frey, and Lapp's (2008) investigation support the contemporary adolescent literacy perspective in which the goal is to help young adolescents become skilled at applying their developing knowledge and skills in an effort to analyze, reason, interpret, and solve problems independently as they read a variety of texts. This study identified four critical components of literacy instruction: comprehension, vocabulary, text structures, and text features; yet an important caveat of this study is that the participants in this investigation were recruited for this study based on the fact that they utilize the integrated read aloud/modeling/think-aloud process on a frequent basis in their classrooms. As a matter of fact, Fisher, Frey, and Lapp indicated that the "expert teachers" in this investigation reported using modeling, through shared reading, as a daily activity in their classrooms followed by multiple opportunities to practice and apply the skills being modeled. Although Fisher, Frey, and Lapp did not include the limitations of their study in the brief article describing their investigation, and based upon the fact that the participants in this study were purposively chosen based upon their consistent use of the read aloud/modeling approach, it is important to note that instructional practices such as these may not be commonly used in all intermediate and middle level classrooms.

The study conducted by Fisher, Frey, and Lapp (2008) lends itself to the current investigation because the current study takes place in different teachers' classrooms and utilizes classroom observations in an effort to reveal teachers' instructional literacy practices. This current investigation differs from Fisher, Frey, and Lapp's study in critical ways, though. The current study takes place in one middle school setting and involves two teachers of English. Further, this study utilizes a range of data collection techniques including interviews, observations, and analysis of relevant documents associated with literacy instruction. Additionally, the current investigation takes place across time and strives to reveal each teacher's 
unique beliefs about literacy as well as the variety of instructional approaches used by each teacher to teach literacy in the middle level classroom rather than focusing on one specific, purposively chosen instructional approach.

The modern day conception of adolescent literacy makes clear that there is an ongoing need for explicit instruction in reading and writing for adolescent students all the way through twelfth grade, including approaches such as those studied and reported by Fisher, Frey, and Lapp (2008). It is suggested that without this ongoing, explicit instruction, many adolescents are faced with the undesired choices of either dropping out of school completely or graduating from high school lacking the skills needed to succeed in higher education or future employment (Carnegie Council on Advancing Adolescent Literacy, 2010). King-Shaver and Hunter (2009) assert that this ongoing adolescent literacy instruction must incorporate a multiplicity of skills associated with developing proficiency in reading, writing, speaking, listening, viewing, and technology, which extends into the content areas, including mathematics, social studies, and science. Further, King-Shaver and Hunter suggest that adolescent literacy instruction must help adolescents learn to make sense of their world ... [as] they literally and figuratively use the tools of education combined with what they learn and know from outside the classroom to comprehend and understand the today and, more importantly, the tomorrow of their lives. (p. 2)

This broader conception of literacy departs from the long-held view that basic literacy instruction as well as reading and writing development conclude in childhood (Moje, 2002).

In an effort to come to a better understanding of the evolving literacy needs of young adolescents, Pitcher, Martinez, Dicembre, Fewster, and McCormick (2010) conducted seven case studies of middle level students who requested help though a university reading clinic. This 
collection of case studies provided an opportunity to analyze the extent to which school literacy programs are meeting the individual needs of young adolescents enrolled in middle schools. Many of the students involved in this study indicated that they were in need of comprehension instruction to help them learn to apply a variety of strategies while reading. Interestingly, the researchers noted that some of these young adolescents had achieved proficient or higher scores on state reading assessments, while others indicated that they were enrolled in reading intervention programs in their schools. The researchers made an effort to come to a comprehensive understanding of the reading needs of the young adolescents attending the university reading clinic in order to better understand the complexity of this issue.

The purported goal of Pitcher, Martinez, Dicembre, Fewster, and McCormick's (2010) investigation was to encourage administrators and teachers to examine the literacy instruction being provided in their schools in order to make insightful changes designed to meet the evolving needs of young adolescents. The students were evaluated using an array of reading assessments that measured word identification level, comprehension level, and reading strategy use, in addition to motivation for reading. Students and their parents also participated in an interview with the researchers. The sixth through eighth grade students were enrolled in the university reading clinic for 12 weeks. In addition, the reading programs that the students were enrolled in at their respective schools were examined to identify the programs' components and to determine the ways in which these programs met the students' unique needs.

Following the conclusion of the case studies, Pitcher, Martinez, Dicembre, Fewster, and McCormick (2010) utilized the constant comparative technique to determine recurring themes across the seven case studies. Based upon this analysis, the researchers were able to draw conclusions about the reading instruction students received in schools and to determine if these 
programs sufficiently met the adolescents' literacy needs. Pitcher, et al. (2010) found that all of the students possessed reading comprehension abilities that were below level, yet none of the students were receiving focused comprehension instruction or interventions at school. The interventions students received were focused on phonics delivered through scripted programs and were not aligned with the identified needs or learning strengths exhibited by the students. In some instances, the students simply lacked any comprehension instruction at all in the school setting. Students reported that in their English language arts classes, they simply read texts and answered questions. In addition, students also expressed concerns about problems with reading in content area classes where they received no help applying strategies or understanding materials.

The findings of Pitcher, Martinez, Dicembre, Fewster, and McCormick’s (2010) study indicated that the students struggled most significantly with expository text, which is the predominant text-type utilized throughout school and into future employment. Pitcher, et al. (2010) suggested that this was where specific strategy instruction in classrooms should focus. Interestingly, the students indicated that they were able to understand text they personally chose to read, including material read on the computer. The team of researchers also concluded that literacy instruction should focus on adolescents' unique needs rather than simply placing them in a haphazardly chosen reading program. Additionally, this instruction should include more selfselected reading; ways to critically think about text in both language arts and other content areas; more before-, during-, and after-reading comprehension instruction; and purposeful use of computers and technology to enhance literacy instruction. An important final conclusion was that what the students needed most was "well prepared ... teachers who integrate individualized 
reading instruction within their content areas" (International Reading Association and the National Middle School Association, 2002, p. 2).

Research suggests that the adolescent literacy perspective is critical to the overall literacy achievement of young adolescents. In order to obtain and lead a successful career in the twentyfirst century, adolescents leaving high school will need to have acquired more complex literacy skills than those needed in the past. Contrary to this notion, though, studies such as Pitcher, Martinez, Dicembre, Fewster, and McCormick's (2010) suggest that young adolescents are not receiving the type of literacy instruction they need in the school setting. Their study conveys the need to conduct meaningful research in the middle school setting. Therefore, the purpose of the current investigation was to spend time in middle level classrooms exploring the instructional approaches utilized by middle level English teachers. The current investigation endeavored to reveal the middle level teachers' unique beliefs about literacy as well as the ways in which these beliefs manifest themselves in the teachers' instructional practices.

The National Council of Teachers of English (2004) suggests that adolescents must learn to make meaning from a wide array of text types including print, electronic, digital, multimedia, visual media, and so on by thinking critically, analyzing, deconstructing, and reconstructing these various text forms. Adolescents must be taught to examine the various forms of text in order to determine what is being stated as well as what is implied (King-Shaver \& Hunter, 2009; NCTE, 2004). From the adolescent literacy perspective, literacy is viewed as a constructive, fluent, strategic, motivated, and lifelong pursuit (Jetton \& Dole, 2004).

Biancarosa (2012) explains that there are three major challenges that adolescent literacy must attend to in order for adolescents to achieve higher-level literacy. These include, "mastering increasingly difficult texts, understanding the distinctions among reading in different 
content areas, and reading digital content” (p. 23). Further, Biancarosa contends that no matter how thorough and successful early reading instruction, there is no way this early instruction can adequately prepare students for the types of literacy demands students will encounter beyond the third grade level. Moore, Bean, Birdyshaw, and Rycik (1999) advocate ongoing literacy instruction beyond the elementary grades because this ongoing instruction will be necessary in order for adolescents to attain the advanced levels of literacy necessary to adequately perform their future jobs, to effectively maintain their household affairs, to contribute meaningfully to society, and to generally conduct their daily personal lives in a continually evolving society that will be constantly flooded with information. Additionally, Alvermann (2002) promotes ongoing literacy instruction because the literacy skills of young adolescents are not progressing adequately considering the ever-evolving demands associated with living in an information age. The National Institute for Literacy (2009) contends that despite the significant advances that have been made regarding adolescent literacy, which include an understanding of the abilities needed to become successful readers as well as the conditions necessary for effective teaching of those skills, there has been minimal converging evidence that explores how adolescents learn and the best ways to teach literacy, including reading and writing, to middle school students. Further, they assert that much of the current research associated with adolescent literacy had been conducted in large urban environments, which was the case in Fisher, Frey and Lapp's (2008) investigation as well as Pitcher, Martinez, Dicembre, Fewster, and McCormick's (2010) study, which took place at a large university that was likely located in an urban area. Therefore, there is a need for additional research associated with adolescent literacy in rural areas, which is the context of this current investigation. 
Another study of adolescent literacy that examines both high-poverty inner city schools as well as middle class suburban schools is Langer's (2001) investigation of English language arts programs in schools that have made an effort to increase student academic performance in reading, writing, and English. In a five-year longitudinal mixed methods investigation of English teachers in middle and high schools, Langer compared and contrasted the English and language arts programs of "higher achieving" schools as opposed to "more typical schools." This study occurred across four states: California, Florida, New York, and Texas and included schools that were striving to increase students' learning and overall performance in English language arts and to "beat the odds" on standardized reading and writing tests despite obstacles associated with serving students of lower socioeconomic status. For the purposes of her study, Langer identified schools that were determined to "gain higher literacy" beyond that of demographically comparable schools. The schools were identified based upon diversity in student populations, existing educational problems, and overall approaches to school improvement. Additionally, test data were examined to identify schools that were either scoring higher than schools with similar student bodies or were scoring more typically as compared to demographically similar schools. Test data that were of greatest interest in making these determinations included literacy-related test data that carried high stakes for the students, the school, and the district. A final determining factor used to identify participating schools was that each school have professionals who were working in interesting ways to improve the overall academic performance of students as well as test scores in English. Once schools were identified for participation, each school was categorized as either a "beating the odds" school (which included schools whose performance on high-stakes literacy assessments were markedly above that for schools serving demographically similar populations) or as a "typically performing" 
school (which included schools whose performance did not deviate from that of schools serving demographically similar populations).

Once the determination was made that the participating schools were comparable in these important ways, yet differed on high-stakes reading and writing tests, Langer (2001) set out to examine what she considered to be the six most salient characteristics of educational practice that complement adolescent student achievement in reading, writing, and English: approaches to skill instruction, approaches to testing, approaches to connecting learnings, approaches for enabling strategies, conceptions of learning, and classroom organization. During this nested multi-case investigation, in which each English program was considered to be a unique case, and each class (including the teachers and student informants) was considered as a case within each case, 44 teachers working in 25 schools that included 2,640 students and 528 student informants, were studied extensively across two years. As each school site was studied over five weeks each school year, the research team focused on the ways that patterns in curriculum and instruction emerged in both the schools and the classrooms across time. This method allowed the researchers to examine three different contexts: the program, the teacher, and the students. Both formal and informal interview techniques were employed as well as classroom observations. During this time, teachers were also shadowed as they participated in a range of professional encounters such as team, department, building, district, or other relevant meetings. Additional artifacts were collected including e-mail messages and artifacts from various school-related and professional experiences.

Across this multi-state, longitudinal investigation, Langer (2001) revealed that the higher achieving schools exhibited the following distinguishing characteristics associated with instruction: 
(a) skills and knowledge are taught in multiple types of lessons; (b) tests are deconstructed to inform curriculum and instruction; (c) within curriculum and instruction, connections are made across content and structure to ensure coherence; (d) strategies for thinking and doing are emphasized; (e) generative learning is encouraged; and (f) classrooms are organized to foster collaboration and shared cognition. (p. 876) An important conclusion that was drawn during Langer's (2001) investigation that is meaningful for the current investigation is that many of the attributes associated with the discernible success achieved by the "beat the odds schools" were related to the classroom teachers" "visions of what counts as knowing” (p. 876). It was apparent that each teacher was instrumental in establishing the goals of instruction that were used to guide the teaching and learning process. The teachers' beliefs as well as the ensuing instructional practices shaped the educational experiences that occurred in the high performing schools. All of the teachers were aware of concerns associated with test scores as well as the students' acquisition of literacy skills. What made the most successful schools stand out from the typically achieving schools was the fact that each of the classroom teachers in the higher-achieving schools exhibited a discernable belief in the students' abilities to become capable and enthusiastic learners. Additionally, these teachers believed that all students can learn and that they, as teachers, could make a difference in the students' academic lives. In response to these perceptible beliefs, each of these teachers provided rich and challenging instructional contexts in which students were meaningfully engaged in discussions about English, language, literature, and all forms of writing. These teachers utilized both direct instruction and contextualized experiences that were instrumental in developing their students' skills and literacy-related knowledge. The teachers in the more successful English language arts programs employed integrated and interconnected learning experiences for their students that 
provided opportunities for the students to develop the knowledge, skills, and strategies needed to become independent, highly literate individuals able to draw upon these skills in various settings including school, home, and their future work.

In regards to the six characteristics of educational practice that complement student achievement in reading, writing, and English, Langer (2001) found discernible differences between the "beating the odds" schools and the typically achieving schools. In the higherachieving schools, the approaches to skills instruction integrated three distinct approaches: separated, simulated, and integrated, whereas the typically achieving schools exhibited instruction that was dominated by one of these specific approaches, which varied across schools and teachers. Langer defined "separated instruction" as involving direct instruction of isolated skills and knowledge that generally occurs separately from the context of a larger activity, introduction, practice, or review. Further, Langer explained that these separated skills are customarily presented through a lesson that is not connected to other lessons or activities that either precede or follow the isolated skill lesson. These skill lessons usually involved presentation of particular rules, conventions, or facts associated with English language arts or instructional materials that focus on rules of English or on vocabulary or spelling lists.

Conversely, Langer (2001) explained that simulated instruction involves the purposeful practice and application of the concepts and/or rules being taught within a targeted unit of reading, writing, or oral language. Langer noted that during simulated skills lessons, students are expected to read or write short authentic texts or to find examples of the targeted skill or concept within the literature and/or writing texts, in addition to out-of-school literacy activities. Lastly, Langer identified integrated skills instruction, which occurs when students are expected to use the newly acquired skills and knowledge embedded within the context of a more complex and 
purposeful activity. These activities may include tasks such as writing a letter, report, poem, research project, or play designed intentionally for an authentic purpose rather than merely for the sake of practicing the skill in isolation. Langer explained that it was during these types of integrated activities when students were reminded of a rule or skill that was previously learned (during separated or simulated activities) and were given the opportunity to discover how the rule or skill may prove valuable in the completion of the authentic task.

Langer (2001) found that when it came to test preparation, the higher-achieving schools integrated test preparation within the daily curriculum so that across time, students would develop the knowledge and skills required for accomplished performance on any required tests. On the other hand, in the schools that did not beat the odds, Langer found that specific time was set aside for test preparation in isolation from the ongoing goals, curriculum, and classroom instruction. This isolated approach required students to engage in taking practice tests and "instruction" that provided test-taking hints.

In the more successful schools, Langer (2001) discovered that teachers overtly emphasized connections among concepts and experiences within lessons; connections between and within knowledge, skills, and ideas across lessons, classes, and even grade levels; and connections between in-school and out-of-school application of knowledge and experiences. In the lesser achieving schools, the teachers tended to make no connections at all, and if they did draw some connections, these tended to be "real world" connections between school and home. Additionally, Langer (2001) found considerable differences in the ways that teachers went about teaching students strategies to engage in reading and writing activities and to reflect on and monitor their academic performance. Langer referred to these as enabling strategies. In the higher achieving schools, Langer found overt teaching of strategies designed to assist 
students with planning, organizing, completing, and reflecting on the content being taught and/or activities being completed. In the typically performing schools, Langer found that instruction focused on content or skills, but did not provide students with procedural or metacognitive strategies that would prove beneficial for future use of the skills or the content being taught.

For the final two characteristics of educational practice that complement student achievement in reading, writing, and English, Langer (2001) found that in the schools that beat the odds, teachers took a generative approach to student learning, continually pushing students beyond the mere acquisition of the targeted skills or knowledge to encourage engagement in deeper understandings of the concepts through challenging or enriching ways. In contrast, in the typically achieving schools, once teachers found evidence that the targeted skills or knowledge had been learned, the teachers tended to move on to new and unrelated goals and/or activities with few or no opportunities for creative or critical experiences designed to reinforce the newly acquired concepts. Finally, in regards to the classroom organization, the higher achieving schools demonstrated classroom organizations that provided students with an array of opportunities to engage in learning through meaningful interaction with each other as well as with the teacher in order to develop depth and complexity of understanding. Learning was considered to be a social activity that benefitted from the shared cognition that emerges from interaction with others. Conversely, in the more typical schools, collaborative work rarely occurred. Students tended to work alone, in groups, or with the teacher to complete tasks, yet students did not have opportunities to work through conceptualizations with others via engagement in rich discussion of ideas. These classrooms emphasized individual activity and individual thinking; when group work did occur, the activity generally involved answering 
teacher-provided questions rather than engagement in substantive discussion from multiple perspectives.

Langer's (2001) work revealed that there are essential differences in the ways learning activities are implemented in the higher performing and more typical schools. The higher performing teachers treated students as members of dynamic learning communities that rely on social and cognitive interactions to enhance learning. On the other hand, the teachers in the more typically achieving schools appeared to treat each student as an individual, with the assumption that classroom interaction has the potential to either diminish the thinking and learning of students or to disrupt the classroom discipline.

The findings of Langer's (2001) investigation provide some unique insights about the differences that exist across schools and across states despite similarities in demographics and attempts at improving English language arts instruction. Langer's study provides insights that may prove beneficial to the current investigation. The current investigation is similar in that interviews, observations, and collection of additional artifacts occurred. In addition, the current investigation spans two separate school years, with opportunities to examine English teachers' instruction with differing student populations across time. Teachers in the current investigation were asked to share their goals, plans, and beliefs about literacy prior to classroom observations. Then, classroom observations took place during four classroom observations across two different weeks in an effort to capture consecutive days of instruction across a unit of instruction. During these classroom observations, informal interviews and/or conversations were conducted in an attempt to clarify ambiguities that surfaced during the classroom observations. While this current investigation was conducted by one novice researcher rather than by an "expert team of field researchers" (as described by Langer, 2001), it is anticipated that at least some of the issues 
described by Langer may emerge during this current investigation since Langer's study examined English language arts instruction across varying contexts.

Kamil (2003) asserts that despite ongoing attempts to explore classroom instruction associated with adolescent literacy, the literacy field does not know enough about adolescent literacy to effect the positive changes that are needed to impact adolescent literacy across the nation. He contends that a great deal is known about the literacy needs of adolescents and the teaching practices that are most effective for adolescent learners, yet there remains a need to explore issues associated with adolescent literacy in greater depth. Kamil reminds educators that in order to be successful in the current knowledge-based society, adolescents must become expert readers, writers, and thinkers in order to effectively compete and succeed in the global economy. Furthermore, Kamil asserts that the current international rankings of reading achievement for our nation's fourth- through eleventh-grade students indicate that investing "in the education of fourth- through twelfth-grade students is not just important-it is a national imperative" (p. 30).

Middle level instruction. Middle school represents a critical time in the literacy development of young adolescents. It has been noted that during the middle school years, literacy instruction is of utmost importance because reading and writing are vital to academic success in each of the content areas (Burns, 2008). As Jackson and Davis (2000) indicate, one of the fundamental goals of middle grades education is to advance young adolescents' literacy development and

to enable every student to think creatively, to identify and solve meaningful problems, to communicate and work well with others, and to develop the base of factual knowledge and skills that is the essential foundation for these "higher order" capacities. As they 
develop these capacities, every young adolescent should be able to meet or exceed high academic standards... and to become active, contributing citizens of... [their country] and the world. (pp. 10-11)

Unfortunately, experts in the field, such as Heller and Greenleaf (2007), suggest that literacy instruction is often discontinued as elementary level students turn into young adolescents and advance to the middle school level. This lack of continued literacy instruction is of concern because as Biancarosa (2012) suggested, the accumulated literacy experiences of elementary readers do little to prepare adolescents for the ever-increasing demands of the texts these students will encounter at the middle school and high school levels. In addition, researchers suggest that when young adolescents reach the middle school level reading below their school-aged peers, these students continue to struggle with reading and typically never have the opportunity to catch up to their peers (Heller \& Greenleaf, 2007). Another concern associated with this lack of ongoing literacy instruction at the middle school level is the fact that researchers repeatedly find that as adolescents reading and writing on grade level continue without additional literacy instruction at the middle school level, it becomes quite likely that even these on-grade-level readers may begin to struggle to understand what is being read in the more complex textbooks and other academic materials encountered at the middle school level (Biancarosa \& Snow, 2006; Heller \& Greenleaf, 2007; Kamil, 2003; Meltzer, Smith, \& Clark, 2002).

As Ivey (1999) revealed in a multicase study of three sixth-grade readers, middle school readers can be considered both complex and multidimensional individuals. Ivey conducted a five-month long investigation of three sixth grade students enrolled in two different classrooms in one middle school. The students included one student who was a successful and motivated reader who read independently at school and at home; one student who was a struggling reader 
who was reluctant to read at school; and one student who was a moderately successful reader who seldom chose to read. Across this five-month study in which Ivey interviewed, observed, and worked one-on-one with each student during shared reading experiences, Ivey found that each of the students performed well in certain settings using specific materials, yet each also experienced inhibition in other reading situations in school. Ivey noted that the students' dispositions toward reading varied according to the contexts in which the reading occurred. For instance, when the reading represented an area of interest or personal need for the students, the participants were more willing to read and engage in the related reading tasks. Most importantly, Ivey discovered that middle level students vary in their levels of reading needs. One of the students clearly continued to struggle with decoding ability and possessed limited word knowledge, which had a significant impact on her reading success at school. A second student was a capable reader who was still developing reading fluency, yet he was able to comprehend most of what was read at school. Despite this reading ability, though, this student rarely chose to read for pleasure. Lastly, one student was identified as a superior reader in the school setting, but she needed interesting opportunities to practice applying her sophisticated reading skills in this particular context in order to continue improving upon her reading ability.

The current investigation draws upon Ivey's (1999) investigation in that it also takes place in two sixth grade classrooms. Instead of studying young adolescent readers, though, this current investigation sought to reveal the literacy beliefs held by two sixth grade English teachers. By utilizing interviews, observations, and analysis of pertinent documents, this current investigation examines the ways in which each sixth grade teacher's literacy beliefs are manifest in the instructional practices utilized in the sixth grade English classroom. 
Although there have been ongoing efforts to improve literacy instruction at the elementary level, the basic literacy skills acquired through the elementary school years are not enough to carry students through their entire academic careers (Carnegie Council on Advancing Adolescent Literacy, 2010), as was revealed in Ivey's (1999) investigation of middle level readers. Quite often the gains that students make in early reading performance diminish as these students proceed through the middle grades. It is apparent that a focus on adolescent literacy must become an overarching national priority (Carnegie Council on Advancing Adolescent Literacy, 2010). There remains a critical need for ongoing literacy instruction for students in fourth through twelfth grades because adolescent learners must engage in more complex reading tasks in order to achieve academic success. Researchers suggest that adolescent learners are confronted with more complex reading materials, which require a higher level of synthesis than previously experienced at the elementary level (Biancarosa, 2012; Carnegie Council on Advancing Adolescent Literacy, 2010; Heller \& Greenleaf, 2007; Kamil, 2003; Meltzer, Smith, \& Clark, 2002). Because adolescents will need to learn to independently interpret these more complex passages, ongoing instruction in various reading skills and strategies must be explicitly taught as students transition from the elementary school to the middle school level (Biancarosa, 2012; Carnegie Council on Advancing Adolescent Literacy, 2010).

Despite the concern for the literacy achievement of adolescents across the nation, research suggests that very little has been done to rectify this situation (Meltzer, Smith, \& Clark, 2002). Unfortunately, as Kamil, et al. (2008) have noted, much of what researchers have discovered about adolescent literacy development does not usually find its way from the research field to the middle school classroom teacher. As a matter of fact, the Carnegie Council on Advancing Adolescent Literacy (2010) suggests that across the nation there are middle schools 
that seem to be "stuck in the $20^{\text {th }}$ century, using outmoded approaches to prepare students for a world that no longer exists" (p. 14). This is a strong statement that implies the need for researchers to focus on the literacy needs of adolescents as well as the instructional approaches being employed at the middle school level in an effort to clarify the factors that continue to contribute to the alarming literacy rate of adolescents.

It has become apparent that our nation's middle schools must strive to create a more engaging literacy environment which compels young adolescents to engage actively in reading and other literacy tasks in the school setting, yet research continues to suggest that this is not happening across all of our nation's middle schools (Biancarosa \& Snow, 2006; Heller \& Greenleaf, 2007; Kamil, 2003; Kamil, et al., 2008; Meltzer, Smith, \& Clark, 2002; NCTE, 2006; Wise, 2009). For years there has been ongoing discussion among educators regarding whose responsibility it is to teach literacy at the middle school (and secondary) level (Kamil, 2003). As Appleman (2010) noted, there was a time in education when it was clear that there were two distinct literacy roles at the secondary level: the reading teacher and the English teacher. For years the English teachers' role was to teach literature, building upon the foundational reading skills that were previously taught by the reading teacher in the elementary school, yet it appears that the perception of the field of English language arts is divided between two perspectives those who view themselves primarily as teachers of literature and those who consider themselves teachers of reading (Appleman, 2010). Heller and Greenleaf (2007) have also suggested that in the early grades it is usually obvious whose responsibility it is to teach literacy and the associated literacy skills, yet at the middle school level the fundamental task of teaching literacy does not appear to be assigned to any particular group of individuals. Appleman indicates that at the secondary and middle school level, the English language arts teacher usually teaches both 
literature and reading, yet she also remarks that many English teachers believe that teaching reading extends beyond the expectations that many English teachers expected as they entered the field of education.

Appleman (2010) further notes that the continuous discussion associated with adolescent literacy and the ongoing literacy crisis has forced her to reconsider her relationship to the teaching of reading and has led her to the conclusion "that all teachers of literature are essentially teachers of reading" (p. 3). She acknowledges that in the context of the adolescent literacy crisis, many English teachers are regrettably likely to experience the sense of being pulled in two opposing directions. English teachers recognize the sense of urgency associated with this crisis, yet they are striving to do all that they can to foster productive literacy practices in their classrooms as they help students become competent readers and writers. While on the other hand, English teachers strive to maintain "the texture, richness, and autonomy" of the literature classroom (Appleman, 2010, p. 8). Appleman advises that although there is a sense of urgency regarding the current state of adolescent literacy, English teachers should not mistakenly conclude that the only way to improve students' reading abilities is to depart completely from literature-based practices to a "drill and skills" approach to reading instruction; instead she provides guidance for English teachers to purposefully weave together reading and literature instruction within the English language arts classroom. The ongoing discussion of whose responsibility it is to teach literacy at the middle school level must continue and one way in which this conversation can move forward is by talking with middle level English language arts teachers in an effort to help these teachers discover their literacy beliefs and determine the ways in which their beliefs are manifest in their instructional practices in the classroom, which is the focus of this current investigation. 
Heller and Greenleaf (2007) contend that one confusion that needs to be clarified is the notion of where young adolescents receive their literacy instruction. In their extensive review of the literature on adolescent literacy, Heller and Greenleaf indicate that if one asks a middle level math, science, or history teacher where young adolescents receive literacy instruction, they will most likely point to the English department. On the other hand, if one asks the English teacher who is responsible for teaching literacy at the middle school level many of these teachers do not appear certain where this instruction occurs because they have a tendency to spend little time explicitly teaching reading and writing skills since they are inclined to view themselves as content area specialists focusing on literature as their primary subject matter (Heller \& Greenleaf, 2007; Kamil, 2003).

Meltzer, Smith, and Clark, (2002) attribute this misunderstanding about the teaching of literacy to the fact that "literacy is not 'visible' as a content area, [therefore] it is not 'owned' by any specific department" (p. 10). This is a perception that has been inadvertently assumed for too many years, leaving our nation's adolescents unprepared to meet the complex demands associated with literacy at the middle school (and high school) level. It is apparent that our nation's schools can no longer afford to assume that the students entering the middle school already possess adequate literacy skills to move them forward through the secondary level (Appleman, 2010; Heller \& Greenleaf, 2007), nor can they afford to hold on to the notion that if literacy were adequately addressed at the elementary level, then there would be no need to address literacy in the middle school (Kamil, 2003; Meltzer, Smith, \& Clark, 2002). As Appleman (2010) so aptly stated

As English teachers, we must heed the call of this new crisis, without defensiveness or apology. As English or language or communication arts teachers, we are at the front line 
of fostering adolescent literacy. We may feel as if we have been doing our job to the best of our abilities and that there is a constellation of factors beyond our control that have contributed to this literacy crisis. That is undoubtedly true. And still, we need to face the challenging terrain of contemporary adolescent literacy and remap our pedagogical strategies. For English teachers, when it comes to what is arguably the core component of adolescent literacy, reading, many of us have not felt ready to heed the call. (p. 6) While the current study of ELA teachers' literacy beliefs is in no way intended to suggest that the weight of this crisis falls to the English language arts teacher, it does suggest that those in positions to effect change (such as literacy researchers, university instructors, professional development specialists, and so on) need to heed this call from those in the field, such as Deborah Appleman, who are passionate about their discipline and are eager to effect change. It is imperative for individuals in influential positions to strive to assist these individuals who are working on the front lines of young adolescent education. Studies such as this current investigation must endeavor to get into the English language arts classroom to help teachers sort through their beliefs, which directly influence their instructional practices. Researchers and other experts in the field of literacy may have the potential to help assure the English language arts educators that they can and will assist in reversing the effects of the ongoing adolescent literacy crisis.

\section{Summary}

This review of the literature examined the importance of investigating teachers' literacy beliefs and practices. It is suggested that studying adolescent literacy from the perspective of those who work most closely with adolescents would prove most valuable because teachers' beliefs play a critical role in shaping young adolescents' views of literacy. Furthermore, it was 
revealed that teachers view literacy in a variety of ways. Research has also shown that literacy can mean very different things to different teachers, even those teaching the same content in similar settings.

In addition, the review of the literature revealed that adolescent literacy is a contemporary view of literacy that suggests that reading, writing, speaking, listening, viewing, and technology each play a role in becoming literate in the twenty-first century. From this adolescent literacy perspective, it is apparent that adolescents must learn to make meaning, think critically, analyze, deconstruct, and reconstruct text using a wide array of text types ranging from print to multimedia. Adolescent literacy is viewed as a constructive, strategic, and lifelong pursuit. The review of literature revealed that literacy researchers believe that there is not enough known about adolescent literacy in the context of the classroom setting to make a meaningful difference in the literacy development of adolescents.

Finally, the review of literature discussed middle level instruction. This review suggested that literacy instruction at the middle school level is of utmost importance because higher levels of literacy are vital to academic success in all content areas. Further, the review of middle level instruction indicated that the accumulated literacy experiences of students at the elementary level do not adequately prepare students for the variety of texts encountered at the middle school level; therefore, it is suggested that literacy instruction must continue at the middle school level in order for students to acquire the literacy skills needed for success in high school and in their future lives. 


\section{Chapter Three}

\section{Methodology}

Chapter three describes the goals and rationale of the combined phenomenological case study approach, the guiding research questions, study design, theoretical framework, role of the researcher, and the context, sample, and participants. This section also describes the procedures for data collection and data analysis. Finally, this chapter describes issues of trustworthiness and ethical considerations that are specific to this study.

The goal of this investigation was to reveal the literacy beliefs and practices of two middle level English language arts teachers. Each of these constructs, literacy and beliefs, are psychologically held constructions that evoke a broad range of meanings which may be dependent upon the context of the conversation in which these terms are being discussed. Both of these constructs are structures that exist within the mind of an individual. Because the goal of this study was to discover these psychologically held constructs and then to discern the ways in which these constructs manifest themselves through the instructional activities employed in middle level English classrooms, the methodological approach for this study utilized a case study approach, integrating concepts from the phenomenological approach in an effort to study the phenomenon literacy from the distinct perspectives of the two participants involved in this study. Through this combined approach, the aim of this study was to allow the participants to essentially speak for themselves, as recurrent patterns, themes, and concepts associated with literacy emerged from within the data. As is customary of the phenomenological approach, every effort was made to suspend or withhold prior assumptions and theories associated with literacy in an effort to be true to the participants' perspectives rather than inadvertently suggesting that there is one "true" or universally held conception of literacy. This goal was 
achieved through an analysis of interviews and observations that lend themselves to describing the beliefs about literacy held by two middle level English teachers.

An integrated qualitative phenomenological case study approach was chosen because the issues under exploration are situated in the paradigm of social constructivism, which suggests that each individual in this investigation developed her own unique construction of literacy as well as subsequent instructional approaches for teaching literacy. The fundamental phenomenological construct applied to this study was the notion of exploring the meaning of the phenomenon literacy through the participants' first-person accounts of their experiences with literacy in a middle level English language arts classroom. A case study design was used because each teacher was initially considered as a unique case given the fact that individuals develop their own distinct beliefs about literacy based upon their personal experiences with literacy.

\section{Integration of the Case Study Approach}

An exploration of the literature revealed that many studies of teachers' beliefs have relied predominately on a case study approach. While the case study approach provides the methodological means to support collecting data through a variety of methods including interviews, observations, and documents, case study methodology also has the potential to narrow the investigation of an abstract construct such as beliefs. For the purposes of this current investigation, the case study approach provided a beneficial means for collecting a variety of data and provided an opportunity to draw conclusions about the participants in this study within their unique context, the sixth grade English classroom. Despite this benefit, though, the case study approach frequently incorporates a predetermined framework for data analysis because the researcher often begins the study expecting to identify particular characteristics during the 
investigation. This was not the case for this current investigation of middle level English teachers' literacy beliefs and instructional practices. Instead, this investigation intended to study the teachers' beliefs from their own unique perspectives. Additionally, case study research customarily utilizes an analytic framework for organizing and presenting the data, yet this approach was not the preferred method for this investigation since the goal of this study was to allow the English teachers' beliefs about literacy to guide the direction of this investigation. One feature of the case study approach that was beneficial for this investigation was the use of multiple participants. At the conclusion of the data collection and analysis phases of this investigation, the two participants' beliefs about literacy were compared and contrasted in an effort to provide a multidimensional profile of the sixth grade English teachers' beliefs about literacy.

Despite the frequent use and perceived benefits of case study methodology for studying teachers' beliefs, key researchers in the field of beliefs studies revealed that in order to effectively examine teachers' beliefs, the research methodology must provide multiple opportunities for the participants to offer evidence of their espoused beliefs. As was previously noted in the research on teachers' beliefs, beliefs are intrinsically held constructs that must be inferred from what teachers say, intend, and do (Pajares, 1992). Researchers, therefore, have suggested that teachers' beliefs can be revealed through statements that refer to their beliefs about a topic (such as literacy), through an exploration of what teachers intend to do in the classroom, and through direct observation of classroom instruction (Pajares, 1992; Rokeach, 1968). In order to arrive at some understanding of middle level English teachers' literacy beliefs and practices, a case study approach was combined with a phenomenological approach in this investigation. While the case study approach has been used frequently to study beliefs, experts 
who study teachers' beliefs suggest integrating qualitative research methods that employ narrative approaches that focus on participants' own narratives in order to acquire the emic perspectives of teachers. It has been suggested that the use of narrative inquiry, life history, biography, or autobiography provide a useful means for achieving this goal. One approach that did not emerge from the literature on teachers' literacy beliefs was the phenomenological approach. Therefore, this method was integrated with the case study approach for the current investigation because it is believed that this combined approach offered a unique context for providing the participants an opportunity to engage in open-ended interviews and for the researcher to observe the teachers' instructional methods so that richer and more accurate inferences could be drawn about these teachers' literacy beliefs and instructional practices, as is suggested by previous research on teachers' beliefs. The integration of the phenomenological approach provided the opportunity to maintain the participants' unique voices in the descriptions of literacy beliefs and practices rather than relying on a subjective or theoretical, objective interpretation of literacy. Rather than employing an analytic data analysis technique customary of the case study approach, a phenomenological analysis of the data occurred. The forthcoming sections provide a brief history of the phenomenological approach and describe the phenomenological methods that were integrated with the case study approach. Additionally, a description of the sequence of steps utilized for analyzing the data once it was collected in the natural context where the teachers' literacy beliefs were enacted, the middle level English language arts classroom, is provided.

A brief history of the phenomenological approach. Phenomenology is not only a qualitative approach to research, but also a twentieth century school of philosophy that emerged through the work of Edmund Husserl (Merriam, 2009). Merriam (2009) explained that the idea 
of focusing on an individual's experience and then exploring how the encounter with the experience is transformed into consciousness is the fundamental notion borrowed from the field of philosophy for application in qualitative research. The phenomenological research method originally emerged in response to the research field's desire to understand an experience of interest in its natural context, as it was lived and experienced by the participant. In order to gain an understanding of an experience in this manner, the researcher must acquire a description of what are referred to as the participants' intentional acts of consciousness, which are directly associated with the phenomenon of interest (Husserl, 1977). According to Husserl (1977), these intentional acts of consciousness include both "real" and "irreal" objects of consciousness. "Real" objects are described as those that are defined by time, space, and causality, while "irreal" objects, on the other hand, are those that do not physically exist, and are instead imagined, remembered, anticipated, and so on by an individual (Husserl, 1977; Zahavi, 2003). It was Husserl's belief that a phenomenological approach would provide the appropriate context for investigating a phenomenon that includes both "real" and "irreal" objects in the process of analysis (Husserl, 2008/1931). These acts of consciousness must be contemplated together in order to arrive at an understanding of the experience in its entirety within the natural context, as it was lived and experienced by the participant.

Integration of the phenomenological approach with the case study method aids in achieving the overall goal of revealing and then describing middle level English teachers' beliefs about literacy, which consist of both "real" and "irreal" objects of consciousness that are associated with literacy. Each of these objects of consciousness must be considered in order to understand the experience from the participants' unique perspectives because it is the first-person beliefs about literacy that are of interest instead of an objective interpretation of literacy based 
upon a preconceived framework for analysis. The phenomenological approach has been integrated with a case study approach for this investigation because an integrated case study design provides an opportunity to describe, analyze, and elucidate (Creswell, 2005) each English teacher's beliefs about literacy as well as the instructional methods employed by each English teacher in this study.

An important premise of the phenomenological approach that applies to this study is based upon the notion that the researcher involved in the investigation has an intense interest in the phenomenon under investigation. Furthermore, the researcher has at least a vague understanding of the phenomenon and has a general sense of some of the expected parameters of the phenomenon (Crotty, 1998; Englander, 2012). One objective I hoped to achieve as a result of this investigation was for the data to go beyond what I already know and understand about the phenomenon, literacy, so that I may achieve an even deeper understanding of this phenomenon. Utilizing characteristics of the phenomenological approach provided an opportunity to challenge my previously held notions of the phenomenon, literacy, so that a new and broader view of this phenomenon could emerge. This approach provided me with an opportunity to engage in critical reflection of the data that was collected. Through this process, I sought to identify, understand, and describe the phenomenon under investigation from the subjective viewpoint of the participants, maintaining the participants' voices in the descriptions. By drawing upon the phenomenological approach, I was able to remain true to the facts and details provided by the participants in an effort to describe, as accurately as possible, the phenomenon, literacy, from each participant's perspective. This approach refrained from applying either my subjective viewpoint or a predetermined theoretical and/or objective framework. The phenomenological research method and its associated data analysis process forced me to reflect deeply on the raw 
data, which led to an eventual reinterpretation of the phenomenon under investigation. These constructs associated with the phenomenological approach to qualitative research were implemented in this study in order to assist me in achieving a greater understanding of literacy as it is viewed through the eyes of two middle school English teachers.

As previously stated, the following initial research questions guided this study:

1. How do middle level English language arts teachers perceive and describe literacy? What are their beliefs about literacy?

2. How are these literacy beliefs manifested in the instructional practices of the middle level English language arts teachers?

\section{Study Design}

This study was the second phase of a two-part investigation. During the first phase of this investigation, I conducted a pilot study, which provided an opportunity to test the phenomenological data collection methods as well as the methods for analysis of the data. During the analysis and written presentation of the pilot study data, I discovered that the approach utilized did not accurately employ a phenomenological approach during the interview process and subsequent data analysis. As a novice researcher lacking a comprehensive understanding of the phenomenological method, a semi-structured interview protocol that contained eleven pre-determined interview questions was created and utilized during the data collection phase of the pilot study. Each participant was interviewed using this interview protocol.

During the subsequent data analysis phase of the pilot study, I discovered that the interview protocol unintentionally narrowed the responses provided by my participants. The semi-structured format of questions unintentionally led the participants to provide answers that 
were too narrow and that were inadvertently associated with my perceptions of literacy (based upon the limiting nature of the questions that I asked during the interviews). Therefore, the phenomenological approach was examined in greater depth and this second study was designed in an effort to more appropriately explore the middle level English teachers' beliefs about literacy through an open-ended interview technique. During the final phase of the investigation, the participants' beliefs about literacy were explored in order to gain a clearer understanding of these beliefs as well as how these beliefs manifest themselves in the participants' instructional practices.

This subsequent, or second phase of the investigation, utilized a somewhat iterative design to collect additional data that was needed to adequately understand the two middle level English teachers' beliefs about literacy from their unique perspectives. During this phase of the investigation, it was the first-person accounts of the experience that were of greatest interest rather than an objective interpretation of the experience based upon preconceived conceptions of literacy. The goal of the combined phenomenological case study approach was to provide a description of the two participants' experiences with literacy, based upon the natural context where this experience occurred, the middle school English classroom. Collecting data in this natural context and then analyzing the thoughts, feelings, interpretations, understandings, and impressions provided by the participants assisted in achieving this goal (Giorgi, 2009).

Throughout this phase of the investigation, the integration of the phenomenological approach provided an opportunity to portray each participant's beliefs about literacy through the participant's voice rather than through an abstraction of preconceived constructs identified prior to the investigation, which inadvertently occurred during the initial phase of this study as a result of the interview protocol that was utilized. Since the goal of utilizing this process was to reveal 
the participants' unique beliefs rather than to verify the existence of preconceived objectives or notions, no hypothesis was proposed, and no a prior framework for data analysis was established. Instead, the phenomenological approach provided an opportunity to describe the structure of the phenomenon, literacy, in a more comprehensive manner than could be achieved through other qualitative methods such as a strictly case study approach. Experts in the field who have studied teachers' beliefs suggest that the most beneficial approaches for establishing individual's beliefs about a notion should be studied through qualitative, narrative methodological approaches such as life history, biography, or autobiography (Fang, 1996; Pajares, 1992). Therefore, the goal of this investigation was to integrate a phenomenological approach in order to provide an opportunity for the participants to describe in as much detail as possible their beliefs about literacy. By interviewing each of the participants in the final phase of the study using an openended questioning technique associated with phenomenological research methods, rather than a semi-structured interview protocol, the phenomenon of interest was more likely to emerge through the participants' descriptions of their experiences with literacy in a middle level English classroom. This open-ended interview approach provided an opportunity for the participants' voices to be revealed rather than my preconceived notions about the phenomenon, literacy. Since the goal of this phase of the investigation was to gain a better understanding of literacy from the perspective of two middle level English teachers, I obtained descriptions of literacy from each teacher through multiple data sources. The data sources included a minimum of one interview of each participant, three classroom observations in each participant's classroom during the course of a unit associated with literacy, and a request for at least two lesson plans provided by each participant. Additional informal interviews took place as needed in order to clarify issues that arose or to ask the participants to provide additional descriptions to 
aid in clarifying unclear information. Data analysis occurred at the conclusion of the data collection phase of the investigation. During this phase of the investigation I was required to assume the phenomenological attitude as a search for the essential beliefs associated with the phenomenon was undertaken. Each of these stages of the investigation are described in greater detail in the forthcoming data collection and data analysis sections.

\section{Theoretical Framework}

This study was situated in the paradigm of naturalistic inquiry. The characteristics of naturalistic inquiry that are present in this investigation include maintaining the natural setting in order to keep the phenomenon under investigation in its original context, qualitative research methods, purposive sampling, inductive analysis, a case study approach to reporting, tentative application of research findings, and the unique criteria of trustworthiness (Lincoln \& Guba, 1985).

The methodological approach was also interpretive in nature (see Figure 3 for an overview of the theoretical framework of this study). It is well documented in the literature that the phenomenological method is situated in the theoretical perspective of interpretivism (Crotty, 1998). Interpretivism is associated with achieving an understanding of a phenomenon, which is the overall goal of the phenomenological case study approach of this investigation. Interpretivism assumes that individual interpretation or understanding of phenomena is continually constructed through various social, cultural, and historical interactions (Crotty, 1998; Hesse-Biber \& Leavy, 2011). Further, it suggests that phenomena can be best explored through an examination of the perspectives of individuals as they are engaged in meaning-making activities that are associated with the phenomenon under investigation (i.e., English teachers teaching literacy) (Hesse-Biber \& Leavy, 2011). 
Figure 3. Overview of the theoretical framework.

\begin{tabular}{|l|l|l|l|}
\hline \multicolumn{1}{|c|}{ Epistemology } & \multicolumn{1}{|c|}{$\begin{array}{c}\text { Theoretical } \\
\text { Perspective }\end{array}$} & Methodology & \multicolumn{1}{c|}{ Methods } \\
\hline $\begin{array}{l}\text { Constructivism } \\
\text { (social } \\
\text { constructivism) }\end{array}$ & $\circ \begin{array}{l}\text { Interpretivism } \\
\text { Naturalistic } \\
\text { Inquiry }\end{array}$ & $\circ \begin{array}{l}\text { Phenomenological } \\
\text { inquiry } \\
\text { Case study } \\
\text { reporting }\end{array}$ & $\circ \begin{array}{l}\text { open-ended } \\
\text { interviews } \\
\text { classroom } \\
\text { observations } \\
\text { document analysis }\end{array}$ \\
\hline
\end{tabular}

In order to adequately explore a classroom teacher's conception of a complex notion such as literacy, multiple factors must be considered. As the extant research on teachers' beliefs has indicated, beliefs cannot be directly observed or measured and must instead be inferred from what individuals say, through statements that describe their intentions to perform associated tasks, and through the behaviors exhibited in the unique context that are related in some manner to the construct under investigation (Pajares, 1992; Rokeach, 1968). Ruddell (2004) recommended that a classroom teacher's awareness and beliefs about instruction as well as the teacher's instructional approaches during instruction play a vital role in creating an effective literacy environment, and as such, must both be explored in order to arrive at an adequate understanding of teachers' beliefs about literacy. Ruddell and Unrau (2004) recognized that because reading and literacy are meaning-construction processes, both affective conditions, such as the classroom teacher's instructional beliefs and philosophy, and cognitive conditions, which are associated with the teacher's conceptual and instructional knowledge, must be explored through individual interviews and observations of middle school English teachers. Therefore, in order to arrive at a deeper understanding of each teacher's beliefs about literacy, individual interviews, classroom observations, and document analysis were combined in an effort to discover and describe each English teacher's beliefs about literacy. 


\section{Role of the Researcher}

My role in this study has evolved over the course of this investigation. This study originally emerged as a direct result of my role as the sole reading specialist in the middle school in which the two participants serve as sixth grade English teachers. While working in this school location for two and a half years, a clear understanding of the role of literacy as well as the specific roles that each teacher played in the development of young adolescent literacy in that setting had not been established. Most recently, I transitioned from the role of middle school reading specialist to that of assistant professor, where I serve as the sole faculty member responsible for teaching reading and literacy methods courses to undergraduate and graduate elementary and middle level preservice teachers. In my current role, I also serve as the coordinator for my university's Reading Specialist Program. In that role I serve as the academic advisor for all candidates enrolled in the program and I design and teach courses for the reading program.

It was during my experience serving as a reading specialist at the middle school level that a unique phenomenon associated with perceptions of literacy emerged. At the middle school level I discovered that the members of my school's English department appeared to view literacy from a completely different perspective than my own. It was this discernible, yet indescribable difference in perceptions that led me to this research project. This disconnect between perceptions emerged as I worked as a literacy coach seeking ways to assist my colleagues in meeting the diverse literacy needs of the young adolescents in our middle school. As the school's literacy coach, I was encouraged by my administrators to work with my colleagues in the English Department to find ways to improve upon our school's overall literacy. During department meetings as my colleagues and I worked together to consider instructional methods 
that may prove beneficial for the young adolescents enrolled in our middle school, it appeared that I did not understand my colleagues' goals and intentions, and similarly, it did not appear that my colleagues understood my goals and intentions. I found that when I recommended researchbased literacy strategies designed specifically to meet the evolving literacy needs of young adolescents to members of my English department, I frequently met with resistance. While I never positioned my views of literacy as being more valuable than my colleagues' views, I found that I was not able to clearly ascertain my colleagues' literacy goals and beliefs in a manner that afforded me an opportunity to provide meaningful assistance and support in helping them to achieve their instructional goals. This gap in our professional perceptions about literacy became an area of great interest as I worked to learn with and from my colleagues. During my day-today interactions with colleagues in the English department, I was unable to clearly ascertain the literacy beliefs held by the school's English teachers because I did not have the opportunity to spend time in their classrooms revealing their instructional goals and beliefs about literacy. Therefore, my interests were continually drawn to issues associated with developing adolescent literacy as I worked with my colleagues in the English department.

As I made the transition from the primary level to the middle school level my beliefs about literacy evolved to encompass the literacy needs of young adolescents. This transition helped me come to the realization that literacy is not a static construct, but rather a complex and multifaceted concept that continually evolves in response to the constantly expanding literacies present in our highly technological and digital society. Therefore, my beliefs about literacy continue to evolve in response to shifting literacy demands. My current perception of literacy is one that merges constructs associated with reading, writing, speaking, listening, viewing, composing, creating, producing, analyzing, evaluating, problem solving, critical thinking, and 
communication. I view literacy as a fundamental element associated with one's ability to achieve success in school and in life.

I believe that the findings of this study in which I endeavored to discern and describe middle level English teachers' beliefs about literacy, prove beneficial in a variety of ways. First, the results of this study will be beneficial for the two teachers involved in this study, as they played a fundamental role in the initial analysis of the data collected (referred to as member checking). During this process, each participant verified the preliminary data analysis to make certain that it was the teacher's unique perspectives that were revealed through the analysis of data rather than an abstraction of the participant's beliefs that did not coincide with the participant's espoused beliefs about literacy (this process is described in detail to follow). Second, this research will be of practical use for me in my current context as a teacher educator teaching literacy methods courses to middle level preservice teachers. It is also projected that this research will provide valuable insights for those involved in professional development and teacher education as well as middle level English language arts teachers.

Due to potential threats to validity associated with my prior work in this school environment, additional measures were employed during data collection and data analysis in an effort to ensure validity of the findings (these are discussed in greater detail in the forthcoming data analysis and trustworthiness sections). Since it was apparent that personal perspectives associated with literacy are continually present, the process of the epoche (or bracketing) were practiced throughout this study in an effort to focus upon potential preconceptions as data were gathered and analyzed. In addition, measures such as memoing and an audit trail (which are described in greater detail in the forthcoming trustworthiness section) were employed in an effort to avoid contaminating the data analyses with personal biases and preconceptions about literacy. 
Every effort was made throughout this study to withhold my subjective views as well as an objective interpretation based upon a preconceived analytic framework.

Engaging in the process of the epoche was a completely new experience for me. Having spent quite a few years pursuing this educational endeavor, it has become apparent that I have accumulated many preconceived perceptions, judgments, and/or biases during this process. In order to enter into this research study with the goal of reporting each participating teacher's unique account of her beliefs and life experiences as a teacher of literacy, the epoche process played a vital role in this investigation. Prior to entering into the research setting it was of utmost importance to spend time engaged in a reflective-meditative stance in order to set aside the preconceived biases and prejudgments that have become so engrained. In an effort to achieve a phenomenological view of the English teachers in this study, I entered each teacher's classroom with a receptiveness that allowed the situation to be viewed in a completely open and unbiased manner. This process required me to enter into the research setting without "being hampered by the voices of the past that tell us the way things are or the voices of the present that direct our thinking” (Moustakas, 1994, p. 85). Instead, since the goal of this phenomenological investigation was to create a clear depiction of the phenomenon from each participant's perception, I endeavored to describe in detail "the whole account of an issue, problem, situation, or experience, using qualities and properties from specific contexts or perspectives, so that the events or experiences take on vivid and essential meanings" (Moustakas, 1994, p. 60). To achieve this goal, I sought "to silence the directing voices and sounds ... to remove from [myself] manipulating or predisposing influences and to become completely and solely attuned to just what appears, to encounter the phenomenon, as such, with a pure state of mind" (Moustakas, 1994, p. 88). Therefore, prior to embarking on this study, and prior to entering into 
the teachers' classrooms for the purposes of data collection, the process of the epoche took place, providing me with an opportunity to thoughtfully reflect upon potential preconceptions and prejudgments. By writing out and then labeling these preconceived constructs in an ongoing list, I was subsequently able to contemplate the ways in which these preconceptions potentially impacted my thoughts and interactions throughout the course of this investigation.

In addition to employing the epoche process throughout this study, the process of memoing and an audit trail were used to record personal biases and preconceptions. This evolving list of preconceptions and biases was repeatedly reviewed throughout this study, providing me with an opportunity to encounter the individuals and the experiences under observation with a more receptive and open stance. This process provided an opportunity to be prepared to more readily "meet something or someone and to listen and hear whatever is being presented, without coloring the other's communication with [one's] own habits of thinking, feeling, and seeing, removing the usual way of labeling or judging, or comparing" (Moustakas, 1994, p. 89). Although it is acknowledged that it is quite difficult to achieve this openness in an absolutely perfect manner, engaging in the process of the epoche in conjunction with the audit trail and memoing process, provided an opportunity to significantly reduce the potential influences of preconceived thoughts, judgments, and biases, which was the goal of engaging in these processes throughout this investigation.

\section{Context and Sample}

This phenomenological case study investigation of middle school English teachers' beliefs about literacy took place in a middle school located in a rural area of Northern Virginia. This middle school is one of five middle schools in a countywide school system situated in the Virginia Piedmont. The school's socioeconomic group ranges from very wealthy families who 
own and operate multi-million dollar equestrian farms to extremely poor families who live in houses with no running water.

This school was chosen for this investigation based partially on convenience and more specifically because it was in this particular setting that a noted disconnect between individual views of literacy emerged. At the outset of this investigation, as the sole reading specialist in this setting, it became apparent that my personal views of literacy differed distinctly from the perceptions of literacy held by the members of the school's English department. Therefore, all of the English teachers in this setting were initially considered for participation in this study. This middle school has two English teachers at each grade level, for a total of six English teachers. Prior to embarking on this study, during a school-wide English Department meeting, all members of the department were invited to participate in this research study of middle level English teachers' beliefs about literacy. Only two of these individuals volunteered for this study despite repeated attempts to recruit three or more participants for this investigation. On more than one occasion when I sought participants for this investigation, my colleagues were quick to volunteer other colleagues in the department for this study, while also making excuses describing why they could not participate. Therefore, two middle school English teachers, both of whom teach at the sixth grade level, were recruited for participation in this research study.

\section{Participants}

Purposive sampling was used for this investigation because the respondents needed to participate in this study required particular characteristics as determined by the specific goals of the research project (Hesse-Biber \& Leavy, 2011). The participants chosen for this investigation must each have the unique qualification of being a middle school English teacher. English teachers were chosen for this study for multiple reasons. First, a divergence in views of literacy 
between myself, as the school's sole reading specialist and literacy coach, and the teachers in the English Department initially prompted this investigation. Second, experts in the field of literacy have suggested that it is unclear who is directly responsible for teaching reading and writing (tasks associated with literacy) at the middle school level, yet this task often purportedly falls to the English department (Appleman, 2010; Heller \& Greenleaf, 2007; Kamil, 2003). Another factor that influenced my decision to study English teachers is the fact that experts in the field of literacy suggest that many teachers of English do not feel adequately prepared to effectively teach literacy to young adolescents because most teacher preparation programs for secondary education require only one course in reading and/or literacy methods, usually a content-area reading course. In addition, there is often an assumption made that English teachers are the most adept at teaching literacy to young adolescents simply because they have studied English as their educational focus. These issues taken together provided a unique backdrop for studying English teachers and their beliefs about literacy. Finally, this study took place in the state of Virginia and the Virginia Department of Education indicates that middle school English teachers are required to teach reading and writing, each of which are referred to directly in the Virginia Standards of Learning (SOLs) for sixth, seventh, and eighth grade (VDOE, 2011) and are generally associated with literacy.

In order to gain multiple and varying perspectives related to teaching English to young adolescents, two teachers, both of whom hold varying years of experience, were recruited for this investigation. Another critical criterion that was considered in this investigation was the willingness and openness of the two participants. The individuals involved in this investigation were willing to participate openly in the interview process and were willing to be observed in their natural classroom setting, whereas the other members of the faculty's English Department 
were not willing to participate in this investigation despite repeated attempts to recruit additional members for this study.

\section{Data Collection}

In keeping with the characteristics common to qualitative research, this study sought to understand the phenomenon of interest (literacy) from the perspective of the participants. Additionally, as is customary in qualitative research, the researcher was the primary instrument for data collection and analysis and the study employed fieldwork, an inductive research strategy, and a final product that is richly descriptive (Merriam, 1998). The data collected for this investigation included descriptive data acquired from the participants' explanations and comments, which were collected in a narrative form through phenomenologically-based interviews, classroom observations, and relevant documents.

Pure phenomenological investigations tend to rely predominantly on data acquired through interviews, yet because this interview approach was integrated with a case study approach and because this study has a small number of participants, multiple data sources were used in an effort to strengthen the findings. Additionally, it is important to note that studying constructs such as literacy and beliefs present complex issues associated with data collection. Prior research of beliefs and literacy have attempted to employ strictly quantitative means such as Likert-style surveys in an effort to isolate teachers' perceptions, yet experts in the field indicate that these instruments do not provide the adequate depth needed to explore these convoluted psychological constructs (Fang, 1996; Pajares, 1992). Therefore, data for this study were collected through purely qualitative means, including interviews, observations, and document analysis. During interviews and observations, digital audio recordings were made and I transcribed each audio recording. The raw data included transcriptions of the interviews and 
observations as well as ethnographic field notes recorded while I was in the field during the interviews and observations, along with pertinent documents, such as lesson plans that were collected from the participants during interviews or following classroom observations.

\section{Interviews}

The interview method utilized for this study was drawn from the phenomenological approach. Although this approach is very open-ended, it was also loosely associated with the semi-structured expert interview approach in which participants' beliefs are expressed through an open-ended interview design rather than through a standardized or structured interview protocol (Flick, 2009). This combined approach utilized one open-ended question as the initial question, followed by opportunities to further explore responses that were of interest to this investigation. This approach was utilized because there are several noted strengths of the semistructured interview as a data collection method including: the notion that this approach has the potential to uncover participants' perspectives; this method can assist participants in describing complex interactions; and this approach can assist the researcher in gaining a better understanding of the research problem without inadvertently imposing preconceived notions on the research setting (Fontana \& Frey, 2005). The expert interview approach was utilized because the participants themselves were of less overall interest (as individuals) than their expertise and experiences associated with their position as middle school English teachers (Flick, 2009). Because the interviews in this investigation were phenomenological in nature, a goal of these interviews was to focus on the participant's own narratives about her beliefs about literacy in an effort to obtain the emic perspectives of the teacher (Fang, 1996). This type of interview data provided a more effective means for acquiring sufficient data from which to reflect upon and elaborate the teachers' literacy beliefs and how these beliefs influenced the instructional methods 
utilized in the teachers' classrooms. The semi-structured nature of the interview process focused on providing an opportunity for the participant to provide "cognitive clarification of the ... experience" (Kvale \& Brinkmann, 2009, p. 25), while also providing the context for the participant to describe her experiences and beliefs as they relate to literacy. During this process, the participants had the freedom to choose which facets of literacy they wished to discuss.

The interviews sought to attain the first-person account of the experience, literacy, as it was lived and understood by the participant in her everyday experiences in the middle school English classroom. The interview consisted of an initial open-ended question designed to offer the participant an array of opportunities to describe her experiences and beliefs about literacy. The opening interview question was, "In as much detail as possible, please describe for me your overall literacy goals for your English classroom this year.” This open-ended question provided an opportunity for the participant to describe her views of literacy, as they are associated with her position as a middle school English teacher. During the interview process, notes were recorded, indicating instances where the participant may have been able to provide greater detail, or where the participant inadvertently strayed from the topic of literacy. Once the participant concluded her initial comments about her literacy goals for the year, additional probing questions were used to follow-up on previously noted gaps. For instance, the participant may have simply been asked to explain why a specific approach or activity was mentioned. A follow-up probe such as, "You mentioned [such and such], can you tell me more about that?" was used to obtain a better understanding of the issue under question. The precise goal of this line of questioning was not to lead the participant to provide a specific response, but rather to delve deeper into an issue that was mentioned by the participant yet was not described as completely as possible. This form of questioning and description was used because the goal of this phenomenological 
approach to the investigation was to acquire as much information as possible from the participant regarding her beliefs about literacy. The interview continued until the participant described all that she wished to share about literacy or until saturation of data occurred, whereby the participant began repeating information that was already shared during the interview process.

\section{Observations}

Although phenomenological investigations typically rely predominantly on descriptions of experiences gathered through individual interviews, this investigation integrated a case study approach and therefore incorporated multiple data sources in order to triangulate the data collected. After completing the initial interviews, observations occurred in each teacher's classroom in an effort to discover first-hand the approaches being used to teach literacy to young adolescents. I observed the teachers' instructional practices in an effort to discern how the teachers' literacy beliefs were manifested in the instructional practices employed in the middle level English classroom.

I conducted classroom observations using ethnographic field notes and transcriptions of audio recordings as the primary data sources. A total of three observations occurred in each classroom over a three-week time frame. The intent of these observations was to observe at differing times across the course of a literacy unit. These observations occurred across a shorter time frame because during the pilot study, observations occurred rather arbitrarily, providing isolated glimpses of the teachers' instructional practices with little consistency across the observations. By conducting these follow-up observations during a shorter time frame, it was anticipated that a more coherent and logical understanding of literacy practices would be acquired. 
Observations were used in an effort to identify the instructional practices associated with literacy that were explicit in each teacher's classroom. This data also provided a source for triangulation of data. Although the interviews likely provided insights that are germane to this investigation, there is always the potential for interviewees to inadvertently bias the data by providing responses based upon what they believe the researcher wants to hear (Flick, 2009; Merriam, 2009; Padgett, 1998). Therefore, a goal of classroom observations was to make certain that the data collected through interviews were not inadvertently biased in this manner. These classroom observations provided a firsthand account of the instructional practices of each English teacher involved in this study (Merriam, 2009). Furthermore, these observations provided an opportunity to verify the interview responses of each participant.

From a phenomenological perspective, the researcher becomes a participant observer during the course of the investigation because she plays a critical role in conducting the interviews and classroom observations (Englander, 2012). During the classroom observations, as well as during the interview process, my goal was to encounter the phenomenon of interest, literacy, through the participant's narrative descriptions and explicit actions being observed in the classroom. Ethnographic field notes were collected during the classroom observations, with no identifying information related to the individuals observed.

An important caveat associated with this investigation is that the actual situation and/or context in which the phenomenon was being observed differed significantly for each participant in this investigation. This premise is one that further substantiates the integration of a phenomenological approach with the case study approach because this is a factor that separates phenomenological research from a traditional experimental research approach because is it not the empirical situation being observed that is of interest, but rather the meaning of the 
phenomenon under investigation that is of greatest importance (Englander, 2012). The situation in which the observations took place simply provided the context for the emergence of the meaning of the phenomenon under investigation.

\section{Document Analysis}

In addition to conducting interviews and observations of the two teachers, an examination of additional documents was intended in an effort to provide additional confirmation of the teachers' beliefs about literacy. As Yin (2014) proposed, analysis of pertinent documents during a case study investigation provides an opportunity to corroborate and strengthen evidence collected through other data sources. Further, Merriam (1998) suggested that a qualitative study of classroom teachers and/or classroom instruction would likely lead to the analysis of documents such as teachers' lesson plans and/or teachers' evaluation materials.

Documents that may have proven beneficial in this particular investigation included lesson plans and yearly evaluation goal statements that describe the tasks the teachers intend to utilize in the English classroom. By attempting to include pertinent documents in the analysis of data for this investigation, triangulation of data sources was intended to strengthen and add an additional layer to aid in achieving saturation of data for this study. Qualitative researchers suggest that integrating document analysis into a qualitative investigation can add an objective source for data analysis (Merriam, 1998). Document analysis also has the potential to add contextual richness to an investigation because documents aid in grounding the research in the natural context of the problem (Lincoln \& Guba, 1985; Merriam, 1998).

Each teacher involved in this study was asked to provide at least two lesson plans from either the lessons that were observed or previous lessons that focused on some facet of literacy instruction (to be determined by the teacher rather than by the researcher). Additionally, both 
teachers were asked to share the goal statements created for their yearly teacher evaluations. Unfortunately, despite repeated attempts to collect this type of documentation from the two teachers, neither teacher involved in this study shared a written copy of the yearly evaluation goals. One of the two teachers shared lesson plans, yet these lesson plans did not serve the intended goal of this investigation because the lesson plans were plans that had been developed for a master's level course, using a lesson plan template created by the university program. These lesson plans did not portray tasks that were integrated into classroom instruction, so they did not serve the intended purposes of this investigation. The second participant shared that she does not write detailed lesson plans and instead merely notes due dates for various tasks that have been assigned in class. Therefore, this intended goal for this investigation was not achieved.

\section{Data Analysis}

Data analysis began at the conclusion of the data collection phase of this investigation. The raw data analyzed included the transcriptions of interviews and observations, along with the ethnographic field notes. The phenomenological approach was used for data analysis in order to provide an opportunity to reflect deeply on the raw data, engaging in critical reflection in the search for recurrent themes, patterns, and concepts associated with literacy within the data. In keeping with the phenomenological tradition, no prior assumptions or theories associated with literacy were determined in advance (Moustakas, 1994). Each piece of data collected was considered with equal value, and was considered "with a horizon of undetermined determinability" (Husserl, 1977, p. 30). Data analysis occurred concurrently with the ongoing process of the epoche, where preconceived notions were bracketed in an effort to make certain that only the participants' views of literacy were integrated into the analysis. As is customary 
with other qualitative research methods, the following basic steps were performed: (1) verbal data were collected, (2) the raw data was read and re-read, (3) data were broken down into meaningful parts, (4) data was organized, and (5) a final synthesis of the data was created in an effort to share the findings with the scholarly community (Giorgi, 1997).

Once data were collected, and a transcription of all audio recordings was completed, the raw data was sequentially organized based upon the order in which the data were collected. For each participant, a chronological collection of the data was compiled with the data from interviews first followed by data collected from observations. Data from each participant was compiled in this order so that it could be viewed as an overall narrative description of the participants' beliefs about literacy. Once the data for each participant was placed in sequential order, then the data analysis process began by assuming the phenomenological attitude. Next, in searching for the essences of the phenomenon, the processes of horizonalization, phenomenological reduction, and imaginative variation were utilized. Finally, in order to describe the essences of the phenomenon, a final synthesis of the overall meanings and essences associated with literacy took place. Each of these steps are described in greater detail to follow. The overall goal of the data analysis process was to understand the phenomenon, literacy, from the first-person perspective of each of the participants.

The data analysis process utilized in this investigation integrated Giorgi's (2009) descriptive phenomenological method with Moustakas' (1994) modified van Kaam method of phenomenological data analysis. These two approaches were combined for the purposes of this investigation because together they provided a clear sequence of tasks that could be employed consistently across both participants' accumulated data. The following steps, which are each described in detail to follow, were used during the data analysis process: 
1. assume the phenomenological attitude

2. search for the essences of the phenomenon through the following steps:
a. horizonalization
b. phenomenological reduction and imaginative variation
c. clustering and thematizing invariant constituents

3. description of the essence, which involves the following steps:

a. construction of an individual textural description of the experience for each participant

b. construction of an individual structural description for each participant

c. construction of a textural-structural description of the meanings and essences of the experience for each participant

d. development of a composite description of the essential meanings and essences of the phenomenon for the entire group (adapted from Giorgi, 2009, pp. 87-89; Moustakas, 1994, pp. 120-121)

The phenomenological method utilized in this study was designed to focus on the lived experiences and narrative descriptions offered by each participant in this study rather than constraining the data collected to a subjective interpretation chosen by the individual conducting the research. In order to effectively engage in phenomenological data analysis, I began this process by assuming a phenomenological attitude. This means that I had to look at the ideas, descriptions, and information shared by the participants from the perspective of how they experience and perceive literacy. I made every effort to understand the experience from the unique perspective of the participant. In order to achieve this goal, I had to break free from my 
"natural attitude," or the manner in which I typically perceive the world, where personal perceptions of phenomenon are taken for granted (Giorgi, 2009).

This step began with an initial reading and re-reading of each of the participant's accumulated descriptions from beginning to end in an effort to achieve a general sense of what each participant's description is all about; this general understanding is considered to be a holistic understanding of the description provided by the participant. The reading process required me to revisit the entire collection of raw data for each participant no fewer than two times over multiple days in order to establish a general sense of the participant's descriptions about literacy. Although a specific number of re-readings could not be delineated prior to this process, this step provided me with an opportunity to come to some coherent understanding of the data. This step was not intended to begin the process of identifying emergent themes or drawing conclusions; it was merely designed to assist in gaining a more vivid understanding of the data that was collected from each of the participants.

The next phase of data analysis began the actual process of searching for the essential meanings associated with the phenomenon literacy. While working from within a phenomenological attitude, I began to systematically determine what was essential about the phenomenon under investigation, based upon the statements made by the participants. This process involved dividing the data into more manageable parts so that distinct elements of meaning could be discovered. In phenomenological analysis, this is referred to as a process of horizonalization (Husserl, 1977; Moustakas, 1994). During this process each detail relevant to the phenomenon under investigation was eventually listed and preliminarily grouped together. These preliminary details eventually became the initial units of meaning. Each detail (or "horizon") identified represents the conditions of the phenomenon that give it its distinctive 
character and enable the researcher to understand the experience from the participant's perspective more clearly (Giorgi, 1997; Giorgi, 2009).

Throughout this process I employed a process of phenomenological reduction, whereby the descriptions of the experiences, which include the transcripts of interviews and observations as well as field notes, were reduced or clarified into meaningful units through my consciousness. This process required that I once again re-read the entire collection of data, marking where shifts in meaning occurred (Giorgi, 1997). In order to discover these meaning units, I had to re-read the description in a slower, more methodical manner than during the initial reading, searching for places in the description where transitions in meaning occurred. Each time a transition was noted, a mark (such as a forward slash) was made, indicating where a transition took place. This process took the raw data, which were originally expressed in the participant's own everyday language, and broke this narrative form of the data down into smaller units of meaning. These discrete chunks of meaning represented distinctive meaning units that were relevant to the study. Each of these units of meaning were recorded in a codebook, which was used to compile all of the emergent codes, themes, patterns, and descriptions utilized throughout the data analysis process. The codebook aided in providing transparency and potential replication of this study (Auerbach \& Silverstein, 2003).

During this process, it was my professional understanding of the phenomenon that allowed for the relevant units of meaning to be discerned and discovered intuitively. This task required me to heighten my level of consciousness, striving to be acutely aware of what it was that the participant was trying to convey through her descriptions (Giorgi, 2009). Critical attention was brought to bear on the present experience, without allowing preconceived notions of the phenomenon to interfere with the analysis of the raw data (Giorgi, 2009; Moustakas, 
1994). This process required a shift in attitude so that I could become fully and attentively present to and aware of the phenomenon without allowing preconceived understandings of the phenomenon to get in the way of data analysis. During this process, I made note of instances when a personal bias interfered with the analysis so that I could reflect more deeply upon the data in an effort to determine what was stated that brought the personal bias to mind (Giorgi, 2009). Therefore, the process of the epoche along with memoing (Maxwell, 2005) and the audit trail were employed throughout this phase to make certain that it was not personal presuppositions or biases that led this process, but rather, a professional, disciplinary perspective that thoughtfully guided this process. Subjecting the data to a "cognitive a priori specification of what one is to look for would not satisfy intuitively based phenomenological criteria" (Giorgi, 1997, Steps of the Human Scientific Phenomenological Method, para. 4).

Next, the meaning units that were identified and recorded in the codebook were clustered into common themes or categories. This phenomenological reduction process involved reducing, or clarifying, the data further in an effort to determine what was texturally meaningful and essential for achieving a coherent and feasible description of the phenomenon under investigation (Giorgi, 2009; Moustakas, 1994). During this phase of data analysis I returned to the beginning of the descriptions, which had been broken down into meaning units, and proceed to interrogate each meaning unit in an effort to discover how to express each unit of meaning in a manner that adequately reflected the phenomenon under investigation. It was during this process that I had to apply the use of imaginative variation. This task required me to view the data as it had been presented from different angles or points of view in an effort to express the meaning more clearly, while also retaining the same original meaning as conveyed by the participants. I sought these possible meanings through the utilization of imaginative variation, considering 
divergent perspectives, different positions, and varying frames of reference (Moustakas, 1994). This required another shift in attitude that allowed me to spend time considering the data, changing it and varying it imaginatively until a final expression could be identified that was appropriate for the investigation (Giorgi, 1997; Giorgi, 2009). The goal of this step was to express each meaning unit in a way that aligned more precisely with the disciplinary perspective of the investigation. During this process, repetitive, overlapping, and irrelevant statements were eventually identified and noted, leaving behind the textural meanings and invariant constituents of the phenomenon that were directly relevant to the phenomenon under investigation (Giorgi, 2009; Spiegelberg, 1995).

It is important to note that while engaged in the concurrent processes involved in the phenomenological reduction phase of data analysis, I searched for the invariant meaning or essences of the phenomenon that appeared across the data that was collected. These units of meaning did not necessarily exist explicitly in the descriptions provided by the participants. Instead, I engaged in the thoughtful and intuitive process of imaginative variation in an effort to derive these meanings from the data. Because the phenomenological approach is discoveryoriented, an unbiased stance was employed in order to reveal the units of meanings from within the data. Once the units of meaning were established, they had to be re-examined, scrutinized, and re-described so that the value of each meaning unit could be made distinctly clear and directly associated with the description of the phenomenon under investigation. These invariant meanings became the structures of the experience, which were simply clarifications of the particular meanings that present themselves in the descriptions provided by the participants. These structures contributed to a deeper understanding of the everyday experiences of the phenomenon, literacy, as encountered by the participants. 
Throughout this process, if an ambiguity arose, these statements were not clarified unless there was direct evidence in the description provided by the participant to shed light on the ambiguity. Instead, the ambiguities were simply described exactly as they were presented in the data; no speculation was made, and I did not bring non-given or speculative factors to bear upon the data (Englander, 2012; Giorgi, 2009). The data analysis process did not attempt to go beyond precisely what was presented by the participant. No a priori framework or past knowledge about the phenomenon was applied during the data analysis process. I had to set aside (or bracket) all preconceived notions about the phenomenon so that unprejudiced attention could be directed specifically to what was present in the descriptions provided by the participants. During the data analysis phase, using an a priori framework does not serve as a valid basis for phenomenological investigations (Englander, 2012; Giorgi, 2009; Moustakas, 1994). If such ambiguities appeared during the data analysis phase of this investigation, these ambiguities were later addressed in the discussion of findings and/or implications, drawing upon research from the field of literacy to bring clarity to these ambiguities.

The essential meanings and invariant constituents of the phenomenon that were discovered through the search for essences portion of the data analysis process were then used to develop individual textural and structural descriptions of the phenomenon for each participant (Moustakas, 1994). The construction of the individual textural descriptions of the experience for each participant involved organizing the essential meanings and invariant constituents into a coherent textural description of the phenomenon. Next, the individual structural description for each participant was developed, which included a description of the underlying and precipitating factors that accounted for what was experienced by the participants. This involved deriving 
structural themes from the textural descriptions that illustrated the underlying themes or contexts that accounted for the emergence of the phenomenon.

Once each individual textural and structural description was developed, an overall textural-structural description of the meanings of the experience for each participant was developed. This involved the integration of the fundamental textural and structural descriptions into a unified statement of the essences of the experience of the phenomenon as a whole. The overall goal of this phase of data analysis was to arrive at a complete textural-structural description of the experience for each participant. The outcome of this process was a written description of each participant's experiences in relation to the phenomenon under investigation (Cresswell, 2007). This process led to the eventual unveiling of the overall understanding of this phenomenon for each participant (Moustakas, 1994, p. 96).

Lastly, a composite description of the meanings of the experience for the entire group was constructed. This step was not intended to draw generalizable conclusions, but rather to portray the commonalities and/or disparities that existed between the two individuals involved in similar roles within the same context. The goal was to attend to, recognize, and describe with clarity the overall phenomenon (Moustakas, 1994). The end result of the complete data analysis process was a thick, rich description of the participants' beliefs rather than a discussion of emergent theories or hypotheses (Giorgi, 2009; Moustakas, 1994).

Throughout the data analysis process, factors designed to assure trustworthiness, rigor, and ethical practices were employed. Padgett (1998) suggested several factors that can be utilized to maintain the trustworthiness and rigor of the data analysis process. Some of the factors that were considered in this particular study include: triangulation of data sources, peer 
debriefing and support, member checking, and auditing. Following a discussion of these issues, an important limitation of this study was acknowledged.

\section{Reliability and Validity - Issues of Trustworthiness}

Because qualitative research is interpretive in nature, issues of trustworthiness were considered rather than issues of internal and external validity, reliability, and objectivity (as recommended by Denzin \& Lincoln, 1994; Lincoln \& Guba, 1985; Padgett, 1998). Lincoln and Guba (1985) suggest examining four factors associated with trustworthiness: credibility, dependability, confirmability, and transferability (see also Flick, 2009; Merriam, 2009; Padgett, 1998).

Issues of credibility are associated with determining if the findings and conclusions drawn from the data are credible given the data that has been presented (Lincoln \& Guba, 1985; Merriam, 2009). Credibility was determined through multiple approaches including: triangulation, member checking, reflexivity, and peer debriefing or review.

Triangulation of data sources occurred in a variety of ways. Multiple data sources were used (interviews and observations). Classroom observations were used to corroborate what was stated during interviews and follow-up interviews were conducted when there was a need to further clarify information acquired through classroom observations. Additionally, for purposes of triangulation, interviews involved different people with different perspectives. Furthermore, data collected through observations were collected over multiple sessions, occurring at different times and in different locations. Lastly, investigator triangulation was used in an effort to make certain that the process of data analysis was credible (Merriam, 2009). Investigator triangulation involved having two uninvolved individuals analyze segments of data, with comparisons of the findings taking place following this independent analysis. Two individuals were chosen to 
provide this secondary analysis. One of these individuals is a literacy coach who teaches at a school located in the same school system, who is not associated in any way with the teachers or school community involved in this investigation. This individual holds a Masters of Education in reading, has served as an elementary classroom teacher, has worked as a reading specialist in multiple school systems, and has been employed as a literacy coach at an elementary school for the past five years. This individual was also a previous recipient of the Agnes Meyer Outstanding Teacher Award, which recognizes teachers who exemplify excellence in their profession. The second individual chosen for investigator triangulation is a high school English teacher with 20 years of experience. This individual holds a Bachelor's degree in secondary English and a Master of Arts Teaching degree; serves as her school's forensics coach; directs the school's yearly children's musical; and teaches general high school English, AP English classes, and remedial classes for students who have not passed the state-mandated high-stakes English assessments.

Credibility was also ensured through the process of member checking or respondent validation (Merriam, 2009). In order to make certain that misrepresentation did not occur during this investigation, each of the study's participants were asked to review the interview transcripts and field notes taken during observations. In addition, as Moustakas (1994) recommended, each participant was asked to examine the preliminary data analysis to make certain that it was her perspectives that were revealed through the analysis of data (Merriam, 2009). This process was conducted throughout the course of the study in an effort to provide credibility to the process of data analysis because as Moustakas suggested, researchers have the potential for misperceiving an experience, which may lead to unintentional misrepresentation. Integrating member checking during the initial phase of data analysis minimized the potential for misrepresentation. 
Another strategy associated with credibility which was employed throughout this investigation was that of researcher reflexivity, whereby the researcher reflects critically upon the role as the primary research instrument (Lincoln \& Guba, 2000; Merriam, 2009). This included utilization of the process of the epoche in which the exploration of biases, previous assumptions, and personal perspectives were continually reflected upon and unveiled. This process assisted in making clear how these personal values and expectations influenced the collection and analysis of data throughout this study (Maxwell, 2005; Merriam, 2009).

Lastly, credibility was ensured through the process of peer review. This process involved the examination of the raw data as well as examination of the data analysis to make certain that the findings were plausible based upon the data that was collected (Merriam, 2009). This process was conducted by the same two individuals who were recruited for conducting investigator triangulation. Peer review or debriefing occurred during preliminary data analysis multiple times over the course of this investigation. Data were peer reviewed during the phenomenological reduction phase, following the development of textural descriptions for each participant, and then occurred prior to the final synthesis of findings.

Issues of dependability were considered in order to ensure stability of findings across time and to ensure internal coherence (Denzin \& Lincoln, 1994). Strategies employed for the purposes of dependability aided in making certain that the findings of the study were consistent with the data collected (Merriam, 2009). These strategies assures that there was consistency and reliability to the study and were achieved through methods of triangulation, peer review, researcher reflexivity, and through an audit trail.

According to Lincoln and Guba (1985) and Padgett (1998) incorporating the method of an audit trail aids in accomplishing both dependability and confirmability. The audit trail 
incorporated both the process of the epoche and memoing. The audit trail was designed to provide transparency in the study by including a description of the steps taken as well as a description of the various processes used throughout the research study (Flick, 2009; Lincoln \& Guba, 1985; Merriam, 2009). An ongoing effort was made to identify potential biases that may have emerged as a result of the researcher's role and previous position as a teacher-researcher in this school setting because as Bogdan and Biklen (1998) suggest, "The data must bear the weight of any interpretation, so the researcher must constantly confront his or her own opinions and prejudices with the data" (p. 34).

The potential effect of bias on this research study was minimized by continually maintaining an awareness of personal opinions, prejudices, and biases associated with the issues under investigation (Bogdan \& Biklen, 1998; Merriam, 1998). Personal biases were explored throughout the data collection and analysis phases of this study using the process of the epoche (as described previously in the role of the researcher section). The process of the epoche occurred before and during data collection so that I was able to enter the research field with an openness that allowed the events and experiences to be perceived with an open mind (Moustakas, 1994). Throughout this investigation the reflective, self-dialogic process of the epoche was also used in an effort to reduce preconceived thoughts, judgments, and biases associated with literacy and literacy instruction at the middle school level (Crotty, 1998; Heron, 1992; Husserl, 1931; Merleau-Ponty, 1962; Merleau-Ponty, 1964; Moustakas, 1994). Moustakas (1994) proposed that the "value of the epoche principal is that it inspires one to examine biases and enhances one's openness even if a pure and perfect state is not achieved" (p. 61). While employing the epoche process, preconceptions and prejudgments were identified, labeled, and written out, providing an opportunity to become more receptive to and attuned to whatever was 
presented in the data without the influence of personal habits of mind, allowing the phenomenon under investigation to be perceived solely from its unique appearance and presence (Moustakas, 1994). Conducting the process of the epoche throughout this study assisted in achieving the overall goal of phenomenological research in which the aim was determining what the experience under investigation means for the individuals who have had the experience (Moustakas, 1994).

In addition to the epoche process, Flick (2009) suggested that the use of memoing has the potential to make the analysis of data explicit and transparent because in addition to recording the steps taken throughout data analysis, additional impressions, associations, questions, ideas, and so on are recorded as memos to complement and further explain the codes and themes that emerge from the process of data analysis. Each of these self-reflective tasks (epoche and memoing) were recorded in a field journal. The combination of these two processes provided an audit trail which was designed to record "in detail how data were collected, how categories were derived, and how decisions were made" throughout the investigation as a means to "authenticate the findings of the study" (Merriam, 2009, pp. 222-223). This audit trail was maintained in a researcher field journal where an ongoing record of the interactions with the data, the process of analysis, and the interpretation process were recorded (Merriam, 2009). As Merriam (2009) recommended, personal reflections, questions, and decisions associated with issues, problems, and/or ideas that arose from the collection and analysis of data were recorded in an effort to explicitly detail the process of data analysis.

Lastly, in order to ensure transferability, whereby the potential for transferring the findings of this study to another setting is enhanced (Merriam, 2009), rich, thick descriptions (Geertz, 1973) of the phenomena under investigation were employed. These rich, thick 
descriptions included a "description of the setting and participants of the study, as well as a detailed description of the findings with adequate evidence presented in the form of quotes from participant interviews [and] field notes" (Merriam, 2009, p. 227). Because this study was situated in one school setting, it should be noted that maximum variation in the sample was not achieved in an effort to ensure transferability.

\section{Ethical Considerations}

Gaining entrée into this research field was hastened by my participation as a reading specialist in this school setting at the commencement of this study. As a teacher-researcher employed in this setting, negotiating consent and building trust with the participants prior to the pilot study was a natural part of my daily interactions in this setting. The school's principal was eager for a research study to be conducted within this setting in hopes of positively influencing the literacy development of the young adolescents in this school community. In addition, being a member of the school's English department, as well as a member of the district-wide Secondary English Council, provided an opportunity to gain the trust of the school's English teachers. Before engaging in the pilot study phase of this investigation, I did not have the opportunity to spend time in any of the teachers' classrooms. Once consent was acquired and I first entered the chosen teachers' classrooms during the pilot study, it appeared that the teachers were open, willing, and perhaps even eager to talk about literacy since little time is given for educators to share their interests in the subjects with which they teach.

Ethical issues were dealt with throughout this investigation. Informed consent was acquired from the superintendent for instruction as well as the school's principal before recruiting teachers for the pilot study phase of this investigation. Consent was also acquired from each teacher participating in the pilot study. For the second phase of this investigation, 
informed consent was acquired once again from the associate superintendent for instruction as well as the school's principal. In addition to acquiring permission to conduct the pilot study through the university's Institutional Review Board, permission to study was once again obtained through the university's Institutional Review Board before proceeding with the final phase of this investigation.

This study was constrained by the willingness and openness of the individuals involved in this investigation. As a teacher-researcher who previously worked in this school setting, every effort was made to maintain an open stance on all topics so that undue influence was not placed on the individuals participating in the interviews and observations. Efforts were made to avoid implying that any one approach to literacy instruction is more effective than any other. The goal was simply to explore the ways in which the teachers in this school environment perceive literacy and implement literacy instruction for the young adolescents in this particular school setting. 


\section{Chapter Four}

\section{Findings}

The purpose of this study was to explore two middle-level English teachers' unique beliefs about literacy and to determine how these beliefs manifest themselves in the teachers' instructional practices. This investigation integrated the phenomenological method with a case study approach. A goal of this investigation was to describe in as comprehensive a manner as possible, each participant's distinctive beliefs about literacy. Through the phenomenological approach, each participant will essentially speak for herself as direct quotes from the interviews and observations are used to illustrate the participant's beliefs about literacy. The findings are drawn from two guiding research questions: 1) how do middle level English language arts teachers perceive and describe literacy; what are their beliefs about literacy; and 2) how are these literacy beliefs manifested in the instructional practices of the middle level English language arts teachers? Data collected from a pilot study conducted during the fall 2012 semester and data collected from the final phase of this investigation during the fall 2014 semester provide multiple descriptions of each teacher's beliefs about literacy and evidence of instructional practices associated with literacy. Data collected from interviews, classroom observations, and field notes were analyzed in an effort to identify themes that reveal each teacher's unique beliefs about literacy.

The findings for each participant are presented through a brief introduction to the participant; a description of the participant's classroom, including a visual image of the classroom layout; the participant's definition of literacy derived from the interview process, which includes a visual model depicting the participant's definition of literacy; and a description of the manifestations of the participant's literacy beliefs identified through classroom 
observations of the participant's instructional practices. Each description of the participant's manifestations of literacy beliefs includes a table that portrays the facet of literacy identified by the participant in her definition of literacy. In addition to each component of literacy, the table includes direct quotes taken from the interviews (to address research question one) and direct quotes taken from classroom observations (to address research question two). Lastly, the table

includes a column that designates whether alignment between the teacher's beliefs and instructional practices was revealed.

\section{Introduction of Participant One}

Mrs. White is a sixth grade English teacher. She holds a Master's degree in Curriculum and Instruction and a Bachelor of Arts in secondary education (grades 7-12) with a concentration in literature. Mrs. White has 26 years of experience. She spent her first ten years teaching English at the eighth grade level and the reminder of those years teaching sixth grade English. Mrs. White is the English Department Chair for her middle school and as such, she serves on the school system's Secondary English Council. Mrs. White has spent her entire career teaching in the same building. She noted that she attended school in the building in which she teachers, stating that this school is "part of my community" and that as an undergraduate student she had hoped to teach in this building although she had no particular interest in teaching at a specific grade level.

\section{Description of Mrs. White's Classroom}

Mrs. White's sixth grade English classroom is a bright classroom lined along the majority of the far left-hand wall with windows letting in an abundance of natural light. Due to the brightness of the natural lighting, Mrs. White does not use the fluorescent overhead lights and relies instead on the light from the oversized windows. On the classroom walls were a few 
purchased posters. Located above the SMARTBoard on the wall directly across from the doorway, was an assortment of pre-cut punctuation marks spread across the narrow space of wall. This bulletin board display included a seven piece bulletin board set with one header, "Punctuation Paradise" and six supporting pieces, which included the question mark (stating "ends a question"), exclamation mark (stating "shows emotion or strong feeling"), parentheses (stating "separate words that could be left out"), comma (stating "separates words and used in dates or addresses"), quotation marks (stating "separate spoken words"), and period (stating "ends a sentence or abbreviation"). The other poster on the classroom wall was a poster of baseball player, Mike Mussina, which stated, "Read." This poster was located directly inside the classroom door to the immediate right above a short bookcase holding a yellow bound Literature anthology set and green hard-bound dictionaries (see Figure 4 for an image of the layout of Mrs. White's classroom). Located on the two doors of the rolling cabinet at the far end of the classroom to the left of the SMARTBoard was a poster set titled, "How to Flunk" and "How to Pass" with one poster on each door. The "How to Flunk" poster on the left-hand door held a list of 25 statements too difficult to read from afar. The "How to Pass" poster on the right-hand door stated, "Show up. Pay attention. Do your work. Behave." On the wall to the immediate left of the classroom door was one small bulletin board with the title, "Grab a Good Book" that was covered with what appeared to be over 50 multi-colored cut-out handprints with a person's name written on each handprint.

The classroom included a total of five bookcases, but did not include a classroom library designed for student access. As mentioned previously, one very short bookcase immediately inside the classroom door held a Prentice Hall Literature anthology and hard-bound Merriam- 
Webster's Intermediate Dictionaries. Two book cases located directly behind the teacher's desk to the left of the classroom held an assortment of teaching books and manuals, one full row of Figure 4. Layout of Mrs. White's sixth grade English classroom - fall 2014.
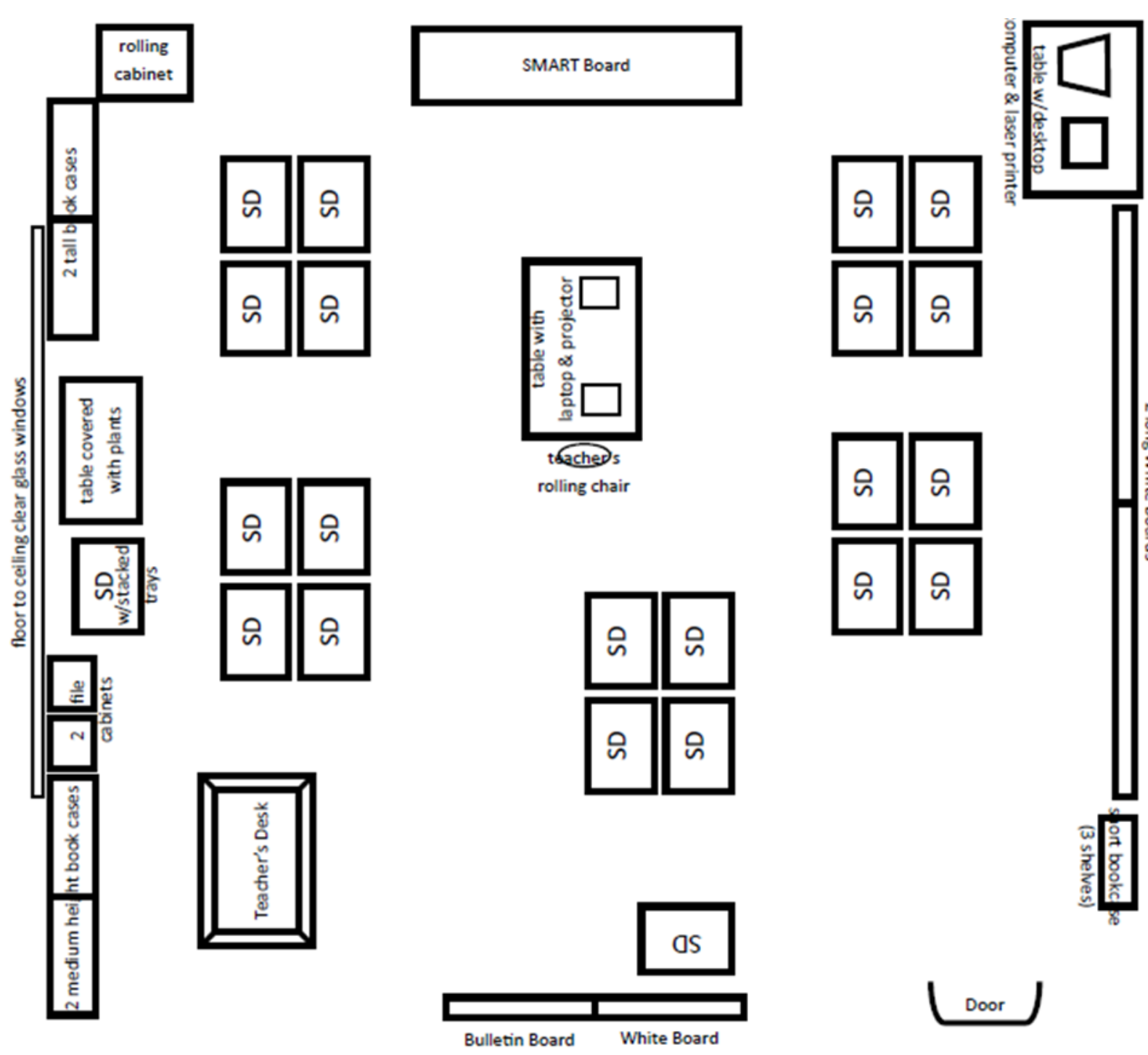

student editions of a Write Source text, and other teaching resources such as, Reading Reasons:

Motivational Mini-Lessons for Middle and High School, by Kelly Gallagher and Student

Achievement Goal Setting: Using Data to Improve Teaching and Learning, by Stronge and

Grant. On top of these bookcases were Mrs. White's framed teaching license, her Bachelor's degree diploma, and her Master's degree diploma, along with a few pictures of Mrs. White and 
her family. The two bookcases located on the far-left corner of the classroom next to the rolling cabinet included multiple titles of classroom sets of novels, including titles such as, No Promises in the Wind, by Irene Hunt; Bud, Not Buddy, by Christopher Paul Curtis; Out of the Dust, by Karen Hesse; To Kill A Mockingbird, by Harper Lee; A Day No Pigs Would Die, by Robert Newton Peck; and Roll of Thunder, Hear My Cry, by Mildred Taylor.

In front of the windows on the far left-hand side of the classroom was one long table covered with a variety of green plants, with more plants sitting on the floor just below the table. To the left of this long table was a student desk with stacking trays on top, each of which had an assortment of what appeared to be copies of student work. To the left of this desk, beside the bookcases located behind the teacher's desk were two file cabinets. There was a table sitting in the center of the classroom near the SMARTBoard holding a laptop and projector, which were used by the teacher to project onto the SMARTBoard. The teacher's padded, rolling chair was placed at the head of this table. In the far right corner of the classroom directly across the room from the classroom door was another long table that held one desktop computer and a laser printer. The only other table in the classroom was a student desk just to the left of the classroom door that held various stacks of papers and a box of tissues. The teacher's desk was located directly to the left of the classroom door backed into the corner in front of the two bookcases described previously. The desk held a variety of papers that appeared to include student work (random piles of papers with student handwriting), stacks of photocopied pages, a binder opened to "English Pacing Guide 2010 - 2011," and buried under many papers, a lesson plan book that contained a grid of five rows with six columns. Although this lesson plan book was not in plain sight, it was apparent that there were a few notes written across these boxes, such as "Project due 
Tuesday, November 25." Very minimal writing appeared in the plan book and did not include objectives or specific steps for lessons.

The class used for observation purposes during the fall 2014 school year was a sixth grade general education English class. This class was designated as the fourth period English class. There was a total of 18 students in this class with 10 girls and 8 boys. The student desks were arranged in clusters of four, with two table groups having girls seated at each desk and one table group having boys seated at each desk. The remaining two table groups had mixed boys and girls seated at the desks, with only two empty desks in the classroom.

On the long white board on the right-hand wall of the classroom, Mrs. White had several notes that appeared to be of importance to the students (as students were observed looking at the board and writing notes in what appeared to be a school agenda). On the far right side of the board near the top were the day's date and an objective. On the day of observation one, November 14,2014 , the objective was written in this manner:

Date: Monday, November14

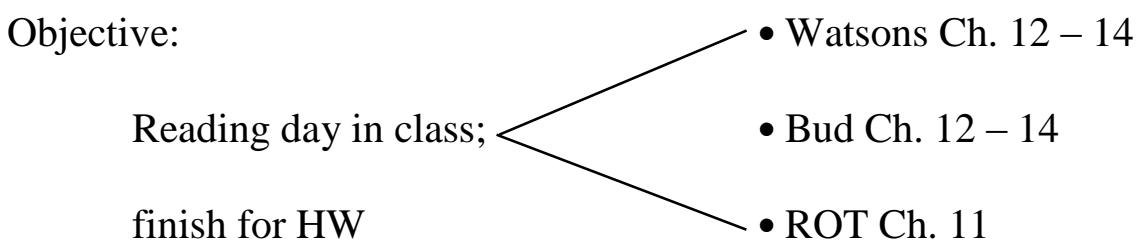

To the left of this information was a note written near the top which stated, "AR points due 12/17." Toward the center of the two boards was a class schedule with a note above it stating: "class schedule for today" (the students were having shortened class periods in order to attend a chorus concert near the end of the school day). Lastly, on the left-hand side of the white board the following notes were written:

1. Quiz total of 4 questions Ch. 11 
2. comic strip beginning middle end

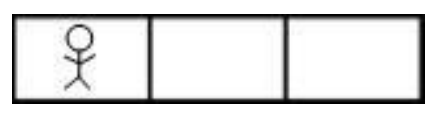

3. 6 word memoir sentence; summarize

During the pilot study, which took place in the fall 2012 school year, the fourth period, sixth grade general education English class was also used for observation purposes. That particular class had a total of 19 students. During the pilot study, precise detail about the makeup of the student population was not noted. Additionally, it is to be noted that the student desks during the pilot study were arranged in rectangular rows around the periphery of the classroom, with three additional desks projecting inward from one of the rows. The majority of the desks were facing the wall containing the long white boards. During subsequent visitations in this classroom, though, the desks had been rearranged, so it appears that the teacher uses a variety of desk arrangements throughout the school year. All other tables, room arrangements, and posters remained the same across the two-year time span in which classroom observations occurred.

\section{Mrs. White's Definition of Literacy}

Mrs. White's overall perception of literacy integrates an array of components (see Figure 5 for a visual representation depicting Mrs. White's definition of literacy). Mrs. White described literacy in terms of skills. She explained, "literacy is ... being proficient at whatever classroom skills are required at that grade level." As indicated in the graphic representation of Mrs. White's literacy beliefs (see Figure 5), "skills" appear to be viewed as an overarching element of literacy with the components reading, writing, and oral communication being subordinate to skills. Mrs. White explicitly identified these three ancillary elements as she described her beliefs about literacy. These elements are explained in greater detail in the forthcoming section. In addition, two peripheral elements that appear to be associated with Mrs. White's beliefs about 
literacy emerged from the data that were collected: vocabulary and literature. These elements are also described in greater detail below.

Figure 5. Visual model depicting Mrs. White's definition of literacy.

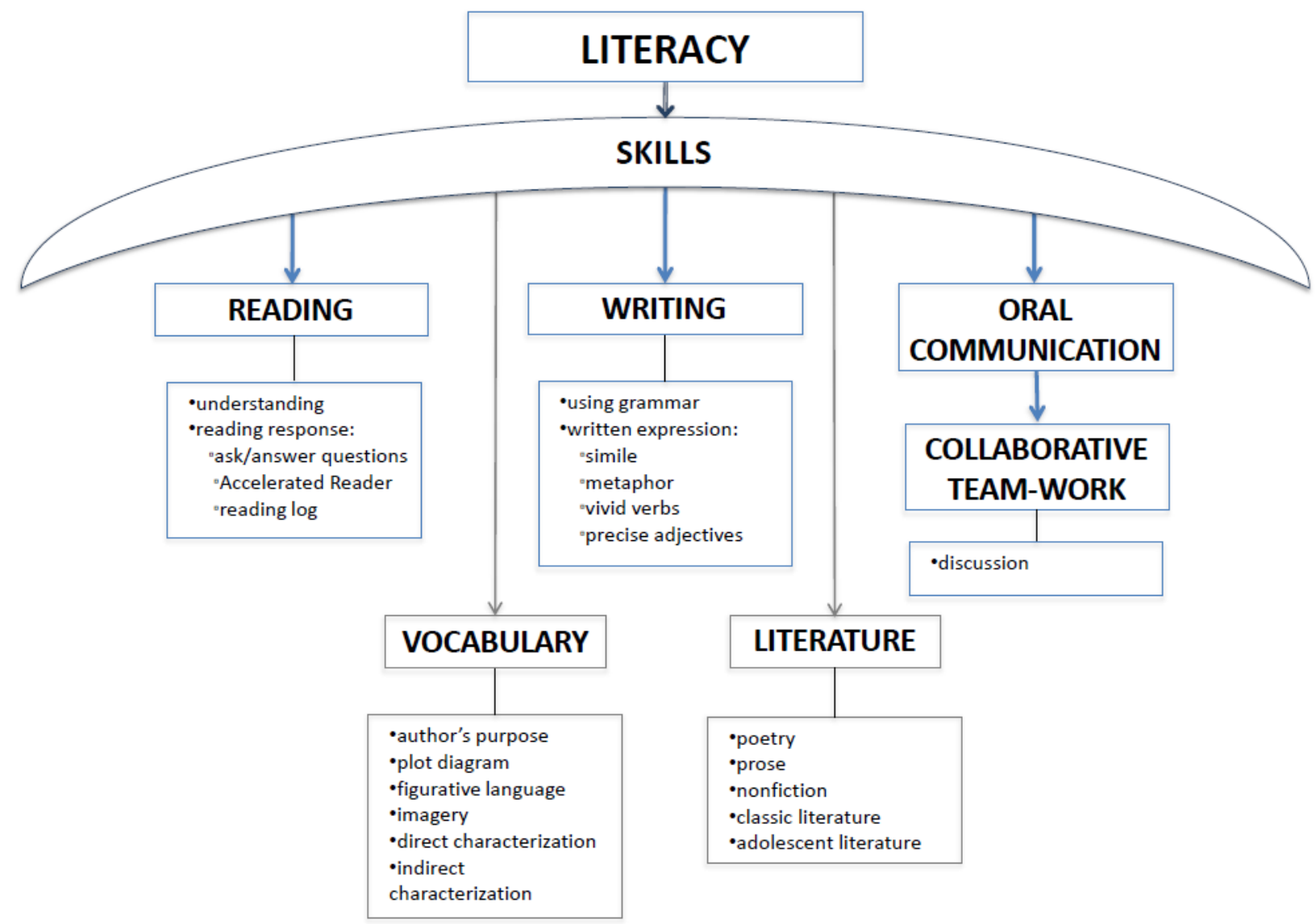

Throughout the interview process, Mrs. White described "skills" as including reading skills, writing skills, communication skills, and other basic skills. Mrs. White explicitly stated, "literacy is not just reading and writing," but it also includes a level of proficiency in "classroom skills" associated with a particular "grade level." She attempted to clarify this notion by explaining that this literacy skill set must include "skill that's going to transfer to real life," noting that students must become "more worldly in their skills." In an effort to elucidate the importance of developing literacy skills, Mrs. White drew an analogy between running and the development of literacy skills associated with reading and writing. She explained, "It's no 
different than running. If you $[s i c]$ want to get better, you've got to run more. You [sic] can work on the skill and improve your technique all along the way, but if you're not running, it's not mattering." As she described the importance of these skills, she commented that it is the "daily application of those skills" in the classroom setting that are most indicative of students' literacy achievement.

As she described her beliefs about literacy, Mrs. White emphasized the view that literacy is not just reading, but it also incorporates writing. This integration of writing, from Mrs. White's perspective, is more important now in the twenty-first century because of the increased emphasis on technology and web-based interactions. In conjunction with this increase in technology, Mrs. White asserted that literacy must also incorporate oral communication, especially as society shifts to a more collaborative, teamwork oriented culture. Mrs. White unequivocally expressed the belief that students "have to be able to write to communicate; they have to be able to discuss" in order to become literate for the twenty-fist century. Mrs. White underscored the importance of literacy as "a building block" that will "have a profound impact on how well [students] perform everywhere else in school and in [future] life." Furthermore, Mrs. White contended, "a literate person expresses himself or herself equally well in reading or writing." As Mrs. White reflected on her view of herself as a teacher of English, she asserted that she has come to see herself as an English teacher who believes that "we have to read, we have to write, we have to talk, we have to know vocabulary." She explained that this view of herself is "a more inclusive description probably of what I do now, than when I was younger."

As she described her beliefs about literacy, vocabulary emerged as a term Mrs. White associated with literacy. Although Mrs. White did not directly mention vocabulary as she initially described her beliefs about literacy, she explained that "knowing the right vocabulary" 
such as "knowing to use author's purpose or a plot diagram" is important. In addition to these specific vocabulary terms, Mrs. White also emphasized terms such as figurative language, imagery, direct characterization, and indirect characterization as being germane to literacy.

Finally, Mrs. White associated literature with her beliefs about literacy. Mrs. White explained, it is "important for [students] to read some classic literature sometimes," noting "it doesn't all need to be adolescent literature." Mrs. White explained that by reading classic literature at times rather than simply relying on adolescent literature, she is able to encourage students to "step out of their comfort level sometimes because I think that's important." As she described the benefits of classic literature, she pointed out that classic literature "shows the kids differences in historical background, historical time periods. The dialect changes, sentence structure changes, and ... that there's more than one way to speak, than the way we speak now." Further, she explained "it's important for them to realize that there's many ways that they can communicate, each appropriate to a certain situation." Mrs. White associated reading classic literature with becoming a "literate person," suggesting that students

need to see the differences in [dialect changes, sentence structure changes, etc.] and I think only in asking them to read classic literature at school are they going to see it; they are not going to do it on their own. It's not on television, it's not in the movies, and if we don't provide them with the opportunity, I think they'll miss it.

Through this description of her beliefs associated with classic and adolescent literature, Mrs. White linked literature with her overall beliefs about literacy.

\section{Manifestations of Literacy in Mrs. White's Instructional Practices}

As described previously (and portrayed in Figure 5), several distinct characteristics can be associated with Mrs. White's beliefs about literacy. In the following section, each of the 
components associated with Mrs. White's beliefs about literacy are described in greater detail with examples taken directly from classroom observations to demonstrate how these literacy beliefs are manifested in Mrs. White's instructional practices. The following facets of literacy (taken from Mrs. White's definition of literacy above) are detailed: skills, reading, writing, and oral communication. Additional peripheral elements that surfaced implicitly across the interviews and classroom observations that appear to be associated with Mrs. White's beliefs about literacy are also described. These elements include vocabulary and literature.

Skills. The construct "skills" is one that is fundamental to Mrs. White's beliefs about literacy. This element of literacy appeared essential to Mrs. White's descriptions of literacy (see Table 1). The manner in which Mrs. White described skills created an image in which the conception skills became more pronounced than other facets of literacy. As such, "skills" is elevated to a position in which all other elements associated with literacy appear subordinate to skills.

During our first interview together as she described the notion of literacy, Mrs. White came to the conclusion that "literacy is like, it's not just reading and writing, it is being proficient at whatever classroom skills are required at that grade level." This belief about skills emerged during the pilot interview process as Mrs. White made reference to "skills" such as reading skills, writing skills, communication skills, grammar skills, classroom skills, and skills that transfer to "real life." Additionally, during the interview associated with the final phase of this investigation, Mrs. White made reference to basic skills, noting that if students "don't get some basic skills down, the struggle is going to get harder."

As Mrs. White attempted to reveal her beliefs associated with literacy, the term skills surfaced as she described various facets of literacy. For instance, Mrs. White stated, "my 
definition of [literacy] ... is becoming more inclusive ... of reading and writing skills;" she continued, students "need to learn more communication skills than just reading." As she described her expectation of students' abilities associated with literacy, she stated, "I think maybe I expected their literacy skills to be a little bit higher." She remarked that students "have to be more ... worldly in their skills. You [sic] know, it just has to be more, it has to be skill that's going to transfer to real life."

Even as she considered the tasks that her grade level colleagues teach in other content areas, Mrs. White noted, "I do understand that history and science teachers don't feel like they have time to teach writing skills. And I don't know that they need to teach the skill that I do." She explained that as she works collaboratively with the "history teacher on my team and the other team," and they work together on "document-based question types of lessons," she is given the opportunity to "increase reading for me but content skills for them" (referring to the subject matter that her colleagues teach). Mrs. White noted the importance of the "idea of transferring skill," noting that students must learn to "take that skill set with [them] to history and to science."

Despite these repeated references to the construct "skills," this concept remains unclear, as Mrs. White used the term "skills" with her students only once during the classroom observations. This occurred during the second observation of the pilot study as Mrs. White was introducing the literature circle roles. Mrs. White explained that as students write discussion questions, they need to be of an open-ended nature, suggesting, "That would be one of those, higher-order thinking skills."

This notion of skills remains an ambiguous term that cannot be directly described in the context of this investigation because although Mrs. White used the term, "skills" on a recurrent 
basis, she never articulated precisely what this construct means to her. Although Mrs. White insisted that students must become "more worldly in their skills" and must "practice" and "generalize skills across content areas," this element of literacy remains obscure and cannot be clarified further based upon the data collected during the interviews and observations.

Table 1

Comparison of Mrs. White's Stated Beliefs about Skills and Instructional Practices Observed

\begin{tabular}{|c|c|c|c|}
\hline $\begin{array}{c}\text { Component of } \\
\text { literacy }\end{array}$ & Statements from interviews & $\begin{array}{c}\text { Statements from } \\
\text { observations }\end{array}$ & $\begin{array}{l}\text { Alignment between } \\
\text { beliefs and practices }\end{array}$ \\
\hline \multirow[b]{2}{*}{ Skills } & $\begin{array}{l}\text { "literacy is like, it's not just } \\
\text { reading and writing, it is being } \\
\text { proficient at whatever classroom } \\
\text { skills are required at that grade } \\
\text { level." }\end{array}$ & $\begin{array}{l}\text { ambiguous and nondescript - } \\
\text { not clearly defined }\end{array}$ & unidentifiable \\
\hline & $\begin{array}{l}\text { "literacy skills; ... reading and } \\
\text { writing skills; } \ldots \text { communication } \\
\text { skills; ... basic skills" }\end{array}$ & $\begin{array}{l}\text { "when you can ask somebody } \\
\text { a question about what you } \\
\text { read with, "why do you } \\
\text { think; what is your opinion" } \\
\text { you're doing higher-level } \\
\text { thinking skills." }\end{array}$ & $\begin{array}{l}\text { Mrs. White's } \\
\text { conception of "skills" } \\
\text { remains ambiguous } \\
\text { and was not } \\
\text { identifiable }\end{array}$ \\
\hline
\end{tabular}

Reading. As Mrs. White described her views about literacy during the interview process, she made reference to reading with statements such as "I think it's [literacy] not just reading.... I think a literate person expresses himself or herself equally well in reading or writing" (see Tables 2 -4). She further explained, "Being able to read at a level when [sic] I can at least understand a newspaper or most magazine print, is important to be a literate person." Mrs. White made it clear that she believes her understanding of literacy has changed somewhat as she explained, "I think my definition of [literacy] has changed so that it is becoming more inclusive, I think, of reading and writing skills, not just reading." As illustrated in Tables 2, 3, and 4, Mrs. White described her beliefs about reading making note of factors such as understanding of reading and questioning techniques, various types of reading response activities, and time and opportunity to practice reading, each of which is described below. 
Understanding and questioning. Mrs. White associated the notion of "understanding" with reading. Mrs. White expressed value in using various questioning processes followed by textual support in an effort to make certain that students develop understanding of the material being read. As portrayed in Table 2, although Mrs. White stated that she strives to "make them [students] give me reasons for their answers," and encourages students to "look for support for the reason they think something and be able to back it up. [by] Show[ing] me the spot in the book that makes you [sic] think that," this practice was not observed during classroom observations. Instead, Mrs. White engaged in a question-answer session with the whole class with students calling out answers with no support for their responses (see Table 2 for examples of classroom discussions that took place).

During the pilot study as Mrs. White experimented with the literature circle approach for her annual novel unit, she explained during her interviews the importance of using a variety of questions to probe the students' understanding of the text. For instance, as she discussed her overall comfort level with the literature circle approach once she had experienced a couple of the literature discussions, Mrs. White shared that she was feeling more comfortable with this approach, but that in order to "reinforce for myself, are they really reading those books," she "did ask them some specific questions that I wanted to be sure we didn't miss a point of." She further explained that she had to develop these assessment-based questions

Because, you know, you don't know really [if they have read the book], but even though I allowed them to use the books to answer the questions because I wanted support, I wanted specifics, they can't look them up; they're not the kinds of questions where there is the answer on a page, so if they didn't read it, they can't find an answer. 
Mrs. White revealed that she was "pleasantly surprised that [the students] have risen to the challenge, most of them; some haven't, but that's typical middle school kids" and that "most of them have and you [sic] can see that in, when I direct a question, they know the answer; so they have to have read the book."

For the literature circle approach that Mrs. White was experimenting with during the pilot investigation, she had developed six literature circle roles based upon information she researched on the Internet. Of these six roles, five involved some form of comprehension and/or understating of the text in order to effectively complete the role. These roles included the summarizer, connector, discussion director, literary luminary, and travel tracer. The sixth role, the vocabulary police, did not necessarily require comprehension because this role involved identifying vocabulary words from within the text and developing a definition with the assistance of a dictionary.

As Mrs. White described each of these roles to her students, she explained the importance of having read and understood the text. She described each of the roles that involved some form of understanding to the class, as follows. For the summarizer role, Mrs. White explained, "your job is to prepare a summary of the reading.... The summarizer will begin the discussion in your group." For the connector role, Mrs. White stated, the connector is "supposed to find a connection between pretty much anything [and the book]. Your job is to be able to explain that connection to the other people in your group." As she described the discussion director role, Mrs. White remarked, "If you're the bossy type, who likes to be in charge, like me, then this is the job for you." She explained this role as, "you get to decide what everybody's going to talk about. You get to decide discussion questions for your group. You have to choose them; you have to write them down; you have to give your answer to them." As she described these 
questions, Mrs. White emphasized, "Think of discussion questions,... as open-ended.... not talking about comprehension questions like you get on AR tests. We're talking about why do you think the author said this? That would be one of those higher-order thinking skills." Mrs. White described the literary luminary role as requiring the student "to find five different things in the reading ... you really found interesting or funny, or creepy, or scary, or for some reason it stood out to you. All you have to do is say, this is what it is and here's why." And lastly, Mrs. White described the travel tracer role by telling the students, "If you are the person who enjoys setting... If you're really good at that or you enjoy that, then you're gonna want to go with the travel tracer."

Since answering questions emerged as an important facet of reading and understanding during the pilot study, evidence of this behavior was also sought during the final phase of this investigation. During this year's whole class novel unit in which all students were reading the same novel, The Watson's Go to Birmingham, 1963, evidence of Mrs. White's interest in asking and answering questions became apparent immediately upon commencement of the first classroom observation. As Mrs. White began class, she asked students to take out their homework assignment from the previous night. This assignment required students to write "five questions about your $[$ sic $]$ chapter ... and five answers." Mrs. White told the students that for the first several minutes of class,

I'd like you to take turns within your reading group please.... I would like you to ask your questions to your group members.... And then I'm going to ask you to share one question with us - your whole group. So, you'll have to pick one that you like with us. After the students spent approximately six minutes sharing their questions with the other students seated at their table groups, Mrs. White called for the students' attention and said, 
Now, what I'd like you to do, please, is listen to each of the groups. One person from the group will read their question out loud. And then, whoever is the question-reader, you get to choose the person who answers. You have to raise your hand. So, go.

Over the next 10 - 15 minutes, the students took turns asking and answering questions. On occasion, Mrs. White would jump into that conversation to say, "Can I ask a follow-up question on that one?" On one occasion, after a student asked, "What did the dad do that the mom did not like at all?" Mrs. White asked, "Why did he do that?" Mrs. White persisted on several questions, probing with open-ended prompts such as, "But why?"; “Do you know?”; "What do you think?"; "Why?"; or "Because it will do what?"

In addition to the homework assignment involving the writing and answering of comprehension questions and the in-class discussion of these questions, Mrs. White also assigned homework during this session that required students to choose from one of three assignments that involve some level of comprehension. These three choices included a "Quiz Time" activity in which students had to write four questions and answers from each of four chapters assigned for homework (as they had just done on the previous night); developing a comic strip that detailed information from the beginning, middle, and end of each of the four chapters to be read for homework; or creating a six-word memoir summary for each of the four chapters assigned for homework. During the subsequent classroom observation that occurred the next time this class met, Mrs. White provided time for students to share six-word memoirs with the class and asked them to identify which chapter each of these events occurred in.

At the conclusion of the audio reading of the whole class novel near the end of this classroom observation, Mrs. White led a question-answer session with the students once again, guiding them with open-ended questions about the novel. These questions involved both literal 
and inferential questions including: "What's a Wool Pooh?"; "So what's he seeing? ... But what do you think he's really seeing?"; "Why then, if the whirlpool or Wool Pooh - or whatever you want to call it - is water, how does it show up at the church bombing?"; "What did he see in the smoke?"; "So, what do you think this is a symbol of? The whirlpool and the thing that Kenny makes up in his head has to symbolize something."; "So, how do you explain that? ... What do you think?"

Across both series of classroom interviews and observations (both the pilot study and the final phase of this investigation), Mrs. White's comments during interviews and her actions during classroom instruction made it clear that asking and answering questions is valued by her as an important facet of reading believed to play a role in developing comprehension. This type of interaction occurred at various times during each classroom observation and Mrs. White led these interactions during whole group instruction.

Response to reading. During both interviews and classroom observations, Mrs. White referenced various responses to reading activities that she valued in her classroom (see Table 3). Two of these approaches include the Accelerated Reader (AR) program and a literature or reading log. Mrs. White described her use of AR in this manner:

I do require AR because I find it to be, for me, one of the quickest ways to just see that they are reading. It's a very superficial, simple way to check for reading, no doubt, but it's fairly quick... Granted, the questions they ask for the kids, are very superficial reading comprehension kinds of questions.... It's certainly not a failsafe way to do reading comprehension, but I think it also holds them accountable ...- it has to be graded, it has to count or they won't do it. 
Table 2

Comparison of Mrs. White's Stated Beliefs about Reading Understanding and Instructional Practices Observed

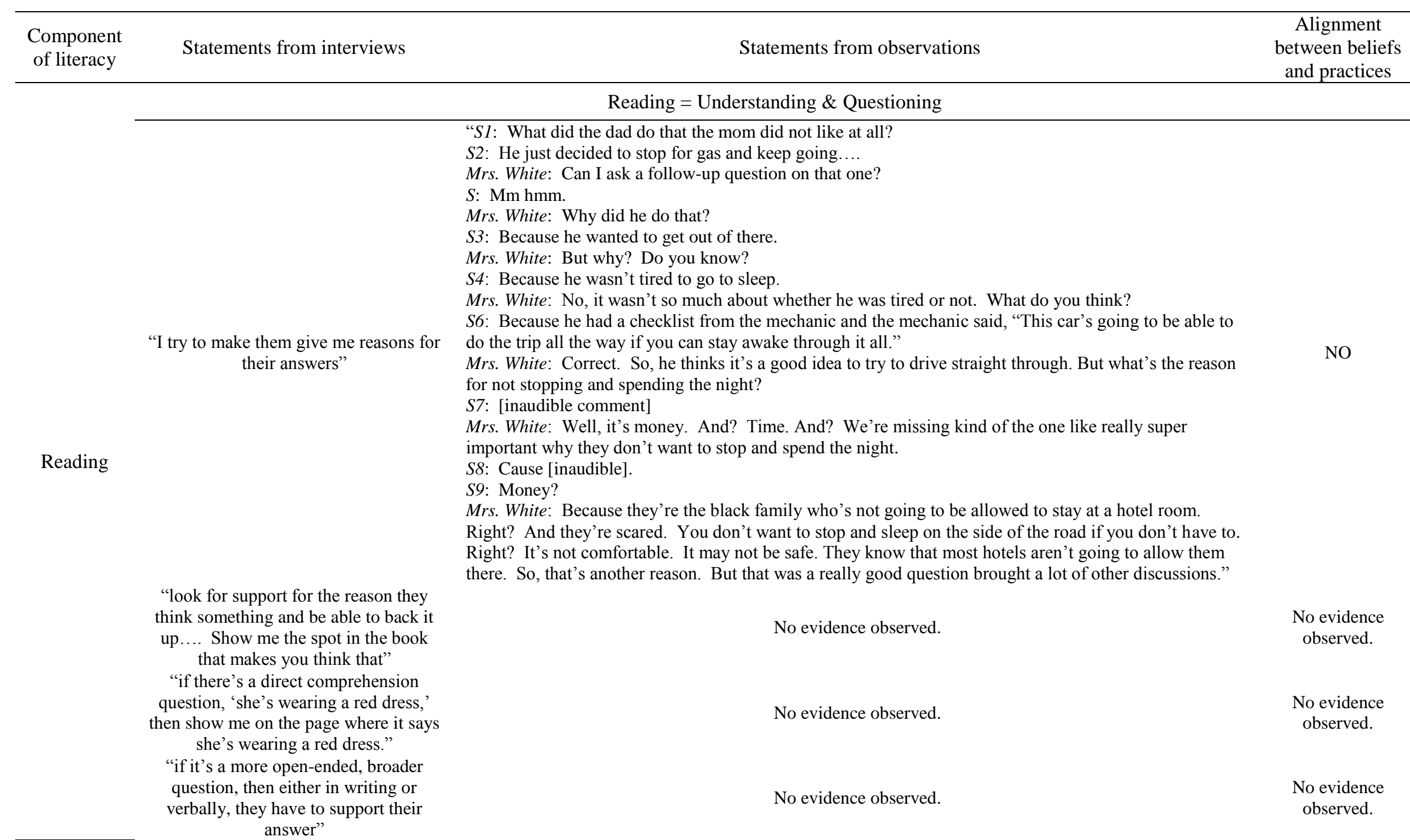


"ask them some specific questions that I wanted to be sure we didn't miss a point of.... to reinforce for myself, are they really reading those books."

"I allowed them to use the books to answer the questions because I wanted support, I wanted specifics.'

"I'm not going to take a one word answer. Find me the words from the text that tell you why that answer is that way."

"getting away from the one word answer"
Mrs. White: All right. Let me ask you a couple questions. I have some questions. What's a Wool Pooh? S1: Um, it's the, Byron said it was the evil twin brother of Winnie-the-Pooh.

Mrs. White: Uh-huh. What is it really?

S2: A whirlpool?

Mrs. White: A whirlpool, right? And you know what that is. In the water, right? And you get that the kids don't understand what Grandma Sands is saying. They think she says Wool Pooh. And then that's why Byron decides he's going to tease Kenny and Joetta about it being Winnie-the-Pooh's evil twin brother. Right? Now, let me ask you this - is the whirl-pool a real thing?

[Students say no and yes followed by general inaudible conversation]

Mrs. White: Yes. When Kenny is in the whirlpool - he's really stuck in it, because remember, he goes swimming where? [students respond inaudibly] Collier's Landing and they're not supposed to go because of this dangerous current in the water there. He acts like the Wool Pooh is a person or a thing.

S3: When it grabbed your ankle.

Mrs. White: Yeah. [several students speak at once] So what's he seeing?

S4: It could be elves? [inaudible comments]

Mrs. White: But what do you think he's really seeing? He's not really seeing...

[several people speaking at once]

S4: It could be elves.

S5: It could be like weeds.

Mrs. White: Now he saw the turtle. I think he...

S6: It could be his imagination.

S7: He's hallucinating.

Mrs. White: Well, I think it may be a combination of both of those things, don't you? Imagination

because of, you know, listening to his brother. Kenny spends a lot of his time being picked on or bothered by somebody, right? Either Byron or Byron's good friend..

[multiple students respond "Buphead"]

Mrs. White: Exactly. So, he's kind of constantly picked on and maybe a little bit of that's going on in his mind. But they talked up too about how scary it is. So, you know how your mind can make things even scarier than they really are, because you're scared yourself. Right? But who said hallucinating?

S7: Me.

Mrs. White: Okay.

S8: And me

Mrs. White: So, why do you think, Jacob, that there's hallucinating going on maybe?

S7: Because he said [inaudible] different things and it's all stuck in his head.

Mrs. White: It's all stuck in his head and he's - isn't he pretty near dying?

S7: Yeah. He is." 
In much the same manner, Mrs. White described how she uses the reading log in her classroom:

I ask them to record pages and get parent signatures.... They were not thinking that they needed to read every night; ... So I instituted that and told the kids it's not a grade, it's simply a way to keep track. I've actually had kids come to me and say, "Can I have another one; it's the only way I remember to read every night?" So even though it's meaningless almost, it helped at least to say, it reminds me I need to read, so I check it off as one of my activities I have to do every night.

Mrs. White admitted that the "literature or reading log, where they just recorded pages, I found that to be more useless because they can make it up; it doesn't mean anything." Despite this admission, Mrs. White chooses to use this form of reading response activity in her classroom because "At least ... they have to do something" that she believes encourages reading.

Both the reading log and AR were referenced during classroom observations as well (as indicated in Table 3). During the pilot study, as Mrs. White introduced the novels from which students could choose to read, she mentioned both AR and the reading log when she stated, Now, I believe if I have it done correctly, that all of these are AR books, so that will be a good thing because you'll complete an assignment that you need for me, and yes, you may take the AR test for the book. And yes, you may include it on the reading log if you choose.

This statement in conjunction with descriptions made during the interviews support Mrs. White's belief that activities such as the Accelerated Reader program and the reading log are practices she values in respect to her students' reading and literacy development. During the final phase of this investigation, AR and the reading log were not mentioned directly during either the interviews or observations. It was noted during observations (through field notes related to 
information recorded on the white board for students to copy into their agendas) that notes about AR were recorded on the white board under the "objective and homework" headings. The notes on the white board were as follows: "AR points due 12/17" was noted during the first observation and two notes, "AR points due 12/17" and "read for AR" were noted during the third observation.

Other forms of reading response were noted during the literature circle unit and the whole class novel unit. As described previously, the literature circle roles offered to students during the novel unit provided students with a variety of methods for responding to the reading. Mrs. White stressed the importance of changing roles each time the groups met so that everyone gets "a feel for each thing each time." Another form of reading response was used during the whole class novel unit. At the conclusion of the novel, The Watson's Go to Birmingham, 1963, Mrs. White provided multiple reading response activities for students to complete. First, students worked on a character analysis worksheet that Mrs. White gave to each of the students. Students had been paired with a partner and had begun work on this task days prior to my visit, so I did not experience the initial description of this activity, but during my visit, Mrs. White reminded the class, "On Tuesday you were beginning to work on a character analysis page." As students completed the character analysis chart with their partners, they were then directed to create an “eye-catching, creative, characterization poster." Mrs. White clarified the purpose of the task stating, "your finished product should be a poster that would say to someone who's never read this book exactly who your character is." In order to create the poster, Mrs. White explained that the "poster needs all the following things: a significant image representing your main character," explaining that "image" did not necessarily mean a picture or drawing, but could be "something that symbolizes or could symbolize your character." Next, Mrs. White explained, "Secondly, I 
would like you to find in the book a direct quote spoken by your character." Next, she asked students to find "one direct quote spoken by another character that tells us what kind of character your chosen one is. So, it's kind of like what other people say about him or her - that indirect characterization thing." Lastly, Mrs. White encouraged students "to decide the five things from your character analysis sheet that are so, so important that they have to go on your poster."

From Mrs. White's perspective, these reading response activities provided multiple opportunities for students to demonstrate their understanding of the novels being read. Mrs. White valued the instructional tasks described here, as these activities were used in an effort to develop her students' overall literacy, especially in regards to their reading development.

Table 3

Comparison of Mrs. White's Stated Beliefs about Response to Reading and Instructional Practices Observed

\begin{tabular}{|c|c|c|c|}
\hline $\begin{array}{c}\text { Component of } \\
\text { literacy }\end{array}$ & Statements from interviews & $\begin{array}{l}\text { Statements from } \\
\text { observations }\end{array}$ & $\begin{array}{l}\text { Alignment between } \\
\text { beliefs and practices }\end{array}$ \\
\hline \multirow{5}{*}{ Reading } & \multicolumn{3}{|c|}{ Reading $=$ Response to Reading } \\
\hline & $\begin{array}{c}\text { "I do require AR because I find it } \\
\text { to be, for me, one of the quickest } \\
\text { ways to just see that they are } \\
\text { reading." }\end{array}$ & $\begin{array}{l}\text { "I believe if I have it done } \\
\text { correctly, that all of these are } \\
\text { AR books, so that will be a } \\
\text { good thing because you'll } \\
\text { complete an assignment that } \\
\text { you need for me, and yes, } \\
\text { you may take the AR test for } \\
\text { the book." }\end{array}$ & \multirow[t]{2}{*}{ YES } \\
\hline & & $\begin{array}{c}\text { noted on white board during } \\
\text { observation: "AR points due } \\
\text { 12/17" and "read for AR" }\end{array}$ & \\
\hline & $\begin{array}{l}\text { "I think [AR] also holds them } \\
\text { accountable in some way ...- it } \\
\text { has to be graded, it has to count or } \\
\text { they won't do it." }\end{array}$ & $\begin{array}{c}\text { "And yes, you may include it } \\
\text { on the reading log if you } \\
\text { choose." }\end{array}$ & YES \\
\hline & $\begin{array}{l}\text { [reading log] I ask them to record } \\
\text { pages and get parent signatures }\end{array}$ & $\begin{array}{l}\text { "yes, you may include it [the } \\
\text { novel being read] on the } \\
\text { reading log if you choose." }\end{array}$ & $\begin{array}{l}\text { evidence of use of the } \\
\text { reading log observed, } \\
\text { but not parent } \\
\text { signature }\end{array}$ \\
\hline
\end{tabular}


Time and practice. Two final themes that emerged from Mrs. White's interviews and observations were her belief that time for reading and reading practice were valued in regards to reading and literacy development (as indicated in Table 4). Mrs. White referenced several issues that she believed would improve students' reading and literacy. Mrs. White stated that "reading a variety of texts" and themed texts would be beneficial for students. This belief was evidenced when Mrs. White spoke about requiring her students to use AR because she believes it is through AR that her students have the opportunity to read multiple books and to choose books of interest (in addition to the texts assigned in class). Additionally, during the literature circle unit, as Mrs. White introduced the novels from which students could choose to read, she pointed out that the idea here is that the books are all related around a historical theme because you are all going to be going soon into the Great Depression [in history class]. So we have people reading different things that are may be on their, you know, different interest levels, but all around the same theme so that we can have whole class discussions about certain topics, even though each of you, or some of you will be reading different books.

Further, as she introduced the variety of novels students could choose from for the literature circle unit, Mrs. White pointed out that some were poetry, written in verse, while others were books in a series. As she described each of the books, she encouraged students to choose from the variety of books based upon their personal interests or their interest in reading a book with a friend.

During one of the pilot interviews, when asked what interventions Mrs. White used to help her students find success with reading, she stated, "An inordinate amount of time." During classroom observations, it was noted that Mrs. White required the majority of reading outside of class (having provided three minutes at the end of one class session for reading; as demonstrated 
in Table 4). She assured students during the literature circle unit that they would be "able to read at your $[$ sic $]$ own pace" and that they "don't have to read aloud to each other." Likewise, during the whole class novel unit observed during the final phase of the investigation, students were assigned a specific number of chapters to read at home for homework, and then in class, they spent class time listening to other sections of chapters as they were read aloud via audio recording. In addition to this required reading, students were also required to complete additional out of class reading in order to meet a required AR goal. These instances of required reading completed predominantly outside of school were the only evidence of providing time and practice for reading.

Writing. During the interview process, Mrs. White made it clear that she views literacy as encompassing more than merely reading, noting that "my definition of [literacy] has changed so that it is becoming more inclusive, I think, of reading and writing skills, not just reading." She reiterated that "a literate person expresses himself or herself equally well in reading or writing." She went on to emphasize that "I think the writing aspect of it is as important probably more so now, than maybe it used to be." From Mrs. White's perspective, writing is such an important element that she shared with me during her most recent interview that she has chosen "writing [as] my professional growth goal" for the school year.

Mrs. White explained during an interview session that she believes her perception of literacy has evolved recently and that although she used to believe that her focus "was literature and everything else revolved around that," she has come to "learn that that is not all literacy is anymore." She explained that "Reading is only a piece of it" and that students "have to be able to write to communicate." Additionally, she explained that although she knows she has to teach 
Table 4

Comparison of Mrs. White's Stated Beliefs about Time to Read and Instructional Practices Observed

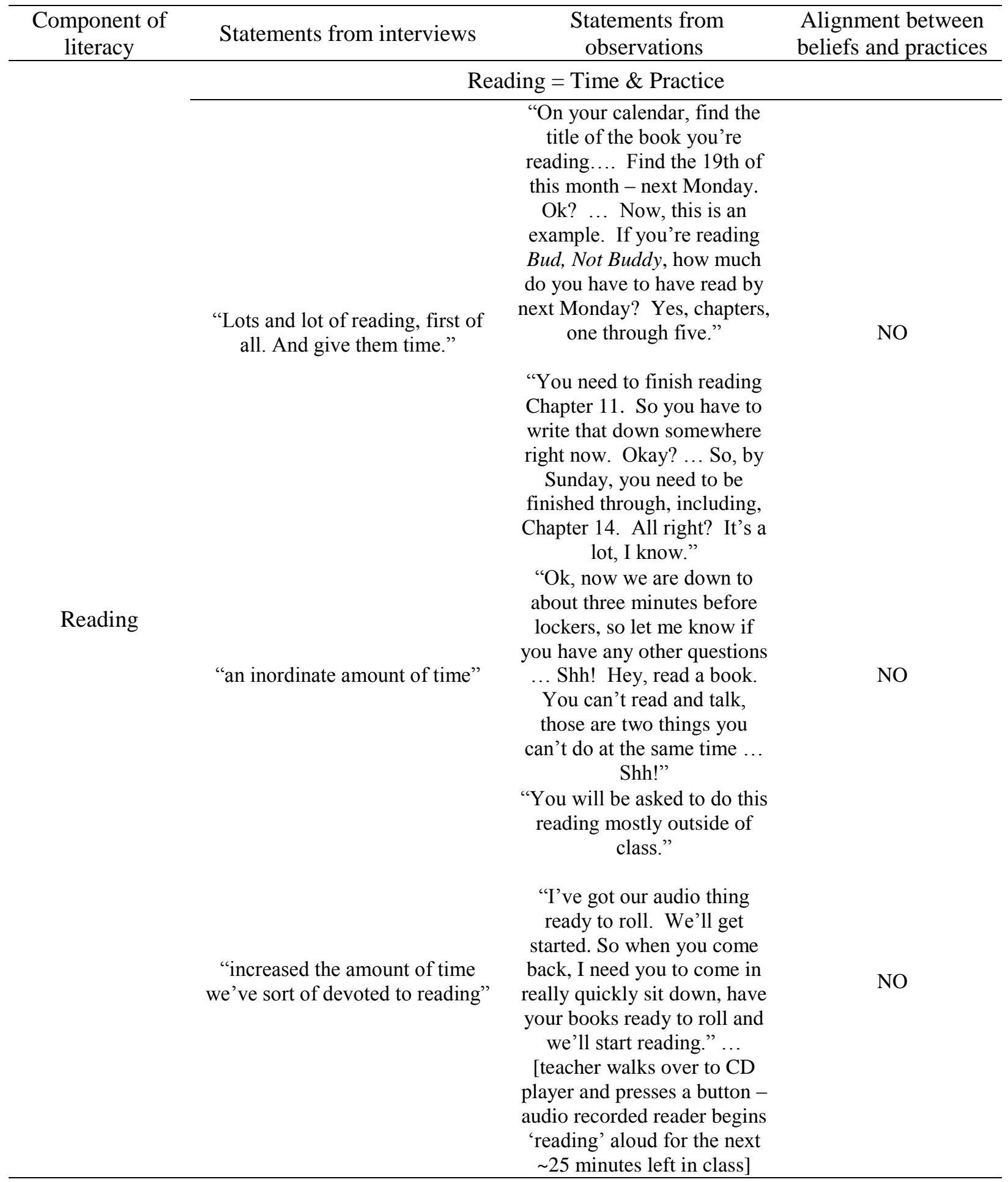


skills associated with writing, such as grammar, she has come to the realization that "that doesn't make much sense by itself, so it's gotta come in at a time where we're writing about something where that seems to work," suggesting that grammar be taught in the context of a larger writing project. Despite these professed beliefs about writing, no evidence of writing instruction was observed during the context of the classroom observations (see Table 5).

Mrs. White explained that she has chosen to attend professional development seminars that focus on writing such as a seminar by Kelley Gallagher that was presented in her county during the summer of 2012. After attending that seminar, Mrs. White shared that this seminar "kind of re-shaped the way I want to do my writing instruction this year." She went on to explain that she "personally want[ed] to spend more time modeling writing this year with my students because I know I don't do that well." During my first observation of the pilot study in November 2012, Mrs. White attempted to model a writing task for her students. After collecting a writing prompt assignment, "writing a recipe for a thunderstorm," from the students (that had been completed as homework), Mrs. White went on to explain to her class that the homework assignment that was due on the upcoming Friday was a "recipe for [student] choice." Before moving on to the day's focus lesson, Mrs. White took a few moments with the students to walk them through the writing assignment. First she asked students to share some ideas that might be used for the writing prompt. Multiple students responded with suggestions such as a sleepover; making friends; a money tree; a kitten; a party; a chocolate milkshake (to which Mrs. White replied, "You can't do food."); and a perfect Christmas. After allowing students to share ideas, Mrs. White explained that in her second period class she "tried to help them out a little bit with this today by writing something quickly for them to read." Then she went on to explain, "So what I'd like to do is just share that same one with you." Instead of developing the piece of 
writing in front of the students, modeling the writing process, she placed the model she had created in second period under the Elmo projection system and proceeded to walk the class through her example, a "recipe for a perfect Saturday" using a think aloud process. She explained, "This is me and this is only like two hours of a Saturday for me, but I would have two cups of coffee; ... one pair of fuzzy pajamas; one old black and white movie," and so on. She stopped on occasion as she read her writing example and talked through her thoughts, modeling her thinking through pieces of this process for the class.

During the most recent interview of the final phase of the investigation, when asked to share her overall goals for her English classroom during this school year, Mrs. White explained that "as always" writing is an area of focus, "particularly written expression." She explained that her students tend to "come from their elementary schools fairly strong with grammar and formatting, but it's the written expression, [particularly] the details about the details that they're struggling with." She explained the notion of written expression suggesting that students need to work on "throwing in a simile or a metaphor to explain something they struggle with." She further explained that her goal "is to get them from technically correct writers to something with more vivid verbs, precise adjectives." She described her instructional techniques for helping her students achieve this goal as conducting "a lot of little mini-lessons on just those things and then we've woven that into a larger writing assignment, just for them to see." Although this instructional technique was not observed during any of the classroom observations, Mrs. White explained that by choosing something as specific as written expression as her instructional evaluation goal, she was able to

narrow it down enough that I think you could really actually see progress [because] a writing prompt itself can change whether the kid passes or not. But I think written 
expression gives me enough real, detailed points I can look for that I can see whether the kid's improved.

The only manifestations of writing that were observed over the five different classroom observations were the homework assignment being collected and the brief modeling of the upcoming homework assignment based upon the writing prompt, "a recipe for" student choice.

Mrs. White did make an attempt to model writing for her students through a piece she had written during a previous class session. It is evident that Mrs. White values writing to the extent that she provides opportunities for students to practice their writing outside of the classroom setting as assigned homework, yet no observations of writing occurred during the context of this investigation to provide evidence of Mrs. White's literacy beliefs associated with writing.

Table 5

Comparison of Mrs. White's Stated Beliefs about Writing and Instructional Practices Observed

\begin{tabular}{|c|c|c|c|}
\hline $\begin{array}{c}\text { Component of } \\
\text { literacy }\end{array}$ & Statements from interviews & $\begin{array}{l}\text { Statements from } \\
\text { observations }\end{array}$ & $\begin{array}{l}\text { Alignment between } \\
\text { beliefs and practices }\end{array}$ \\
\hline \multirow{11}{*}{ Writing } & $\begin{array}{l}\text { "the writing aspect of it is as } \\
\text { important probably more so now, } \\
\text { than maybe it used to be." }\end{array}$ & No evidence observed. & No evidence observed. \\
\hline & $\begin{array}{l}\text { "I went to the Kelley Gallagher } \\
\text { thing this summer, and so that's } \\
\text { kind of re-shaped the way I want } \\
\text { to do my writing instruction this } \\
\text { year." }\end{array}$ & No evidence observed. & No evidence observed. \\
\hline & \multirow{8}{*}{$\begin{array}{l}\text { "I personally want to spend more } \\
\text { time modeling writing this year } \\
\text { with my students because I know } \\
\text { I don't do that well." }\end{array}$} & "My second period class & \\
\hline & & wrote a recipe for a perfect & \\
\hline & & Saturday. So let me just & \\
\hline & & I tried to help them out a & \\
\hline & & & \\
\hline & & $\begin{array}{l}\text { for them to read, so what I'd } \\
\text { like to do is just share that } \\
\text { same one with you. Ok, } \\
\text { now, um, recipe for a perfect }\end{array}$ & NO \\
\hline & & $\begin{array}{l}\text { Saturday. This is me and this } \\
\text { is only like two hours of a }\end{array}$ & \\
\hline & & $\begin{array}{c}\text { Saturday for me, but I would } \\
\text { have..." }\end{array}$ & \\
\hline & $\begin{array}{l}\text { "have to be able to write to } \\
\text { communicate" }\end{array}$ & No evidence observed. & No evidence observed. \\
\hline
\end{tabular}


Oral communication and collaborative teamwork. While describing her beliefs about literacy during the interview process, Mrs. White suggested that oral communication also plays a role in literacy and she linked that facet of literacy with collaborative teamwork. Mrs. White stated, "Oral communication has to be part of that literacy package too. Especially with the way the world is changing to this collaborative teamwork kind of thing all the time" (see Table 6).

During the pilot study, Mrs. White chose to utilize a literature circle approach for her annual novel unit. This approach provided evidence of Mrs. White's beliefs about oral communication because as she told her students, "literature circles are made up of a group of people reading the same book, but those people in the group have a lot of power in driving the discussion of that book." She made it clear to the class,

we could do this the old fashioned-way by everybody reading the same book, or we could all read different books and then I could just hand you the list of review questions and say answer all of these in detail, find these 12 vocabulary words, draw a picture of this chapter; I could do all that, but as I told you all the other day, I'm trying something new with the literature circles, so it is going to give you a lot of power to decide what you want to talk about in your book.

This new approach that Mrs. White implemented in her class clearly provided the students with opportunities for discussion and collaborative team work in class as each student had a particular job to complete in order to contribute to the discussion about the group's novel (the literature circle roles were described previously in the "Reading" section above). While discussing the literature circle approach during a follow-up interview after the pilot study observations, Mrs. White noted that she told [the students] "that the whole point of this [literature circle approach] is the oral communication; the discussion." 
As she reflected on her literature circle groups, Mrs. White identified places where she knew the students still needed to grow in regards to the discussion aspect of this approach. She noted, "I knew I had to give them some more specific examples of discussion, not being, you read your paper, great you're done; you read your paper, great you're done.” In addition, she found that "There were a lot of kids the first time whose discussion questions were really more comprehension questions, but that's getting better; they just don't know how to do that yet, and that's fine; they're getting there." Despite these statements about discussion and the literature circle approach, there was no evidence of tasks associated with these statements during the classroom observations that were conducted.

Overall, Mrs. White commented that she found the literature circle approach to be "more authentic because, as just a reader, not just as a teacher, but as a reader, on my own, that's what I do. I share books with friends, or people who have common interests." Mrs. White stated, "I think this is a much more real world, authentic way to do that" and that "It's been a good thing." Despite these professed beliefs about this particular approach for discussion and teamwork, during the classroom observation cycle of the final phase of this investigation, Mrs. White chose to utilize a whole class novel approach for her annual novel unit.

During the current investigation, evidence of discussion occurred as Mrs. White led the discussion of the novel assigned to the whole class. After listening to a portion of the text via audio recording in class, Mrs. White led a question-answer session with the students, providing them with an opportunity to answer her questions and to share their personal connections to the novel. (The question-answer discussions were described previously in the "Understating and Questioning Reading” section and were detailed in Table 2.) 
Another example of student discussion during this whole class novel unit occurred when Mrs. White gave students the opportunity to discuss personal connections associated with the novel, The Watsons Go to Birmingham, 1963. After the students finished listening to the end of the novel via audio recording, the students were discussing the whirlpool, being led by Mrs. White's questions, and one student stated, "I kind of have a story" and Mrs. White responded, "Okay." The student proceeded to share his personal connection to the life and death situation that the class had been discussing from the novel. He said, "About, like similar to the wool pool." (Mrs. White replied, "All right, go ahead.") The student explained, "I was in North Carolina, the Outer Banks, and I got into the rip current and I started going under the water and I had a boogie board. I was bobbing, and then" (Mrs. White replied, "I would have been so scared.") and the student proceeded, "I wasn't panicking because I knew I wasn't supposed to." At this point, Mrs. White paused the student's personal connection to redirect the discussion by stating, "Right. Well, that was good. It was very smart. Because I'm not sure I could have done it. All right. Hang on. We'll share our stories in a minute." As the class concluded their discussion about the events from the novel, Mrs. White provided the students with a few minutes to talk among themselves sharing their stories as she prepared to move on to the next activity associated with the novel.

A final example of Mrs. White's beliefs about communication and teamwork took place during the final observation session. At the conclusion of the novel unit, the students were paired with another classmate to complete a character analysis chart. Once the details of this chart were completed, the students were then asked to work collaboratively with their classmate to develop a poster. Mrs. White explained, "Here's the part where you get some more choices.... You and your partner will need to decide the five things from your character analysis sheet that 
are so, so important that they have to go on your poster." Mrs. White encouraged the students to work collaboratively to make some important decisions about their poster together. She told the class, “Once you've completed your character analysis sheet, I would like you and your partner to give a rough sketch of what you think you're going to have on your poster."

These examples taken directly from Mrs. White's interviews as well as the classroom observations indicate how Mrs. White associates oral communication and collaborative teamwork with her overall views about literacy. She demonstrated these beliefs through the choice of instructional activities she chose to implement in the classroom setting. During one series of classroom observations Mrs. White integrated a literature circle approach for her annual novel unit proving the students with multiple opportunities to engage in discussion about the novel being read while also working together collaboratively to complete this discussion. During the second series of observations Mrs. White integrated a different approach for her annual novel unit whereby she led the classroom discussion of the whole class read novel. At the conclusion of this unit, the students engaged in a shared reading response activity associated with the novel, which provided students with the opportunity to engage in discussion with each other while also working collaboratively to create a poster demonstrating their understating of a character from the novel.

Vocabulary. Vocabulary appears to be an element Mrs. White associated with her beliefs about literacy. Although Mrs. White did not directly refer to vocabulary in her initial definition of literacy, this element emerged through the interviews and classroom observations as being connected to literacy (see Table 7). For example, during the initial pilot interview process, Mrs. White suggested that students need to be "able to communicate in the terms that are important to that content. In English, that would be general reading and writing; knowing the 
Table 6

Comparison of Mrs. White's Stated Beliefs about Oral Communication and Collaborative Teamwork and Instructional Practices Observed

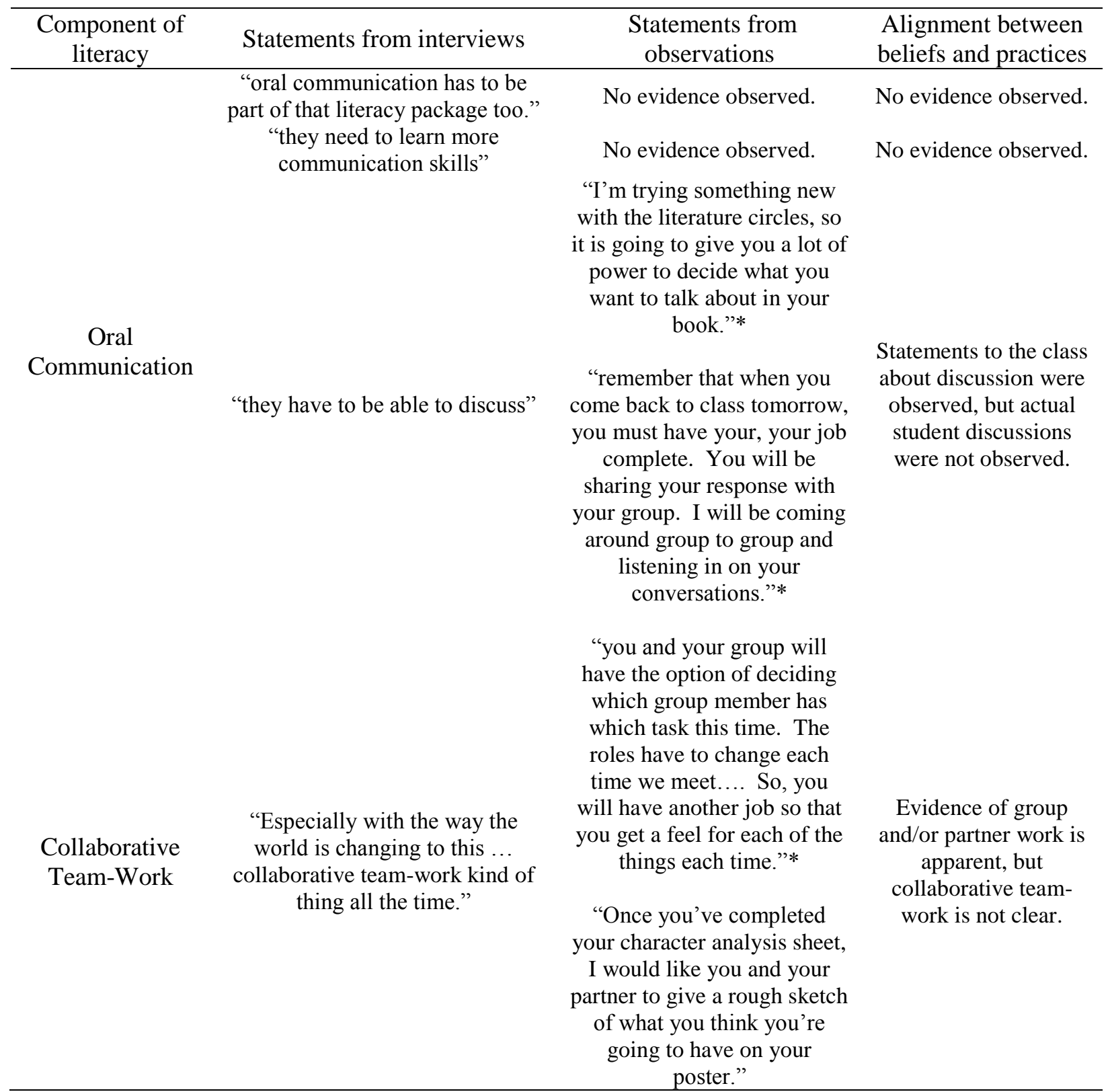

*the literature circle approach was observed during the pilot study but did not appear to be part of the typical classroom routine since the whole class novel approach was observed during the current investigation

right vocabulary; knowing to use author's purpose or a plot diagram as necessary." She further explained that the type of vocabulary needed for other subject areas, such as history and science, changes "because the vocabulary is specific to those subjects." Additionally, Mrs. White noted 
"if you [sic] start to see that as [students] are talking or working in groups, you [sic] start hearing them use the vocabulary you've used, and they're expanding the way they think," then she can be certain the students are learning the vocabulary being taught. It appears she believes it is the application of the vocabulary associated with her content area that is of importance.

An analysis of the classroom observations in Mrs. White's classroom revealed that she used a packaged program for teaching vocabulary to her students. The program used is SadlierOxford's Vocabulary Workshop. No mention of this program was made until the final classroom observation of the final phase of this investigation. During this classroom observation, a note on the white board indicated "Unit 4 Vocabulary quiz" would occur on "11/25." The homework note on the white board also indicated "Unit 4, p. 57 - 58; study for quiz." As students entered the classroom during this class session, students were heard making comments to the teacher such as, "I didn't understand these words; they were hard," to which Mrs. White replied, "No they're not, they're like the easiest words we've had all year." As students settled down, Mrs. White turned on the Elmo projection system with the teacher's edition of the Vocabulary Workshop workbook under the projector showing the answers to the class. Mrs. White addressed the whole class stating,

So ladies and gentlemen we will have a quiz on this set of vocabulary words on Tuesday. I realize that there may be some people who are traveling on Tuesday and may or may not be here. That's fine, whatever, then you have a vocabulary quiz on December $1^{\text {st }}$, the day you come back.

Next, Mrs. White told the class, “Today we're just going to quickly check some answers for these vocabulary words." She encouraged students to "remember that now is the time to correct answers. If you missed it, it's practice." Mrs. White encouraged students to correct any errors 
made, noting, "it doesn't do any good just to put an X over it and you think to yourself, 'Well yeah I missed that many"'... If you don’t fix your answer, how are you gonna learn from it?" As students checked their answers, Mrs. White asked students if there were particular words that proved difficult for them. On occasion Mrs. White would state a word, give a definition, and then provide clarification and/or a clue to help students remember the words. For instance, Mrs. White told the class,

People were getting repent and discredit confused. If I repent of something I feel sorry about it. Correct? If I've done something wrong and I repent not only that the idea is I'm feeling sorry for either something I did or a commitment, like something I failed to do. Like I was supposed to be somewhere at a certain time and just didn’t show up. I can feel bad about it so that's repentant or to repent, right? But to discredit something means that you want people to doubt it. So think of, I think it will be easy to remember discredit if you can put the two d's together in your head, discredit and doubt, to cast doubt upon something it will be easier to remember those.

An example of a student asking for clarification during this vocabulary workbook review occurred in this manner:

Mrs. White: Deem? No, okay good, that's fine. Let's see what do we have here? ... Petty, stranded, strife, keepsake. I don't think those are bad, but you tell me if they are confusing and we'll see if we can figure out a clue or something that you can use to help figure them out.

Student 1: Petty?

Mrs. White: Petty, it's unimportant.

Student 2: I had trouble with keepsake. 
P1: Keepsake? It's like a memory, a memoir, something that you can hold on to and keep that remind you of things. Anybody else have anything? It's always good to stay in the definitions but sometimes I think you really just need a little clue, a little hint that you can grab onto when you're trying to remember what these words mean. Okay? Alright, let's check out the rest of our sentences. I think number 16's kind of tricky unless you've read all of the words carefully in the sentence because you might pick up the word scan and go, "Oh scan the record is the best receiver - well, that's going to make sense." But you gotta read your whole sentence. Don't be too quick just to read after the blank or after the choice. You should know by now enough using this book. These sentences are not easy. So, you've got to read the whole sentence to get your context clues. How about anything on there?

Student 3: No, not really. Mrs. White: No? Good. Questions? How about the rest of those? Any of those too hard? [pause] Alright, so good? What was confusing on those, anything with repenting, idolize, keepsake...

Student 4: Yeah, repenting is kind of....

Mrs. White: Repenting? Just remember I feel sorry. To repent is to feel sorry for. Student 5: Well, I use it in church.

Mrs. White: Yes, you do.

Student 5: Repent against your sins.

Mrs. White: Yes, absolutely. Okay? Synonyms, then ladies and gentlemen. At the conclusion of this vocabulary workbook check, Mrs. White reminded students of the homework for the upcoming evening when she said, "take note of the homework assignment that 
you have - when it says it's 57 and 58 that means it's the completing the sentence piece." Next she asked the class, "When's our vocabulary quiz?" Several students replied, talking over each other stating, "Friday, Tuesday." "Tuesday." "Friday’s today." Mrs. White made no additional comment and moved on to the focus lesson for the day.

Since this vocabulary program had not been mentioned prior to this experience, a followup question was asked at the end of this class session to inquire about the vocabulary program. When asked to share her thoughts about the vocabulary workbook, Mrs. White responded, "I like it, I do. I know that that's not necessarily the one way to teach vocabulary. The one thing I would say that is good about it, though, is that it's consistent." Mrs. White further explained that when studying vocabulary terms such as those offered through this program, "If they're not in context - what's the point of any of it?" She went on to explain, "At least these [the Vocabulary Workshop units] do have a little story." Despite the fact that she applauded this program for integrating the vocabulary words in some context with the brief stories included, Mrs. White noted, "we're not gonna do it this time, just time constraint wise, but I haven't had them do one of those writing assignments with the words that come at the end of the lesson." As Mrs. White reflected on this vocabulary approach, she stated, "at least we know they've been through a program.... Would root words be better, yeah probably but honestly when we looked at some examples of things for the middle school level to teach with root words - it was just lacking." She finalized this conversation by asserting, "It's not a perfect world, but of what we saw I think it's the best."

Mrs. White also made reference to vocabulary terms that she may have associated with her subject area during classroom instruction. For instance, while introducing the literature circle unit to the class during the pilot study, Mrs. White emphasized a term that can be 
associated with the English subject area. As she introduced the novels for students to choose from, Mrs. White made note that each of the novels was set during the Great Depression. She explained "there all historical fiction, which is?" She then clarified this vocabulary term by stating, "They're based around a historical time period. It could have happened, some of the events actually did happen... there is definitely some historical fact in it, but there are fictional characters, so it's a nice blend of things."

During the final phase of the investigation one example of Mrs. White's effort to reinforce vocabulary terms associated with her content area occurred during the final observation. As Mrs. White introduced the final reading response poster activity at the conclusion of the whole class novel unit, she reminded students of the terms direct and indirect characterization. She explained

I would like you to find in the book a direct quote spoken by your character. What is something your character said that tells us about who he or she is as a person? I would like you to do one direct quote spoken by another character that tells us what kind of character your chosen one is. So, it's kind of like what other people say about him or her - that indirect characterization thing.

At the conclusion of this classroom observation, during a follow-up interview, Mrs. White explained that she chose this particular reading response project because I was trying to come up with something that would tie together the other topics that we talked about this time and its direct and indirect characterization was a big part of this nine weeks through short stories. That's part of why we chose these novels because they all have such strong, easy to identify with characters. So this came from, I guess, sort of trying to tie everything together within the nine weeks. 
When this explanation is paired with the example of Mrs. White asking student to identify direct and indirect characterization quotes for their poster project, it becomes clear that Mrs. White strives to integrate vocabulary in somewhat authentic ways as she encourages her students to identify examples of the terminology she has taught in her classroom.

These examples of Mrs. White's integration of vocabulary discussion, vocabulary review, and application of vocabulary terminology suggest that Mrs. White values vocabulary in her English classroom. During both the pilot study and the final phase of this investigation, Mrs. White integrated various activities that demonstrate her interest in increasing her students' knowledge and understanding of various vocabulary terms. Students are assigned a vocabulary workbook program that introduces and reinforces vocabulary terms and Mrs. White also reinforces vocabulary terminology that is apparently linked with her subject matter, such as historical fiction and direct and indirect characterization during classroom instruction.

Table 7

Comparison of Mrs. White's Stated Beliefs about Vocabulary and Instructional Practices Observed

\begin{tabular}{|c|c|c|c|}
\hline $\begin{array}{c}\text { Component of } \\
\text { literacy }\end{array}$ & Statements from interviews & $\begin{array}{l}\text { Statements from } \\
\text { observations }\end{array}$ & $\begin{array}{l}\text { Alignment between } \\
\text { beliefs and practices }\end{array}$ \\
\hline \multirow{3}{*}{ Vocabulary } & $\begin{array}{l}\text { "knowing the right vocabulary; } \\
\text { knowing to use author's purpose } \\
\text { or a plot diagram as necessary." }\end{array}$ & No evidence observed. & No evidence observed. \\
\hline & & $\begin{array}{c}\text { "we will have a quiz on this } \\
\text { set of vocabulary words on } \\
\text { Tuesday." }\end{array}$ & \multirow[b]{2}{*}{ YES } \\
\hline & "we have to know vocabulary" & $\begin{array}{l}\text { "Today we're just going to } \\
\text { quickly check some answers } \\
\text { for these vocabulary words." }\end{array}$ & \\
\hline
\end{tabular}

Literature. One final element of literacy that emerged as a result of this investigation of Mrs. White's beliefs about literacy was the term "literature." Although this term was not stated directly as Mrs. White shared her beliefs associated literacy, literature was mentioned in the 
context of the pilot interviews and appears to play a role in Mrs. White's beliefs about literacy (see Table 8). Mrs. White explained that it is "important for [students] to read some classic literature," noting that "it doesn't all need to be adolescent literature" such as, The Hunger Games. She clarified the benefits of classic literature, stating that classic literature "shows the kids differences in historical background, historical time periods. The dialect changes, sentence structure changes, and ... that there's more than one way to speak, than the way we speak now." Further, she explained that "it's important for them to realize that there's many ways that they can communicate, each appropriate to a certain situation" and that classic literature in conjunction with adolescent literature helps students to develop literacy.

In addition, during the second pilot interview, Mrs. White referenced an emphasis on literature when she described herself:

I think when I first started teaching and I was an eighth grade teacher 24 years ago I would have called myself an English teacher and it was literature and everything else revolved around that. But, I have come to learn that that is not all literacy is anymore. During classroom observations, the use of literature was noted during both the pilot study and the final phase of this investigation. During the pilot study when Mrs. White began her annual novel unit, she chose to use a literature circle approach. During this unit, she permitted each student to choose the novel he/she would like to read. She introduced a variety of titles, each of which was a work of historical fiction associated with the Great Depression. Mrs. White provided a brief overview of each of the novels from which students could choose: No Promises in the Wind, by Irene Hunt; Bud, Not Buddy, by Christopher Paul Curtis; Out of the Dust, by Karen Hesse; and Roll of Thunder, Hear My Cry, by Mildred Taylor. Mrs. White introduced the novels in this manner: 
If you enjoy reading poetry, this would be good [holding up Out of the Dust]; it doesn't rhyme, thank the Lord for small favors - it's not like Dr. Seuss, hate that. But if you enjoy poetry, this is an option. And because it is told in verse it's a quicker read, which is something to consider. But, I do want you to look at the back of the book. Roll of Thunder, Hear My Cry is part of a series, if you're the type of person who enjoys a series of books, if you enjoy, if you like, find characters that you like and you go, "ooo, but I want to know what they're doing next" so here because we have other books at our school library in this series. Bud, Not Buddy, same thing; there's more to the story. Ok? And, No Promises in the Wind, this is not part of a series, Irene Hunt is the author. Following this introduction and a few moments for students to explore the books, each student chose a book and that novel group became the literature circle group for this novel unit. During the final phase of the investigation, Mrs. White chose to use the whole class novel unit approach with her class and she chose the novel, The Watsons Go to Birmingham, 1963 as the novel for students to read.

Mrs. White also made an ambiguous reference to various types of literature including poetry, prose, and nonfiction as she explained that students "have to be more worldly in their skills." She went on to explain that reading classic novels, "as much as I kinda like that, it's not what we do. It doesn't prepare them for anything, really, except to be English teachers." This reference to literature remains ambiguous and cannot be clarified further in the context of this investigation, yet it appears that Mrs. White associates literature with her beliefs about literacy. 
Table 8

Comparison of Mrs. White's Stated Beliefs about Literature and Instructional Practices Observed

\begin{tabular}{cccc}
\hline $\begin{array}{c}\text { Component of } \\
\text { literacy }\end{array}$ & Statements from interviews & $\begin{array}{c}\text { Statements from } \\
\text { observations }\end{array}$ & $\begin{array}{c}\text { Alignment between } \\
\text { beliefs and practices }\end{array}$ \\
\hline Literature & $\begin{array}{c}\text { "I think it's important for them } \\
\text { to read some classic literature } \\
\text { sometimes too, it doesn't all } \\
\text { need to be, um, adolescent } \\
\text { literature." }\end{array}$ & No evidence observed. & No evidence observed. \\
\hline
\end{tabular}

\section{Introduction of Participant Two}

Ms. Swift is a sixth grade English teacher in her fifth year of teaching. She has spent her entire career in her current position. Ms. Swift began her undergraduate studies as an English major and during her junior year changed her major to English with teacher licensure. Ms. Swift completed her student teaching experience in Mrs. White's sixth grade English classroom. At the conclusion of her student teaching experience, Ms. Swift completed a long-term substitute position, which eventually led to being hired in her current full time sixth grade English position.

\section{Description of Ms. Swift's Classroom}

Ms. Swift's sixth grade English classroom is a bight classroom with large windows directly behind the teacher's desk, which sits on the far wall directly across from the doorway, pushed toward the right-hand corner (see Figure 6 for an image of the layout of Ms. Swift's classroom). The classroom walls were decorated with an assortment of purchased posters and themed sets of literary terms. For instance, placed around the classroom were various pre-cut bulletin board pieces that include literary terms and figurative language, such as: simile, metaphor, personification, mood, hyperbole, imagery, point of view, plot, theme, characters, conflict, and setting. Each bulletin board piece includes a picture and brief narrative describing the term. In addition to this pre-cut bulletin board poster set, there were several other posters. 
One poster had a picture of Darth Vader reading Harry Potter and the Deathly Hallows, while another had Willie Wonka and it stated, "So you want more extra credit? How about doing all of the regular credit?" In addition to these posters, there were instructional posters such as one suggesting how to "Avoid Plagiarism." The classroom had only one small bulletin board to the immediate right of the doorway, beside a small white board. This bulletin board had the heading, "We're all stories in the end. Just make it a good one." Below the heading were many different papers that were word-processed. These papers appeared to be short stories, but were across the classroom and behind a group of students, so they could not be read to confirm the contents.

The classroom included a total of six bookcases ranging in height. Directly across from the doorway in the left corner was the classroom library. The classroom library included two short bookcases with a variety of baskets placed on each shelf. Each of the baskets on the classroom library were labelled including the following topics: mystery (two baskets), action (three baskets), sports, Star Wars, historical fiction (four baskets), fantasy (three baskets), realistic fiction (three baskets), and one labeled "silly." In addition to these baskets were sets of series novels such as the boxed Harry Potter set and Chronicles of Narnia set. Additionally, there were two rows of sets of $6-8$ books of the same title. This included titles such as, The Giver. On the other bookcases around the classroom were a variety of materials. On the bookcases on the front wall to the left of the SMARTBoard were classroom sets of texts such as the Write Source text titled, All Write; Jamestown Education's Goodman's Five-Star Stories readers, including classroom sets of titles such as Encounters, Surprises, and Chills; assorted workbooks; and stacks of photocopied papers. On the remaining two bookcases in the far right 
corner were assorted books including classroom sets of the Prentice Hall Literature anthology and hardbound dictionaries.

Figure 6. Layout of Ms. Swift's sixth grade English classroom - fall 2014.

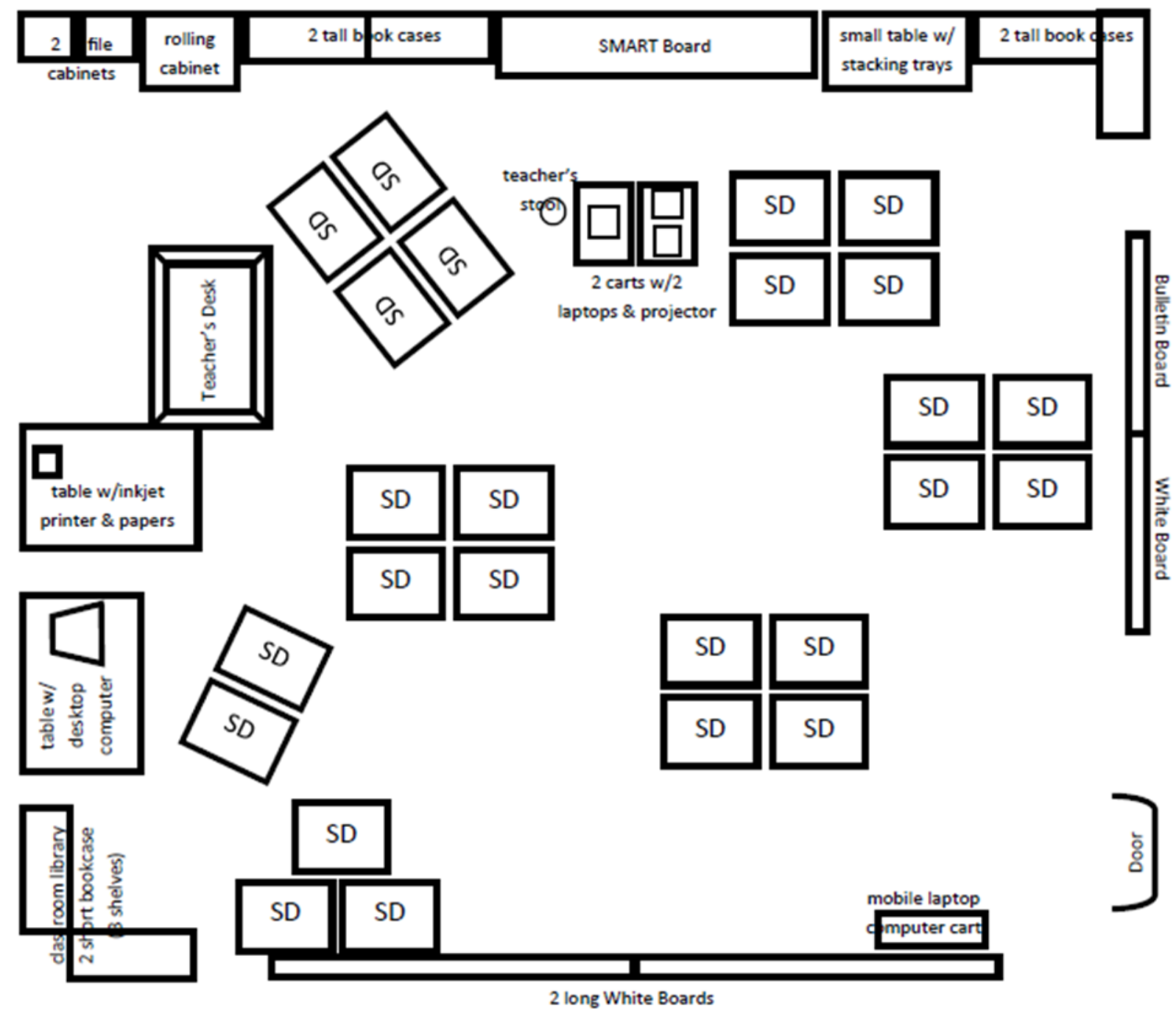

In the corner around the teacher's desk were two file cabinets, a rolling cabinet, and beside the teacher's desk was a long table projecting out from the wall holding assorted stacks of papers and an inkjet printer, Next to that table, parallel to and touching the wall was another long table holding a desktop computer, an assortment of binders, and what appeared to be studentmade projects. Directly inside the classroom door on the wall to the left were two long white 
boards, nearly the length of the classroom, with the classroom library sitting at the far end of these white boards. In front of these long white boards, near the classroom door was a large rolling cabinet holding a mobile laptop computer lab. On the opposite wall, across from the white boards was the SMARTBoard. Upon entering the class, projected onto the SMARTBoard (from a laptop and projector placed on a rolling cart a few feet from the SMARTBoard) was an image of a book with the note, "We're actually reading today!" Upon each observation, some image and note were projected onto the SMARTBoard. The teacher's stool sat beside the laptop carts (there are two of these rolling carts, one of which holds a laptop, the other holding a laptop and projector, projecting onto the SMARTBoard). The only other table in the classroom was situated to the right of the SMARTBoard. This table held stacking trays, each labeled with a period number. Additional papers and classroom materials appeared to be located on this table.

The students' desks were arranged in table groups, most of which had four desks in a group. Two four-desk groups and one two-desk group were placed between the teacher's desk and the laptop/projector carts (beside which the teacher's stool is placed and the majority of "instruction" appears to occur from) and three table groups of four desks were placed to the other side of the teacher's instructional position. There were three additional desks placed in a triangle against the white board beside the classroom library area, yet no students sat at these desks. On the long white board on the left-hand wall immediately inside the classroom door, Ms. Swift had a few notes written on the boards. Immediately inside the door on the white board, above the mobile laptop lab, notes regarding how to access school computers were recorded. This note included "'ID + password info." and information for accessing BlackBoard: "ID + password info." Hanging on the white board, at the bottom near the chalk ledge and to the right of this note, was a large piece of poster board with rows of numbered sticky-it notes. This poster board 
was laminated and had the heading, "Ticket Out the Door" across the top. Written above this poster board, at the top of the white board were the notes:

$\begin{array}{cc}\text { bene } \rightarrow \text { good } & \text { mal } \rightarrow \text { bad } \\ \text { benefit } & \text { malevolent } \\ \text { benevolence } & \text { malicious } \\ \text { beneficiary } & \text { malpractice }\end{array}$

To the right of these notes was written, "Today's Schedule” with the day's schedule posted (during the first observation of the final phase of this investigation the school had shortened class periods in order for students to attend a chorus concert near the end of the school day). The only other note was the word "reverie" with no other notes regarding this term. In the far lower righthand corner of the white board, next to the classroom library area were what appeared to be six small student-drawn doodles.

On the small white board to the immediate right of the classroom door were the following notes:

\begin{tabular}{|c|c|c|}
\hline \multirow{3}{*}{ 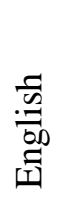 } & Obj.: & $\underline{\mathrm{HW}}:$ \\
\hline & Read & Vocab. pp. 57-58 \\
\hline & Quiz & complete sentences \\
\hline & Obj.: & HW: \\
\hline :07 & Mood & Read \\
\hline 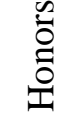 & Project & \\
\hline
\end{tabular}

During the pilot study, which took place in the fall of 2012, the fourth period, sixth grade general education English class was used for classroom observation purposes. That particular 
class had a total of 22 students including 12 boys and 10 girls. During the final phase of this investigation, which took place during the fall of 2014, the second period, sixth grade general education English class was used for classroom observations. This class had a total of 18 students, with 10 boys and 8 girls. This change of class periods for observation purposes occurred because Ms. Swift shared that her fourth period class this school year is a mixed inclusion and English Language Learner class with at least one additional certified teacher working collaboratively with her during that class period. In order to maintain a similar classroom make-up, Ms. Swift recommended using her current second period class so that the class composition for both observation cycles was comparable.

The only difference in the physical room arrangements between the fall 2012 observations and the fall 2014 observations was the precise location of the table groups. During both observation cycles, the student desks were broken primarily into five table groups with either four or five desks at each table group. The difference was the location of the desks, with three four- or five-desk table groups to the left-hand side of the classroom and two four- or fivedesk table groups to the right-hand side of the classroom during the 2012 observation cycle. All other tables, room arrangements, and posters appeared the same across the two-year time span in which classroom observations occurred.

\section{Ms. Swift's Definition of Literacy}

Ms. Swift's preliminary definition of literacy was simply "the ability to read and write." Throughout the course of this investigation, though, Ms. Swift's beliefs about literacy became clearer as she revealed that she views literacy though a language arts perspective, which incorporates "reading," "an emphasis on writing," and "an element of speaking" (see Figure 7 for a visual representation depicting Ms. Swift's definition of literacy). Ms. Swift explained that 
from her perspective, "reading breaks down into reading skills and literature," with reading skills being divided into literary analysis skills, "regular" literary terms, and "academic" terms.

Figure 7. Visual model depicting Ms. Swift's definition of literacy.

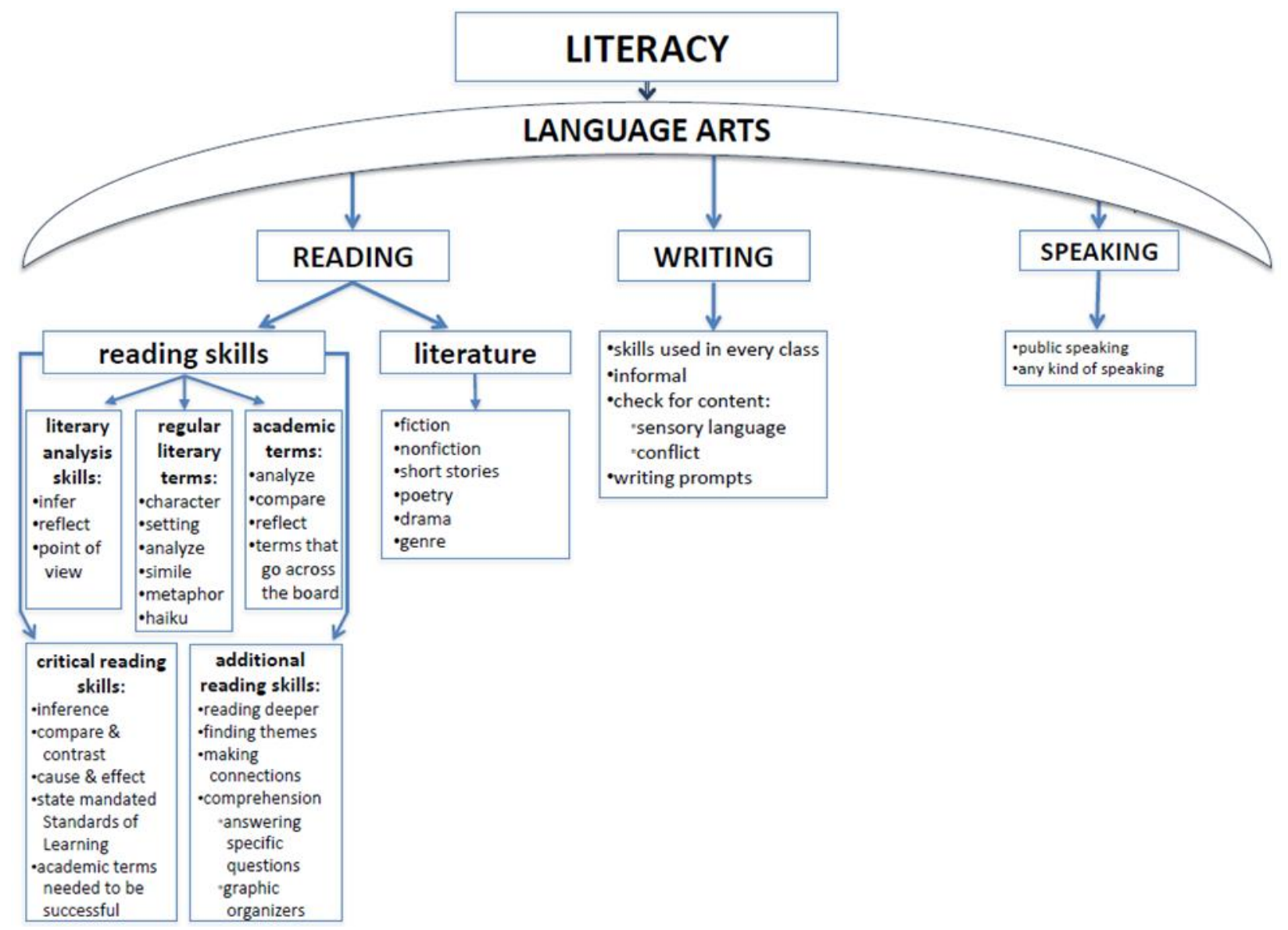

Ms. Swift drew the distinction between these different elements by explaining, "literary analysis words like infer, reflect, ... [and] point of view" are important as well as the academic terms such as "analyze, compare, reflect, [and other] things that go across the board." In addition, Ms. Swift referred to other elements needed for developing reading skills, which she referred to as "regular" literary terms. According to Ms. Swift, these include terms that can be associated with the English class and include character, setting, characterization, analyze, simile, metaphor, and haiku. As Ms. Swift described these various terms associated with literacy, she acknowledged, "I guess I would put the emphasis on the academic terms that can go across the 
board because if they know those,,. at least they have a starting point. But they're equally important."

While describing her perception of reading, Ms. Swift described a few critical reading skills she believes need to be taught in the English classroom. These include inference, where students "take clues and draw conclusions based on a guess;" compare and contrast; cause and effect; and other skills that "are part of our SOLs [state mandated Standards of Learning]." In conjunction with these skills, Ms. Swift also remarked that there are a variety of "academic terms that [students] have to know in order to be successful" since these "are things that apply across pretty much everything you $[$ sic $]$ read."

As she further clarified her perception of reading skills, Ms. Swift indicated that reading involves "reading deeper into things as opposed to just reading in general." She explained that reading deeper involves making "those kind of connections, things that you [sic] don't see with just a first reading." These connections may include "things in their lives, or maybe in history." Additionally, Ms. Swift believes that reading skills incorporate comprehension, which involves asking students "specific questions about a passage and they have to either come up with the answers on their own or with a partner." Ms. Swift also noted that reading comprehension may also involve "things like graphic organizers."

In addition to these reading skills, which make up one portion of the construct "reading," Ms. Swift believes that reading is also divided into literature. She explained, "when I think of language arts, I usually think of reading,... I guess reading breaks down into reading skills and literature because literature's gotta be a part of it too." As Ms. Swift made reference to literature, she mentioned various forms of literature such as fiction, nonfiction, short stories, poetry, drama, and studying the various genres associated with literature. 
Next, from Ms. Swift's perception, the construct "language arts" also has "an emphasis on writing." She explained that writing is another skill that is "used in every single class." She further clarified, writing is "sort of the baseline of every other academic course [students are] going to take." From Ms. Swift's perspective, writing involves tasks such as "respond[ing] to a prompt," developing "organization," having "voice," and applying "elaboration" skills, which involves "including details that actually help the story rather than just listing a bunch of adjectives."

Lastly, Ms. Swift conveyed the importance of speaking, noting that "there should be an element of speaking.... Public speaking or any kind of speaking." As Ms. Swift described the role speaking plays in her paradigm of literacy, she noted tasks such as talking as a class about books, "talking about the elements of fiction," "talk[ing] about how good writers" write, and "talk[ing] about [passages] together." As Ms. Swift reflected on the types of activities she integrates in her classroom, she underscored the importance of providing "class time for discussion," whether that discussion is focused on a novel or on "specific questions about a passage."

\section{Manifestations of Literacy in Ms. Swift's Instructional Practices}

As described previously (and portrayed in Figure 7), Ms. Swift's beliefs about literacy are broken into three fundamental elements: reading, writing, and speaking, each of which falls under the overarching construct, language arts. In the following section, each of these characteristics are described in greater detail with examples taken directly from classroom observations to demonstrate how these literacy beliefs are manifested in Ms. Swift's instructional practices. The following facets of literacy (taken from Ms. Swift's definition of literacy above) 
are detailed: language arts, reading, writing, and speaking (see Tables $9-18$ for comparisons of Ms. Swift's stated beliefs and instructional practices observed in her classroom).

Language arts. The construct "language arts" is viewed by Ms. Swift as being the primary construct under which all other beliefs about literacy exist. Although Ms. Swift never provided a precise definition of the term "language arts," this was the first term mentioned as Ms. Swift described her role as a teacher of English and literacy. As she described the types of tasks she must focus on in her instruction, she explained that her focus is "mainly language arts. ... different literary terms, reading deeper into things as opposed to just reading in general.... [and] I also see the language arts ... as having an emphasis on writing.... [and] an element of speaking." Ms. Swift described this focus "on the language arts" as including "poetry terms,... literary terms, ... [and] helping them $[$ sic $]$ with their reading skills,... comprehension and the reading deeper."

Although the precise meaning of the term "language arts" itself remains ambiguous and cannot be directly described in the context of this investigation, each of the elements associated with this construct can be revealed through Ms. Swift's instructional practices. In order to identify each of the fundamental elements of literacy Ms. Swift associated with literacy and her language arts perspective, all data collected during the interviews and classroom observations were analyzed in an effort to locate evidence of this perspective in her instruction. As portrayed in Table 9, Ms. Swift associated specific elements of her literacy beliefs with language arts. Table 9 includes direct quotes made by Ms. Swift during the interview process as well as direct quotes from classroom instruction, which demonstrate her literacy beliefs associated with the language arts perspective. This analysis revealed the most definitive example of Ms. Swift's beliefs during the classroom observations that occurred during the pilot study. Across these two 
observations, Ms. Swift introduced a novel unit to her class. For her novel unit, Ms. Swift chose to utilize a modified literature circle approach in which her class was broken down into six predetermined reading groups. Each group had no fewer than three, but no more than four students per group. The groups were assigned a pre-determined novel, each of which was set during the Great Depression. Students were given an opportunity to choose one of four different roles to assume throughout the novel study - discussion leader, recorder, participation officer, or project coordinator (although only groups of four had the opportunity to choose the project coordinator role).

Throughout the course of the classroom observations of this literature circle unit, evidence of each of the major elements of literacy were revealed. Students were actively engaged with literature and reading and also applied various reading skills including literary analysis, use of literary terms, and use of academic terms. Each student was assigned a novel and discussion group to which he/she was responsible for reading and participating in throughout the novel study. During these instructional activities, every student was given responsibility for various tasks that involved writing and all students were given time to participate in small group discussions. This literature circle unit epitomizes the notion of language arts, as viewed from Ms. Swift's perspective, because each of the elements she described were integrated into this unit. The following sections describe each of Ms. Swift's perceived facets of literacy and detail how each of these elements of literacy were manifested through this literature circle novel unit. Reading. As Ms. Swift described her views about literacy during the interview process, she described reading as a foundational element of literacy that is vital for success across all other subject areas. Reading emerged as a primary element of Ms. Swift's beliefs as she initially defined literacy in simple terms as "the ability to read and write." As she delved deeper into her 
Table 9

Comparison of Ms. Swift's Stated Beliefs about Language Arts and Instructional Practices Observed

\begin{tabular}{|c|c|c|c|}
\hline $\begin{array}{l}\text { Component of } \\
\text { literacy }\end{array}$ & Statements from interviews & Statements from observations & $\begin{array}{l}\text { Alignment } \\
\text { between beliefs } \\
\text { and practices }\end{array}$ \\
\hline $\begin{array}{l}\text { Language } \\
\text { Arts }\end{array}$ & $\begin{array}{c}\text { "when I think of language arts, I usually } \\
\text { think ... literature because literature's } \\
\text { gotta be a part of it too." } \\
\text { "I also see the language arts ... as having } \\
\text { an element of speaking." } \\
\text { "language arts ... almost has a two-fold } \\
\text { mentality. There's our set of vocabulary } \\
\text { words like fiction/nonfiction, haiku, point } \\
\text { of view, those type of things that really } \\
\text { they're just lists of vocabulary words; but } \\
\text { then on the other branch of that, I mean, } \\
\text { our content literacy deals with analyze, } \\
\text { compare, reflect, um, things that go across } \\
\text { the board. But since we are teaching } \\
\text { reading skills we have to particularly focus } \\
\text { on applying to English class." }\end{array}$ & $\begin{array}{l}\text { ambiguous and nondescript - not clearly defined } \\
\text { "This week you'll have a certain amount of chapters or pages that you'll have } \\
\text { to read and be prepared for next Tuesday when you join your group" } \\
\text { "some people are going to do a poster for their project. Do you remember Part } \\
1 \text { you're telling me about the plot characters and set? Okay? This [inaudible] } \\
\text { book report without being the boring handwritten book report. So this is } \\
\text { Griffin's book report. He's telling me about the characters, he's telling me } \\
\text { about the setting. And then when you open this, he's telling me the plot. } \\
\text { Okay?" } \\
\text { "Your books are out and you are reading. I'm going to be calling up to me one } \\
\text { at a time to talk about the book that you're doing for your project and then - so } \\
\text { bring your book up when I call you.... So as you guys could tell, I was going } \\
\text { through and checking up on your progress with your reading and helping you } \\
\text { situate how much you need to read each night in order to stay on target. How } \\
\text { many of you are worried about finishing your book?" } \\
\text { "by the time you get back from Thanksgiving break, that's when we start } \\
\text { working on our project. That's when I start having conferences with you } \\
\text { talking about your project". }\end{array}$ & unidentifiable \\
\hline
\end{tabular}


descriptions of literacy, she revealed that reading is a multi-faceted element that "breaks down into reading skills and literature," with reading skills being divided even further into literary analysis skills, "regular" literary terms, "academic" terms, and other skills that are essential to reading. These subcomponents of literacy are described in the sections following this description of reading manifestations (and portrayed in Tables $10-16$ ).

During the pilot study, Ms. Swift's literature circle novel unit provided an example of how reading was integrated into her instructional practices. During the literature circle unit, each student was assigned to a group and given a specific book to read. Ms. Swift explained the reading assignments by telling the students, “This week you'll have a certain amount of chapters or pages that you'll have to read and be prepared for next Tuesday when you join your group" for the book discussion. She explained the expectation to the class in this manner: If you're reading Roll of Thunder ... chapters one through three; that's what you're responsible for. If you're reading Witness pages three through thirty-one, that's what you're responsible for.... And if you're reading Out of the Dust pages three through fiftynine. All of these books take place during the Great Depression; that's what they have in common. Actually, Witness is a little bit before, but a lot of the issues they talk about ... have to do with the Great Depression.

In an effort to encourage all students to complete the reading and actively participate in this novel unit, each student was given the opportunity to choose a role to take responsibility for and students were given additional tasks to complete and share with their literature circle groups. During the subsequent novel discussion day (which was the second observation of the pilot study), field notes and an audio recording of the observation revealed that students appeared to have read the material assigned because as the teacher circulated from group to group, active 
conversations associated with the book were observed. Two of the three groups within close proximity to my location during this observation were on-task, asking each other questions, flipping through the book sharing statements from the text to support their answers, and debating the issues under investigation using various statements from the text in support of their answers.

During both the pilot study and the current investigation, manifestations of Ms. Swift's beliefs about reading were evidenced. She provided time for students to read in school, created assignments for students to read out of school, and provided multiple types of activities for students to practice their reading.

Reading skills. From Ms. Swift's perspective, reading is an element of literacy that can be broken down into two components: reading skills and literature. Ms. Swift explained that in her English classroom, she has come to the realization that although "by sixth grade [students] should know the basics of reading, obviously there are those who don't," therefore, she has to help students "with their reading skills." As she described the various reading skills her students need, she broke these skills down into distinct subcomponents that are needed for success. She described these subcomponents as literary analysis skills, regular literary terms, academic terms, reading skills that are critical for reading success, and additional reading skills that contribute to the reading process. Each of these subcomponents was defined in Ms. Swift's definition of literacy above and is exhibited through direct quotes in Tables 10-15. As Ms. Swift taught her modified literature circle unit, she was able to integrate many of the subcomponents she described as being associated with reading skills. These subcomponents are described in each of the subsections below. 
Table 10

Comparison of Ms. Swift's Stated Beliefs about Reading Skills and Instructional Practices Observed

\begin{tabular}{|c|c|c|c|}
\hline $\begin{array}{c}\text { Component of } \\
\text { literacy }\end{array}$ & Statements from interviews & $\begin{array}{c}\text { Statements from } \\
\text { observations }\end{array}$ & $\begin{array}{l}\text { Alignment between } \\
\text { beliefs and practices }\end{array}$ \\
\hline \multirow[b]{3}{*}{ Reading } & \multicolumn{3}{|c|}{ Reading Skills } \\
\hline & $\begin{array}{l}\text { "I guess reading breaks down } \\
\text { into reading skills...." }\end{array}$ & $\begin{array}{l}\text { ambiguous and nondescript - } \\
\text { not clearly defined }\end{array}$ & unidentifiable \\
\hline & $\begin{array}{l}\text { "to read without having - } \\
\text { without me having to tell them } \\
\text { to read. Just read on your own." }\end{array}$ & $\begin{array}{l}\text { "Your books are out and you } \\
\text { are reading." [in class } \\
\text { students had to be reminded } \\
\text { to open books to read } \\
\text { silently] }\end{array}$ & NO \\
\hline
\end{tabular}

Literary analysis skills. As Ms. Swift described her beliefs about reading, she indicated that reading skills are an important facet of reading, with literary analysis skills being a subcomponent of reading skills. Ms. Swift defined her beliefs about this topic when she stated, "literary analysis words like infer, reflect,... [and] point of view" are important (as indicated in Table 11). During the literature circle novel unit students were assigned novels to read and discuss with their assigned group. During the first discussion cycle of the literature circle unit, Ms. Swift circulated from group to group to listen in and to guide the discussions on occasion. As Ms. Swift stopped to talk with a group who was actively engaged in a discussion of the book, she encouraged the students to infer information from the novel. She encouraged the group by stating, "Go back to chapter two ... look at what [inaudible] talks about and predict ..." [some conversation is inaudible] "but it doesn't happen in chapter three, it happens in ..." "what do you think ...." These questioning prompts helped students apply literary analysis skills such as inferring and reflecting, each of which Ms. Swift identified as elements of her perception of literary analysis skills. 
Table 11

Comparison of Ms. Swift's Stated Beliefs about Literary Analysis Skills and Instructional Practices Observed

\begin{tabular}{|c|c|c|c|}
\hline $\begin{array}{c}\text { Component of } \\
\text { literacy }\end{array}$ & Statements from interviews & $\begin{array}{c}\text { Statements from } \\
\text { observations }\end{array}$ & $\begin{array}{l}\text { Alignment between } \\
\text { beliefs and practices }\end{array}$ \\
\hline \multicolumn{4}{|c|}{ Literary Analysis Skills } \\
\hline Reading & $\begin{array}{c}\text { "I think the literary analysis } \\
\text { words like infer, reflect, those } \\
\text { type of things are incredibly } \\
\text { important; but you know, you } \\
\text { can't cut out things like point of } \\
\text { view" }\end{array}$ & $\begin{array}{l}\text { "Go back to chapter two ... } \\
\text { look at what [inaudible] talks } \\
\text { about and predict ..." [some } \\
\text { conversation is inaudible] } \\
\text { "but it doesn't happen in } \\
\text { chapter three, it happens in } \\
\text {.." "what do you think ..." } \\
\text { [prompts helped students } \\
\text { apply literary analysis skills } \\
\text { such as inferring and } \\
\text { reflecting] }\end{array}$ & YES \\
\hline
\end{tabular}

Regular literary terms. From Ms. Swift's perception, another subcomponent of reading skills is what she referred to as regular literary terms (see Table 12). These include terms such as character, setting, characterization, analyze, simile, metaphor, and haiku. It was this particular set of reading skills that was most easily identified in Ms. Swift's instructional practices. As Ms. Swift introduced the novel unit, she explained to the class that as they read the novel, one of their assignments was to complete a characterization chart. She explained,

The other thing you'll be responsible for is coming up with one of these [pointing to a document being projected onto the SMARTBoard] and I will give you this paper at the end of class. You're gonna write down the name of your main character. For Roll of Thunder Hear My Cry your main character is Cassie; if you want to write that on your paper now you may. For Out of the Dust your main character is Billie Jo.... And for Witness I'm going to give you a choice. You can do Leonora; ... you can do Esther, or you can do Sara.... In fact, I'll throw in a boy in there, too, you can do ... Merlin. 
In addition to this task that each student completed prior to the discussion session, students were also encouraged to "write down the names of the characters and setting of your book" prior to the beginning of the first literature circle discussion. Throughout this novel study students were encouraged to locate, identify, and share information associated with these literary terms.

Table 12

Comparison of Ms. Swift's Stated Beliefs about Regular Literary Terms and Instructional Practices Observed

\begin{tabular}{|c|c|c|c|}
\hline $\begin{array}{c}\text { Component of } \\
\text { literacy }\end{array}$ & Statements from interviews & $\begin{array}{c}\text { Statements from } \\
\text { observations }\end{array}$ & $\begin{array}{l}\text { Alignment between } \\
\text { beliefs and practices }\end{array}$ \\
\hline \multirow{3}{*}{ Reading } & \multicolumn{3}{|c|}{ Regular Literary Terms } \\
\hline & $\begin{array}{l}\text { "the regular literary terms ... } \\
\text { look at all the terms together, } \\
\text { and then as we go through the } \\
\text { individual stories, or pieces of } \\
\text { literature, we'll identify those } \\
\text { terms inside.... We take it into } \\
\text { the text itself." }\end{array}$ & $\begin{array}{l}\text { "You're gonna write down } \\
\text { the name of your main } \\
\text { character. For Roll of } \\
\text { Thunder Hear My Cry your } \\
\text { main character is Cassie; if } \\
\text { you want to write that on } \\
\text { your paper now you may. } \\
\text { For Out of the Dust your } \\
\text { main character is Billie Jo.... } \\
\text { And for Witness I'm going to } \\
\text { give you a choice. You can } \\
\text { do Leonora; ... you can do } \\
\text { Esther, or you can do Sara.... } \\
\text { In fact, I'll throw in a boy in } \\
\text { there, too, you can do ... } \\
\text { Merlin.” }\end{array}$ & YES \\
\hline & $\begin{array}{c}\text { "the regular literary terms ... } \\
\text { You know, like, ok, who is the } \\
\text { character in this? What is the } \\
\text { setting in this?" }\end{array}$ & $\begin{array}{c}\text { "write down the names of the } \\
\text { characters and setting of your } \\
\text { book" }\end{array}$ & YES \\
\hline
\end{tabular}

Academic terms. A third subcomponent of reading skills that Ms. Swift believes to be necessary for reading is what she referred to as "academic terms that [students] have to know in order to be successful." Ms. Swift defined these terms as including "analyze, compare, reflect, [and other] things that go across the board" (see Table 13). During the literature circle novel unit, Ms. Swift assigned a characterization chart for each of the students to complete. This task 
encouraged each student to apply his/her analysis skills. As she introduced this chart to the class, she said, "I'm going to give you this characterization chart" and on this chart

You are going to tell me about your character. First, you are going to say something that your character said and then tell me what you learned about the character from that.... What your character looks like and what that tells you about them. Something your character thinks, what that tells you about them; something someone else says about the character and what we learn about your character from that and finally something that your character does. So five things about your character - something they say, something they do, something they think, something about how they look, and what someone else says about them.

By having the students return to the text to break the narrative down into meaningful statements about the main character, then examine the meaning of these statements to determine what these pieces convey about the main character, Ms. Swift encouraged students to analyze the text in meaningful ways as they drew inferences about the main characters.

Critical reading skills. Ms. Swift's description of reading skills included a few skills she believed to be critical for success in reading (see Table 14). As she considered these critical reading skills, Ms. Swift noted that inference, where students "take clues and draw conclusions based on a guess;" compare and contrast; cause and effect; and other skills that "are part of our SOLs [state mandated Standards of Learning]" are each important in this process. As the example above illustrated, Ms. Swift encouraged her students to apply a variety of the skills she believes to be critical for reading, such as inference and analysis. In addition, during the first discussion session, students were given several tasks to complete during approximately a 30minute discussion of the novel. The fourth step in this process was to "discuss this character 
chart that you did for homework and talk about how" these charts were similar of different.

Students were encouraged to compare their answers and to "fix each other's" answers through

this discussion.

Table 13

Comparison of Ms. Swift's Stated Beliefs about Academic Terms and Instructional Practices Observed

\begin{tabular}{|c|c|c|c|}
\hline $\begin{array}{c}\text { Component of } \\
\text { literacy }\end{array}$ & Statements from interviews & $\begin{array}{c}\text { Statements from } \\
\text { observations }\end{array}$ & $\begin{array}{l}\text { Alignment between } \\
\text { beliefs and practices }\end{array}$ \\
\hline \multirow[b]{3}{*}{ Reading } & & Academic Terms & \\
\hline & $\begin{array}{l}\text { "I would put the emphasis on the } \\
\text { academic terms that can go } \\
\text { across the board because if they } \\
\text { know those, at least they can, at } \\
\text { least they have a starting point." }\end{array}$ & $\begin{array}{l}\text { ambiguous and nondescript - } \\
\text { not clearly defined }\end{array}$ & unidentifiable \\
\hline & $\begin{array}{l}\text { "our [academic terms] deals [sic] } \\
\text { with analyze, compare, reflect, } \\
\text { things that go across the board" }\end{array}$ & $\begin{array}{l}\text { "You are going to tell me } \\
\text { about your character. First, } \\
\text { you are going to say } \\
\text { something that your character } \\
\text { said and then tell me what } \\
\text { you learned about the } \\
\text { character from that... What } \\
\text { your character looks like and } \\
\text { what that tells you about } \\
\text { them. Something your } \\
\text { character thinks, what that } \\
\text { tells you about them; } \\
\text { something someone else says } \\
\text { about the character and what } \\
\text { we learn about your character } \\
\text { from that and finally } \\
\text { something that your character } \\
\text { does. So five things about } \\
\text { your character - something } \\
\text { they say, something they do, } \\
\text { something they think, } \\
\text { something about how they } \\
\text { look, and what someone else } \\
\text { says about them." }\end{array}$ & YES \\
\hline
\end{tabular}

At one point during this discussion cycle, Ms. Swift met with a group who appeared to be engaged in an active discussion of the characterization chart. Ms. Swift joined this group and told the students, "Awesome, just agree to disagree; you guys are definitely ... [inaudible] what 
do you think of, do you remember that conversation? [inaudible - character's name] says ... what about this?" This group appeared particularly interested in commenting on each other's statements and were quite engaged in this conversation, comparing and contrasting the answers on their characterization chart. Throughout this discussion process, students were involved in conversations that provided opportunities for inferring, comparing and contrasting, and applying other reading skills Ms. Swift would likely identify as being critical for success in reading.

Table 14

Comparison of Ms. Swift's Stated Beliefs about Critical Reading Skills and Instructional Practices Observed

\begin{tabular}{|c|c|c|c|}
\hline $\begin{array}{c}\text { Component of } \\
\text { literacy }\end{array}$ & Statements from interviews & $\begin{array}{l}\text { Statements from } \\
\text { observations }\end{array}$ & $\begin{array}{l}\text { Alignment between } \\
\text { beliefs and practices }\end{array}$ \\
\hline \multirow{3}{*}{ Reading } & \multicolumn{3}{|c|}{ Critical Reading Skills } \\
\hline & $\begin{array}{l}\text { "inference is one that they have } \\
\text { to know. They have to be able to } \\
\text { take clues and draw conclusions } \\
\text { based on a guess" }\end{array}$ & $\begin{array}{l}\text { "I'm going to give you this } \\
\text { characterization chart" [this } \\
\text { chart - as described } \\
\text { previously - required } \\
\text { students to provide specific } \\
\text { statements about the } \\
\text { characters in the novel and to } \\
\text { infer what these statements } \\
\text { mean to them] }\end{array}$ & YES \\
\hline & $\begin{array}{l}\text { "I teach some of the skills, like } \\
\text { the ones I've mentioned, infer, } \\
\text { compare and contrast, cause and } \\
\text { effect, because those are part of } \\
\text { our SOLs [Standards of } \\
\text { Learning]." } \\
\text { "need to focus more ... [on] the } \\
\text { academic terms that they have to } \\
\text { know in order to be successful." }\end{array}$ & $\begin{array}{l}\text { "discuss this character chart } \\
\text { that you did for homework } \\
\text { and talk about how [these } \\
\text { charts are similar or } \\
\text { different]" } \\
\text { ambiguous and nondescript - } \\
\text { not clearly defined }\end{array}$ & unidentifiable \\
\hline
\end{tabular}

Additional reading skills. As Ms. Swift clarified her beliefs about reading skills she mentioned that reading involves "reading deeper into things as opposed to just reading in general," which involves making "those kind of connections, things that you [sic] don't see with just a first reading." She explained that these connections may include "things in their lives, or 
maybe in history." Additionally, Ms. Swift explained that reading skills incorporate comprehension, which involves asking students "specific questions about a passage and they have to either come up with the answers on their own or with a partner." In addition, Ms. Swift also mentioned that "things like graphic organizers" contribute to the development of reading skills.

Throughout Ms. Swift's literature circle novel unit, each of the elements of this component of reading skills was identified during the classroom observation cycle. For instance, the use of the characterization chart (described previously) employed a graphic organizer that provided an opportunity for students to organize their thinking in response to the reading. Students were also given a specific list of comprehension questions to discuss during the group discussion session. Ms. Swift told the class, "All of the books have the same four discussion questions. You all will discuss the questions." In addition, Ms. Swift made note of the fact that each of the novels she chose for this unit had a common theme, explaining, "They all take place in the 1930s during the Great Depression, except for, Witness," which she noted, takes place "a little bit before, but a lot of the issues they talk about ... have to do with the Great Depression.” It appeared that Ms. Swift planned to draw connections between these novels, although through the course of these two observations, this task was not evidenced. Although this specific connection was not observed explicitly (it was merely implied as Ms. Swift described the connection between the novels), all other elements Ms. Swift described in association with these additional reading skills were observed during the course of this literature circle novel unit (as evidenced in Table 15). 
Table 15

Comparison of Ms. Swift's Stated Beliefs about Additional Reading Skills and Instructional Practices Observed

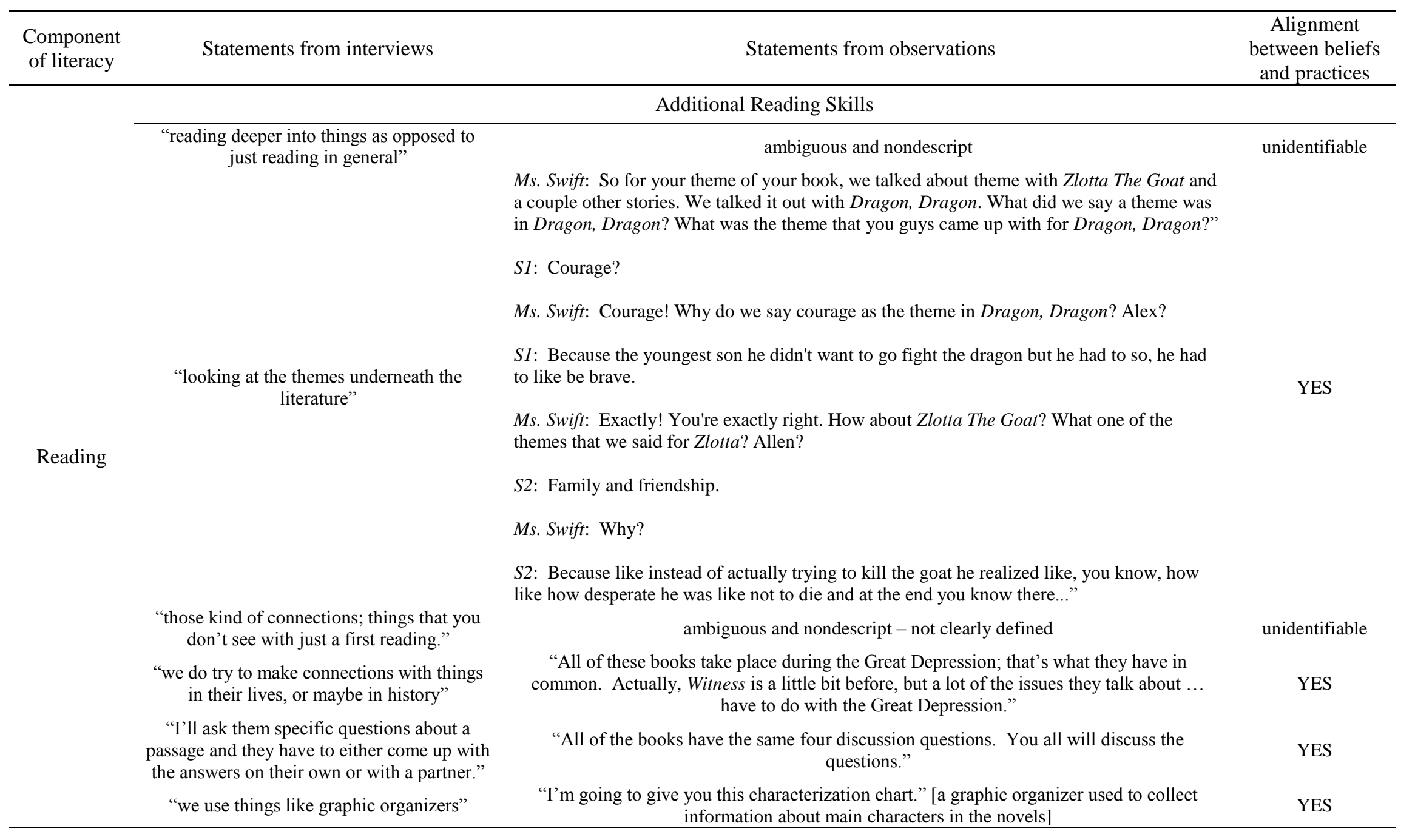


Literature. In addition to the reading skills described above, which make up one component of Ms. Swift's beliefs about reading, Ms. Swift believes that reading is divided into a second component, literature (see Table 16). As she described how literature is integrated into her beliefs about literacy, Ms. Swift remarked, what I expected when I came to teaching ... was to be a content teacher in the area of literature. I was an English major, not an education major in college. As I have learned about the real world, I've realized that I can't teach my content if they can't read, so I've had to focus more on the skills.

She clarified this belief by stating, as an English teacher, "you [sic] have to teach the skills and then you [sic] have to apply the skills to your content area, because I'm not ready to give up that content yet." Ms. Swift described literature's role in this paradigm as she explained, I teach some of the skills, like the ones I've mentioned, infer, compare and contrast, cause and effect,... and we practice that and we read examples of it.... [Then there are] the academic terms that they have to know in order to be successful. And then ... for the regular literary terms,... we practice that and we read examples of it. ... We'll look at all the terms together, and then as we go through the individual stories, or pieces of literature, we'll identify those terms inside. ... like, who is the character in this? What is the setting in this? We take it into the text itself."

She added,

I think that in a language arts class, it almost has a two-fold mentality. There's our set of vocabulary words like fiction/nonfiction, haiku, point of view, those type of things that really they're just lists of vocabulary words; but then on the other branch of that,... our content literacy deals with analyze, compare, reflect, things that go across the board. 
Ms. Swift explained, "since we are teaching reading skills we have to particularly focus on applying [those skills] to [literature in the] English class."

As the descriptions above revealed, Ms. Swift teaches these terms and other reading skills she believes are of value and then has students apply these skills to the literature. By assigning students to different groups and then assigning different novels associated with a common theme to each of the groups, Ms. Swift has demonstrated her interest in integrating a variety of literature into her instructional practice. During the first day of the literature novel unit as students first began exploring their novels with their groups, Ms. Swift stopped to talk with one particular group of students. This group was assigned the novel, Witness. As the students opened the novel they discovered the unique format of this novel. Ms. Swift commented to this group, "Yours is very interesting because it's written in free verse." She explained, "You don't have as much to read in Witness, but it's harder to understand." One of the students in this group questioned, "Do we have the hardest book?" to which Ms. Swift replied, "I don't know if it is the hardest, but it is difficult; so pay attention to what is happening." In addition to assigning the novel Witness, by Karen Hesse, which is written in free verse told from several characters' perspectives, Ms. Swift also assigned Out of the Dust, by Karen Hesse, which is written as firstperson free verse and differs from the format in Witness. Ms. Swift's integration of various novels written in a variety of formats demonstrates her interest in utilizing an assortment of literature to practice and apply reading skills and the reading process to her language arts instruction.

Writing. As Ms. Swift described her views about literacy, she identified writing as one of the foundational elements of literacy, explaining that writing is needed for success across all other subject areas. During the interview process, Ms. Swift indicated that she considered 
Table 16

Comparison of Ms. Swift's Stated Beliefs about Literature and Instructional Practices Observed

\begin{tabular}{|c|c|c|c|}
\hline $\begin{array}{c}\text { Component of } \\
\text { literacy }\end{array}$ & Statements from interviews & $\begin{array}{c}\text { Statements from } \\
\text { observations }\end{array}$ & $\begin{array}{l}\text { Alignment between } \\
\text { beliefs and practices }\end{array}$ \\
\hline \multirow{3}{*}{ Reading } & & Literature & \\
\hline & $\begin{array}{c}\text { "I guess reading breaks down } \\
\text { into ... literature because } \\
\text { literature's gotta be a part of it } \\
\text { too." }\end{array}$ & $\begin{array}{l}\text { "Last week I talked to you } \\
\text { about how we are going to be } \\
\text { doing novels in this class, but } \\
\text { that not everyone will be } \\
\text { doing the same novel. You } \\
\text { are the only group that has } \\
\text { three books going on in the } \\
\text { same classroom; that's pretty } \\
\text { special." }\end{array}$ & \multirow[t]{2}{*}{ YES } \\
\hline & & $\begin{array}{l}\text { "Yours is very interesting } \\
\text { because it's written in free } \\
\text { verse... You don't have as } \\
\text { much to read in Witness, but } \\
\text { it harder to understand." }\end{array}$ & \\
\hline
\end{tabular}

writing to be a primary element of her beliefs about literacy given the fact that her preliminary definition of literacy was simply "the ability to read and write." As she shared her descriptions of literacy, Ms. Swift stressed that the construct "language arts" needs to have "an emphasis on writing." Ms. Swift explained that because of its importance across the content areas, one of the goals in her English classroom is "for my class to be much more comfortable with their writing" since "what's really going to help them in the rest of their education in the rest of their life is being able to read and write."

Although a specific unit designed for teaching writing was not observed across the course of the two studies, instances of Ms. Swift's interest in engaging her students in writing were noted during the literature circle novel unit (see Table 17). As Ms. Swift introduced the novel unit and assigned her students the task of completing the characterization chart, students were required to write out the information needed to complete this characterization chart. This task required not only copying information directly from the text, but also an opportunity for students 
to write information they inferred from the analysis of these statement taken directly from the novel. In addition to this opportunity for writing information pertinent for the novel study, Ms. Swift also provided opportunities for each student to engage in writing during the novel unit. Ms. Swift told the students, "You'll write down the names of the characters and setting of your book." For each of the roles assigned for the literature circle unit, students were required to complete and submit some form of writing as evidence of the group's discussion.

Despite the fact that a writing unit was not observed during the course of this investigation, Ms. Swift explained (during the last interview of the final phase of this investigation) that she is working to facilitate greater comfort with writing for all of her students. Ms. Swift explained,

We are trying to write more, to write stuff that's not necessarily graded. It's checked for okay today we are focusing on sensory language. Do you have your sensory language? Today we are focusing on having a conflict in the story. Do you have your conflict in the story? So, that way they ... can focus on specific tasks, one at a time. And those are very informal. They'll typically do those in the first fifteen to twenty minutes of a class period and they don't have much instruction other than what's presented on the board. The brief writing tasks described previously in addition to Ms. Swift's description of her instructional processes suggest that she strives to integrate writing into her language arts instruction even when the focus of the current unit is not a specific writing activity.

Speaking. While describing her beliefs about literacy during the interview process, Ms. Swift suggested that speaking also plays a role in literacy, yet she considers this facet of literacy to include merely "an element of speaking." During the interview process, Ms. Swift explained, 
Table 17

Comparison of Ms. Swift's Stated Beliefs about Writing and Instructional Practices Observed

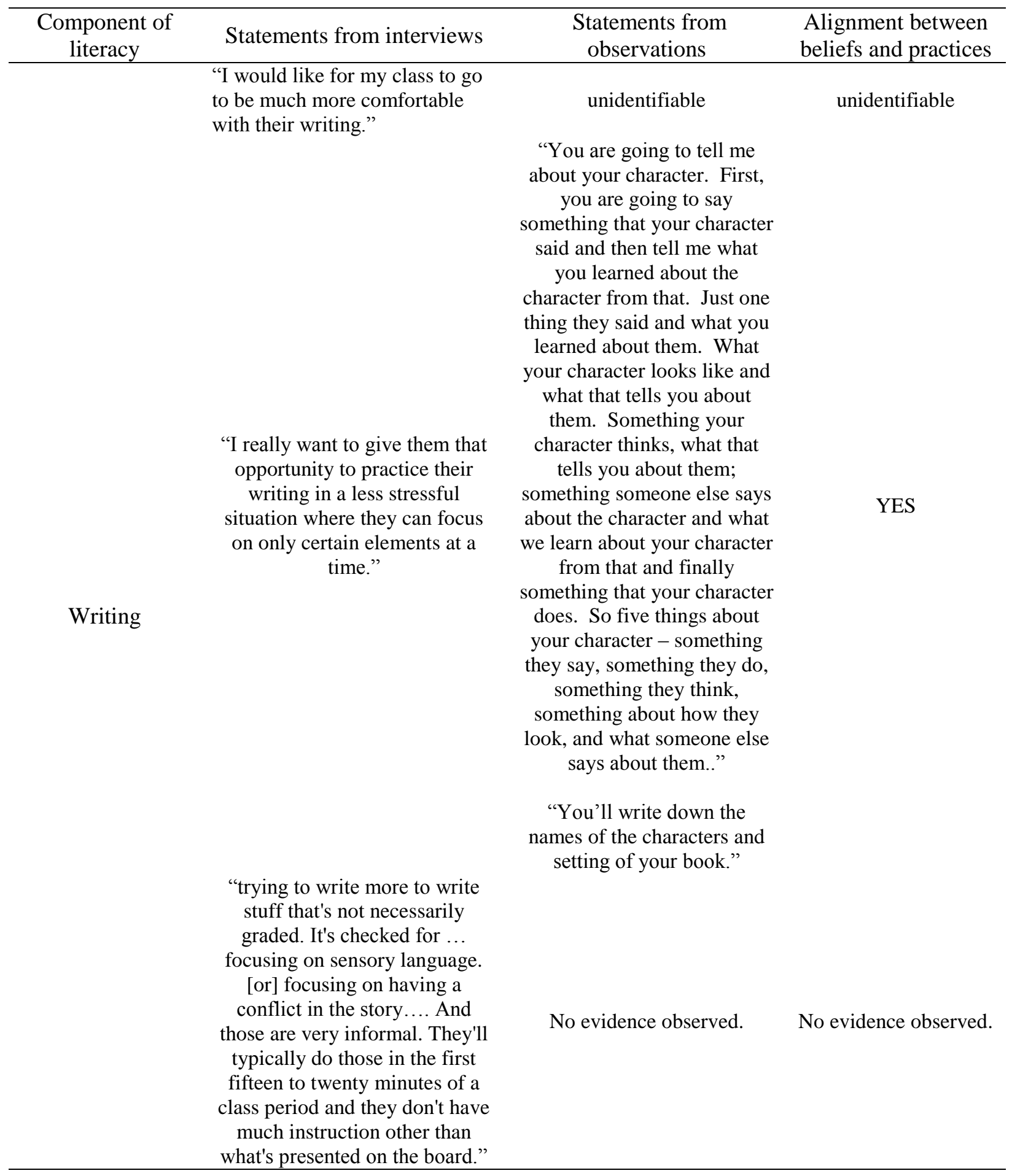


we talk about what we read. We don't ... necessarily talk about what we're thinking while we read, which is a new concept to me that I'd like to implement more this year, but we do talk about what we read. We read a little bit, we chat about it.

In addition, Ms. Swift explained, "as far as talking about the reading, sometimes we'll get into groups and they'll have a very specific, either question that they have to answer or something that they have to look for. And then often they have to share with everyone else."

In order to confirm Ms. Swift's beliefs about speaking in her classroom instructional practices, statements taken from the literature circle novel unit as well as statements from the most recent classroom observations were used to verify Ms. Swifts beliefs (as evidenced in Table 18). During the literature circle novel unit, Ms. Swift's interest in discussion was evidenced during the second observation of the pilot study. When the class began, Ms. Swift encouraged students to move into their discussion groups and reminded the students, "Who participates in the discussion?... It would be everybody, yes." She reminded the students that each group will "answer discussion questions" and that "All of the books have the same four discussion questions." She made it clear that "You all will discuss the questions." The final step of the day's discussion session was to "discuss this character chart that you did for homework" and for students to talk about similarities and differences in their charts. Ms. Swift also encouraged the students to help each other "fix" their charts if needed. After Ms. Swift guided the students through the various steps needed for completion of this discussion, so told the class, "You have a little less than thirty minutes. Pace yourself accordingly. Go ahead and start, I will give you your questions." Evidence of active, engaged discussions were observed throughout this discussion session as students worked through the discussion questions, shared information from the text to support their answers, and discussed their characterization charts with each other. 
Ms. Swift's literature novel unit provided an ideal example of how she integrates the various facets she believes to be associated with literacy into her instructional practices. The three fundamental elements Ms. Swift associated with literacy were exhibited through the classroom instruction that occurred during the literature circle novel unit. Evidence of Ms. Swift's beliefs about reading, writing, and speaking were observed, and although the overarching construct "language arts" was not explicitly defined, it is evident that the elements Ms. Swift associates with her language arts perspective were apparent in her sixth grade classroom instruction.

\section{Chapter Summary}

This chapter described the results of data analysis and the findings of this study. Two sixth grade English teachers' literacy beliefs and classroom practices were described. Each teacher shared her beliefs about literacy through multiple interviews across a two-year time span. In addition, each teacher's instructional practices were observed across five classroom observations that occurred across this two-year study. As each teacher's beliefs about literacy were described here, every effort was made to maintain the teacher's voice in the final portrayal of her beliefs about literacy while also revealing how the teacher's literacy beliefs manifest themselves in the instructional practices implemented in the sixth grade English classroom (as revealed in the comparison tables aligning each teacher's stated beliefs with her instructional practices). The forthcoming chapter describes the commonalities between the two teachers' beliefs about literacy and their instructional practices. This is contained in the discussion of findings. The final chapter also includes the conclusions drawn from these findings, implications, and recommendations for further study. 
Table 18

Comparison of Ms. Swift's Stated Beliefs about Speaking and Instructional Practices Observed

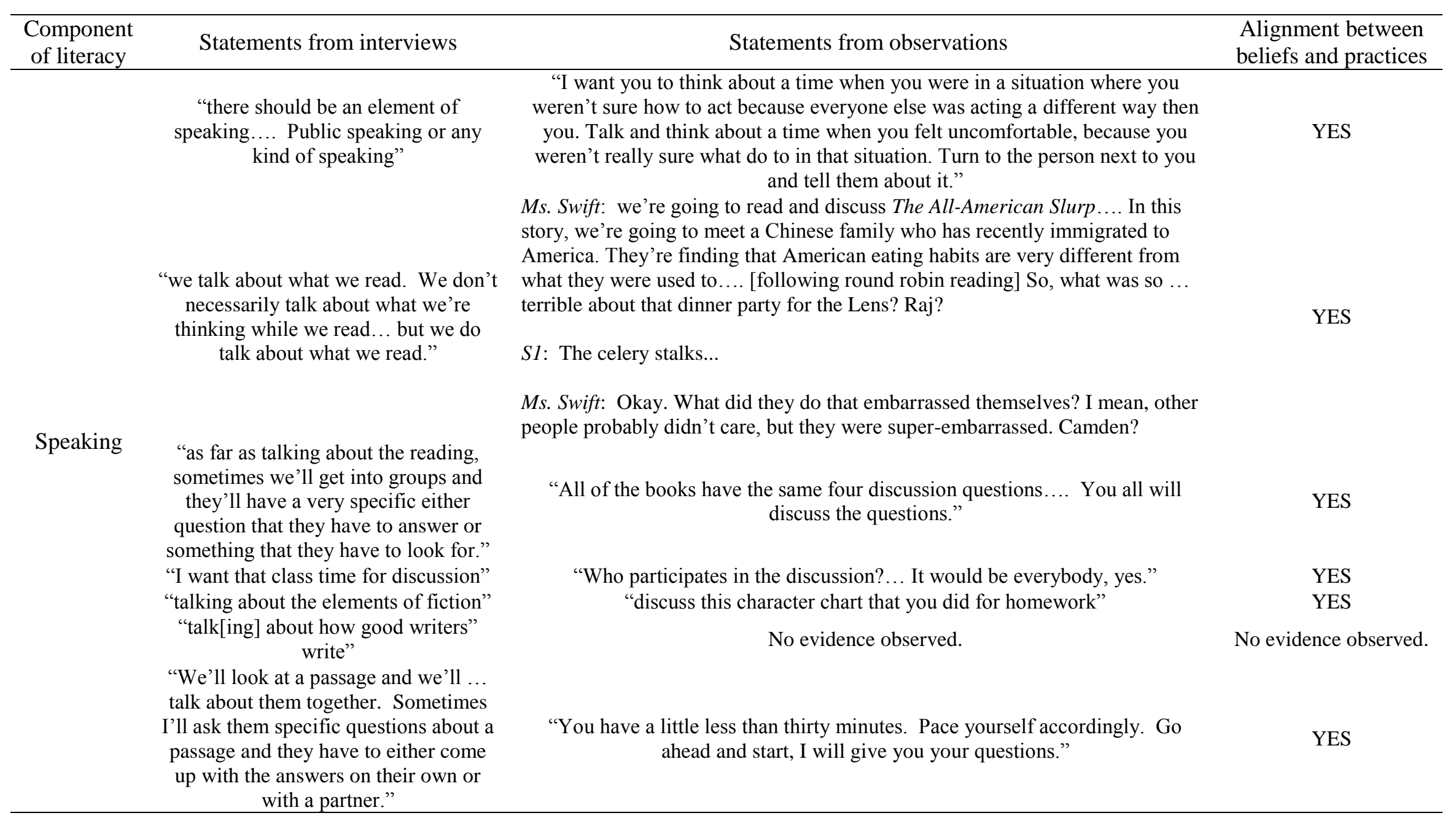




\section{Chapter Five}

\section{Discussion}

The purpose of this study was to ascertain two middle-level English teachers' beliefs about literacy and to determine how these beliefs manifest themselves in the teachers' instructional practices. Conclusions about the teachers' beliefs and instructional practices are discussed in relation to the two research questions that guided this study. In addition, implications for pre-service and in-service practice, study limitations, and recommendations for future research are discussed.

\section{Conclusions}

The conclusions drawn from the findings of this investigation are based upon the perceptions of the two teachers involved in this study and are aligned with the two research questions used to guide this study: 1) how do middle level English language arts teachers perceive and describe literacy; what are their beliefs about literacy; and 2) how are these literacy beliefs manifested in the instructional practices of the middle level English language arts teachers? Conclusion one, which is related to the first research question, is presented through a discussion demonstrating that the participants defined their literacy beliefs in terms of what they do in the classroom. Next, the conclusions related to the second research question are presented through a discussion of three conclusions: aspects of beliefs are shared; expressed beliefs do not consistently align with observed practices; and evidence of a shifting belief system emerged.

\section{Conclusion 1: Participants defined their literacy beliefs in terms of what they do in}

the classroom. Through the course of this investigation, it was evident that the teachers involved in this study had a difficult time isolating and describing their beliefs about literacy. This conclusion is supported in the research, as others have found that teachers tend to have a 
difficult time accurately articulating their beliefs (Pajares, 1992; Rokeach, 1968). Both teachers in this study linked their beliefs to a particular instructional approach rather than with a specific belief system or theoretical orientation associated with literacy (DeFord, 1985; Lenski, Wham, \& Griffey, 1998). For example, Mrs. White associated her beliefs with a skills approach to classroom instruction while Ms. Swift had difficulty isolating and describing personal beliefs about literacy because she immediately linked literacy to a language arts perspective.

Traditional beliefs about literacy. A traditional teacher is described as one who believes that specific skills are the overall goal of classroom instruction (Lenski, Wham, \& Griffey, 1998). Mrs. White's beliefs about literacy align with the traditional conception of literacy. This notion was evidenced directly when Mrs. White stated that literacy is being proficient in skills required at a specific grade level.

Classrooms associated with the traditional perspective tend to be associated with a transmission model of instruction, which is dominated by teacher talk (Lenski, Wham, \& Griffey, 1998). From this perspective, learning is considered to be something that is transmitted from a teacher, who is considered to be the "source of knowledge," to the student, who is viewed as a "blank slate" or "vessels to be filled" (Grierson \& Nokes, 2010; Lenski, Wham, \& Griffey, 1998). Although teachers who associate with this perspective may suggest that student inquiry is critical for learning, this student-centered approach is seldom evident in instructional practices (Lenski, Wham, \& Griffey, 1998). Traditional teachers tend to rely predominantly on direct instruction as their instructional approach (Grierson \& Nokes, 2010).

This traditional belief system corresponds with a mastery model of English language arts instruction. At the middle school level, research suggests that English language arts instruction generally aligns with one of three instructional approaches: the mastery model, the cultural 
heritage model, or the process model (Grierson \& Nokes, 2010; Peters \& Wixson, 2003). Rather than concentrating on literature, content, or the processes associated with literacy, the focus of mastery model English language arts instruction is on the acquisition of a disconnected assortment of skills considered to be essential for traditional reading comprehension (Grierson \& Nokes, 2010). Through this mastery model, the reading process is narrowly defined and classroom instruction is broken down into a series of desired behaviors considered to be essential to the mastery of a variety of skills linked to literacy (Grierson \& Nokes, 2010). This view of literacy tends to rely solely on traditional print literacies and is associated with the teaching of skills in a decontextualized manner that is not connected with "authentic" literature (Grierson \& Nokes, 2010). Evidence of this mastery model belief emerged frequently throughout this investigation as Mrs. White repeatedly demonstrated issues of teacher authority as well as a reluctance to release responsibility to the students in her classroom. Throughout this investigation, the vast majority of the interactions that occurred in Mrs. White's classroom were teacher-centered, relied predominantly on direct instruction, and integrated traditional printbased texts, each of which aligns with a mastery model of English language arts instruction and can be associated with a traditional conception of literacy.

Evolving beliefs about literacy. Ms. Swift's beliefs about literacy were more challenging to align with one particular belief system because it appears that her beliefs are experiencing a shift in perspective. Throughout the course of this investigation, Ms. Swift did not exhibit a clear and consistent belief system associated with literacy. Initially, Ms. Swift's beliefs appeared to align with the mastery model of English instruction because she associated literacy with classroom instruction focused on a variety of skills and literary terms, which she referred to as a language arts perspective. Evidence of this belief quickly emerged during the initial observation 
of the pilot study as Ms. Swift began class with a grammar skills worksheet review. In addition, during the final phase of the investigation, Ms. Swift integrated a round robin reading of a short story from a literature anthology, which also aligns with a traditional approach to literacy instruction.

At first glimpse, Ms. Swift's beliefs align with a traditional, skills mastery model of English instruction. Traditional classrooms generally rely on tasks such as practicing skills through workbooks and students reading aloud to the class without errors (Lenski, Wham, \& Griffey, 1998). Evidence of workbook-based instruction was substantiated through the grammar worksheet completed during the pilot study and a round robin reading occurred during the reading of the short story. Ms. Swift's classroom instruction utilized a basal reader (traditional print literacy) and she taught grammar skills in a decontextualized manner (Grierson \& Nokes, 2010). Despite this evidence of a traditional, skills mastery focused approach to instruction, it is difficult to characterize Ms. Swift's beliefs as being associated with one particular belief system or theoretical orientation to literacy. Through the course of this investigation there was also conflicting evidence of a more eclectic or varied literacy belief system in Ms. Swift's interview statements and instructional practices during both the pilot study and the most recent phase of this investigation.

A perceptible change in Ms. Swift's beliefs about literacy emerged from the pilot study to the final phase of the investigation. During the pilot study, Ms. Swift made it clear that during the novel unit she had chosen to implement a modified literature circle approach and students would be required to complete their assigned reading outside of school. Ms. Swift initially remarked that she did not want to waste class time reading a novel, instead she wanted to use 
class time for discussion. During the final phase of this study, though, a noted difference in instructional approach associated with reading emerged.

Ms. Swift shared her changing belief system as she noted that she recently came to the realization that students tend not to read outside of school. Ms. Swift explained that despite using the Accelerated Reader (AR) Program in her classroom, she still had many students who were not reading. Ms. Swift shared that she came to the eventual realization that if students are not reading outside of school, they are not reading at all. Therefore, she recognized that she needed to find a way to make time for students to read in school.

Ms. Swift explained that in response to this realization, she began reflecting on previous professional development experiences in an effort to determine an appropriate response to her concerns about her students' reading (or lack thereof). She explained that just over a year ago she heard Donalyn Miller speak at a local professional development conference. She recalled Donalyn's text, The Book Whisperer: Awakening the Inner Reader in Every Child (2009), and decided to read it over the summer months. In response to what she discovered through Donalyn Miller's book in conjunction with an increase in length of instructional class periods in her school (which were increased from 44 minutes to 58 minutes), Ms. Swift chose to increase the amount of reading her students completed in her classroom each day. Ms. Swift altered her instructional approach to provide time for her students to read books of their choice each day during class time. According to Ms. Swift, the additional ten minutes of class time added to her instructional class period created the perfect opportunity to give students time to read in class, which she noted Donalyn Miller had done in her classroom.

This noticeable change in perception as well as observations from Ms. Swift's classroom instruction during the literature circle novel unit provided evidence of a more student-centered 
approach to literacy instruction with opportunities for students to engage in the collaborative construction of understanding about the texts being read. These shifting perspectives situate Ms. Swift's beliefs about literacy in a more eclectic belief system in which teachers combine traditional elements with some elements associated with a constructivist approach (Lenski, Wham, \& Griffey, 1998).

Evidence of an eclectic approach appeared in Ms. Swift's instruction as she integrated a skills driven and "basalized" approach with opportunities for students to use their prior knowledge to construct meaning during the process of learning (Lenski, Wham, \& Griffey, 1998). It is suggested that when teachers are in the process of learning about constructivist teaching and its associated beliefs, this learning process may result in a shift in beliefs (Lenski, Wham, \& Griffey, 1998). Further, it is noted that when a teacher's beliefs are in a state of flux as a result of this evolution, his/her beliefs and instructional practices may become inconsistent (Lenski, Wham, \& Griffey, 1998). Although it cannot be determined for certain that this is what is occurring with Ms. Swift's beliefs, there is evidence that her beliefs about literacy are evolving, which may account for the lack of clarity and consistency associated with her beliefs about literacy.

Conclusion 2: Aspects of beliefs are shared. Although the two participants involved in this study portrayed their beliefs about literacy in differing ways, there were several noted similarities between their expressed beliefs. Both teachers shared similar beliefs associated with reading, writing, skills, oral communication, and literature.

Belief that reading and writing are foundational elements. The two participants involved in this study described literacy as encompassing reading and writing. Moreover, they both expressed the belief that reading and writing function as fundamental elements of literacy. 
This belief that literacy is associated with both reading and writing and that each serves as a foundational element needed for future success is one that is shared by experts in the field of literacy who align with a traditional perception of literacy. From a traditional perspective, literacy is defined in terms of the ability to fluently read and write traditional printed materials that contain words, sentences, and paragraphs (Draper \& Siebert, 2010). While current literacy researchers acknowledge the fundamental contribution that reading and writing make to literacy, these researchers advocate using reading and writing to learn rather than merely teaching the discrete skills associated with reading and writing (Draper \& Siebert, 2010; Fisher \& Ivey, 2005). From this modern-day perspective a broader view of both reading and writing are needed in order to adequately incorporate the meaning-making and meaning-representing practices associated with both traditional print-based texts as well as nontraditional texts that represent the wide array of resources or objects that may be infused with meaning (Cope \& Kalantzis, 2000; Draper \& Siebert, 2010; Grierson \& Nokes, 2010). Appleman (2009) ascertained that English teachers not only maintain responsibility for helping students improve and apply their reading and writing abilities, but must also teach students how to use reading and writing in an effort to understand the world around them.

Belief that skills are essential. The belief that skills are essential to literacy was apparent in both Mrs. White's and Ms. Swift's beliefs about literacy. Mrs. White's beliefs were defined in terms of each element of literacy being subordinate to the overarching component "skills." In similar fashion, Ms. Swift also described literacy as incorporating a variety of skills associated with reading and writing. As the previous discussion of Mrs. White's and Ms. Swift's beliefs about literacy demonstrated, both teachers' views about literacy align with a mastery model of English language arts instruction in which classroom instruction is focused on the development 
of an assortment of literacy skills (Grierson \& Nokes, 2010). This model of instruction most readily aligns with a traditional view of literacy that assumes that literacy develops through the mastery of discrete skills (Lenski, Wham, \& Griffey, 1998).

Current research suggests that this view of literacy lacks both the essential real-world application of literacy as well as the needed connection to other processes associated with literacy such as speaking, listening, viewing, creating, and producing (Grierson \& Nokes, 2010; Peters \& Wixon, 2003). Because the skills mastery approach relies predominately on traditional print-based texts, students do not have the opportunity to learn how to navigate or create meaning through a variety of text types. Current research suggests a need to shift from a skills mastery approach to a strategic approach to literacy in which students are taught to become proficient and strategic learners. The skills based approach provides isolated practice of automatic procedures used in an unconscious manner (Grierson \& Nokes, 2010; Paris, Wasik, \& Turner, 1991). These skills include tasks such as finding the main idea of a paragraph, sequencing the events from a story, or writing a summary (Dole, Nokes, \& Drits, 2009). One of the shortcomings of this skills mastery approach is that there is limited instruction regarding the meaning of these skills leaving students unable to apply these skills to their everyday reading tasks (Dole, Nokes, \& Drits, 2009; Durkin, 1978-1979).

Therefore, a cognitive and metacognitive strategic approach is promoted because through this approach, students are explicitly taught how to utilize an array of strategies that can be applied to various learning contexts. Through this approach students become strategic and proficient readers as they develop a repertoire of strategies that can be consciously and deliberately employed in order to construct meaning from a wide array of text types across all content areas (Dole, Nokes, \& Drits, 2009; Grierson \& Nokes, 2010). Through this approach, 
students learn how to employ research-based strategies such as activating prior knowledge, making connections, making inferences, questioning, visualizing, synthesizing, determining importance, and employing fix-up strategies (Grierson \& Nokes, 2010).

Belief that speaking is associated with literacy. As both teachers in this study described their beliefs about literacy, speaking or oral communication emerged as an element each teacher associated with literacy. Ms. Swift described literacy in terms of a language arts perspective, which she believed incorporates some form of speaking. Similarly, Mrs. White suggested that oral communication is an element of literacy as well.

This perspective also appears within the research about literacy. Draper and Siebert (2010) explained that "producing" or "speaking" represent a method for demonstrating meaning through the spoken word, which is referred to as a "meaning representing" practice. Additionally, Shumway and Wright (2010) posit that teachers integrate class discussions and dialogues in an effort to positively influence student understanding and interpretation of texts. Shumway and Wright described instructional techniques employed by teachers that are purposefully designed to provide opportunities for students to meet in collaborative groups as they work together to better understand the texts encountered in the classroom. This approach was evidenced in both Mrs. White's and Ms. Swift's classrooms during the literature circle novel units. Both teachers chose specific roles for their students to assume as the students met on a weekly basis to discuss the assigned reading with groups of students reading the same novel. This method of discussion and collaborative dialogue aligns with approaches described in the research supporting this facet of literacy.

Atheoretical perspective of literature. As the two teachers in this study described their literacy beliefs, literature emerged as an element that both associated with literacy. Despite the 
fact that both teachers made reference to literature in conjunction with their beliefs about literacy, neither teacher described literature in a manner that provided a clear and unambiguous understanding of her beliefs about literature's role in literacy. The lack of clarity and minimal description regarding literature's role in literacy conveys the notion that both teachers' beliefs about literature appeared atheoretical in terms of literature use, as neither teacher explicitly expressed a particular theoretical stance toward literature or its uses in the English classroom.

Although Mrs. White made a specific reference to using classic literature in her classroom, it is not clear if her beliefs about literacy align completely with the cultural heritage model of English instruction. According to Grierson and Nokes (2010), teachers who align with this perspective tend to rely on classic novels that have been used across decades of English instruction because these novels provide students with an opportunity to understand and value the themes and unique language expressed through classic works. Instead of positioning literature as serving an influential role in literacy, it appeared that the teachers in this study focused solely on the reading of the literature rather than on interpretation and critique of the literature (Appleman, 2009; Scholes, 1985).

Evidence of this approach to reading occurred throughout this investigation. When both teachers involved in this study introduced their novel units, both chose a variety of historical fiction novels that were set during the Great Depression. As the teachers introduced the novels to their students, they simply situated these texts within the setting of the Great Depression, with no other discussion about how these texts portray this era. Neither teacher developed background for the students and both simply shared with the students that the Great Depression was the common link between the novels. In both of these classrooms, neither teacher referenced any form of interpretation or critique of these texts. Further, Mrs. White and Ms. 
Swift did not prepare the students in any other manner for interpreting or critiquing the texts.

The teachers simply provided the novels, assigned a number of pages or chapters to read, and a literature circle role or other task to complete. It appears that both teachers involved in this study did as Appleman (2009) predicted; both teachers appear to have merely assigned the reading to the students with little focus on a critical approach to the reading task, merely suggesting a single interpretive stance (the Great Depression) from which the students were to view these texts.

\section{Conclusion 3: Expressed beliefs do not consistently align with observed practices.}

The analysis of the participants' beliefs about literacy revealed instructional practices and/or belief statements that were incongruous to the teachers' professed beliefs about literacy. The most notable inconsistency that emerged during this investigation was the alignment between the teachers' beliefs and practices. The teachers' espoused beliefs did not always align with their instructional practices. Mrs. White's expressed beliefs were rarely observed during classroom instruction, while Ms. Swift's stated beliefs and classroom instruction aligned more consistently in the data.

The misalignment between Mrs. White's stated beliefs and observed practices revealed a preponderance of traditional, mastery model instructional approaches in the classroom despite professed beliefs that contradicted this perspective. For instance, although Mrs. White stated the belief that students need to spend more time working in collaborative, discussion-based groups, Mrs. White made it clear to her students that if they did not demonstrate active engagement in focused discussions about the novels assigned, she would have to "take over" and students would be forced to do exactly as she says. From Mrs. White's perspective, this level of authority and control in the classroom was what she believed encouraged students to "pay attention" in class. Mrs. White also made it clear to her students that she was reluctant to release responsibility for 
novel discussions to the students. Although Mrs. White attempted to integrate a more studentcentered instructional approach not associated with the traditional mastery model of instruction during the pilot study, it was evident that this approach was one that Mrs. White found uncomfortable, leading her to integrate a variety of steps to maintain control over the students' interactions and overall learning during this unit.

Despite attempting to integrate a literature circle novel unit during the pilot study, it was revealed during the final phase of the investigation that Mrs. White had returned to her typical whole-class novel unit approach. The classroom interactions observed during this phase of the study revealed classroom discussions dominated by teacher talk with minimal opportunity for student response. During these discussions when students had a difficult time arriving at the answers desired by Mrs. White, she would simply provide the answer and then move on to the next series of questions.

Several additional inconsistencies between Mrs. White's articulated beliefs about literacy and her observed instructional practices emerged throughout the course of this investigation. These inconsistencies included an expressed belief in providing students with an "inordinate amount of time" for reading, yet classroom observations revealed little to no time for reading in school. Mrs. White also professed the belief that students need to provide textural support for their answers, yet this belief was not supported by observations that occurred during classroom instruction. Instead, classroom discussions of the novel being read progressed quickly through a series of questions provided by Mrs. White with no opportunity for students to return to the text to show textural support for answers. During observed classroom interactions in which the students and teacher engaged in a text-based discussion, Mrs. White prompted students in an effort to lead them to an understanding about the text, but when students were unable to arrive at 
the desired answer, Mrs. White simply stated the answer and explained her thoughts about the answer. Along a similar line, Mrs. White stated during interviews that providing wait time for students is important during classroom discussions, yet this belief was not evidenced during the classroom discussion interchanges that occurred during the classroom observations. Mrs. White seldom provided wait time and would instead continue prompting by rewording questions, giving another question prompt, or calling on different students to attempt an answer.

Another noted inconsistency emerged during the literature circle unit in Mrs. White's classroom. Mrs. White explained that she chose the literature circle roles because she needed roles that were differentiated to meet students' needs, yet she also explained that the students have to change roles throughout this process. Mrs. White noted that she kept track of which roles had been completed by each student in an effort to keep students from repeating roles. This checklist approach in which students were required to complete each task is counterproductive to the stated need for differentiated roles.

Mrs. White also expressed inconsistent statements about a reading log required in her classroom and the Accelerated Reader Program (AR), which she requires for a grade in her English class. Mrs. White described the reading log as being "useless" because students can simply "make up" information to include on this log, yet this is a task she required students to complete every night for homework. In similar fashion, Mrs. White made contradictory remarks about the AR Program when she noted that the questions provided through AR represent "very superficial" comprehension questions. Further, she noted that AR is "not a failsafe way to do reading comprehension," yet she assigns her students a grade based upon their participation in the AR program for each nine weeks' grading period. 
Lastly, Mrs. White made contradictory statements regarding her writing and vocabulary instruction. In regards to the writing instruction, Mrs. White asserted that writing prompts can set students up for failure, yet the only observed instances of writing assignments came in the form of two different homework assignments, each of which required the students to complete a writing prompt. Similarly, a contradiction occurred as Mrs. White described the current vocabulary workbook she used to teach vocabulary in her classroom. As she described the Vocabulary Workshop program Mrs. White stated that she liked the program, yet she also stated that it is not necessarily the best way to teach vocabulary. She went on to explain that she believed a root word approach would be better, yet she was unable to find a pre-packaged program that taught root words in a meaningful manner.

These somewhat contradictory statements and misalignments between professed beliefs and observed practices emerged more frequently during Mrs. White's interviews and observations than were apparent in Ms. Swift's descriptions of literacy and subsequent instructional practices. Although Ms. Swift indicated through her descriptions of literacy during the course of the interviews that she integrates a variety of text types including digital and/or electronic sources, this was not evidenced in the classroom observations because of the nature of the instruction that took place during the observation cycle.

The lack of inconsistencies evidenced in Ms. Swift's descriptions and instructional practices appear to have occurred because of Ms. Swift's status as a fairly new teacher in the field. Many of Ms. Swift's descriptions about her beliefs associated with literacy focused predominantly on the tasks she performs in class.

Conclusion 4: Evidence of a shifting belief system emerged. Based upon Ms. Swift's descriptions of her beliefs about literacy, it appears that Ms. Swift continues to learn about 
literacy and reflects upon her instruction in an effort to improve her students' literacy experiences. Evidence of a shifting belief system emerged across the course of the investigation of Ms. Swift's beliefs and practices. Ms. Swift's beliefs about literacy appear to be associated with her instructional practices, but it is evident that she is still in a state of flux as she discovers what is most beneficial for her students. Mrs. White's beliefs, on the other hand, appear to be somewhat indistinct as multiple inconsistencies between her professed beliefs about literacy and her instructional practices emerged as result of this investigation.

\section{Discussion}

The teachers involved in this study generally aligned their beliefs about literacy with a traditional belief system associated with the mastery model of English language arts instruction. This perspective suggests a very narrow view of literacy, which, according to literacy researchers, is not useful for conceptualizing literacy in the twenty-first century (Draper \& Siebert, 2010; Grierson \& Nokes, 2010). Despite Appleman's (2010) suggestion that English teachers are cognizant of the notion of an adolescent literacy crisis, no evidence of this awareness emerged during the course of this investigation. Instead, both teachers involved in this study emphasized a predominately skills-based approach to literacy instruction that lacked acknowledgement of the wide array of texts students engage with outside of the school setting. The narrow view of literacy exhibited by the teachers involved in this study does not align with the adolescent literacy perspective (Alvermann, 2002; Finders, 1997; Moje, 2002; Stevens, 2002).

Literacy research associated with the contemporary adolescent literacy perspective suggests that a more suitable perception broadens the notion of literacy beyond merely the ability to read and write traditional printed text to include non-print materials that incorporate pictures, 
images, audio, and video content in an effort to acknowledge the continually evolving literate practices of young adolescents (Alvermann, 2002; Bean, Bean, \& Bean, 2001; Cope \& Kalantiz, 2000; Draper \& Siebert, 2010; Finders, 1997; Moje, 2002; Stevens, 2002). In order to help adolescents become contributing members of society and to promote their ability to lead productive work, public, and private lives (Cope \& Kalantiz, 2000; Draper \& Siebert, 2010), this narrow view must be expanded to include a variety of literacies, such as visual, media, Internet, computer, graphic, critical, and out-of-school literacies (Alvermann, 2002; Mallette, Henk, Waggoner, \& DeLaney, 2005; Moje, 2002). As research has revealed, an overemphasis on literacy skills taught in isolation has the potential to lead to disconnected and fragmented literacy learning. This may inadvertently drive pedagogy in an unconstructive manner, pushing aside other approaches that emphasize a more holistic approach to literacy that incorporates experience and engagement with a wide array of texts within purposeful literacy activities (Dadds, 1999).

Despite the fact that both teachers in this study considered themselves to be content area specialists with literature as their concentration and both suggested the value of literature in conjunction with literacy, it is important to note the lack of emphasis on literary theory in both teachers' classroom instruction. As literary theorists have emphasized, it is important to teach students to read and interpret texts through a critical lens because as Staton (1987) suggested, there is no such thing as an "innocent" or "value-free" reading. Instead, whenever a text is read, each individual brings to the text a unique perspective laden with personally held assumptions about the topic addressed within the text. The types of texts both teachers integrated through their annual novel units provided an ideal opportunity for the teachers to present students with a chance to explore these texts in a meaningful, critical, and interpretive manner (Appleman, 2009; Scholes, 1985; Staton, 1987), yet this did not occur during this investigation. 
Although both teachers utilized novels that contained potentially culturally sensitive issues, the teachers did little to prepare the students for the content of the novels other than to say that they were set during the Great Depression. Neither teacher referenced the themed choice of the texts, the varying perspectives shared across the novels as different characters portray the Great Depression through multiple perspectives, the potentially offensive nature of the interactions that occur within the texts, or the potentially derogatory and/or offensive language contained within the novels. Both teachers merely suggested that their novel choice was based pragmatically and arbitrarily on the number of books available.

Rather than merely relegating the reading of arbitrarily chosen texts to students, teachers need to teach students how to engage in a critical and interpretive reading of texts. This can be achieved through ongoing explicit reading strategy instruction at the middle school level designed to teach adolescents how to independently interpret complex texts such as those taught through the literature circle novel units that were integrated into the middle level English teachers' instructional practices in this investigation (Biancarosa, 2012; Carnegie Council on Advancing Adolescent Literacy, 2010).

This investigation revealed that middle level English teachers have a difficult time articulating their beliefs about literacy and instead described instructional practices utilized in their classrooms. This struggle may have contributed to the inconsistent alignment between professed beliefs and observed practices. Evidence of an evolving belief system associated with current research on literacy was apparent in some statements made about beliefs, yet these beliefs were not revealed through instructional practices.

One factor that likely contributed to the teachers' narrow beliefs about literacy was the fact that both of the teachers involved in this study received their undergraduate training in 
secondary English programs with a concentration in literature. Both teachers mentioned that their undergraduate studies did little to prepare them to teach English at the middle school level. In addition, both teachers made reference to their initial teacher education training as preparing them to teach literature as content.

This finding is not surprising because research has suggested that most middle level English language arts teachers have not received extensive training in literacy instruction and may not be familiar with literary theory or its potential contribution as a tool for developing literacy (Appleman, 2009; Faggella-Luby, Ware, \& Capozzoli, 2009; Heller \& Greenleaf, 2007). This suggests one reason why the teachers in the study placed little value on the novels chosen for the literature circle units. Presenting literature as content or as artifacts that represent cultural heritage does little to prepare students for the modern-day demands associated with literacy (Appleman, 2009). Providing teachers with opportunities to learn about literary theory and its potential to provide students with the necessary interpretive tools required for recognizing and interpreting the cultural influences that impact students' lives is vital to improving the literacy practices in the middle level English classroom.

The good news is, evidence of a shifting belief system emerged from this investigation. This finding suggests that although beliefs are constructs that are challenging for teachers to isolate and describe, teachers' beliefs about literacy can be influenced and continue to evolve. For instance, Ms. Swift shared an opportunity in which she heard Donalyn Miller speak at a reading conference and it was this experience that contributed to her desire to read Donalyn's book, The Book Whisperer. As a result of this experience, Ms. Swift integrated a "new" approach to reading in her classroom. In similar fashion, Mrs. White mentioned attending a workshop in which Kelly Gallagher spoke about approaches to writing in which the teacher 
models the writing and thinking process. Although this approach was not evidenced in Mrs. White's instruction, she did note that this professional development experience influenced her beliefs about writing instruction. This noteworthy discovery provides the grounding for the following implications.

\section{Implications}

As this study revealed, the majority of instructional practices occurring in these middle level English classrooms is associated with a narrow and traditional perspective of literacy, which suggests that there is a need to improve upon the instructional practices taking place in these middle school English classrooms. This finding aligns with issues that appear to be associated with the nationwide adolescent literacy crisis. Prior research revealed that teachers' beliefs play a role in how pedagogical knowledge is interpreted, how teaching tasks are conceptualized, and how teaching practices are subsequently enacted in the classroom (Bryan, 2003). Although beliefs are difficult for teachers to discern and describe (Pajares, 1992), it is apparent that established beliefs can be influenced through middle level teacher education programs, staff-development activities, and professional development opportunities. Therefore, implications associated with these efforts will be described.

Experts in the field of literacy believe that in order to effectively meet the needs of our nation's young adolescents, three instructional approaches should be integrated in order to create effective English language arts classrooms. Integrating the mastery model, the cultural heritage model, and the process model provides the opportunity to capitalize upon the corresponding strengths of each model to develop skilled and strategic readers and writers (Grierson \& Nokes, 2010). This integrated approach lends itself to improving upon issues that potentially contribute to the adolescent literacy crisis. Because English language arts teachers maintain the primary 
responsibility for teaching comprehension strategies to young adolescents (Graves \& Liang, 2008), these teachers need to be taught how to purposefully integrate the process model which focuses on explicit, strategic reading comprehension instruction of critical strategies such as activating background, inferring, summarizing, predicting, clarifying, questioning, visualizing, monitoring, synthesizing, evaluating, and connecting (Fisher, Frey, \& Lapp, 2008). Given the fact that many middle level English teachers (including the two teachers involved in this study) feel unprepared to teach literacy and lack a an effective array of strategies for teaching literacy (Graves \& Liang, 2008), it is critical to reexamine pre-service teacher education programs as well as professional development for these teachers in order to ensure that these teachers are effectively prepared to meet the continually evolving literacy needs associated with our highlytechnological, global society.

\section{Implications for Middle Level Teacher Education}

The fact that both of the teachers involved in this study received their teacher education training through a secondary English teacher education preparation program with a focus on literature and both participants suggested that perhaps this approach was not the best preparation for a middle level English position, holds important implications for this study. This finding suggests that there is a need to move middle level teacher education preparation away from the secondary education program to a program focused specifically on middle level education and the unique and evolving needs of the young adolescent learner. Both teachers shared their experiences as an undergraduate student and both admitted that most of their coursework, projects, and lesson plans developed during their undergraduate preparation were focused on high school English instruction, leaving them feeling unprepared to meet the unique demands associated with young adolescent literacy. 
The middle school years serve as an important time in young adolescents' literacy development. During this crucial time, students tend to refine their reading preferences, become skilled readers of informational text, and establish the foundation for lifelong reading habits that will prove beneficial throughout their personal, professional, and public lives (International Reading Association and the National Middle School Association, 2002). Therefore, it is fundamental for young adolescents to received continued and systematic literacy instruction across the middle school years.

As this study revealed, much of the instruction that occurs at the middle level is associated with a traditional approach to literacy, which utilizes a teacher-centered approach that emphasizes "skill and drill" and passive learning approaches (Alvermann, 2001). Current research associated with the adolescent literacy perspective, on the other hand, suggests the importance of utilizing an approach that integrates a metacognitive, strategic instructional approach to literacy development, incorporating an array of texts, including not only textbooks, but also magazines, student-generated texts, digital media, images, audio, and so on (Alvermann, 2001; Grierson \& Nokes, 2010; Wade \& Moje, 2000).

Throughout the course of this investigation, neither teacher made reference to an explicit, strategic approach to instruction that demonstrates for young adolescents what it means to be a good reader or writer (Ehren, 2009; Heller \& Greenleaf, 2007). As both teachers described their beliefs about literacy and manifestations of their instructional practices were revealed, the teachers' beliefs and instruction clearly focused on the basic skills of reading or language arts. Contemporary research suggests that in order to counteract the current adolescent literacy crisis, teachers of young adolescents must move beyond the teaching of basic skills to provide intensive, high-quality literacy instruction that focuses on reading comprehension strategies, 
vocabulary, writing, and other forms of communication while also providing opportunities to construct, analyze, interpret, and respond critically to what has been read, to write sophisticated texts, and to discuss, debate, and defend ideas (Alliance for Excellent Education, 2006; Appleman, 2009; Draper \& Siebert, 2010; Grierson \& Nokes, 2010 ).

Clearly, it is unfair to hold middle level English teachers accountable for the stagnant literacy rates of young adolescents when their teacher preparation programs have not adequately prepared them for the unique demands associated with middle level English instruction. Teacher preparation programs must do a better job of preparing these teachers to meet the evolving needs of young adolescents. Simply preparing all teachers who plan to teach beyond the elementary level from a secondary perspective is not the best approach for these particular teachers, especially given the stagnant literacy rates experienced by young adolescents in the middle grades.

There are at least three transformations in literacy instruction that should occur in order to improve upon the instruction that adolescents are receiving (Grierson \& Nokes, 2010). These three reforms need to be strategically integrated into the teacher preparation programs for middle level English teachers and include:

(a) a shift in instructional focus from the mastery of skills to the development of highly proficient strategic readers; (b) a broadening of the English curriculum to embrace the richness of written, spoken, and visual language; and (c) a focus on the literacies relevant to adolescents' lives. (Grierson \& Nokes, 2010, p. 121)

While this shift of instruction at the pre-service level is vital in an effort to adequately prepare prospective teachers for the challenges of working with young adolescents at the middle school level, this is an issue than must also be addressed for current in-service teachers. 


\section{Implications for Middle Level Staff-Development Activities and Professional Development}

While it is important to shift the methodological approach for pre-service teacher preparation for middle level English teachers, this shift will do little good for the young adolescents currently enrolled in our nation's schools. Therefore, one cannot merely consider a change in pre-service teacher education as there are clearly implications for current in-service teachers as well. As suggested by the research of Grierson and Nokes (2010), these changes in perspective need to take place in schools in order to meet the evolving demands of all adolescent students. This shift in current instructional practices cannot occur without meaningful opportunities for current in-service teachers to learn about these recommended reforms. Professional development opportunities need to be developed with this focus in mind and need to occur across our nation's schools rather than occurring haphazardly in a few schools sprinkled across the nation.

The findings of this investigation suggest little evidence that the teachers involved in this study hold knowledge of current research or the existing adolescent literacy crisis as neither teacher mentioned theoretical approaches or contemporary scientifically-based research associated with literacy. This lack of knowledge about current research such as the reforms suggested by Grierson and Nokes (2010) or Appleman (2009) regarding literary theory, suggests the need to develop purposeful literacy-based professional development opportunities for middle level English teachers. It is not prudent for the experts in the field of literacy to sit back and expect teachers to shift their instructional methods from a traditional approach to a modern-day research-based approach if they have not been exposed to these practices through meaningful professional development opportunities. 
As both participants in this current investigation reflected on professional development opportunities they have received, both mentioned that they have their choice of attending various workshops offered by their school system, yet these opportunities were described as one-shot opportunities with no guidance or support once the staff development or professional development opportunity ends. Therefore in order to bring about meaningful reform and lasting changes such as those suggested by this study, these professional development opportunities must extend beyond the single or half-day workshop format and into the teachers' classrooms to support them as they strive to implement new approaches for literacy instruction. Perhaps it would also be of benefit to provide opportunity for teachers to become more involved in the decision-making process associated with these professional development opportunities. Both of the teachers involved in this study were able to articulate professional development needs associated with the teaching of literacy that they believed would be of benefit for their instructional purposes.

Given the limiting nature of current professional development activities in addition to the fact that teachers tend to have a difficult time isolating, discerning, and describing their implicitly held beliefs, a multifaceted professional development approach is needed. Moving from the traditional workshop approach would prove most valuable in bringing about a significant change in classroom instructional practices. The integration of a professional learning community (PLC) led by a school-based literacy coach would provide the much needed opportunity for English teachers to engage in the transformation of their instructional practices away from the mastery model to an integrated process model approach to English instruction that is aligned with the contemporary adolescent literacy perspective. 
In order for meaningful change to occur, research suggests that professional development needs to provide opportunities for teachers to reconsider their instructional practices as they work through the process of developing new instructional routines and procedures designed specifically to improve student learning (Darling-Hammond \& McLaughlin, 1995; Vescio, Ross, \& Adams, 2008). By inviting a school's entire English department to participate in a professional learning community facilitated by the school's literacy coach, a structured and supported learning opportunity emerges. As an introductory task, the teachers could be invited to complete the Literacy Orientation Survey (LOS) in an effort to assist them in identifying where their beliefs lie, in a traditional or holistic perspective or in line with traditional, eclectic, or constructivist teaching practices (Lenski, Wham, \& Griffey, 1998). Once the teachers have identified their existing literacy beliefs, then the professional learning community would provide teachers with the opportunity to collaboratively reflect upon their day-to-day experiences in the classroom, as well as their beliefs, as they strive to shift their focus from merely the instructional methods used in the classroom to student learning (Buysse, Sparkman, \& Wesley, 2003; Vescio, Ross, \& Adams, 2008). By integrating a PLC approach facilitated by a literacy coach, teachers would have the opportunity to engage in ongoing conversations about their instructional practices with all members of their English department, with multiple opportunities to critically examine the curriculum and instructional approaches, as well as student learning (Newmann, 1996; Vescio, Ross, \& Adams, 2008).

By helping the English teachers determine their beliefs at the outset of the professional learning community opportunity and then providing the support of a literacy coach, who can contribute to the experience by modeling lessons and contributing to the ongoing conversations, then there are increased opportunities to shape teachers' beliefs and instructional practices to 
align with a constructivist approach associated with a balanced and process model of instruction. Through this ongoing, collaborative, and supportive professional development, teachers would be more likely to learn about and understand how to integrate the various strengths of the mastery model, the cultural heritage model, and the process model (Grierson \& Nokes. 2010) as they develop constructivist classrooms where students have the opportunity to become strategic and metacognitive learners.

It has become unmistakably clear to me through the course of this investigation that middle level English teachers want to learn current approaches designed to improve young adolescents' literacy, yet they are not provided with appropriate opportunities to learn about these instructional approaches when they have so many other demands placed on them in their schools and classrooms. Improving literacy instruction in the middle level English classroom is a vital step in increasing the overall literacy achievement of young adolescents (Faggella-Luby, Ware, \& Capozzoli, 2009). However, many middle level English teachers have not received extensive training in literacy instruction, which presents a genuine challenge for these teachers (Faggella-Luby, Ware, \& Capozzoli, 2009; Heller \& Greenleaf, 2007).

\section{Limitations}

This research investigation focused on two middle level English teachers and employed a phenomenological approach to data collection and analyses. When utilizing the phenomenological approach, the data analysis process could continue ad infinitum; therefore, the conclusions drawn are never completely exhaustive. Consequently, the conclusions shared in the findings and discussion sections of this work must be considered to represent one particular time and place revealed from the vantage point of an individual novice researcher following a comprehensive imaginative and reflective study of the phenomenon literacy (Husserl, 1931; 
Moustkas, 1994). Additionally, it should be noted that incorporating a greater number of participants into this investigation over a longer period of time, with more than one school location, would have led to a deeper understanding of middle level English teachers' beliefs about literacy.

\section{Directions for Future Research}

Pajares (1992) suggested that studying teachers' beliefs represents one of the most promising areas of educational research; therefore ongoing investigations associated with teachers' beliefs about literacy are warranted. While this study investigated teachers' beliefs about literacy, it did not attempt to examine in greater depth each of the elements of literacy that were revealed through this investigation. For instance, this study did not delve deeper into the teachers' specific beliefs associated with various components of literacy such language arts, skills, reading, writing, speaking, vocabulary, and literature. Future studies could identify these components and then proceed to interrogate each of these components more deeply in an effort to reveal how these beliefs were established.

The current investigation studied two teachers across a two-year time span and revealed that at least one participant's beliefs evolved somewhat across that time frame. Another potential line of inquiry that may prove beneficial would be exploring teachers' beliefs across time in an effort to reveal the extent to which teachers' beliefs evolve. Further, this may provide an opportunity to determine elements that bring about changes in teachers' beliefs about literacy. As Kagan (1992) emphasized the "lack of naturalistic, longitudinal studies of how teacher belief evolves represents a critical gap in our knowledge of teaching" (p. 81). Kagan suggested that it is important to come to an understanding of how teachers' beliefs and practices evolve across time because this type of study may provide beneficial insights about events and/or elements that 
serve as catalysts for teacher growth. Findings from this type of longitudinal study would prove valuable for designing programs and/or professional development opportunities for pre-service and in-service teachers (Kagan, 1992). Therefore, including both experienced teachers and beginning teachers in such a study may prove to be of greater benefit.

An interesting discovery that emerged through the course of this investigation was the fact that Ms. Swift served as a student teacher in Mrs. White's classroom during her undergraduate education. When this issue emerged, there was some concern as to how this factor may have influenced Ms. Swift's beliefs about literacy as well as her instructional practices. Due to the nature of this investigation, though, this issue was not explored in great depth. This scenario suggests that another interesting line of investigation may be to explore the impact of the mentor teacher's beliefs about literacy on the student's teacher's beliefs and instructional practices as well as how long the mentor teacher's beliefs influence the student teacher's beliefs. While no evidence of direct influence emerged from the course of this investigation, this line of inquiry would prove beneficial for educators at the higher education level, as these issues are of critical importance in the preparation of the preservice teacher. Research suggests that the mentor teacher plays an influential role in shaping the student teacher (Alsup, 2006; Anderson, 2007; Mays-Woods and Weasmer, 2003), which may include the development of beliefs associated with literacy and literacy instruction; therefore this line of inquiry warrants further exploration.

Finally, this current investigation was not a study of policy. There are likely issues of policy that influence the development of all teachers' beliefs and instructional practices associated with literacy. Therefore, a study of teachers' literacy beliefs set in the context of policy associated with curriculum, high-stakes assessment, curriculum reform, and/or teacher 
evaluation systems may prove beneficial in determining the effects these issues have on teachers' overall beliefs about literacy.

\section{How My Views Have Changed as a Result of this Investigation}

At the outset of this study one of my goals for this investigation was to achieve a deeper understanding of literacy, moving beyond what I already know and understand about literacy. By focusing on my participants' unique descriptions of literacy as well as the ways in which their beliefs were manifested in their instructional practices in the middle level English classroom, I was able to discover several key elements each of my participants associated with literacy.

I discovered that the disconnect I was experiencing as I worked to assist my middle level English colleagues occurred because I view literacy from a process model of instruction focused on explicit cognitive and metacognitive comprehension strategies instruction, which stood in stark contrast to the model of English instruction adopted by at least two of my middle level English colleagues, as evidenced through the two participants involved in this investigation. The process model of English instruction promotes the development of strategic readers and writers through explicit instruction designed to develop students' "affective, cognitive, and social engagement with language in its various written and oral forms" (Grierson \& Nokes, 2010, p. 117). This approach integrates a wide variety of traditional and nontraditional texts chosen purposefully to connect with students' interests, cultures, literacy needs, and their unique environment. On the other hand, my colleagues with whom I have experienced differing perspectives, appear to lie somewhere between the mastery model and the cultural heritage model of English instruction. These teachers tend to focus their instruction on a skills mastery approach achieved through teacher-centered instruction of isolated skills believed to be associated with literacy, using traditional printed texts (Grierson \& Nokes, 2010). 
As I reflect on my endeavors throughout this academic pursuit, I realize how much I have grown and learned over the course of this experience. As I approach the end of this endeavor I would be remiss to overlook one of the greatest challenges I faced through the course of this investigation. Because I spent the vast majority of my teaching career at the primary level before transitioning to the middle school level, I spent a considerable amount of time engaged in reading and exploring the research and literature on the adolescent literacy perspective in order to adequately prepare for my position as a reading specialist at the middle school level. As a result of countless hours spent reading and learning about the most effective practices for teaching literacy to young adolescents in the context of the twenty-first century, I developed deep-seated beliefs associated with the adolescent literacy perspective. At the outset of this investigation I found that my personally held views about literacy and the teaching of literacy clouded my judgment as I worked through this process. Therefore, I invested time searching for methods that could be integrated into this investigation to ensure that my views about literacy did not unintentionally narrow the lens through which I viewed my participants and their instructional practices.

At the beginning of this investigation, once I was certain I could proceed without having my personal belief and biases influence this study, I found myself facing my own shortcomings as a researcher. During the pilot study when I met individually with each of my participants prior to beginning this investigation, I shared with them my goals and we established a timeline for completing the interviews and observations. Each teacher shared a brief overview of her intentions, indicating that a novel study would be conducted through the course of my investigation. Ms. Swift shared that she was going to experiment with a literature circle approach for her novel unit because she had heard about this approach and was interested in 
giving it a try. On the other hand, when I met with Mrs. White she explained that she was in the process of choosing her novel for her whole class novel unit, but was having a difficult time choosing which novel to use. She mentioned that when she and Ms. Swift met to share with each other their plans for the unit, Ms. Swift told her she was going to try the literature circle approach. During this conversation, Mrs. White made it unmistakably clear that she was not interested in trying the literature circle approach because she viewed this as an elementary approach for reading instruction and she was not comfortable attempting such an approach. Our conversation ended with a timeline for observations and I looked forward to returning to her classroom on the day she introduced her annual novel unit to the class.

When I returned to Mrs. White's classroom to observe how she introduced her novel unit I found myself confronted with a combination of emotions. As Mrs. White introduced her novel unit, she told her students,

Alright, now, today ladies and gentlemen, we are going to embark on something that kind of makes my heart race, and not in a good way. It makes me a little nervous, but I'm branching out.... we are going to try, and I almost hate to say the word, literature circles. I found myself in a state of shock. As the literacy coach working in this school setting I was proud of Mrs. White for attempting a new approach (especially given the fact that I would be observing during this unit), yet as a researcher I found myself in a state of panic. This was not how I had envisioned this research project proceeding and I immediately began to worry about how this would impact my research investigation. As I reflect back upon this situation I realize that it was my own personally held beliefs and biases that were creating this tension. I was initially unsure of myself as a novice researcher. I recognized that early in this study I lacked confidence in my ability to withhold my beliefs and biases. This task was critical to the 
phenomenological approach in which the goal was to describe the phenomenon, literacy, in as precise and detailed a manner as possible from my participants' perspectives without interpreting the data that was collected. This early encounter forced me to continually confront my personal biases throughout this investigation in an effort to ensure that my personal beliefs about literacy did not bias this research endeavor.

Another factor that clearly influenced my role as a researcher was the fact that I had established a congenial working relationship with each of my participants prior to the outset of this investigation. I was concerned that my professional as well as amicable relationship would make this endeavor more challenging than I had anticipated. As a result of these tensions, I had to grapple with my preexisting notions about literacy as well as managing my personal relationship with my colleagues. Because I came to this investigation with so many preconceived notions and biases, I continually struggled with the negotiation of these factors throughout this investigation. By asking two colleagues involved in teaching literacy to serve as peer reviews, I was able to make certain that it was not my personal beliefs about literacy that emerged during the data analysis process. In addition, by asking my participants to provide member checking throughout the initial data analysis process, I was able to ensure that my personal biases did not cloud my work.

The course of this investigation has been incredibly eye-opening for me. I have learned a great deal about myself as a researcher as well as a teacher of literacy. This was an extraordinarily humbling process as there were multiple times I realized the depth of my naïveté and inexperience as a researcher. Although there were times when I was certain this task was beyond my capabilities, I did not allow myself to give up. I struggled through this process, continually striving to withhold my personal views and biases as I worked through this 
investigation, while also striving to retain professional respect for my colleagues who so willingly invited me into their classrooms, allowing me to explore their beliefs and practices.

The most challenging piece of this work came as I struggled to draw conclusions about my colleagues and their beliefs about literacy. As a teacher, it is often easy to critique and judge the work of others, yet when I approached this task as a researcher I found myself in a rather uncomfortable position. After analyzing my data and beginning the process of discussing the findings, I realized that my colleagues' views stood in stark contrast to my own views about literacy. It was during this process that I was confronted with another immense struggle. I had a difficult time describing my findings without appearing judgmental or critical of my English colleagues' work, which was never my intent. In order to work through this process, I had to rely on the literature from the field and to allow this work, in essence, to speak for me. I relied predominantly on the work of Appleman (2009) and Grierson and Nokes (2010) who helped me come to many incredibly important realizations about English language arts instruction. These two works in particular played a fundamental role in helping me to discover why my perspectives and beliefs about literacy are so drastically different from those of my English language arts colleagues. Without these works, I would not have been able to adequately surmise the differences in beliefs about literacy that existed, nor would I have learned so many valuable lessons.

As a lifelong learner, I am continually seeking ways to improve upon my instruction in the classroom as I also seek ways to help my colleagues at every grade level and in higher education to meet the needs of their students. The many revelations that emerged as a result of this investigation have proven valuable for me as I continue to develop a growing repertoire of 
strategies designed to meet the continually evolving needs of young adolescents. I am eternally grateful to my colleagues for their willingness to share with me their beliefs about literacy. 


\section{References}

Alexander, P. (2007). The path to competence: A lifespan developmental perspective on reading. Oak Creek, WT: National Reading Conference.

Alliance for Excellent Education. (2006). Finding and keeping the teachers we need fact sheet. Retrieved from http://www.all4ed.org/files/TeacherQualityFactSheet.pdf

Alliance for Excellent Education. (2007). The high cost of high school dropouts. Retrieved from http://www.all4ed.org/files/archive/publications/HighCost.pdf

Alliance for Excellent Education. (2009). Alliance for Excellent Education analysis of U.S. Department of Education, National Center for Education Statistics, The Nation's Report Card: Reading 2009 (NCES 2010-458) (Washington, DC: Government Printing Office, 2010).

Alliance for Excellent Education. (2012). Confronting the crisis: Federal investments in state birth-through-grade-twelve literacy education. Retrieved from http://www.all4ed.org/ files/ConfrontingTheCrisis.pdf

Alliance for Excellent Education. (2013). About the crisis: Impact on American society. Retrieved from http://www.all4ed.org/about_the_crisis/impact

Alsup, J. (2006). Teacher identity discourses: Negotiating personal and professional spaces. National Council of Teachers of English, Urbana, IL.

Alvermann, D. E. (2002). Effective literacy instruction for adolescents, Journal of Literacy Research, 34(2), 189 - 208. doi:10.1207/s15548430j1r3402_4

Antonacci, P. A., \& O'Callaghan, C. M. (2011). Developing content area literacy: 40 strategies 
for middle and secondary classrooms: Adolescent literacy: The need for literacy

instruction in content area classrooms. Retrieved from http://www.sagepub.com/upmdata/34118_Intro.pdf

Applebee, A. (1993). Literature in secondary school: Studies of curriculum and instruction in the United States. Urbana, IL: Nation Council of Teachers of English.

Appleman, D. (2009). Critical encounters in high school English: Teaching literacy theory to adolescents. New York, NY: Teachers College Press.

Appleman, D. (2010). Adolescent literacy and the teaching of reading: Lessons for teachers of literature. Urbana, IL: National Council of Teachers of English.

Assaf, L. C. (2006). One reading specialist's response to high-stakes testing pressures. The Reading Teacher, 60, 158-167.

Association for Middle Level Education (AMLE, formerly National Middle School Association). (2010). This We Believe: Keys to Educating Young Adolescents. The position paper of the Association for Middle Level Education.

Atkinson, D. (2004). Theorising how student teachers form their identities in initial teacher education. British Educational Research Journal, 30(3), 379-394.

Au, K. (1998). Social constructivism and the school literacy learning of students of diverse backgrounds. Journal of Literacy Research, 30(2), 297-319.

Auerbach, C. \& Silverstein, L. B. (2003). An introduction to coding and analysis. New York, NY: University Press.

Bean, T. W., Bean, S. K., \& Bean, K. F. (2001). Intergenerational conversations and two 
adolescents' multiple literacies: Implications for redefining content area literacy. In J.A. Rycik \& J. L. Irvin (eds.), What adolescents deserve: A commitment to students' literacy learning (pp. 207-255). Newark, DE: International reading Association.

Bear, D. R., Invernizzi, M., \& Templeton, S. (1996). Words their way: Phonics, spelling and vocabulary instruction, K-8. Columbus, OH: Merrill/Prentice Hall.

Biancarosa, C. (2012). Adolescent literacy: More than remediation. Educational Leadership: Reading the Core Skill, 69(6), $22-27$.

Biancarosa, C. \& Snow, C. E. (2006). Reading next-A vision for action and research in middle and high school literacy: A report to Carnegie Corporation of New York (2nd ed.). Washington, DC: Alliance for Excellent Education.

Bogdan, R.C. \& Biklen, S.K. (1998). Qualitative research for education - An introduction to theory and methods. Boston, MA: Allyn and Bacon.

Brody, C. M. (1998). The significance of teacher beliefs for professional development and cooperative learning. In C. M. Brody \& N. Davidson (Eds.), Professional development for cooperative learning: Issues and approaches (pp. 25-48). Albany, NY: State University of New York Press. Retrieved from http://books.google.com/books?id= vTv85mExoUC\&pg=PA25\&source=gbs_toc_r\&cad=3\#v=onepage\&q\&f=false

Brophy, J. E., \& Good, T. (1974). Teacher-student relationships: Causes and consequences. New York, NY: Holt, Rinehart, and Winston.

Bryan, L. A. (2003). Nestedness of beliefs: Examination a prospective elementary teacher's belief system about science teaching and learning. Journal of Research in Science Teaching, 40, 835-868.

Burns, L. D. (2007). On being unreasonable: NCTE, CEE, and political action. English 
Education, 39, 120-145.

Burns, L. D. (2008). New literacies and pragmatic research. Middle Grades Research Journal, 3(3), 1-28.

Buysse, V., Sparkman, K. L., \& Wesley, P. W. (2003). Communities of practice: Connecting what we know with what we do. Exceptional Children, 69(3), 263-277.

Carnegie Council on Advancing Adolescent Literacy. (2010). Time to act: An agenda for advancing adolescent literacy for college and career success. New York, NY: Carnegie Corporation of New York.

Clandinin, D. J., \& Connelly, F. M. (1987). Teachers' personal knowledge: What counts as 'personal' in studies of the personal. Curriculum Studies, 19(61), 487-500.

Clark, C. M., \& Peterson, P. L. (1984). Teachers' thought processes. East Lansing, MI: Institute for Research on Teaching, Michigan State University.

Coiro, J., Knobel, M., Lankshear, C., \& Leu, D.J. (Eds). (2008). Handbook of research on new literacies. Mahwah, NJ: Lawrence Erlbaum.

Common Core State Standards Initiative. (2012). English language arts standards. Retrieve from http://www.corestandards.org/ELA-Literacy

Cope, B., \& Kalantiz, M. (Eds.). (2000). Multiliteracies: Literacy learning and the design of social futures. New York, NY: Routledge.

Creswell, J. W. (1998). Qualitative inquiry and research design: Choosing among five traditions. Thousand Oaks, CA: Sage.

Creswell, J. W. (2005). Educational research: Planning, conducting, and evaluating quantitative and qualitative research. Columbus, $\mathrm{OH}$ : Pearson Merrill Prentice Hall.

Creswell, J. W. (2007). Qualitative inquiry and research design: Choosing among five 
approaches (2nd ed.). Thousand Oaks, CA: Sage.

Crotty, M. (1998). The foundations of social research: Meaning and perspective in the research process. Thousand Oaks, CA: Sage.

Dadds, M. (1999). Teachers' values and the literacy hour. Cambridge Journal of Education, 29(1), 7-19.

Darling-Hammond, L., \& McLaughlin, M. W. (1995). Policies that support professional development in an era of reform. Phi Delta Kappan, 76(8). Retrieved from http://www. oest.oas.org/iten/documentos/Investigacion/randd-engaged-darling.pdf

Deford, D.E. (1985). Validating the construct of theoretical orientation in reading. Reading Research Quarterly, 20(3), 351-367.

Denzin, N. K., \& Lincoln Y. S. (1994). Entering the field of qualitative research. In N. K. Denzin \& Y. S. Lincoln (Eds.), Handbook of qualitative research (pp. 1-17). Thousand Oaks, CA: Sage.

Dewey, J. (1910). How we think. Boston, MA: D.C. Heath and Co.

Dewey, J. (1933). How we think: A restatement of the relation of reflective thinking to the educative process. New York, NY: D.C. Heath and Co.

Dole, J.A., Nokes, J.D., \& Drits, D. (2009). Cognitive strategy instruction. In S.E. Israel, \& G.G. Duffy (Eds.), Handbook of research on reading comprehension (pp. 347-372). New York, NY: Routledge. Retrieved from http://www.ucrl.utah.edu/researchers/pdf/ cognitive_strategy_instruction.pdf

Donahue, P., Daane, M., \& Grigg, W. (2003). The nation's report card: Reading highlights 2003 (No. NCES 2004452). Washington DC: U.S. Department of Education, Institute for Education Sciences, National Center for Education Statistics. 
Donahue, P.L., Daane, M.C., \& Jin, Y. (2005). The nation's report card: Reading 2003 (NCES 2005-453). U.S. Department of Education, Institute of Education Sciences, National Center for Education Statistics. Washington, D.C.: U.S. Government Printing Office.

Dooley, C. M. (2005). One teacher's resistance to the pressures of test mentality. Language Arts, $82,177-185$.

Dooley, C. M., \& Assaf, L. C. (2009). Contexts matter: Two teachers' language arts instruction in this high-stakes era. Journal of Literacy Research, 41(3), 354-391. doi:10.1080/ 10862960903133743.

Draper, R. J., \& Siebert, D. (2010). Rethinking texts, literacies, and literacy across the curriculum. In R. J. Draper (Ed.), (Re)Imagining content-area literacy instruction (pp. 20-39). New York, NY: Teachers College Press.

Duffy, G.G., \& Metheny, W. (1979). Measuring teachers' beliefs about reading (Research Series No. 41). Michigan: Michigan State University, The Institute for Research on Teaching.

Durkin, D. (1978-1979). What classroom observations reveal about reading comprehension Instruction. Reading Research Quarterly, 14, 481-533.

Eagleton, T. (1983). Literary theory: An introduction. Minneapolis, MN: University of Minnesota Press.

Eckert, L. S. (2006). How does it mean: Engaging reluctant readers though literary theory. Portsmouth, NH: Heinneman.

Englander, M. (2012). The interview: Data collection in descriptive phenomenological human scientific research. Journal of Phenomenological Psychology, 43, 13-35. 
Faggella-Luby, M. N., Ware, S. M., \& Capozzoli, A. (2009). Adolescent literacy — Reviewing adolescent literacy reports: Key components and critical questions. Journal of Literacy Research, 41, 453-475, doi: 10.1080/10862960903340199.

Fang, Z. (1996). A review of research on teacher beliefs and practices. Educational Research Review, 38(1), 47-65.

Fenstermacher, G. D. (1993). A philosophical consideration of recent research on teacher effectiveness. In M.C. Wittrock (Ed.), Review of research in education, (pp. 157-185). Ithasca, IL: Peacock.

Finders, M. (1997). Just girls: Hidden literacies and life in junior high. New York: Teachers College Press.

Fisher, D. Frey, N. \& Lapp, D. (2008). Shared readings: Modeling comprehension, vocabulary, text structures, and text features for older readers. The Reading Teacher, 61(7), 548-556, doi:10.1598/RT.61.7.4

Fisher, D., \& Ivey, G. (2005). Literacy and language as learning in content-area classes: A departure from "every teacher a teacher of reading." Action in Teacher Education, 277(2), 3-11.

Flick, U. (2009). An introduction to qualitative research (4th ed.). Los Angeles, CA: Sage.

Fontana, A. \& Frey, J. H. (2005). The interview: From neutral stance to political involvement. In N. K. Denzin and Y. S. Lincoln (Eds.), The Sage handbook of qualitative research (3rd ed.) (pp. 695-727). Thousand Oaks, CA: Sage.

Geertz, C. (1973). The interpretation of cultures: Selected essays. New York, NY: Basic Books. Goodenough, W. (1963). Cooperation in change. New York, NY: Russell Sage.

Giorgi, A. (1997). The theory, practice, and evaluation of the phenomenological method as a 
qualitative research procedure. Journal of Phenomenological Psychology, 28(2), 235261.

Giorgi, A. (2009). The descriptive phenomenological method in psychology: A modified Husserlian approach. Pittsburgh, PA: Duquesne University.

Gove, M. K. (1983). Clarifying teacher's beliefs about reading. The Reading Teacher, 37(3), 261-268.

Goodman, J. (1988). Constructing a practical philosophy of teaching: A study of preservice teachers' professional perspectives. Teaching \& Teacher Education, 4, 121-137.

Graham, S., \& Hebert, M. A. (2010). Writing to read: Evidence for how writing can improve reading. A Carnegie Corporation Time to Act Report. Washington, DC: Alliance for Excellent Education.

Graham, S., \& Perin, D. (2007). Writing next: Effective strategies to improve writing of adolescents in middle and high schools -A report to Carnegie Corporation of New York. Washington, DC: Alliance for Excellent Education.

Graves, M. F., \& Liang, A. L. (2008). Four facets of reading comprehension instruction in the middle grades. Middle School Journal, 39(4), 6-45.

Grierson, S., \& Nokes, J. D. (2010). (Re)Imagining literacies for English language arts classrooms. In R. J. Draper (Ed.), (Re)Imagining content-area literacy instruction (pp. 113-126). New York, NY: Teachers College Press.

Harste, J. C., \& Burke, C. L. (1977). A new hypothesis for reading teacher researcher: Both the teaching and learning of reading are theoretically based. In P. D. Pearson (Ed.). Reading: Theory Research and Practice, pp. 32-40.

Hativa, N., \& Goodyear, P. (Eds.) (2002). Teacher thinking, beliefs and knowledge in higher 
education. MA: Kluwer Academic Press.

Heller, R. \& Greenleaf, C. (2007). Literacy instruction in the content areas: Getting to the core of middle and high school improvement. Washington, DC: Alliance for Excellent Education.

Heron, J. (1992). Feeling and personhood: Psychology in another key. London: Sage.

Hesse-Biber \& Leavy, (2011). The practice of qualitative research (2nd ed.). Thousand Oaks, CA: Sage.

Husserl, E. (1931). Ideas: General introduction to pure phenomenology. London: G. Allen \& Unwin.

Husserl, E. (1977). Cartesian meditations: An introduction to metaphysics. The Hague: Martinus Nijhoff.

Husserl, E. (2008/1931). Ideas pertaining to a pure phenomenology and to a phenomenological philosophy: First book. K. Kersten (Trans.). New York: Springer.

International Reading Association. (2000). Excellent reading teachers: A position statement of the International Reading Association. Newark, DE: Author. Retrieved from http://www. reading. org/downloads/positions/ps1041_excellent.pdf

International Reading Association. (2012). Adolescent literacy (Position statement, Rev. 2012 ed.). Newark, DE: Author.

International Reading Association and the National Middle School Association (2002). Supporting young adolescents' literacy learning: A joint position statement of the International Reading Association and the National Middle School Association. Retrieved from http://www.reading.org/Libraries/position-statements-and resolutions/ ps1052_supporting.pdf 
Irwin, P. (1991). National Literacy Act of 1991: Major Provisions of P.L. 102-73. CRS Report for Congress. Retrieved from http://www.eric.ed.gov/PDFS/ED341851.pdf

Ivey, G. (1999). A multicase study in the middle school: Complexities among young adolescent readers. Reading Research Quarterly, 34(2), 172-192.

Jackson, A. W., \& Davis, G. A. (2000). Turning points 2000: educating adolescents in the $21^{\text {st }}$ century. New York: Teachers' College Press.

Jetton, T. L., \& Dole, J. A. (2004). Adolescent literacy research and practice. New York: Guilford Press.

Kagan, D. M. (1993). Implications of research on teacher beliefs. Educational Psychologist, 27(1), 65-90.

Kamil, M. L. (2003). Adolescents and literacy: Reading for the 21 st century. Washington, DC: Alliance for Excellent Education.

Kamil, M. L., Borman, G. D., Dole, J., Kral, C. C., Salinger, T., \& Torgesen, J. (2008). Improving adolescent literacy: Effective classroom and intervention practices: A Practice Guide (NCEE \#2008-4027). Washington, DC: National Center for Education Evaluation and Regional Assistance, Institute of Education Sciences, U.S. Department of Education.

King-Shaver, B. \& Hunter, A. (2009). Adolescent literacy and differentiated instruction. Portsmouth, NH: Heinemann.

Kvale, S. \& Brinkmann, S. (2009). Interviews: Learning the craft of qualitative research interviewing (2nd ed.). Los Angeles, CA: Sage.

Langer, J. (2001). Beating the odds: Teaching middle and high school students to read and write well. American Educational Research Journal, 38(4), 837-880. 
Lee, J., Grigg, W., \& Donahue, P. (2007). The nation's report card: Reading 2007 (NCES 2007496). Washington, DC: National Center for Education Statistics, Institute of Education Sciences, U.S. Department of Education.

Lenski, S. D., Wham, M. A., \& Griffey, D. C. (1998). Literacy orientation survey: A survey to clarify teachers' beliefs and practices. Reading Research and Instruction, 37(3), 217-236.

Leu, D. (2001). Internet project: Preparing students for new literacies in a global village. The Reading Teacher, 54(6).

Leu, D. J., \& Kinzer, C. K. (1995). Effective reading instruction in the elementary grades, K-8 (3rd ed.). Englewood Cliffs, NJ: Merrill.

Lincoln, Y. S., \& Guba, E. G. (1985). Naturalistic inquiry. Beverly Hills, CA: Sage.

Lincoln, Y. S., \& Guba, E. G. (2000). Paradigmatic controversies, contradictions, and emerging confluences. In N. K. Denzin \& Y. S. Lincoln (Eds.), Handbook of qualitative research (2nd ed.) (pp. 163-188). Thousand Oaks, CA: Sage. Retrieved from http://faculty. washington.edu/pnhoward/teaching/methods/readings/com501_lincoln_paradigmatic_co ntroversies.pdf

Mallette, M. H., Henk, W. A., Waggoner, J. E., \& DeLaney, C. J. (2005). What matters most? A survey of accomplished middle level educators' beliefs and values about literacy. Action in Teacher Education, 27(2), 33-42.

Maxwell, J. A. (2005). Qualitative research design: An interactive approach (2nd ed.). Thousand Oaks, CA: Sage.

Mays-Woods, A. and Weasmer, J. (2003). Great expectations for student teachers: Explicit and implied. Education, 123(4), 681-687.

McCutchen, D., Abbott, R. D., Green, L. B., Beretvas, S. N., Cox, S., Potter, N. S., Quiroga, T., 
\& Gray, A. (2002). Beginning literacy: Links among teacher knowledge, teacher practice, and student learning. Journal of Learning Disabilities, 35, 69-86.

McCutchen, D., Green, L., Abbott, R. D., \& Sanders, E. A. (2009). Further evidence for teacher knowledge: Supporting struggling readers in grades three through five. Reading and Writing: An Interdisciplinary Journal, 22, 401-423.

Meltzer, J., Smith, N. C., \& Clark, H. (2002). Adolescent literacy resources: Linking research and practice. Providence, RI: The Education Alliance at Brown University. Retrieved from http://www.brown.edu/academics/education-alliance/publications/adolescentliteracy-resources-linking-research-and-practice

Merleau-Ponty, M. (1962). Phenomenology of perception. London: Routledge and Kegan Paul. Merleau-Ponty, M. (1964). Signs. Evanston, IL: Northwestern University Press. Retrieved from http://books.google.com/books?id=Qj-iZurbei4C\&printsec=frontcover\&source=gbs_ge _ summary_r\&cad=0\#v=onepage $\& \mathrm{q} \& \mathrm{f}=\mathrm{false}$

Merriam, S. B. (1998). Qualitative research and case study applications in education, revised and expanded from case study research in education. San Francisco, CA. Jossey-Bass.

Merriam, S. B. (2009). Qualitative research: A guide to design and implementation. San Francisco, CA. Jossey-Bass.

Moje, E. B. (2002). Re-framing adolescent literacy research for new times: Studying youth as a resource. Reading Research and Instruction, 41(3), 211-228.

Moje, E. B., Overby, M., Tysvaer, N., \& Morris, K. (2008). The complex world of adolescent literacy: Myths, motivations, and mysteries. Harvard Educational Review, 78(1), 107154.

Moje, E. B., Young, J. P., Readence, J. E., \& Moore, D. W. (2000). Reinventing adolescent 
literacy for new times: Perennial and millennial issues. Journal of Adolescent and Adult Literacy, 43, 400-410.

Moore, D. W. (1996). Contexts for literacy in secondary schools. In D. J. Leu, C. K. Kinzer, \& K. A. Hinchman. Literacies for the 21 st century: Research and practice (pp. 97-112). Chicago: National Reading Conference.

Moore, D.W., Bean, T.W., Birdyshaw, D., \& Rycik, J.A. (1999). Adolescent literacy: A position statement for the commission on adolescent literacy of the International Reading Association. Newark, DE: International Reading Association.

Moustakas, C. (1994). Phenomenological research methods. Thousand Oaks, CA: Sage.

Mujis, D. \& Reynolds, D. (2001). Effective teaching: Evidence and practice. Thousand Oaks, CA: Sage.

Munby, H. (1982). The place of teachers' beliefs in research on teacher thinking and decision making, and an alternative methodology. Instructional Science, 11, 201-225.

Munby, H. (1984). A qualitative approach to the study of a teacher's beliefs. Journal of Research in Science Teaching, 21, 27-38.

Murphy, P. K., Delli, L. A. M., \& Edwards, M. N. (2004). The good teacher and good teaching: Comparing beliefs of second grade students, pre-service teachers, and inservice teachers. The Journal of Experimental Education, 72, 69-72.

National Center for Education Statistics (2009). The Nation's Report Card: Reading 2009 (NCES 2010-458). Institute of Education Sciences, U.S. Department of Education, Washington, D.C.

National Center for Education Statistics (2011). The Nation's Report Card: Reading 2011 
(NCES 2012-457). Institute of Education Sciences, U.S. Department of Education, Washington, D.C.

National Council of Teachers of English. (2004). A position/action statement from NCTE's Commission on Reading. A call to action: What we know about adolescent literacy and ways to support teachers in meeting students' needs. Retrieved from http://www.ncte. org/positions/ statements/adolescentliteracy

National Council of Teachers of English (2006). NCTE principles of adolescent literacy reform: A policy research brief. Retrieved from http://www.ncte.org/library/nctefiles/resources/ policyresearch/adollitprinciples.pdf

National Council of Teachers of English (2007). Adolescent literacy: An NCTE policy research brief. Retrieved from http://www.ncte.org/library/NCTEfiles/Resources/Magazine/ Chron0907AdLitBrief.pdf

NCTE Position Statement on Reading. (2007). Retrieved from http://www.ncte.org/positions/ statements/positiononreading

National Council of Teachers of English (NCTE) and the International Reading Association (IRA). (1996). Standards for the English Language Arts. Retrieved from http://www. ncte.org/library/NCTEFiles/Resources/Books/Sample/StandardsDoc.pdf

National Institute for Literacy. (2009). Adolescent literacy: Research needs. Retrieved from lincs.ed.gov/sites/default/files/adolescence/research_needs.doc

Nespor, J. (1987). The role of beliefs in the practice of teaching. Journal of Curriculum Studies, 19(4), 317-328.

Newmann, F. M. (1996). Authentic achievement: Restructuring schools for intellectual quality. San Francisco, CA: Jossey-Bass Publishers. 
Nisbett, R.E., \& Ross, L. (1980). Human inference: Strategies and shortcomings of social judgment. Englewood Cliffs, NJ: Prentice-Hall.

Nolen, S. (2001). Constructing literacy in kindergarten: Task, structure collaboration and motivation. Cognition and Instruction, 19(1), 95-142.

O’Brien, D.G., Stewart, R.A., \& Moje, E.B. (1995). Why content literacy is difficult to infuse into the secondary school: Complexities of curriculum, pedagogy, and school culture. Reading Research Quarterly, 30(3), 442-463.

Organization for Economic Co-Operation and Development (OECD). (2010). PISA 2009 results: Executive summary. Paris: Author. Retrieved from www.oecd.org/dataoecd/34/60/ 46619703.pdf

Padgett, D. K. (1998). Qualitative methods in social work research: Challenges and rewards. Thousand Oaks, CA: Sage.

Paris, S. G., Wasik, B. A., \& Turner, J. C. (1991). The development of strategic readers. In R. Barr, L. Kamil, P.B. Mosenthal, \& P. D. Pearson (Eds.), Handbook of reading research (Vol. 2, pp. 815-860). New York, NY: Longman.

Pajares, M. F. (1992). Teachers' beliefs and educational research: Cleaning up a messy construct. Review of Educational Research, 62, 307-332.

Patton, M. Q. (2002). Qualitative research and evaluation methods (3rd ed.). Thousand Oaks, CA: Sage.

Peters, C. W., \& Wixson, K. K. (2003). Unifying the domain of K-12 English language arts curriculum. In J. Flood, D. Lapp, J. R. Squire, \& J. M. Jensen (Eds.), Handbook of research on English language arts (2nd ed., pp. 573-589). Mahwah, NJ: Erlbaum.

Pinkus, Lyndsay. (2006). Who's counted? Who's counting? Understanding high school 
graduation rates. Washington, DC: Alliance for Excellent Education.

Pintrich, P. R. (1990). Implications of psychological research on student learning and college teaching for teacher education. In W. R. Houston (Ed.), Handbook of research on teacher education (pp. 826-857). New York, NY: Macmillan.

Pitcher, S. M., Martinez, G., Dicembre, E. A., Fewster, D., \& McCormick, M. K. (2010). The literacy needs of adolescents in their own words. Journal of Adolescent \& Adult Literacy, 53(8), 636-645, doi:10.1598/JAAL.53.8.2

Rabinowitz, P. J., \& Smith, M. W. (1998). Authorizing readers: Resistance and respect in the teaching of literature. New York, NY: Teachers College Press.

Readance, J. E., Kile, R. S., \& Mallette, M. H. (1998). Secondary teachers' beliefs about literacy: Emerging voices. In D. E. Alvermann, K. A., Hinchman, D. W. Moore, S. F. Phelps, \& D. R. Waff (Eds.), Reconceptualizing the literacies in adolescents' lives (pp. 129-148). Mahwah, NJ: Erlbaum.

Resnick, L. B. (2000). Literacy in school and out. In M. A. Gallego \& S. Hollingsworth (Eds.), What counts as literacy: Challenging the school standard (pp. 27-41). New York: Teachers College Press.

Richards, J., \& Lockhart, C. (1994) Reflective teaching in second language classrooms. New York, NY: Cambridge University Press.

Richardson, V. (1996). The role of attitudes and beliefs in learning to teach. In J. Sikula (Ed.), Handbook of research on teacher education (2nd ed., pp. 109-112). New York: Macmillan.

Rimm-Kaufman, S. E., \& Sawyer, B. E. (2004). Primary-grade teachers' self-efficacy beliefs, 
attitudes toward reaching, and discipline and teaching practice priorities to the responsive classroom approach. The Elementary School Journal, 104(4), 321-342.

Ruddell, R.B. (2004). Researching the influential literacy teacher: Characteristics, beliefs, strategies, and new research directions. In R.B. Ruddell \& N.J. Unrau (Eds.), Theoretical models and processes of reading (5th ed., pp. 979-997). Newark, DE: International Reading Association.

Ruddell, R.B., \& Unrau, N.J. (2004). Reading as a meaning-construction process: The reader, the text, and the teacher. In R.B. Ruddell \& N.J. Unrau (Eds.), Theoretical models and processes of reading (5th ed., pp. 1462-1521). Newark, DE: International Reading Association.

Scherff, L. \& Hahs-Vaughn, D. L. (2008). What we know about English language arts teachers: An analysis of the 1999-2000 SASS and 2000-2001 TFS databases. English Education, 40(3), 174-200.

Schmoker, M. J. (2006). Results now: How we can achieve unprecedented improvements in teaching and learning. Alexandria, VA: Association for Supervision and Curriculum Development.

Scholes, R. (1985). Textual power: Literary theory and the teaching of English. New Haven, CT: Yale University Press.

Scholes, R. (1985). The crafty reader. New Haven, CT: Yale University Press.

Schunk, D. H. (1991). Self-efficacy and academic motivation. Educational Psychologist, 26, $207-231$.

Scribner, S. (1988). Literacy in three metaphors. In E. G. Kintgen, B. M. Knoll, \& M. Rose 
(Eds.), Perspectives on literacy (pp. 71-81). Carbondale, IL: Southern Illinois University Press.

Shumway, S. L., \& Wright, G. A. (2010). (Re)Imagining literacies for technology classrooms. In R. J. Draper (Ed.), (Re)Imagining content-area literacy instruction (pp. 20-39). New York, NY: Teachers College Press.

Snow, C. E., \& Biancarosa, G. (2003). Adolescent literacy and the achievement gap: What do we know and where do we go from here? New York: Carnegie Corporation of New York.

Spear-Swerling, L., \& Brucker, P. (2004). Preparing novice teachers to develop basic reading and spelling skills in children. Annals of Dyslexia, 54, 332-364.

Spiegelberg, H. (1995). Phenomenology through vicarious experience. In H. Spiegelberg (Ed.), Doing phenomenology (pp. 35-53). The Hague: Martinus Nijhoff.

Staton, S. F. (1987). Literary theories in praxis. Philadelphia, PA: University of Pennsylvania Press.

Stevens, L. P. (2002). Making the road by walking: The transition from content area literacy to adolescent literacy. Reading Research and Instruction, 41, 267-278.

Street, B. (2001). The new literacy studies. In E. Cushman, E.R. Kintgen, B.M. Kroll, \& M. Rose (Eds.), Literacy: A Critical Sourcebook (pp. 430-442). Boston: Bedford/St. Martin's.

Theriot, S., \& Tice, K. C. (2008). Teachers' knowledge development and change: Untangling beliefs and practices. Literacy Research and Instruction, 48(1), 65-75, doi: 10.1080/ 19388070802226287

U.S. Department of Education, National Center for Education Statistics, The Nation's Report 
Card: Reading 2011 (NCES 2012-457) (Washington, DC: U.S. Government Printing Office, 2011). Retrieved from http://nces.ed.gov/nationsreportcard/pdf/main2011/ 2012457.pdf

Vescio, V., Ross, D. \& Adams, A. (2008). A review of research on the impact of professional learning communities on teaching practice and student learning. Teaching and Teacher Education, 24, 80-91. Retrieved from https://www.k12.wa.us/Compensation/pubdocs/ Vescio2008PLC-paper.pdf

Virginia Department of Education. (2011). Standards of Learning Documents for English: Curriculum Framework. Retrieved from http://www.doe.virginia.gov/testing/sol/ standards_docs/english/index.shtml

Warschauer, M. (1997). A sociocultural approach to literacy and its significance for CALL. In K. Murphy-Judy \& R. Sanders (Eds.), Nexus: The convergence of research \& teaching through new information technologies (pp. 88-97). Durham: University of North Carolina. Retrieved from http://gse.uci.edu/person/warschauer_m/sociocultural.html

Wise, B. (2009). Adolescent literacy: The cornerstone of student success. Journal of Adolescent and Adult Literacy, 52(5), 369-375. doi:10.1598/JAAL.52.5.1

Wray, D., Medwell, J., Poulson, L., \& Fox, R. (2002). Teaching Literacy Effectively in the Primary School. Routledge Falmer: London.

Yero, J. L. (2002). Teaching in mind: How teacher thinking shapes education. Montana: MindFlight Publishing.

Yin, R. K. (2014). Case study research: Design and methods (5th ed.).Los Angeles, CA: Sage. Zahavi, D. (2003). Husserl's phenomenology. Stanford, CA: Stanford University. 


\section{Appendix A}

Overview of Methodological Considerations Drawn From Articles about Beliefs

Quantitative Research Methods

\begin{tabular}{|c|c|c|c|c|c|}
\hline Author \& Title & $\begin{array}{c}\text { Research Method(s) \& } \\
\text { Questions }\end{array}$ & Data Sources & Number of Participants & $\begin{array}{l}\text { Context for the } \\
\text { Investigation }\end{array}$ & $\begin{array}{l}\text { Time Frame for } \\
\text { Collecting Data }\end{array}$ \\
\hline $\begin{array}{l}\text { Duffy, Gerald \& } \\
\text { Metheney, William } \\
\text { (1979) } \\
\text { Measuring Teachers' } \\
\text { Beliefs About } \\
\text { Reading }\end{array}$ & $\begin{array}{l}\text { - development of a } \\
\text { quantitative } \\
\text { instrument for } \\
\text { determining if } \\
\text { teachers possess } \\
\text { beliefs about } \\
\text { reading and if so, } \\
\text { whether these } \\
\text { beliefs influence } \\
\text { instructional } \\
\text { decision making } \\
\text { and student } \\
\text { outcomes } \\
\text { "reading } \\
\text { propositional } \\
\text { inventory" } \\
\text { (no research } \\
\text { questions included) }\end{array}$ & $\begin{array}{l}\text { - identified (through } \\
\text { observations) } \\
\text { teacher decision- } \\
\text { making categories: } \\
\text { o judging pupil } \\
\text { success } \\
\text { o criteria for forming } \\
\text { instructional groups } \\
\text { o allocation of time } \\
\text { to reading activities } \\
\text { o allocation of time } \\
\text { to ability groups } \\
\text { o favored word } \\
\text { recognition prompts } \\
\text { o comprehension } \\
\text { emphasis } \\
\text { o instructional role }\end{array}$ & $\begin{array}{l}\text { - } 5 \text { categories of } \\
\text { beliefs about } \\
\text { reading identified: } \\
\text { o basal textbook } \\
\text { o linear skills } \\
\text { o interest-based } \\
\text { selection of trade } \\
\text { books } \\
\text { o natural language } \\
\text { (psycholinguistics \& } \\
\text { language experience) } \\
\text { o integrated } \\
\text { curriculum models } \\
\text { - later used } \\
\text { categories to } \\
\text { develop statement } \\
\text { cards which were } \\
\text { sorted by } \\
\text { agree/disagree } \\
\text { - then converted to } \\
\text { 5-point Likert-scale } \\
\text { w/6 conceptual } \\
\text { categories; factor } \\
\text { analysis led to three } \\
\text { clusters: } \\
\text { o basal text \& linear }\end{array}$ & $\begin{array}{l}\text { - } 10 \text { elementary } \\
\text { classrooms - } 3 \\
\text { states }\end{array}$ & $\begin{array}{l}\text { (time frame not } \\
\text { indicated) }\end{array}$ \\
\hline
\end{tabular}




\begin{tabular}{|c|c|c|c|c|c|}
\hline & & & $\begin{array}{l}\text { skills cluster } \\
\text { o interest-based, } \\
\text { natural language, and } \\
\text { integrated } \\
\text { curriculum models } \\
\text { cluster } \\
\text { o "confused- } \\
\text { frustrated" category } \\
\text { (this category was } \\
\text { eliminated - could } \\
\text { not be validated) } \\
\text { - Next, conducted } \\
150 \text { observations of } \\
10 \text { different } \\
\text { elementary } \\
\text { classrooms in } 3 \\
\text { states } \\
\text { - led to a 50-item } \\
\text { Likert-scale } \\
\text { inventory w/both } \\
\text { theoretical } \\
\text { conceptions and } \\
\text { observational data }\end{array}$ & & \\
\hline Author \& Title & $\begin{array}{c}\text { Research Method(s) \& } \\
\text { Questions }\end{array}$ & Data Sources & Number of Participants & $\begin{array}{l}\text { Context for the } \\
\text { Investigation }\end{array}$ & $\begin{array}{l}\text { Time Frame for } \\
\text { Collecting Data }\end{array}$ \\
\hline $\begin{array}{l}\text { DeFord, Diane (1985) } \\
\text { Validating the } \\
\text { Construct of } \\
\text { Theoretical } \\
\text { Orientation in } \\
\text { Reading } \\
\text { Instruction }\end{array}$ & $\begin{array}{l}\text { validated } \\
\text { instrument to } \\
\text { determine a } \\
\text { teacher's } \\
\text { theoretical } \\
\text { orientation to } \\
\text { reading instruction } \\
\text { (Theoretical }\end{array}$ & $\begin{array}{l}\text { - Likert-scale survey } \\
\text { responses } \\
\text { - judges from field of } \\
\text { reading asked if } \\
\text { agree on what } \\
\text { responses are } \\
\text { indicative of } \\
\text { phonics, skills, or }\end{array}$ & $\begin{array}{l}\text { - pilot used } 47 \\
\text { experts in the field } \\
\text { and teachers of } \\
\text { known orientation } \\
\text { - validation used } 90 \\
\text { teachers; } 30 \text { for } \\
\text { each of three }\end{array}$ & $\begin{array}{l}\text { (location not } \\
\text { specified) }\end{array}$ & $\begin{array}{l}\text { (time frame not } \\
\text { indicated) }\end{array}$ \\
\hline
\end{tabular}




\begin{tabular}{|c|c|c|c|c|c|}
\hline & $\begin{array}{l}\text { Orientation to } \\
\text { Reading Profile - } \\
\text { TOPR) } \\
\text { - used to determine } \\
\text { teacher beliefs } \\
\text { about practices in } \\
\text { reading instruction } \\
\text { (no research } \\
\text { questions included) }\end{array}$ & $\begin{array}{l}\text { whole language } \\
\text { orientation; } \\
\text { - observations of } \\
\text { teachers by } \\
\text { "experts" } \\
\text { - } 3 \text { observers trained } \\
\text { to select salient } \\
\text { features of } \\
\text { theoretical } \\
\text { orientation in } \\
\text { videotapes of } \\
\text { teachers } \\
\text { - } 3 \text { separate sessions, } \\
\text { viewed videotaped } \\
\text { reading lessons - } \\
\text { analyzed for overt } \\
\& \text { covert indices of } \\
\text { teachers' models of } \\
\text { reading }\end{array}$ & $\begin{array}{l}\text { groups identified as } \\
\text { holding phonics, } \\
\text { skills, \& whole } \\
\text { language } \\
\text { orientations } \\
\text { - } 14 \text { teachers } \\
\text { involved in } \\
\text { evaluation project } \\
\text { asked to respond to } \\
\text { TORP - then } \\
\text { observed by one of } \\
\text { the trained } \\
\text { observers }\end{array}$ & & \\
\hline Author \& Title & $\begin{array}{c}\text { Research Method(s) \& } \\
\text { Questions } \\
\end{array}$ & Data Sources & Number of Participants & $\begin{array}{l}\text { Context for the } \\
\text { Investigation }\end{array}$ & $\begin{array}{l}\text { Time Frame for } \\
\text { Collecting Data }\end{array}$ \\
\hline $\begin{array}{l}\text { Lenski, Susan Davis } \\
\text { Wham, Mary Ann \& } \\
\text { David C. Griffey } \\
\text { (1998) } \\
\text { Literacy Orientation } \\
\text { Survey: A Survey to } \\
\text { Clarify Teachers' } \\
\text { Beliefs and Practices }\end{array}$ & $\begin{array}{l}\text { - development of } \\
\text { Literacy Orientation } \\
\text { Survey (LOS) } \\
\text { - used for assessing } \\
\text { teachers' beliefs } \\
\text { about literacy } \\
\text { learning and } \\
\text { classroom practices } \\
\text { as they relate to } \\
\text { constructivism } \\
\text { - define practice of }\end{array}$ & $\begin{array}{l}\text { - } 10 \text { principles LOS } \\
\text { based on include: } \\
\text { - Principle 1: The } \\
\text { teacher views } \\
\text { literacy as a } \\
\text { meaning-making } \\
\text { process. } \\
\text { - Principle 2: The } \\
\text { teacher facilitates } \\
\text { child-centered } \\
\text { instruction. } \\
\text { - Principle 3: The } \\
\text { teacher creates an }\end{array}$ & $\begin{array}{l}\text { - preliminary pool of } \\
118 \text { survey items - } \\
\text { approximately } 1 / 2 \\
\text { focused on beliefs } \\
\& 1 / 2 \text { focused on } \\
\text { practices } \\
\text { - } 20 \text { experts } \\
\text { conducted } \\
\text { judgmental review } \\
\text { - item analysis - } \\
\text { retained } 44 \text { items }\end{array}$ & - elementary schools & $\begin{array}{l}\text { (time frame not } \\
\text { indicated) }\end{array}$ \\
\hline
\end{tabular}




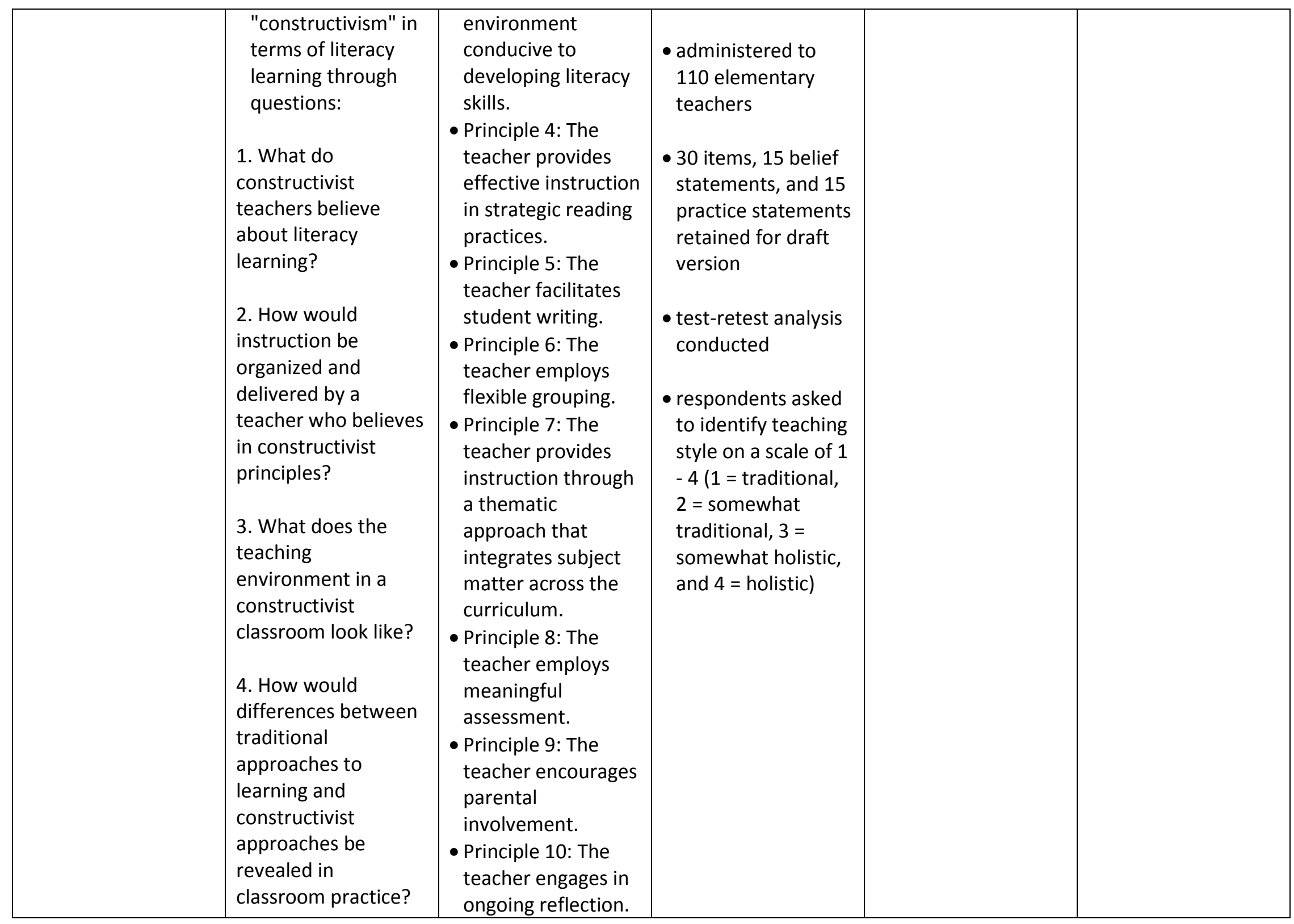


Qualitative Research Methods

\begin{tabular}{|c|c|c|c|c|c|}
\hline Author \& Title & $\begin{array}{c}\text { Research Method(s) \& } \\
\text { Questions }\end{array}$ & Data Sources & Number of Participants & $\begin{array}{l}\text { Context for the } \\
\text { Investigation }\end{array}$ & $\begin{array}{l}\text { Time Frame for } \\
\text { Collecting Data }\end{array}$ \\
\hline $\begin{array}{l}\text { Nolen, Susan } \\
\text { Bobbbitt (2001) } \\
\text { Constructing Literacy } \\
\text { in the Kindergarten: } \\
\text { Task Structure, } \\
\text { Collaboration, and } \\
\text { Motivation }\end{array}$ & $\begin{array}{l}\text { - ethnographic study } \\
\text { 1. What are the } \\
\text { shared contexts of } \\
\text { meaning that } \\
\text { constitute literacy- } \\
\text { related social activity } \\
\text { in these classrooms? } \\
\text { 2. How is the } \\
\text { construction of what } \\
\text { it means to read and } \\
\text { write enacted within } \\
\text { particular activity } \\
\text { structures? } \\
\text { 3. What do individual } \\
\text { children, specifically } \\
\text { those at risk for } \\
\text { reading and writing } \\
\text { difficulty or disability, } \\
\text { and the teacher } \\
\text { contribute to this } \\
\text { flow of literate } \\
\text { activity? } \\
\text { 4. How do individual } \\
\text { children's } \\
\text { reconstructions of } \\
\text { social meaning of } \\
\text { literacy change over }\end{array}$ & $\begin{array}{l}\text { - data from } 3 \\
\text { perspectives: } \\
\text { teacher's, } \\
\text { students', and } \\
\text { research-observer } \\
\text { - observations - } \\
\text { averaged } 1 \frac{1 / 2}{\mathrm{hrs} .} \\
\text { ranged from } 45 \mathrm{~min} \\
\text { to } 21 / 2 \mathrm{hrs} \text {. } \\
\text { - field notes } \\
\text { - teacher interviews } \\
\text { - student interviews } \\
\text { (lowest } 5 \text { qualifying } \\
\text { students in each } \\
\text { class became a } \\
\text { target group) }\end{array}$ & - 4 teachers & $\begin{array}{l}\text { - } 3 \text { kindergarten } \\
\text { classrooms located } \\
\text { in } 2 \text { suburban } \\
\text { school districts }\end{array}$ & $\begin{array}{l}\text { (time frame not } \\
\text { indicated - noted } \\
\text { interviews at the end } \\
\text { of the school year) }\end{array}$ \\
\hline
\end{tabular}




\begin{tabular}{|c|c|c|c|c|c|}
\hline & $\begin{array}{l}\text { time? } \\
\text { 5. How does the } \\
\text { nature of literacy as } \\
\text { constructed by } \\
\text { kindergarten } \\
\text { students and } \\
\text { teachers relate to } \\
\text { students' motivation } \\
\text { to read and write? In } \\
\text { particular, how might } \\
\text { this jointly } \\
\text { constructed literacy } \\
\text { context influence or } \\
\text { interact with the } \\
\text { motivation of } \\
\text { children for whom } \\
\text { reading and writing } \\
\text { are particularly } \\
\text { difficult? }\end{array}$ & & & & \\
\hline Author \& Title & $\begin{array}{c}\text { Research Method(s) \& } \\
\text { Questions }\end{array}$ & Data Sources & Number of Participants & $\begin{array}{l}\text { Context for the } \\
\text { Investigation }\end{array}$ & $\begin{array}{l}\text { Time Frame for } \\
\text { Collecting Data }\end{array}$ \\
\hline $\begin{array}{l}\text { Dooley, Caitlin } \\
\text { McMunn \& Assaf, } \\
\text { Lori Czop (2009) } \\
\text { Contexts Matter: Two } \\
\text { Teachers' Language } \\
\text { Arts Instruction in } \\
\text { this High-stakes Era }\end{array}$ & $\begin{array}{l}\text { - ethnographic case } \\
\text { studies } \\
\text { - retrospective cross- } \\
\text { case analysis } \\
\text { occurred after prior } \\
\text { studies } \\
\text { 1. What do two } \\
\text { language arts } \\
\text { teachers, one from } \\
\text { an urban and one } \\
\text { from a suburban }\end{array}$ & $\begin{array}{l}\text { - observed in } \\
\text { exemplary language } \\
\text { arts teachers' } \\
\text { classrooms } \\
\text { - formal interviews } \\
\text { - informal interviews } \\
\text { of teachers \& } \\
\text { students to clarify } \\
\text { issues and/or } \\
\text { questions }\end{array}$ & - 2 teachers & $\begin{array}{l}-4^{\text {th }} \text { grade language } \\
\text { arts classrooms } \\
\text { - } 2 \text { different school } \\
\text { districts }\end{array}$ & $\begin{array}{l}\text { (time frame not } \\
\text { indicated) }\end{array}$ \\
\hline
\end{tabular}




\begin{tabular}{|c|c|c|c|c|c|}
\hline & $\begin{array}{l}\text { school, say and do in } \\
\text { response to the } \\
\text { influence of the high- } \\
\text { stakes testing on } \\
\text { their teaching and } \\
\text { students? } \\
\text { 2. What role do } \\
\text { contextual factors } \\
\text { (e.g., teacher } \\
\text { development } \\
\text { opportunities, } \\
\text { student population, } \\
\text { resources) play in the } \\
\text { two teachers' belief } \\
\text { statements and } \\
\text { practices? }\end{array}$ & & & & \\
\hline \multicolumn{6}{|c|}{ Mixed Methods } \\
\hline Author \& Title & $\begin{array}{c}\text { Research Method(s) \& } \\
\text { Questions }\end{array}$ & Data Sources & Number of Participants & $\begin{array}{l}\text { Context for the } \\
\text { Investigation }\end{array}$ & $\begin{array}{l}\text { Time Frame for } \\
\text { Collecting Data }\end{array}$ \\
\hline $\begin{array}{l}\text { Dadds, Marion } \\
\text { (1999) } \\
\text { Teachers' Values and } \\
\text { the Literacy Hour }\end{array}$ & $\begin{array}{l}\text { - critical action } \\
\text { research - seven } \\
\text { case studies (later } \\
\text { to evolve into } 10 \text { as } \\
\text { new members } \\
\text { joined) } \\
\text { 1. What do teachers } \\
\text { in our schools value } \\
\text { in literacy? }\end{array}$ & $\begin{array}{l}\text { - different methods } \\
\text { \& contexts were } \\
\text { used } \\
\text { - some conducted } \\
\text { individual teacher } \\
\text { interviews } \\
\text { - one used a } \\
\text { questionnaire } \\
\text { - one used an open- } \\
\text { ended discussion } \\
\text { with part of the } \\
\text { staff group } \\
\text { - preliminary meta- }\end{array}$ & $\begin{array}{l}\text { - } 10 \text { "case studies" - } \\
\text { number of } \\
\text { members not } \\
\text { specified } \\
\text { - experienced } \\
\text { teacher-researchers } \\
\text { from primary } \\
\text { schools }\end{array}$ & $\begin{array}{l}\text { - primary schools in } \\
\text { East Anglia \& } \\
\text { London }\end{array}$ & $\begin{array}{l}\text { (time frame not } \\
\text { specified) }\end{array}$ \\
\hline
\end{tabular}




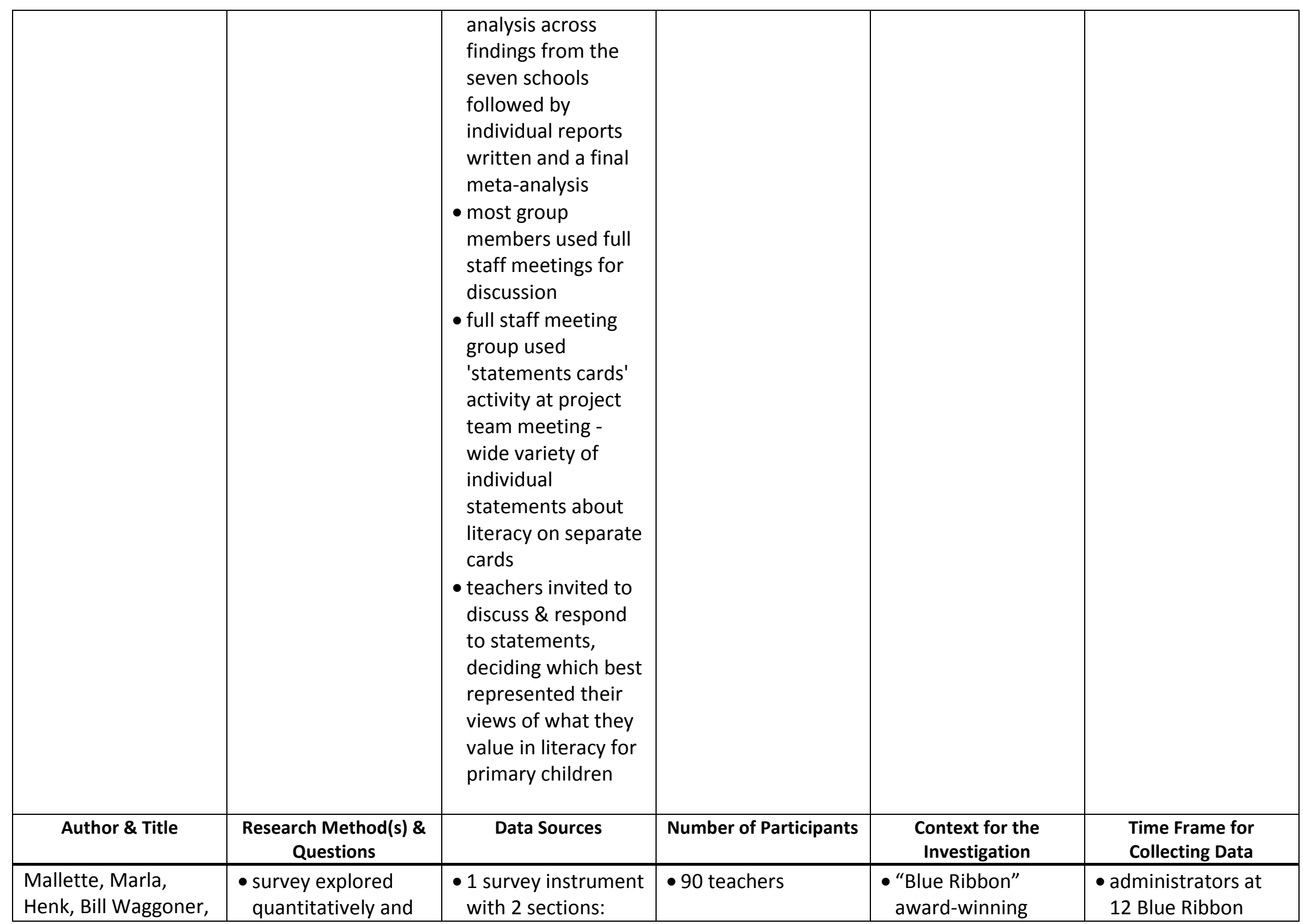




\begin{tabular}{|c|c|c|c|c|}
\hline $\begin{array}{l}\text { Jan \& DeLaney, Carol } \\
\text { (2005) } \\
\text { What Matters Most? } \\
\text { A Survey of } \\
\text { Accomplished } \\
\text { Middle-Level } \\
\text { Educators' Beliefs } \\
\text { and Values about } \\
\text { Literacy }\end{array}$ & $\begin{array}{l}\text { qualitatively how } \\
\text { accomplished } \\
\text { middle-level } \\
\text { educators' defined } \\
\text { selves as teachers } \\
\text { of literacy, how } \\
\text { they viewed } \\
\text { multiliteracies, \& } \\
\text { valued these } \\
\text { literacies in } \\
\text { classroom } \\
\text { 1. Do middle-grade } \\
\text { educators recognize } \\
\text { and value multiple } \\
\text { literacies? } \\
\text { 2. How do these } \\
\text { educators define } \\
\text { their roles in } \\
\text { teaching literacy? } \\
\text { 3. What aspects of } \\
\text { literacy do they value } \\
\text { most? }\end{array}$ & $\begin{array}{l}\text { o first section } \\
\text { questions focused on } \\
\text { demographics, years } \\
\text { of teaching, grade } \\
\text { levels taught or } \\
\text { administered, } \\
\text { subjects taught, } \\
\text { levels of education, } \\
\text { other certification } \\
\text { and endorsements, } \\
\text { professional } \\
\text { development, \& } \\
\text { gender } \\
\text { o second section, } \\
\text { open-ended } \\
\text { questions: } \\
\text { 1) Do you consider } \\
\text { literacy instruction to } \\
\text { be a major part of } \\
\text { your teaching } \\
\text { responsibilities? } \\
\text { Please explain. } \\
\text { 2) In what specific } \\
\text { ways do you think } \\
\text { your students use } \\
\text { literacy in their } \\
\text { personal lives? } \\
\text { 3) Do you believe } \\
\text { middle-grade } \\
\text { students' uses of } \\
\text { literacy should } \\
\text { influence the nature } \\
\text { of literacy } \\
\text { instruction? Please }\end{array}$ & middle schools & $\begin{array}{l}\text { Schools in state } \\
\text { were telephoned to } \\
\text { ask for participation } \\
\text { \& participation of } \\
\text { teaching staff } \\
\text { - respondents given } \\
2 \text { weeks to } \\
\text { complete survey } \\
\text { - then principals } \\
\text { were telephoned } \\
\text { again with a further } \\
\text { request to } \\
\text { encourage } \\
\text { participation of all } \\
\text { teachers }\end{array}$ \\
\hline
\end{tabular}




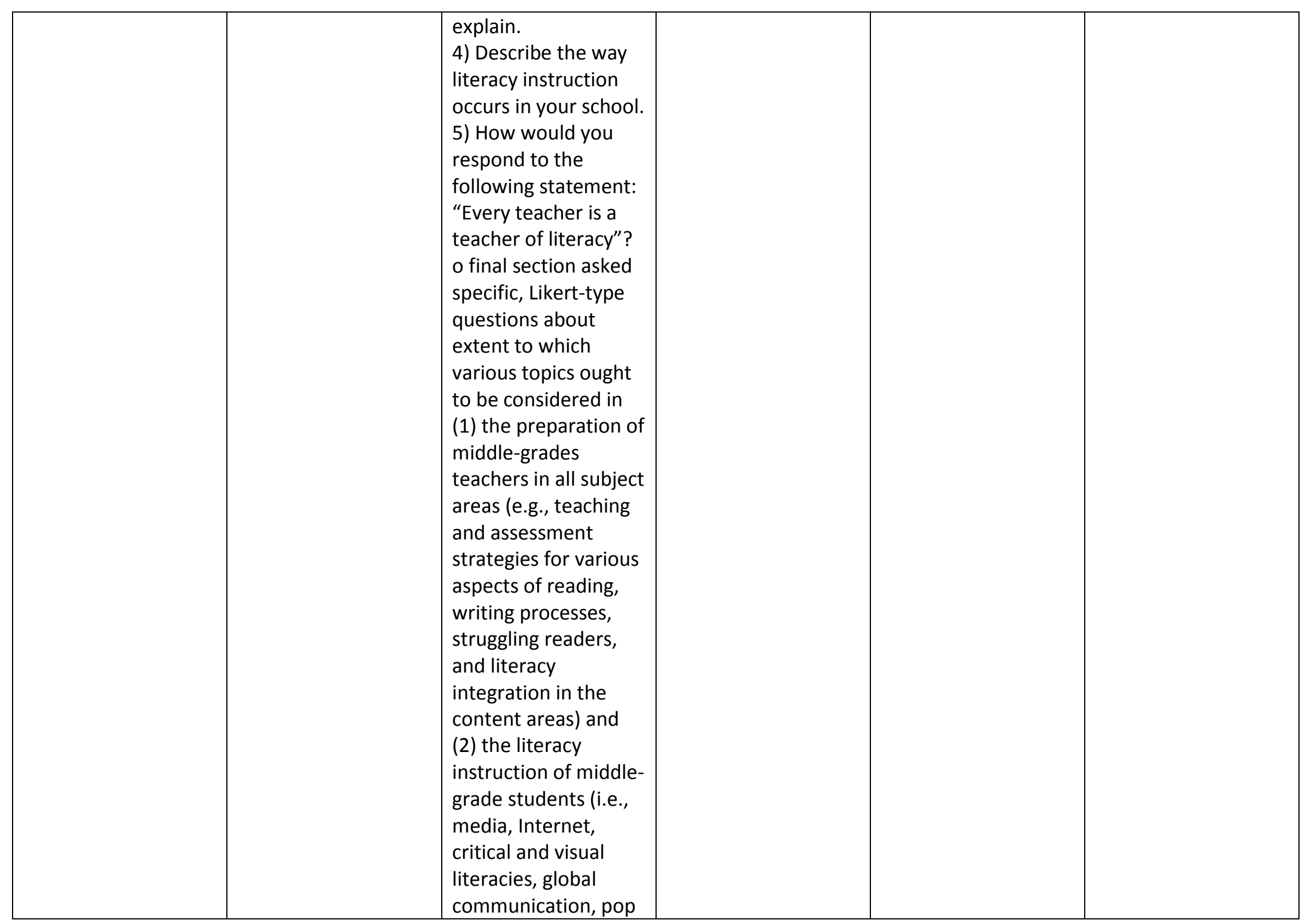




\begin{tabular}{|c|c|c|c|c|c|}
\hline & & $\begin{array}{l}\text { culture, in and out- } \\
\text { of-school literacies, } \\
\text { and cultural and } \\
\text { linguistic diversity); } \\
\text { response choices } \\
\text { were: Essential, Very } \\
\text { Important, } \\
\text { Somewhat } \\
\text { Important, and Not } \\
\text { Important. }\end{array}$ & & & \\
\hline Author \& Title & $\begin{array}{c}\text { Research Method(s) \& } \\
\text { Questions }\end{array}$ & Data Sources & Number of Participants & $\begin{array}{l}\text { Context for the } \\
\text { Investigation }\end{array}$ & $\begin{array}{l}\text { Time Frame for } \\
\text { Collecting Data }\end{array}$ \\
\hline $\begin{array}{l}\text { Theriot, Shirley \& } \\
\text { Tice, Kathleen C. } \\
\text { (2008) } \\
\text { Teachers' Knowledge } \\
\text { Development and } \\
\text { Change: Untangling } \\
\text { Beliefs and Practices }\end{array}$ & $\begin{array}{l}\text { - collective case } \\
\text { studies of } 6 \\
\text { teachers } \\
\text { (initial guiding } \\
\text { research questions } \\
\text { not included - article } \\
\text { shared only } 1 \text { of } 6 \\
\text { case studies) }\end{array}$ & $\begin{array}{l}\text { - } 1 \text { individual semi- } \\
\text { structured } \\
\text { interview - teachers } \\
\text { shared information } \\
\text { about teaching } \\
\text { career \& their } \\
\text { teaching } \\
\text { - responses to } \\
\text { instrument } \\
\text { designed to reveal } \\
\text { teachers' beliefs } \\
\text { how a person reads } \\
\text { \& how reading is } \\
\text { developed (Leu \& } \\
\text { Kinzer, 1995) } \\
\text { - classroom } \\
\text { observations (2 } \\
\text { hour observation of } \\
\text { each teacher } \\
\text { providing literacy } \\
\text { instruction) } \\
\text { - field notes } \\
\end{array}$ & - 6 teachers & $\begin{array}{l}\text { - middle-school in } \\
\text { one school district } \\
\text { in a southern } \\
\text { region } \\
\text { - teachers attended } \\
\text { workshops district } \\
\text { language arts } \\
\text { coordinator } \\
\text { planned } \\
\text { - outside consultants } \\
\text { or teacher leaders } \\
\text { presented } \\
\text { - workshops focused } \\
\text { on ways to provide } \\
\text { authentic literacy } \\
\text { experiences as an } \\
\text { alternative to } \\
\text { traditional practices } \\
\text { that focused on } \\
\text { isolated skill } \\
\text { development }\end{array}$ & $\begin{array}{l}\text { (time frame not } \\
\text { specified) }\end{array}$ \\
\hline
\end{tabular}


Recent Dissertations

\begin{tabular}{|c|c|c|c|c|c|}
\hline Author \& Title & $\begin{array}{c}\text { Research Method(s) \& } \\
\text { Questions }\end{array}$ & Data Sources & Number of Participants & $\begin{array}{l}\text { Context for the } \\
\text { Investigation }\end{array}$ & $\begin{array}{l}\text { Time Frame for } \\
\text { Collecting Data }\end{array}$ \\
\hline $\begin{array}{l}\text { Al-Arfajr, Ahlam M. } \\
\text { (2001) } \\
\text { dissertation } \\
\text { Philosophical Beliefs } \\
\text { and Instructional } \\
\text { Practices of Two } \\
\text { Effective Literacy } \\
\text { Teachers: A } \\
\text { Qualitative Case } \\
\text { Study }\end{array}$ & $\begin{array}{l}\text { - case studies of two } \\
\text { "effective literacy } \\
\text { teachers" } \\
\text { 1. What kinds of } \\
\text { literacy events and } \\
\text { practices occurred in } \\
\text { the classrooms of } \\
\text { two effective literacy } \\
\text { teachers? } \\
\text { 2. What beliefs about } \\
\text { literacy teaching and } \\
\text { learning guided their } \\
\text { instructional } \\
\text { practices? } \\
\text { 3. What personal } \\
\text { and/or professional } \\
\text { experiences had } \\
\text { influenced the } \\
\text { development of their } \\
\text { beliefs and } \\
\text { instructional } \\
\text { practices? }\end{array}$ & $\begin{array}{l}\text { - non-participant } \\
\text { observation } \\
\text { (audiotaped then } \\
\text { transcribed) } \\
\text { - formal \& informal } \\
\text { interviews - total of } \\
8 \text { semi-structured } \\
\text { interviews } \\
\text { - teaching artifacts } \\
\text { - extensive field } \\
\text { notes } \\
\text { - total of } 34 \text { visits } \\
\text { across } 2 \\
\text { classrooms; } 15 \text { one } \\
\text { classroom \& } 19 \text { in } \\
\text { the other } \\
\text { - visits conducted } 2 X \\
\text { a week; lasted } \\
\text { about } 3 \text { hours in } \\
\text { each classroom } \\
\text { during reading, } \\
\text { writing, \& language } \\
\text { arts sessions } \\
\text { - semi-structured } \\
\text { interview list of } \\
\text { questions/topics to } \\
\text { be explored w/o } \\
\text { exact wording and } \\
\text { sequence pre- } \\
\text { determined }\end{array}$ & $\begin{array}{l}- \text { two teachers } \\
-3^{\text {rd }} \& 6^{\text {th }} \text { grade }\end{array}$ & $\begin{array}{l}\text { - two different } \\
\text { school districts }\end{array}$ & $\begin{array}{l}\text { - data collected over } \\
4 \text { months }\end{array}$ \\
\hline
\end{tabular}




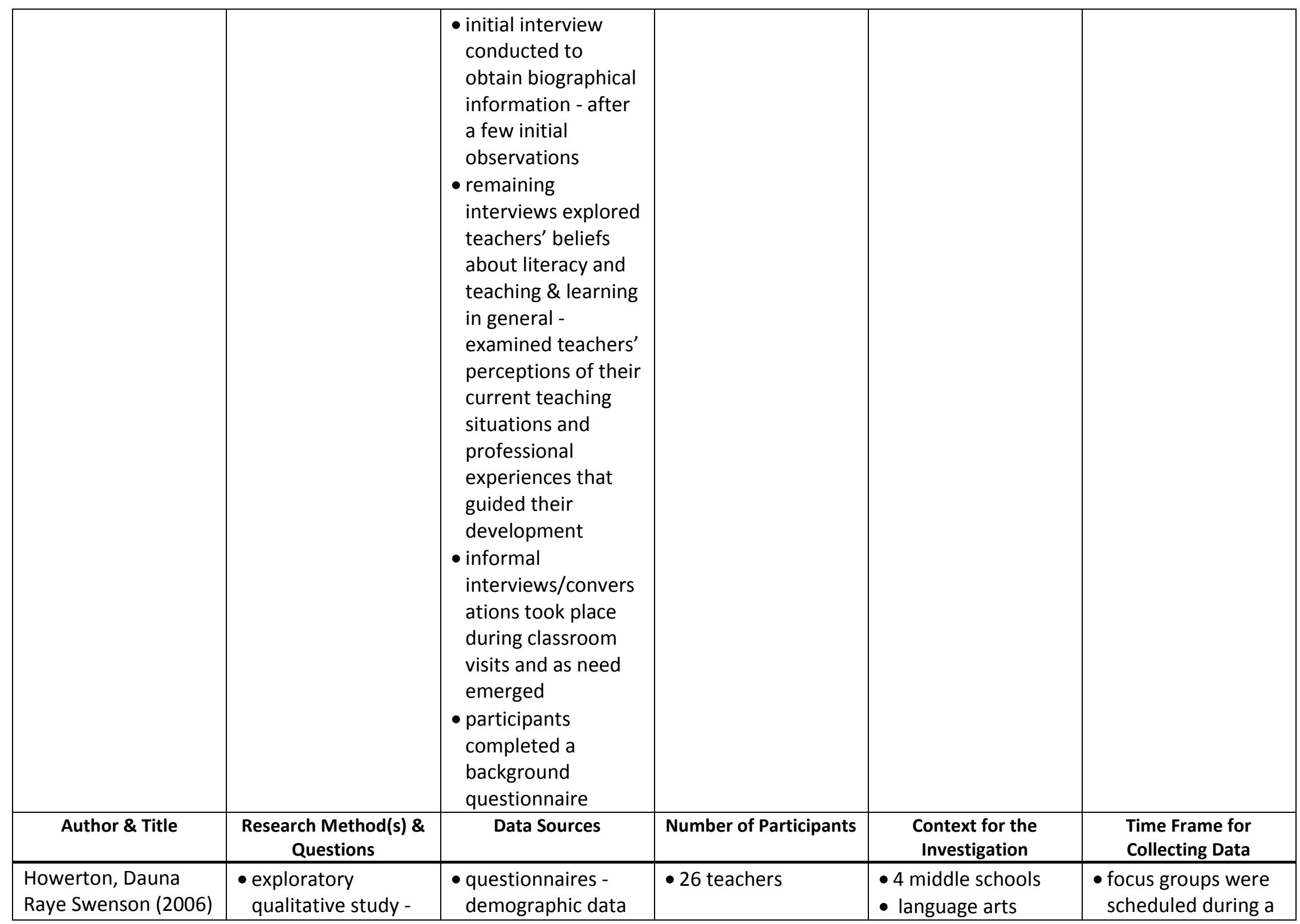




\begin{tabular}{|c|c|c|c|c|c|}
\hline $\begin{array}{l}\text { dissertation } \\
\text { Middle School } \\
\text { Language Arts } \\
\text { Teachers' Beliefs } \\
\text { about Reading } \\
\text { Instruction }\end{array}$ & $\begin{array}{l}\text { Interpretive } \\
\text { Interactionism } \\
\text { Process } \\
\text { 1. What are middle } \\
\text { school language arts } \\
\text { teachers' perceptions } \\
\text { and beliefs about } \\
\text { their roles as } \\
\text { providers of reading } \\
\text { instruction? } \\
\text { 2. What are their } \\
\text { perceptions and } \\
\text { beliefs about } \\
\text { providing reading } \\
\text { instruction to } \\
\text { struggling readers? } \\
\text { 3. What factors do } \\
\text { teachers perceive } \\
\text { affect how they } \\
\text { enact their beliefs } \\
\text { about reading } \\
\text { instruction? }\end{array}$ & $\begin{array}{l}\text { \& perceptions } \\
\text { about roles, } \\
\text { students, and type } \\
\text { of instruction } \\
\text { provided } \\
\text { - } 2 \text { focus groups } \\
\text { discussions (90 - } \\
120 \text { minutes) - } \\
\text { open ended } \\
\text { questions to } \\
\text { encourage } \\
\text { discussion about } \\
\text { perceptions \& } \\
\text { beliefs about } \\
\text { reading instruction } \\
\text { \& role teachers } \\
\text { played } \\
\text { - } 1 \text { semi-structured } \\
\text { interview (60 - } 120 \\
\text { minutes) to probe } \\
\text { deeper questions } \\
\text { requiring } \\
\text { reconsideration } \\
\text { between focus } \\
\text { groups } \\
\text { - field note template } \\
\text { - discussions \& } \\
\text { interviews video- \& } \\
\text { audiotaped }\end{array}$ & & $\begin{array}{l}\text { teachers } \\
\text { - } 1 \text { school district in } \\
\text { Texas }\end{array}$ & 2-week period \\
\hline Author \& Title & $\begin{array}{c}\text { Research Method(s) \& } \\
\text { Questions }\end{array}$ & Data Sources & Number of Participants & $\begin{array}{l}\text { Context for the } \\
\text { Investigation }\end{array}$ & $\begin{array}{l}\text { Time Frame for } \\
\text { Collecting Data }\end{array}$ \\
\hline $\begin{array}{l}\text { Maziarz, Margaret } \\
\text { Kennedy (2007) } \\
\text { dissertation }\end{array}$ & $\begin{array}{l}\text { - "qualitative } \\
\text { research" - case } \\
\text { study methodology }\end{array}$ & $\begin{array}{l}\text { - teacher interviews } \\
\text { - responses to } \\
\text { literacy beliefs }\end{array}$ & $\begin{array}{l}\text { - } 16^{\text {th }} \text {-grade social } \\
\text { studies teacher }\end{array}$ & $\begin{array}{l}\text { - } 1 \text { middle school } \\
\text { - researcher is }\end{array}$ & $\begin{array}{l}\text { - } 3 \text { months of } \\
\text { observations in } \\
\text { each class }\end{array}$ \\
\hline
\end{tabular}




\begin{tabular}{|c|c|c|c|c|c|}
\hline $\begin{array}{l}\text { Middle-School } \\
\text { Content-Area } \\
\text { Teachers' Beliefs } \\
\text { About Literacy and } \\
\text { Their Classroom } \\
\text { Practices }\end{array}$ & $\begin{array}{l}\text { 1. What beliefs about } \\
\text { literacy instruction } \\
\text { are valued by a } \\
\text { middle-school } \\
\text { science teacher and a } \\
\text { middle-school social } \\
\text { studies teacher? } \\
\text { 2. What literacy } \\
\text { activities are evident } \\
\text { in these middle- } \\
\text { school content-area } \\
\text { teachers' } \\
\text { classrooms? } \\
\text { 3. What is the } \\
\text { relationship between } \\
\text { these teachers' } \\
\text { beliefs about literacy } \\
\text { instruction and their } \\
\text { classroom practice? }\end{array}$ & $\begin{array}{l}\text { profiles (Kucer's, } \\
\text { 2005, Literacy } \\
\text { Beliefs Profile to } \\
\text { assess beliefs about } \\
\text { literacy learning \& } \\
\text { classroom } \\
\text { practices) } \\
\text { - transcripts from } \\
\text { - aggregated } \\
\text { teacher-made } \\
\text { materials } \\
\text { - student work } \\
\text { samples } \\
\text { - interviews } \\
\text { - Literacy Beliefs } \\
\text { Profile } \\
\text { - classroom } \\
\text { observations (8-10 } \\
\text { obs.); total = 10 } \\
\text { hours } \\
\text { - field notes } \\
\text { - audiotapes }\end{array}$ & $\begin{array}{l}\text { - } 17^{\text {th }} \text {-grade science } \\
\text { teacher }\end{array}$ & $\begin{array}{l}\text { assistant principal } \\
\text { in this middle } \\
\text { school }\end{array}$ & \\
\hline Author \& Title & $\begin{array}{c}\text { Research Method(s) \& } \\
\text { Questions } \\
\end{array}$ & Data Sources & Number of Participants & $\begin{array}{l}\text { Context for the } \\
\text { Investigation }\end{array}$ & $\begin{array}{l}\text { Time Frame for } \\
\text { Collecting Data }\end{array}$ \\
\hline $\begin{array}{l}\text { Guise, Megan } \\
\text { Elizabeth (2009) } \\
\text { dissertation } \\
\text { How Three English } \\
\text { Language Arts } \\
\text { Teachers Negotiate } \\
\text { Their Beliefs and } \\
\text { Instructional }\end{array}$ & $\begin{array}{l}\text { - detailed case } \\
\text { studies in } \\
\text { - descriptive in } \\
\text { nature } \\
\text { - life history } \\
\text { methodology to } \\
\text { inform interview } \\
\text { design } \\
\text { 1. How did } 3\end{array}$ & $\begin{array}{l}\text { - } 5 \text { interviews (open- } \\
\text { ended \& narrative } \\
\text { in nature) with } \\
\text { teachers, } \\
\text { administrators, and } \\
\text { students } \\
\text { - interviews w/3 } \\
\text { teacher participants } \\
\text { conducted at } 5 \\
\text { different stages }\end{array}$ & $\begin{array}{l}\text { - } 3 \text { secondary English } \\
\text { Language Arts } \\
\text { teachers }\end{array}$ & $\begin{array}{l}\text { - } 3 \text { different school } \\
\text { contexts }\end{array}$ & $\begin{array}{l}\text { - observations once a } \\
\text { week in } 1 \text { class for } \\
\text { each teacher for } 6 \\
\text { months }\end{array}$ \\
\hline
\end{tabular}




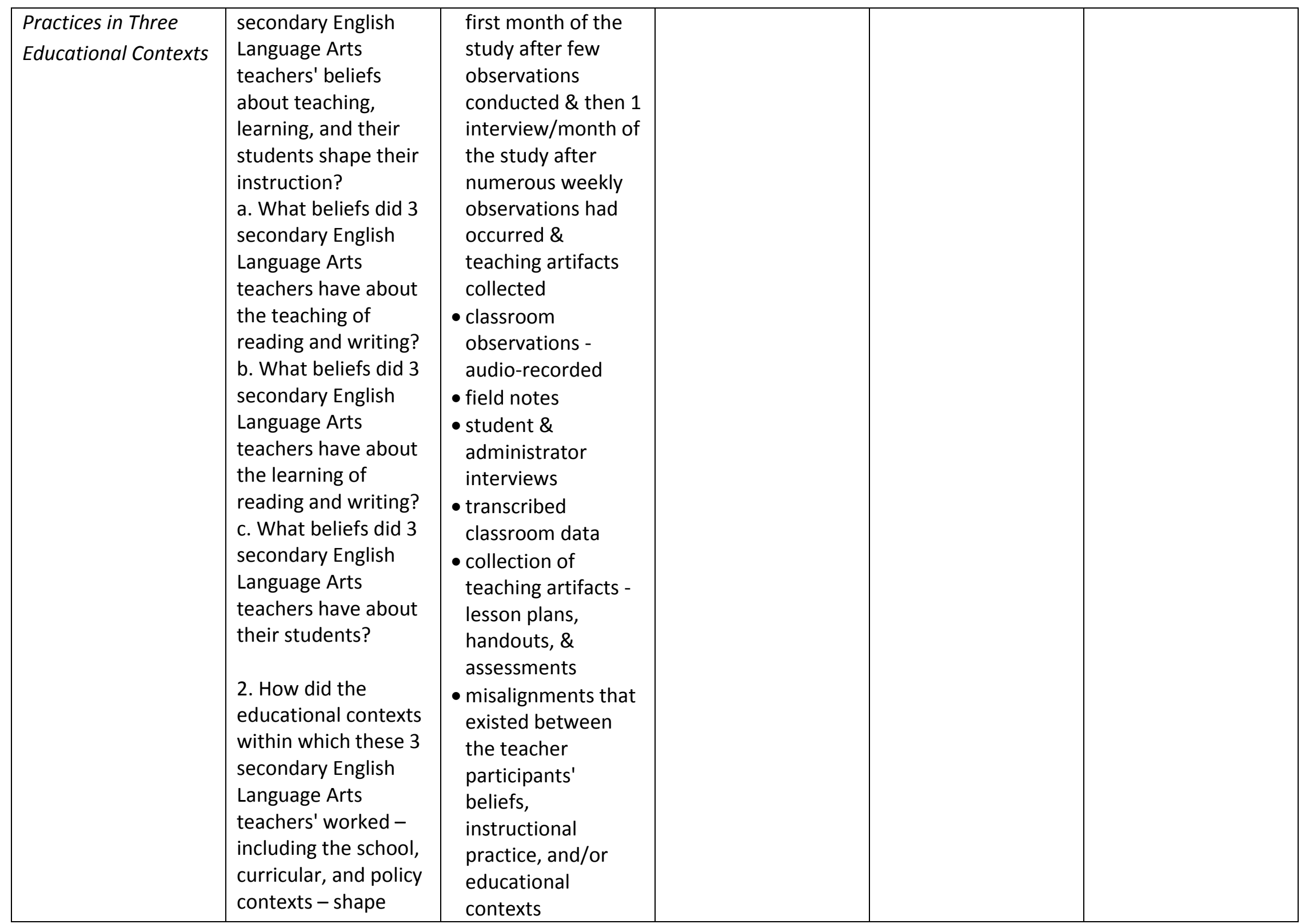




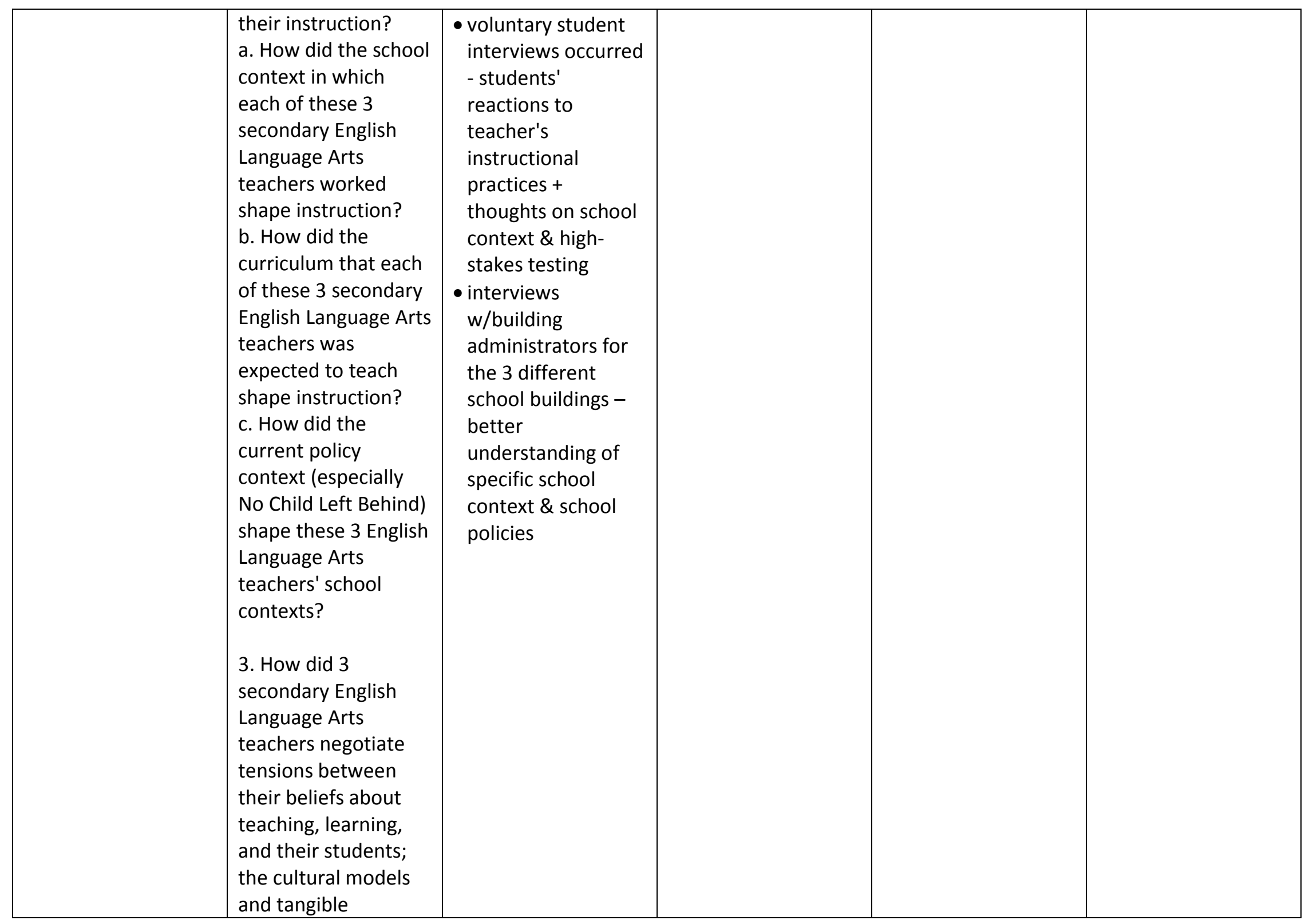




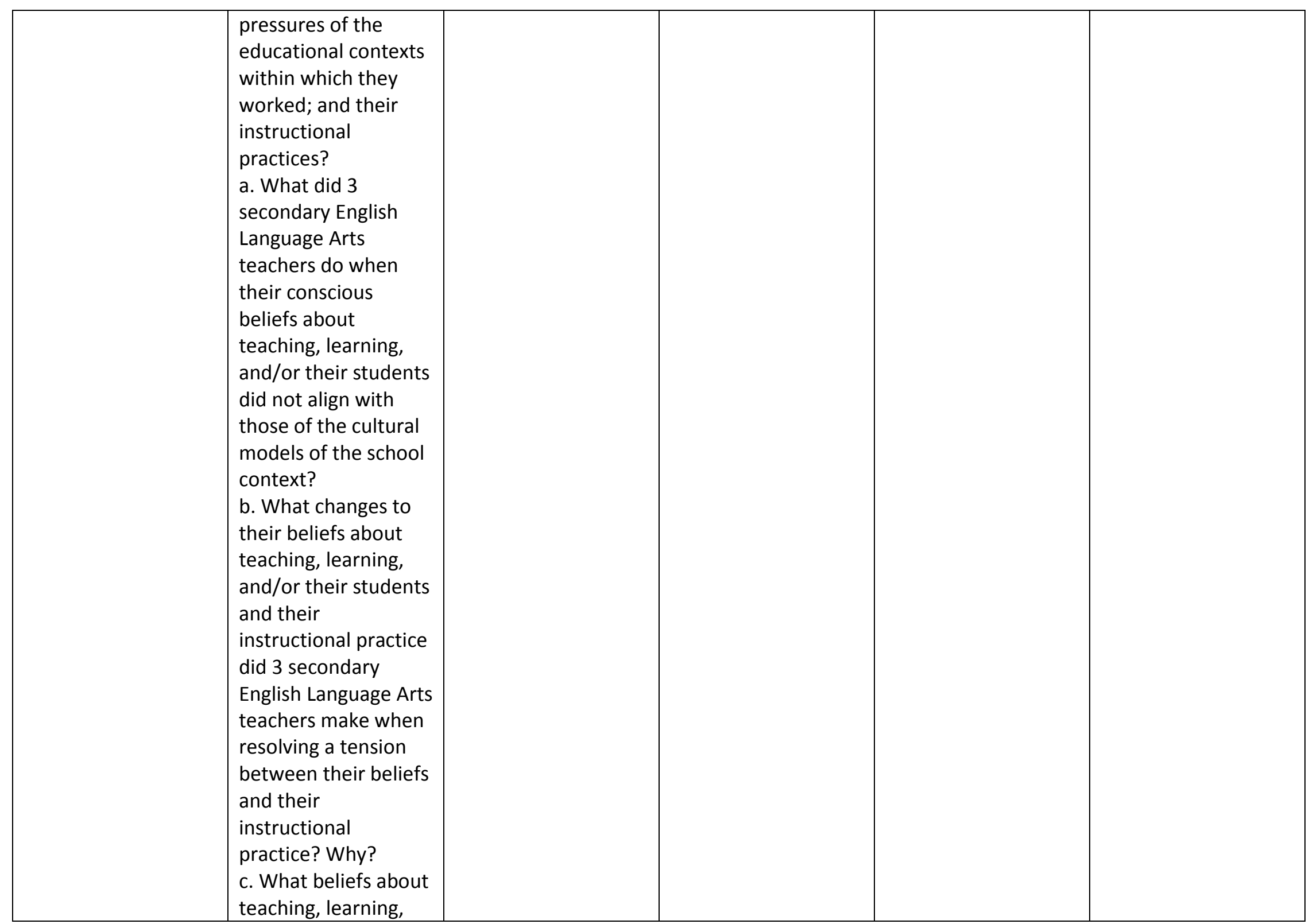




\begin{tabular}{|c|c|c|c|c|c|}
\hline & $\begin{array}{l}\text { and/or their students } \\
\text { and their } \\
\text { instructional practice } \\
\text { did } 3 \text { secondary } \\
\text { English Language Arts } \\
\text { teachers keep the } \\
\text { same when faced } \\
\text { with a tension } \\
\text { between their beliefs } \\
\text { and instructional } \\
\text { practice? Why? }\end{array}$ & & & & \\
\hline Author \& Title & $\begin{array}{c}\text { Research Method(s) \& } \\
\text { Questions }\end{array}$ & Data Sources & Number of Participants & $\begin{array}{l}\text { Context for the } \\
\text { Investigation }\end{array}$ & $\begin{array}{l}\text { Time Frame for } \\
\text { Collecting Data }\end{array}$ \\
\hline $\begin{array}{l}\text { Poole-Christian, } \\
\text { Kerantha N. (2009) } \\
\text { dissertation } \\
\text { Linking Teacher } \\
\text { Beliefs to Classroom } \\
\text { Practices that } \\
\text { Support Literacy Skills }\end{array}$ & $\begin{array}{l}\text { - qualitative } \\
\text { methodology [used } \\
\text { research assistant] } \\
\text { 1. How are teacher } \\
\text { beliefs about } \\
\text { emergent literacy } \\
\text { linked to classroom } \\
\text { practices? [To what } \\
\text { extent do teacher } \\
\text { beliefs influence } \\
\text { classroom practices } \\
\text { that are linked to } \\
\text { emergent literacy?] } \\
\text { (a) What do } \\
\text { preschool teachers } \\
\text { understand about } \\
\text { the concept of } \\
\text { emergent literacy? } \\
\text { (b) What are the } \\
\text { activities that }\end{array}$ & $\begin{array}{l}\text { - classroom activities } \\
\text { audiotaped \& } \\
\text { transcribed; } 1-3 \\
\text { hours each visit } \\
\text { - interviews with } \\
\text { teachers (45-60 } \\
\text { minutes - after } \\
\text { observations) } \\
\text { audiotaped \& } \\
\text { transcribed } \\
\text { - teachers } \\
\text { interviewed once } \\
\text { except in cases } \\
\text { where researcher } \\
\text { needed clarification } \\
\text { about certain } \\
\text { responses } \\
\text { - field notes taken \& } \\
\text { - Early Language and } \\
\text { Literacy Classroom } \\
\text { Observation }\end{array}$ & $\begin{array}{l}\text { - } 4 \text { preschool } \\
\text { teachers }\end{array}$ & $\begin{array}{l}\text { - } 2 \text { preschools with } \\
\text { half- or whole-day } \\
\text { classrooms serving } \\
\text { 3- to } 4 \text {-year old } \\
\text { children } \\
\text { - } 2 \text { classrooms in } 1 \\
\text { private preschool } \\
\text { owned \& operated } \\
\text { by a religious } \\
\text { organization; } \\
\text { - } 2 \text { classrooms in a } \\
\text { public preschool } \\
\text { program }\end{array}$ & $\begin{array}{l}\text { 3-week period } \\
\text { during the regular } \\
\text { school year } \\
\text { 3 visits made to } \\
\text { each classroom in } \\
\text { each of the schools }\end{array}$ \\
\hline
\end{tabular}




\begin{tabular}{|c|c|c|c|c|c|}
\hline & $\begin{array}{l}\text { support emergent } \\
\text { literacy in preschool } \\
\text { classrooms? } \\
\text { (c) Do these activities } \\
\text { reflect teachers' } \\
\text { beliefs? } \\
\text { (d) Is there a } \\
\text { connection between } \\
\text { the classroom } \\
\text { environment and the } \\
\text { teachers' beliefs? }\end{array}$ & $\begin{array}{l}\text { (ELLCO) used to } \\
\text { develop } \\
\text { observation guide } \\
\text { as standardizing } \\
\text { means for detecting } \\
\text { strategies that } \\
\text { support instructor's } \\
\text { beliefs about } \\
\text { literacy in } \\
\text { preschool children }\end{array}$ & & & \\
\hline \multicolumn{6}{|c|}{ Focus on ELA Teachers } \\
\hline Author \& Title & $\begin{array}{c}\text { Research Method(s) \& } \\
\text { Questions }\end{array}$ & Data Sources & Number of Participants & $\begin{array}{l}\text { Context for the } \\
\text { Investigation }\end{array}$ & $\begin{array}{l}\text { Time Frame for } \\
\text { Collecting Data }\end{array}$ \\
\hline $\begin{array}{l}\text { Meyer, Carla K. } \\
\text { (2009) } \\
\text { dissertation } \\
\text { An Assessment of } \\
\text { Middle and High } \\
\text { School Content-Area } \\
\text { Teachers' Knowledge } \\
\text { of Adolescent } \\
\text { Literacy }\end{array}$ & $\begin{array}{l}\text { - developed 50-item } \\
\text { knowledge survey } \\
\text { to measure middle } \\
\text { \& high school } \\
\text { teachers' } \\
\text { knowledge of } \\
\text { research-based } \\
\text { practice in } \\
\text { adolescent literacy } \\
\text { - Content-Area } \\
\text { Teachers' } \\
\text { Assessment of } \\
\text { Adolescent Literacy } \\
\text { (CATAAL) } \\
\text { - Hypothesis: Middle } \\
\text { \& high school } \\
\text { teachers who teach } \\
\text { English/Language } \\
\text { Arts will score } \\
\text { higher on }\end{array}$ & $\begin{array}{l}\text { - framed \& written } \\
\text { using research base } \\
\text { on adolescent } \\
\text { literacy } \\
\text { - reliability - internal } \\
\text { consistency } \\
\text { determined for } \\
\text { each section } \\
\text { - item analysis } \\
\text { conducted to } \\
\text { measure quality of } \\
\text { individual test } \\
\text { items } \\
\text { - confirm validity - } \\
\text { content \& construct } \\
\text { validity tested } \\
\text { - next stage of } \\
\text { development } \\
\text { creation of test }\end{array}$ & $\begin{array}{l}\text { - } 51 \text { middle \& high } \\
\text { school content-area } \\
\text { teachers completed } \\
\text { pilot (2 PA school } \\
\text { districts) } \\
\text { - second stage } \\
\text { solicited } 161 \text { middle } \\
\text { \& high school } \\
\text { content-area } \\
\text { teachers to } \\
\text { complete } \\
\text { assessment via } \\
\text { online survey } \\
\text { platform }\end{array}$ & $\begin{array}{l}\text { - middle \& high } \\
\text { school }\end{array}$ & $\begin{array}{l}\text { (time frame not } \\
\text { indicated) }\end{array}$ \\
\hline
\end{tabular}




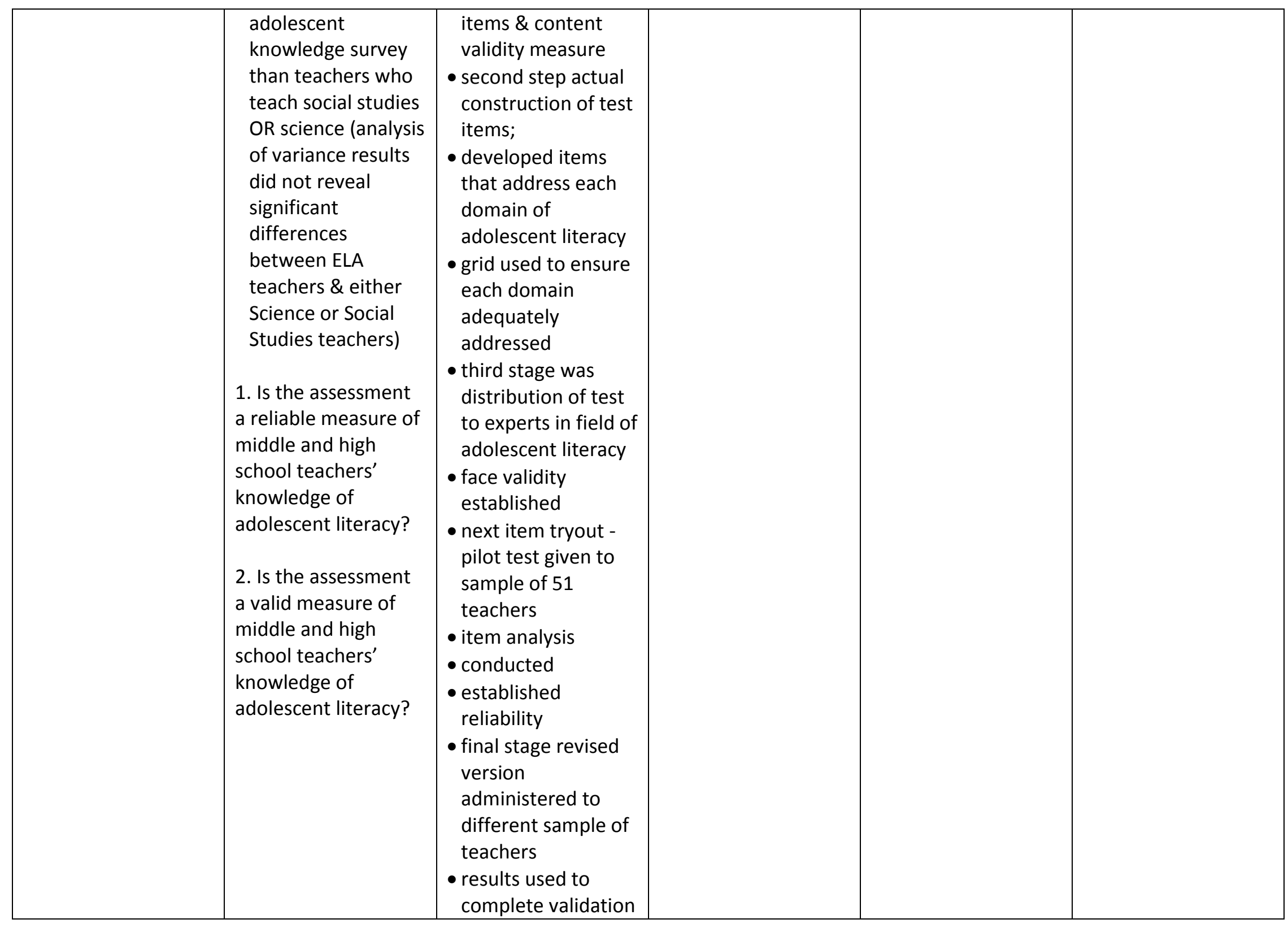




\begin{tabular}{|c|c|c|c|c|c|}
\hline Author \& Title & $\begin{array}{c}\text { Research Method(s) \& } \\
\text { Questions }\end{array}$ & Data Sources & Number of Participants & $\begin{array}{l}\text { Context for the } \\
\text { Investigation }\end{array}$ & $\begin{array}{l}\text { Time Frame for } \\
\text { Collecting Data }\end{array}$ \\
\hline $\begin{array}{l}\text { Vélez, Raúl Alberto } \\
\text { Mora (2010) } \\
\text { dissertation } \\
\text { An Analysis of the } \\
\text { Literacy Beliefs and } \\
\text { Practices of Faculty } \\
\text { and Graduates From } \\
\text { a Preservice English } \\
\text { Teacher Education } \\
\text { Program }\end{array}$ & $\begin{array}{l}\text { - qualitative research } \\
\text { paradigm with } \\
\text { descriptive data } \\
\text { 1. How have the } \\
\text { literacy beliefs and } \\
\text { practices of } \\
\text { instructors and } \\
\text { graduates from a } \\
\text { Secondary English } \\
\text { Teacher Education } \\
\text { program evolved in } \\
\text { the past } 15 \text { years? } \\
\text { 2. How have the } \\
\text { messages about } \\
\text { literacy beliefs and } \\
\text { practices changed } \\
\text { within the context of } \\
\text { a Secondary English } \\
\text { Education program } \\
\text { over the last } 15 \\
\text { years? }\end{array}$ & $\begin{array}{l}\text { - in-depth interview- } \\
3 \text { in-depth } \\
\text { interviews with } \\
\text { each participant } \\
\text { - series of written } \\
\text { documents from all } \\
\text { participants } \\
\text { - Background } \\
\text { Information Sheet } \\
\text { - first round of } \\
\text { interviews followed } \\
\text { a predetermined } \\
\text { protocol } \\
\text { - developed second } \\
\text { \& third interview } \\
\text { protocols after } \\
\text { conducting each } \\
\text { round of interviews } \\
\text { - written documents: } \\
\text { o syllabi from the } \\
\text { faculty } \\
\text { o assignments that } \\
\text { graduates carried out } \\
\text { during time as } \\
\text { preservice teachers } \\
\text { o lesson plans } \\
\text { o online information } \\
\text { from selected, } \\
\text { participant-created } \\
\text { blogs and websites }\end{array}$ & $\begin{array}{l}\text { - } 12 \text { participants } \\
\text { - methods course } \\
\text { instructors } \\
\text { - instructors in } \\
\text { English Dept. } \\
\text { - teachers who } \\
\text { graduated from } \\
\text { program in } 2009 \\
\text { - teachers who } \\
\text { graduated from } \\
\text { program before } \\
2002\end{array}$ & $\begin{array}{l}\text { - } 2 \text { Contexts: } \\
\text { University and } \\
\text { Schools }\end{array}$ & $\begin{array}{l}\text { - interviews occurred } \\
\text { over course of } 4 \\
\text { months }\end{array}$ \\
\hline
\end{tabular}


Appendix B

Overview of Methodological Considerations Drawn From Adolescent Literacy Articles

Studies Associated with Adolescent Literacy and/or Middle Level Instruction

\begin{tabular}{|c|c|c|c|c|c|}
\hline Author \& Title & $\begin{array}{c}\text { Research Method(s) \& } \\
\text { Questions }\end{array}$ & Data Sources & Number of Participants & $\begin{array}{l}\text { Context for the } \\
\text { Investigation }\end{array}$ & $\begin{array}{l}\text { Time Frame for } \\
\text { Collecting Data }\end{array}$ \\
\hline $\begin{array}{l}\text { Fisher, Douglas, Frey, } \\
\text { Nancy, \& Lapp, Diane } \\
\text { (2008) } \\
\text { Shared Readings: } \\
\text { Modeling } \\
\text { Comprehension, } \\
\text { Vocabulary, Text } \\
\text { Structures, and Text } \\
\text { Features for Older } \\
\text { Readers }\end{array}$ & $\begin{array}{l}\text { - constant } \\
\text { comparative } \\
\text { method } \\
\text { (no research } \\
\text { questions included) }\end{array}$ & $\begin{array}{l}\text { - identified } \\
\text { procedures used to } \\
\text { implement a shared } \\
\text { reading and } \\
\text { modeled think- } \\
\text { aloud } \\
\text { - observations of } \\
\text { expert teachers } \\
\text { during shared } \\
\text { readings } \\
\text { - observational field } \\
\text { notes } \\
\text { - transcriptions of all } \\
\text { audiotaped } \\
\text { interviews }\end{array}$ & $\begin{array}{l}\text { - } 25 \text { teachers from } \\
25 \text { schools }\end{array}$ & $\begin{array}{l}\text { - grades } 3-8 \\
\text { classrooms }\end{array}$ & $\begin{array}{l}\text { (time frame not } \\
\text { indicated) }\end{array}$ \\
\hline Author \& Title & $\begin{array}{c}\text { Research Method(s) \& } \\
\text { Questions }\end{array}$ & Data Sources & Number of Participants & $\begin{array}{l}\text { Context for the } \\
\text { Investigation }\end{array}$ & $\begin{array}{l}\text { Time Frame for } \\
\text { Collecting Data }\end{array}$ \\
\hline $\begin{array}{l}\text { Ivey, Gay (1999) } \\
\text { A Multicase Study in } \\
\text { the Middle School: } \\
\text { Complexities Among } \\
\text { Young Adolescent } \\
\text { Readers }\end{array}$ & $\begin{array}{l}\text { - multicase study of } \\
\text { three sixth-grade } \\
\text { readers } \\
\text { - constant } \\
\text { comparative } \\
\text { method - generate } \\
\text { categories that } \\
\text { captured essence }\end{array}$ & $\begin{array}{l}\text { - observations } \\
\text { - structured and } \\
\text { unstructured } \\
\text { interviews with } \\
\text { each participant } \\
\text { - met w/ each } \\
\text { student for one-on- } \\
\text { one shared reading } \\
\text { experiences }\end{array}$ & $\begin{array}{l}\text { - three sixth grade } \\
\text { readers from two } \\
\text { sixth grade } \\
\text { classrooms } \\
\text { - } 1 \text { student - } \\
\text { successful and } \\
\text { motivated reader } \\
\text { who read } \\
\text { independently at }\end{array}$ & $\begin{array}{l}\text { - two sixth grade } \\
\text { classrooms }\end{array}$ & - 5 months \\
\hline
\end{tabular}




\begin{tabular}{|c|c|c|c|c|c|}
\hline & $\begin{array}{l}\text { and specifics of } \\
\text { students' reading }\end{array}$ & $\begin{array}{l}\text { - all interactions } \\
\text { audiotaped } \\
\text { - maintained } \\
\text { researcher journal - } \\
\text { interactions and } \\
\text { overall perceptions } \\
\text { of students' reading } \\
\text { recorded }\end{array}$ & $\begin{array}{l}\text { school and at home } \\
\text { - } 1 \text { student - } \\
\text { struggling reader, } \\
\text { reluctant to read at } \\
\text { school } \\
\text { - } 1 \text { student - } \\
\text { moderately } \\
\text { successful reader } \\
\text { who seldom chose } \\
\text { to read } \\
\text { - two girls; one boy }\end{array}$ & & \\
\hline Author \& Title & $\begin{array}{c}\text { Research Method(s) \& } \\
\text { Questions } \\
\end{array}$ & Data Sources & Number of Participants & $\begin{array}{l}\text { Context for the } \\
\text { Investigation }\end{array}$ & $\begin{array}{l}\text { Time Frame for } \\
\text { Collecting Data }\end{array}$ \\
\hline $\begin{array}{l}\text { Langer, Judith A. } \\
\text { (2001) } \\
\text { Beating the Odds: } \\
\text { Teaching Middle and } \\
\text { High School Students } \\
\text { to Read and } \\
\text { Write Well }\end{array}$ & $\begin{array}{l}\text { - nested multicase } \\
\text { design w/each } \\
\text { English program as } \\
\text { a case, and the } \\
\text { class including the } \\
\text { teachers and } \\
\text { student } \\
\text { - How are the } \\
\text { following enacted } \\
\text { in school English } \\
\text { programs where, } \\
\text { when the schools } \\
\text { are otherwise } \\
\text { comparable, } \\
\text { students score } \\
\text { higher on high- } \\
\text { stakes reading and } \\
\text { writing tests than } \\
\text { where they do not: } \\
\text { approaches to skill }\end{array}$ & $\begin{array}{l}\text { - observations } \\
\text { - field notes of all } \\
\text { meetings, observed } \\
\text { classes, and } \\
\text { conversations } \\
\text { - interviews } \\
\text { - tape recordings and } \\
\text { transcripts of all } \\
\text { interviews and } \\
\text { observed class } \\
\text { sessions } \\
\text { - e-mail messages } \\
\text { - artifacts from } \\
\text { school and } \\
\text { professional } \\
\text { experiences } \\
\text { - identification \& } \\
\text { testing of patterns } \\
\text { over time } \\
\text { - examined English } \\
\text { teachers w/in }\end{array}$ & $\begin{array}{l}\text { - sample involved } 2 \\
\text { years each with } 44 \\
\text { teachers working in } \\
25 \text { schools, and } \\
\text { included some } 2640 \\
\text { students and } 528 \\
\text { student informants }\end{array}$ & $\begin{array}{l}\text { - middle school and } \\
\text { high school English } \\
\text { and/or language } \\
\text { arts classrooms }\end{array}$ & $\begin{array}{l}\text { - across } 5 \text { years } \\
\text { - } 2 \text { years in each } \\
\text { school }\end{array}$ \\
\hline
\end{tabular}




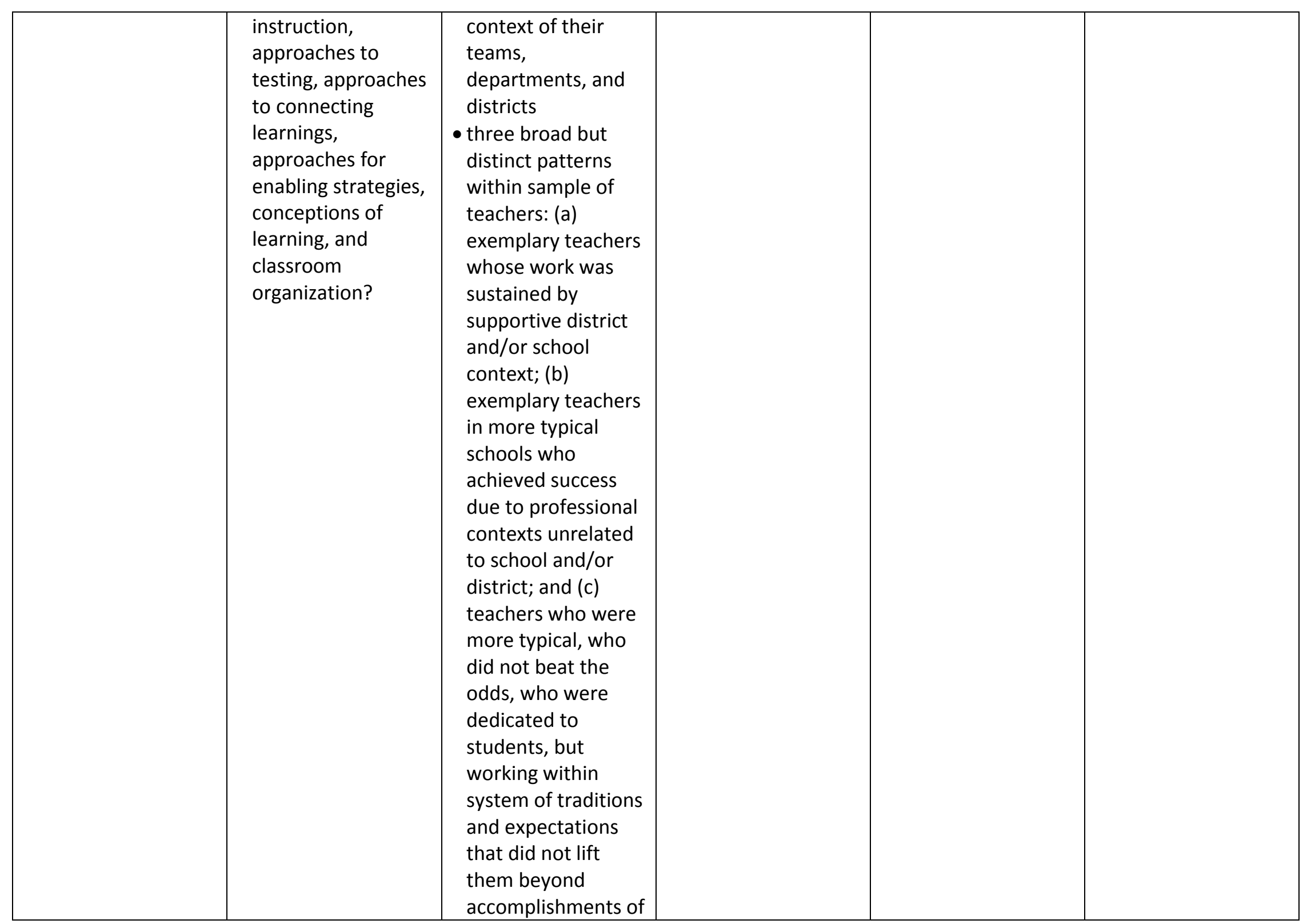




\begin{tabular}{|c|c|c|c|c|c|}
\hline & & $\begin{array}{l}\text { other comparable } \\
\text { schools } \\
\text { - studied } \\
\text { instructional } \\
\text { concerns, plans, \& } \\
\text { enactments over } \\
\text { time }\end{array}$ & & & \\
\hline Author \& Title & $\begin{array}{c}\text { Research Method(s) \& } \\
\text { Questions }\end{array}$ & Data Sources & Number of Participants & $\begin{array}{l}\text { Context for the } \\
\text { Investigation }\end{array}$ & $\begin{array}{l}\text { Time Frame for } \\
\text { Collecting Data }\end{array}$ \\
\hline $\begin{array}{l}\text { Pitcher, Sharon M., } \\
\text { Martinez, Gilda, } \\
\text { Dicembre, Elizabeth } \\
\text { A., Fewster, Darlene, } \\
\text { \& McCormick, } \\
\text { Montana K. (2010) } \\
\text { The Literacy Needs of } \\
\text { Adolescents in Their } \\
\text { Own Words }\end{array}$ & $\begin{array}{l}\text { - seven case studies } \\
\text { - researchers } \\
\text { individually } \\
\text { analyzed cases } \\
\text { using constant } \\
\text { comparative } \\
\text { method to } \\
\text { determine } \\
\text { recurring themes }\end{array}$ & $\begin{array}{l}\text { - students were } \\
\text { tested with } \\
\text { assessments (QRI-4; } \\
\text { Lexia } \\
\text { Comprehensive } \\
\text { Reading Test; } \\
\text { Adolescent } \\
\text { Motivation to Read } \\
\text { Survey-R) } \\
\text { - interviews of each } \\
\text { student } \\
\text { - parents also } \\
\text { interviewed } \\
\text { - researched the } \\
\text { reading programs } \\
\text { students were } \\
\text { currently } \\
\text { experiencing in } \\
\text { schools }\end{array}$ & $\begin{array}{l}\text { - seven adolescents } \\
\text { in grades } 6 \text { - } 8\end{array}$ & $\begin{array}{l}\text { - students who } \\
\text { attended the } \\
\text { university reading } \\
\text { clinic }\end{array}$ & - 12 weeks \\
\hline Author \& Title & $\begin{array}{c}\text { Research Method(s) \& } \\
\text { Questions }\end{array}$ & Data Sources & Number of Participants & $\begin{array}{l}\text { Context for the } \\
\text { Investigation }\end{array}$ & $\begin{array}{l}\text { Time Frame for } \\
\text { Collecting Data }\end{array}$ \\
\hline $\begin{array}{l}\text { Stevens, Lisa Patel } \\
\text { (2002) } \\
\text { Making the Road by }\end{array}$ & $\begin{array}{l}\text { What does the } \\
\text { term adolescent } \\
\text { literacy imply that } \\
\text { secondary and/or }\end{array}$ & $\begin{array}{l}\text { - explored the } \\
\text { complexities of } \\
\text { plotting transition } \\
\text { of adolescent }\end{array}$ & $\begin{array}{l}\text { - } 24 \text { undergraduate } \\
\text { students }\end{array}$ & $\begin{array}{l}\text { - preservice } \\
\text { university class on } \\
\text { content area } \\
\text { literacy }\end{array}$ & - one semester \\
\hline
\end{tabular}




\begin{tabular}{|c|c|c|c|c|c|}
\hline $\begin{array}{l}\text { Walking: The } \\
\text { Transition from } \\
\text { Content Area Literacy } \\
\text { to Adolescent } \\
\text { Literacy }\end{array}$ & $\begin{array}{l}\text { content area } \\
\text { literacy does not? } \\
\text { - What role should } \\
\text { digital literacies } \\
\text { play in the lives of } \\
\text { adolescents and in } \\
\text { teachers? } \\
\text { - What discourses } \\
\text { surround teaching } \\
\text { adolescents that } \\
\text { provide and restrict } \\
\text { opportunities for } \\
\text { adolescents? }\end{array}$ & $\begin{array}{l}\text { literacy - not only a } \\
\text { shift in } \\
\text { terminology, but } \\
\text { also a purposeful } \\
\text { change in } \\
\text { framework and } \\
\text { ideology } \\
\text { - considered the } \\
\text { traditional topics, } \\
\text { pedagogy, and } \\
\text { curricula of content } \\
\text { area literacy against } \\
\text { the broader } \\
\text { backdrop of } \\
\text { adolescent literacy }\end{array}$ & & & \\
\hline Author \& Title & $\begin{array}{c}\text { Research Method(s) \& } \\
\text { Questions }\end{array}$ & Data Sources & Number of Participants & $\begin{array}{l}\text { Context for the } \\
\text { Investigation }\end{array}$ & $\begin{array}{l}\text { Time Frame for } \\
\text { Collecting Data }\end{array}$ \\
\hline $\begin{array}{l}\text { Thomson, Louise } \\
\text { Elizabeth (2010) } \\
\text { dissertation } \\
\text { Constructions of } \\
\text { Literacy: A Study of } \\
\text { Reading Instruction } \\
\text { in Middle School } \\
\text { Content Areas }\end{array}$ & $\begin{array}{l}\text { - comparative case } \\
\text { study method } \\
\text { - In a selected middle } \\
\text { school, which } \\
\text { approximates the } \\
\text { average state-wide } \\
\text { demographics, how } \\
\text { are young } \\
\text { adolescents } \\
\text { instructed in } \\
\text { content area } \\
\text { literacy in three } \\
\text { disciplinary areas, } \\
\text { [science, social } \\
\text { studies, and } \\
\text { mathematics] and }\end{array}$ & $\begin{array}{l}\text { - demographic } \\
\text { survey } \\
\text { - classroom } \\
\text { observations } \\
\text { - interviews } \\
\text { - documents }\end{array}$ & $\begin{array}{l}\text { - } 3 \text { eighth-grade } \\
\text { middle school } \\
\text { teachers in } 3 \\
\text { specific content } \\
\text { areas: social } \\
\text { studies, science, } \\
\text { and mathematics }\end{array}$ & $\begin{array}{l}\text { - } 8^{\text {th }} \text { grade middle } \\
\text { school content area } \\
\text { classrooms: social } \\
\text { studies, science, } \\
\text { and mathematics }\end{array}$ & $\begin{array}{l}\text { - over } 4 \text { months - } 16 \\
\text { weeks }\end{array}$ \\
\hline
\end{tabular}




\begin{tabular}{|l|l|l|l|l|l|}
\hline & $\begin{array}{l}\text { how does the } \\
\text { context of that } \\
\text { middle school } \\
\text { shape the delivery } \\
\text { of this instruction? }\end{array}$ & & & & \\
\hline
\end{tabular}

